\title{
Effects of Grit Roughness and Pitch Oscillations on the NACA 4415 Airfoil
}

M. J. Hoffmann

R. Reuss Ramsay

G. M. Gregorek

The Ohio State University

Columbus, Ohio
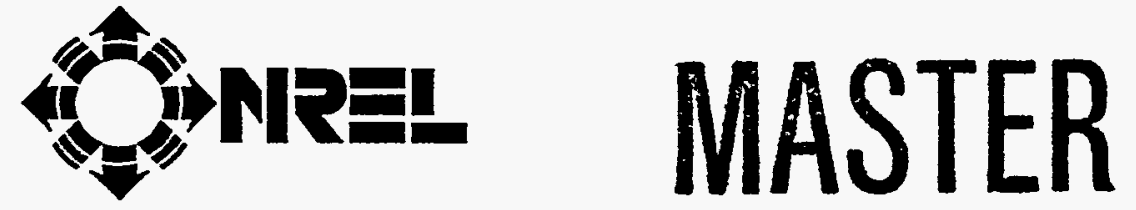

National Renewable Energy Laboratory 1617 Cole Boulevard Golden, Colorado 80401-3393

A national laboratory of the U.S. Department of Energy Managed by Midwest Research Institute for the U.S. Department of Energy under Contract No. DE-AC36-83CH10093 


\section{Effects of Grit Roughness and Pitch Oscillations on the NACA 4415 Airfoil}

M. J. Hoffmann

R. Reuss Ramsay

G. M. Gregorek

The Ohio State University

Columbus, Ohio

NREL Technical Monitor:

C. P. Butterfield

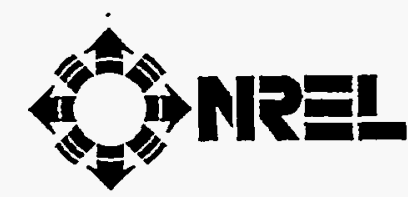

National Renewable Energy Laboratory 1617 Cole Boulevard

Golden, Colorado 80401-3393

A national laboratory of the U.S. Department of Energy Managed by Midwest Research Institute for the U.S. Department of Energy under contract No. DE-AC36-83CH10093

Prepared under Subcontract No. XF-1-11009-3

July 1996 


\section{NOTICE}

This report was prepared as an account of work sponsored by an agency of the United States government. Neither the United States govemment nor any agency thereof, nor any of their employees, makes any warranty, express or implied, or assumes any legal liability or responsibility for the accuracy, completeness, or usefulness of any information, apparatus, product, or process disclosed, or represents that its use would not infringe privately owned rights. Reference herein to any specific commercial product, process, or senvice by trade name, trademark, manufacturer, or otherwise does not necessarily constitute or imply its endorsement, recommendation, or favoring by the United States govemment or any agency thereof. The views and opinions of authors expressed herein do not necessarily state or reflect those of the United States government or any agency thereof.

Available to DOE and DOE contractors from:

Office of Scientific and Technical Information (OSTI)

P.O. Box 62

Oak Ridge, TN 37831

Prices available by calling (423) $576-840-1$

Available to the public from:

National Technical Information Service (NTIS)

U.S. Department of Commerce

5285 Port Royal Road

Springtield, VA 22161

(703) $487-4650$ 


\section{DISCLAIMER}

Portions of this document may be illegible in electronic image products. Images are produced from the best available original document. 


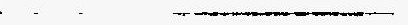
$-$ 


\section{Foreword}

Airfoils for wind turbines have been selected by comparing data from different wind tunnels, tested under different conditions, making it difficult to make accurate comparisons. Most wind tunnel data sets do not contain airfoil performance in stall commonly experienced by turbines operating in the field. Wind turbines commonly experience extreme roughness for which there is very little data. Finally, recent tests have shown that dynamic stall is a common occurrence for most wind turbines operating in yawed, stall or turbulent conditions. Very little dynamic stall data exists for the airfoils of interest to a wind turbine designer. In summary, very little airfoil performance data exists which is appropriate for wind turbine design.

Recognizing the need for a wind turbine airfoil performance data base, the National Renewable Energy Laboratory (NREL), funded by the U.S. Department of Energy, awarded a contract to Ohio State University (OSU) to conduct a wind tunnel test program. Under this program, OSU tested a series of popular wind turbine airfoils. A standard test matrix was developed to assure that each airfoil was tested under the same conditions. The test matrix was developed in partnership with industry and is intended to include all of the operating conditions experienced by wind turbines. These conditions include airfoil performance at high angles of attack, rough leading edge (bug simulation), steady and unsteady angles of attack.

Special care has been taken to report as much of the test conditions and raw data as practical so that designers can make their own comparisons and focus on details of the data relevant to their design goals. Some of the airfoil coordinates are proprietary to NREL or an industry partner. To protect the information which defines the exact shape of the airfoil, the coordinates have not been included in the report. Instructions on how to obtain these coordinates may be obtained by contacting C.P. (Sandy) Butterfield at NREL.

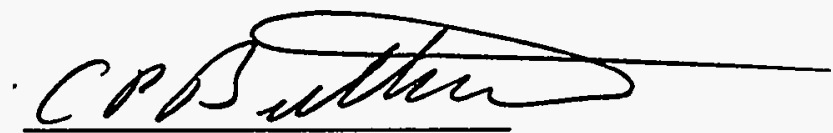

C. P. (Sandy) Butterfield

Wind Technology Division

National Renewable Energy Laboratory

1617 Cole Blvd.

Golden, Colorado, 80401 USA

Internet Address: Sandy_Butterfield@NREL.GOV

Phone 303-384-6902

FAX 303-384-6901 


\section{Preface}

The Ohio State University Aeronautical and Astronautical Research Laboratory is conducting a series of steady state and unsteady wind tunnel tests on a set of airfoils that have been or will be used for horizontal axis wind turbines. The purpose of these tests is to investigate the effect of pitch oscillations and leading edge grit roughness (LEGR) on airfoil performance. The study of pitch oscillation effects can help to understand the behavior of horizontal-axis wind turbines in yaw. The results of these tests will aid in the development of new airfoil performance codes that account for unsteady behavior and also aid in the design of new airfoils for wind turbines. The application of LEGR simulates surface irregularities that occur on wind turbines. These irregularities on the blades are caused by the accumulation of insect debris, ice, and the aging process and can significantly reduce the output of horizontal-axis wind turbines. The experimental results from the application of LEGR will help the development of airfoils that are less sensitive to roughness.

This work was made possible by the efforts and financial support of the National Renewable Energy Laboratory which provided major funding and technical monitoring, the U.S. Department of Energy is credited for its funding of this document through the National Renewable Energy Laboratory under contract number DE-AC36-83CH10093 and KENETECH, Windpower Inc. provided technical assistance and funding for the test model. The staff of The Ohio State University Aeronautical and Astronautical Research Laboratory appreciate the contributions made by personnel from both organizations. In addition, the authors would like to recognize the efforts of the following graduate and undergraduate research assistants: Jolanta M. Janiszewska, Fernando Falasca and Monica Angelats i Coll. 


\section{Summary}

A NACA 4415 airfoil model was tested in The Ohio State University Aeronautical and Astronautical Research Laboratory $3 \times 5$ subsonic wind tunnel under steady state and unsteady conditions. The test defined baseline conditions for steady state angles of attack from $-10^{\circ}$ to $+40^{\circ}$ and examined unsteady behavior by oscillating the model about its pitch axis for three mean angles, three frequencies, and two amplitudes. For all cases, Reynolds numbers of $0.75,1,1.25$, and 1.5 million were used. In addition, these were repeated after the application of leading edge grit roughness (LEGR) to determine contamination effects on the airfoil performance.

Steady state results of the NACA 4415 testing at Reynolds number of 1.25 million showed a baseline maximum lift coefficient of 1.30 at $12.3^{\circ}$ angle of attack. The application of LEGR reduced the maximum lift coefficient by $20 \%$ and increased the 0.0090 minimum drag coefficient value by $62 \%$. The zero lift pitching moment of -0.0967 showed a $13 \%$ reduction in magnitude to -0.0842 with LEGR applied.

Data were also obtained for two pitch oscillation amplitudes: $\pm 5.5^{\circ}$ and $\pm 10^{\circ}$. The larger amplitude consistently gave a higher maximum lift coefficient than the smaller amplitude, and both unsteady maximum lift coefficients were greater than the steady state values. Stall is delayed on the airfoil while the angle of attack is increasing, thereby causing an increase in maximum lift coefficient. A hysteresis behavior was exhibited for all the unsteady test cases. The hysteresis loops were larger for the higher reduced frequencies and for the larger amplitude oscillations. As in the steady case, the effect of LEGR in the unsteady case was to reduce the lift coefficient at high angles of attack. In addition, with LEGR, the hysteresis behavior persisted into lower angles of attack than for the clean case.

In general, the unsteady maximum lift coefficient was $10 \%$ to $55 \%$ higher than the steady state maximum lift coefficient, and variation in the quarter chord pitching moment coefficient magnitude was from $-30 \%$ to $+45 \%$ relative to steady state values at high angles of attack. These findings indicate the importance of considering the unsteady flow behavior occurring in wind turbine operation in order to obtain accurate load estimates. 


\section{Contents}

Preface

Summary v

List of Symbols ix

Introduction

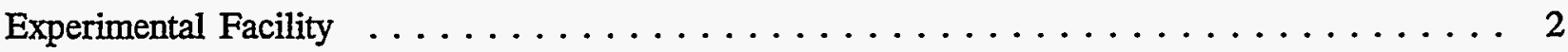

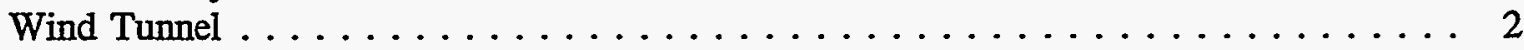

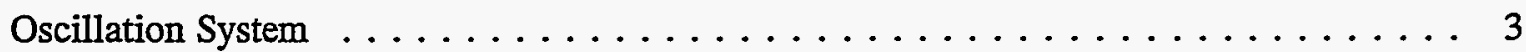

Model Details $\ldots \ldots \ldots \ldots \ldots \ldots \ldots \ldots \ldots \ldots \ldots \ldots \ldots \ldots \ldots \ldots$

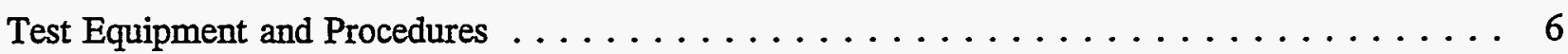

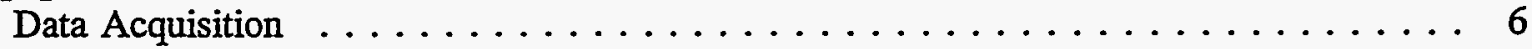

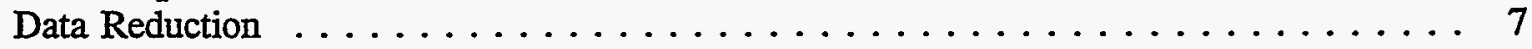

Test Matrix . . . . . . . . . . . . . . . . . . . . . 8

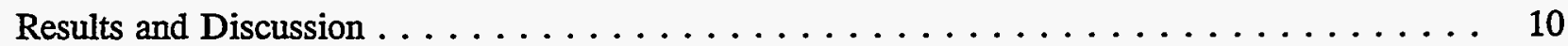

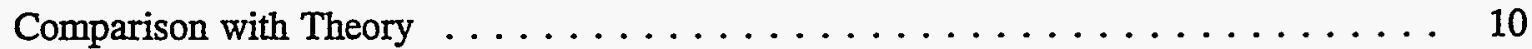

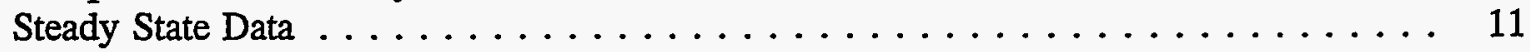

Unsteady Data . . . . . . . . . . . . . . . . . . . . 13

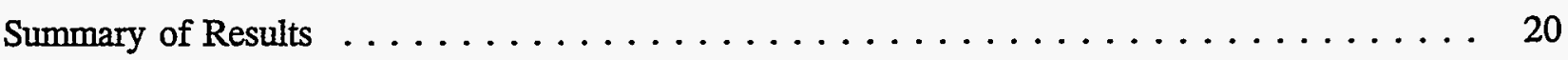

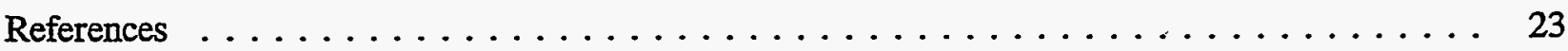

Appendix A: Model and Surface Pressure Tap Coordinates $\ldots \ldots \ldots \ldots \ldots \ldots$

Appendix B: Steady State Data $\ldots \ldots \ldots \ldots \ldots \ldots \ldots \ldots \ldots \ldots \ldots \ldots \ldots$

Appendix C: Unsteady Integrated Coefficients $\ldots \ldots \ldots \ldots \ldots \ldots \ldots \ldots \ldots \ldots$ 


\section{List of Figures}

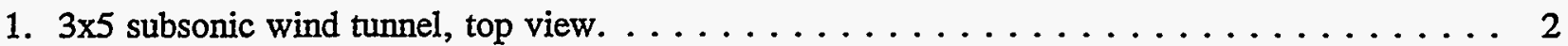

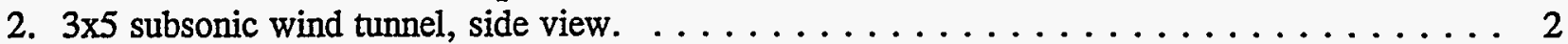

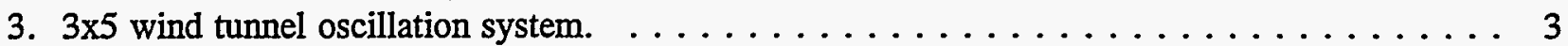

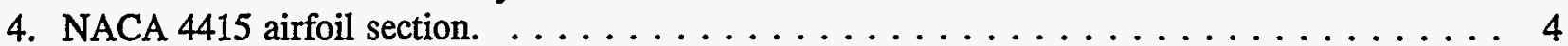

5. Measured-to-desired model coordinates difference curves. . . . . . . . . . . . . 4

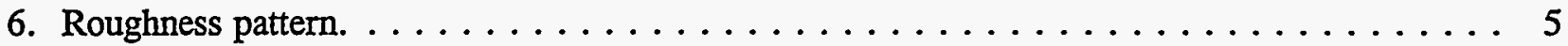

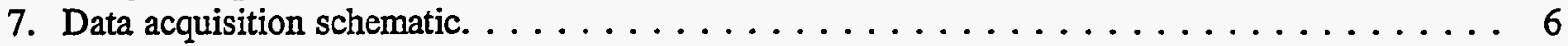

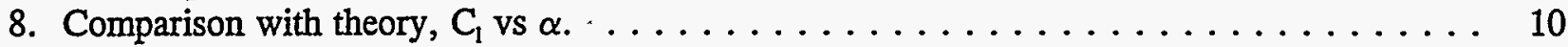

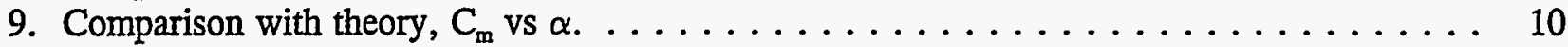

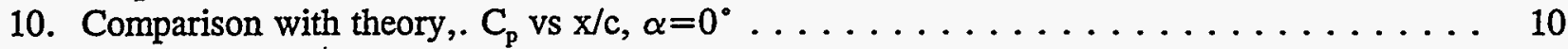

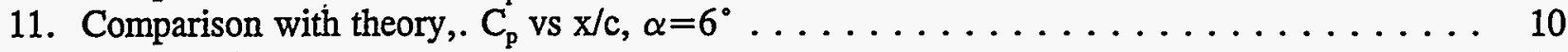

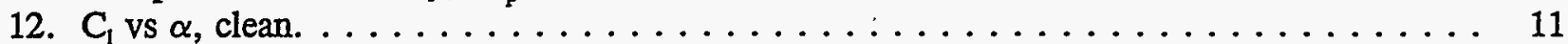

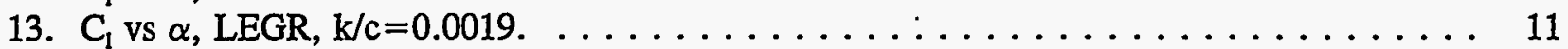

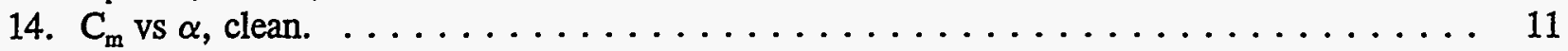

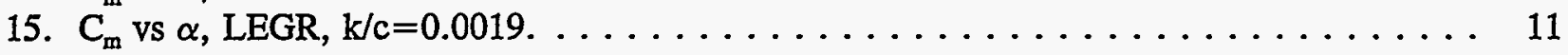

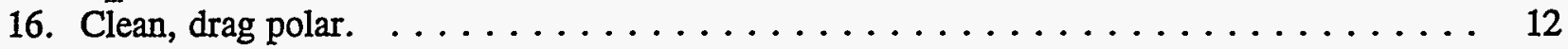

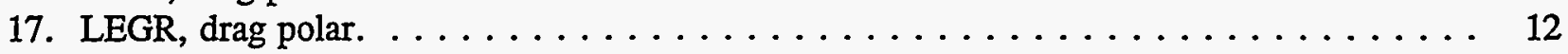

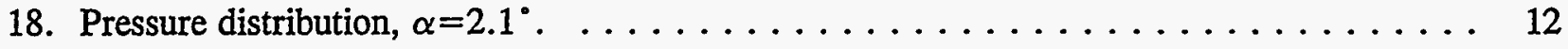

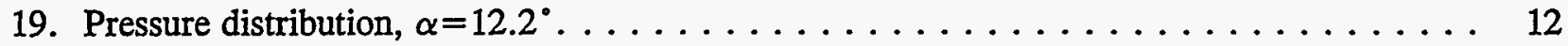

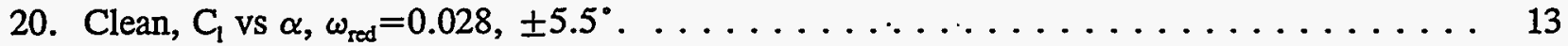

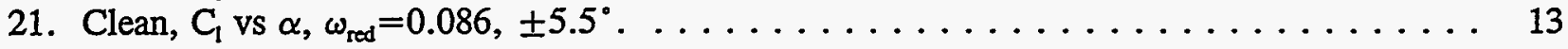

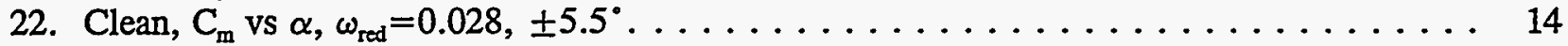

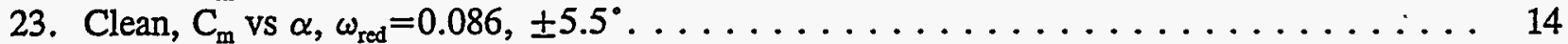

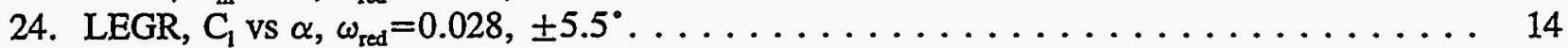

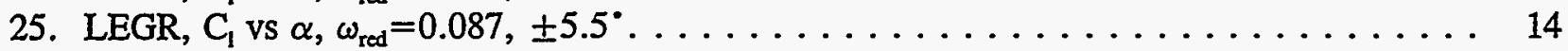

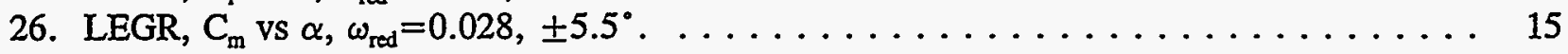

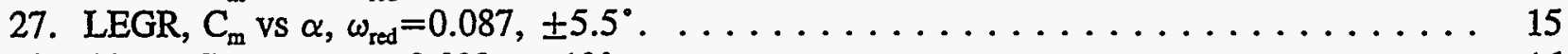

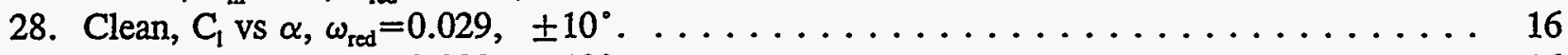

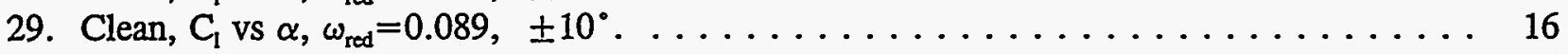

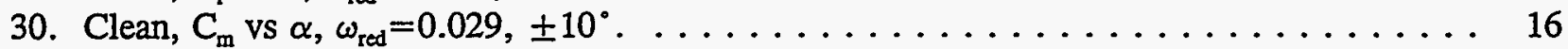

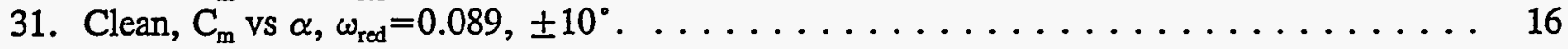

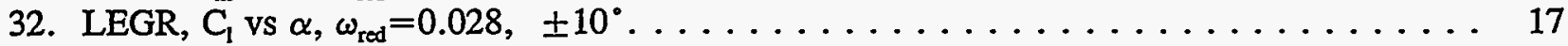

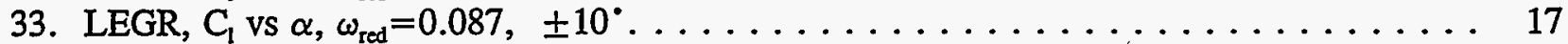

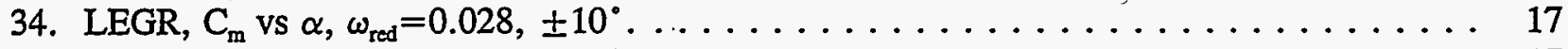

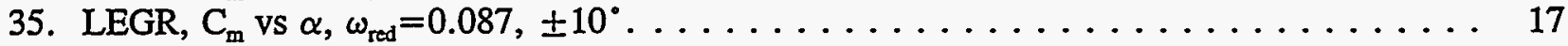

36. Clean, unsteady pressure distribution, $\pm 10^{\circ} \ldots \ldots \ldots \ldots \ldots \ldots \ldots \ldots \ldots \ldots \ldots$

37. LEGR, unsteady pressure distribution, $\pm 10^{\circ} \ldots \ldots \ldots \ldots \ldots \ldots \ldots \ldots \ldots$

38. Clean, unsteady pressure distribution, $\pm 10^{\circ} . \ldots \ldots \ldots \ldots \ldots \ldots \ldots \ldots$

39. Clean, unsteady pressure distribution, $\pm 5.5^{\circ} \ldots \ldots \ldots \ldots \ldots \ldots \ldots$ 


\section{List of Tables}

\section{Page}

1. NACA 4415 Steady State Parameters Summary. . . . . . . . . . . . . . . 20

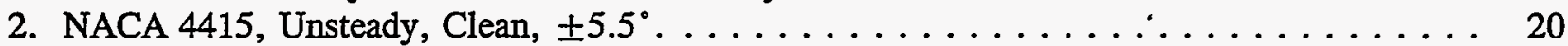

3. NACA 4415 , Unsteady, LEGR, $\pm 5.5^{\circ} \ldots \ldots \ldots \ldots \ldots \ldots \ldots \ldots \ldots \ldots \ldots$

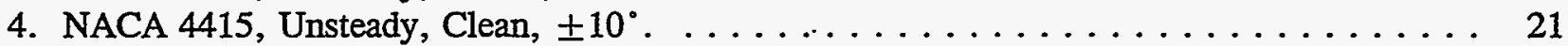

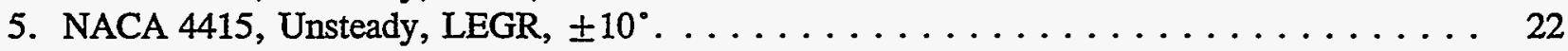




\section{List of Symbols}

$\mathrm{AOA}$

$\mathrm{A} / \mathrm{C}$, a.c.

c

$\mathrm{C}_{\mathrm{d}}$

$\mathrm{C}_{\mathrm{dmin}}$

$\mathrm{C}_{\mathrm{dp}}$

$\mathrm{C}_{\mathrm{dw}}$

$\mathrm{C}_{\mathrm{du}}$

$\mathrm{C}_{1}$

$\mathrm{C}_{\operatorname{lmax}}$

$\mathrm{C}_{\mathrm{ldec}}$

$\mathrm{C}_{\mathrm{lu}}$

$\mathrm{C}_{\mathrm{m}}, \mathrm{C}_{\mathrm{m} / \mathrm{k}}$

$\mathrm{C}_{\mathrm{m} \text { dec }}$

$\mathrm{C}_{\mathrm{minc}}$

$\mathrm{C}_{\mathrm{mo}}$

$\mathrm{C}_{\mathrm{m} k \mathrm{u}}$

$\mathrm{C}_{\mathrm{p}}$

$\mathrm{C}_{\mathrm{pmin}}$

f

$\mathrm{h}$

hp, Hp, HP

$\mathrm{Hz}$

$\mathrm{k}$

$\mathrm{k} / \mathrm{c}$

$\mathrm{p}$

q

$q_{u}$

$\mathrm{q}_{\mathrm{w}}$

$q_{\infty}$

$\operatorname{Re}$

$\mathrm{Re}_{\mathrm{u}}$

$\mathrm{t}$

$\mathrm{U}_{\infty}$

$\mathrm{V}$

$\mathrm{V}_{\mathrm{u}}$

$\mathrm{x}$

$y$
Angle of attack

Alternating current

Model chord length

Drag coefficient

Minimum drag coefficient

Pressure drag coefficient

Wake drag coefficient

Uncorrected drag coefficient

Lift coefficient

Maximum lift coefficient

Lift coefficient at angle of maximum lift, but with angle of attack decreasing Uncorrected lift coefficient

Pitching moment coefficient about the quarter chord

Pitching moment coefficient at angle of maximum lift, but with angle of attack decreasing

Pitching moment coefficient at angle of maximum lift, but with angle of attack increasing

Pitching moment coefficient about the quarter chord, at zero lift

Uncorrected pitching moment coefficient about the quarter chord

Pressure coefficient, $\left(p-p_{\infty}\right) / q_{\infty}$

Minimum pressure coefficient

Frequency

Wind tunnel test section height

Horsepower

Hertz

Grit particle size

Grit particle size divided by airfoil model chord length

Pressure

Dynamic pressure

Uncorrected dynamic pressure

Dynamic pressure through the model wake

Free stream dynamic pressure

Reynolds number

Uncorrected Reynolds number

Time

Corrected free stream velocity

Velocity

Uncorrected velocity

Axis parallel to model reference line

Axis perpendicular to model reference line 
$\alpha$

$\alpha_{\text {dec }}$

$\alpha_{\text {inc }}$

$\alpha_{m}$

$\alpha_{\text {mean }}$

$\alpha_{u}$

$\epsilon$

$\epsilon_{\mathrm{sb}}$

$\epsilon_{\mathrm{wb}}$

$\Lambda$

$\pi$

$\sigma$

$\omega_{\text {red }}, \omega_{\text {rectuced }}$

Angle of attack

Decreasing angle of attack

Increasing angle of attack

Median angle of attack

Mean angle of attack

Uncorrected angle of attack

Tunnel solid wall correction scalar

Solid blockage correction scalar

Wake blockage correction scalar

Body-shape factor

3.1416

Tunnel solid wall correction parameter

Reduced frequency, $\pi \mathrm{fc} / \mathrm{U}_{\infty}$ 


\section{Introduction}

Horizontal-axis wind turbine rotors experience unsteady aerodynamics due to wind shear when the rotor is yawed, when rotor blades pass through the support tower wake, and when the wind is gusting. An understanding of this unsteady behavior is necessary to assist in the calculation of rotor performance and loads. The rotors also experience performance degradation due to surface roughness. These surface irregularities are caused by the accumulation of insect debris, ice, and the aging process. Wind tunnel studies that examine both the steady and unsteady behavior of airfoils can help define pertinent flow phenomena, and the resultant data can be used to validate analytical computer codes.

A NACA 4415 airfoil model was tested in The Ohio State University Aeronautical and Astronautical Research Laboratory (OSU/AARL) $3 \times 5$ subsonic wind tunnel $(3 \times 5)$ under steady flow and stationary model conditions, as well as with the model undergoing pitch oscillations. To study the possible extent of performance loss due to surface roughness, a standard grit pattern (LEGR) was used to simulate leading edge contamination. After baseline cases were completed, the LEGR was applied for both steady state and model pitch oscillation cases. The Reynolds numbers used for steady state conditions were $0.75,1,1.25$ and 1.5 million, while the angle of attack ranged from $-10^{\circ}$ to $+40^{\circ}$. With the model undergoing pitch oscillations, data were acquired at Reynolds numbers of $0.75,1,1.25$, and 1.5 million, at frequencies of $0.6,1.2$, and $1.8 \mathrm{~Hz}$. Two sine wave forcing functions were used, $\pm 5.5^{\circ}$ and $\pm 10^{\circ}$, at mean angles of attack of $8^{\circ}, 14^{\circ}$, and $20^{\circ}$. For purposes herein, any reference to unsteady conditions means the airfoil model was in pitch oscillation about the quarter chord. 


\section{Experimental Facility}

\section{Wind Tunnel}

The OSU/AARL $3 \times 5$ was used to conduct tests on the NACA 4415 airfoil section. Schematics of the top and side views of the tunnel are shown in Figure 1 and Figure 2, respectively. This open circuit tunnel has a velocity range of $0-55-\mathrm{m} / \mathrm{s}(180-\mathrm{ft} / \mathrm{s})$ produced by a $2.4-\mathrm{m}$ (8-ft) diameter, six-bladed fan.

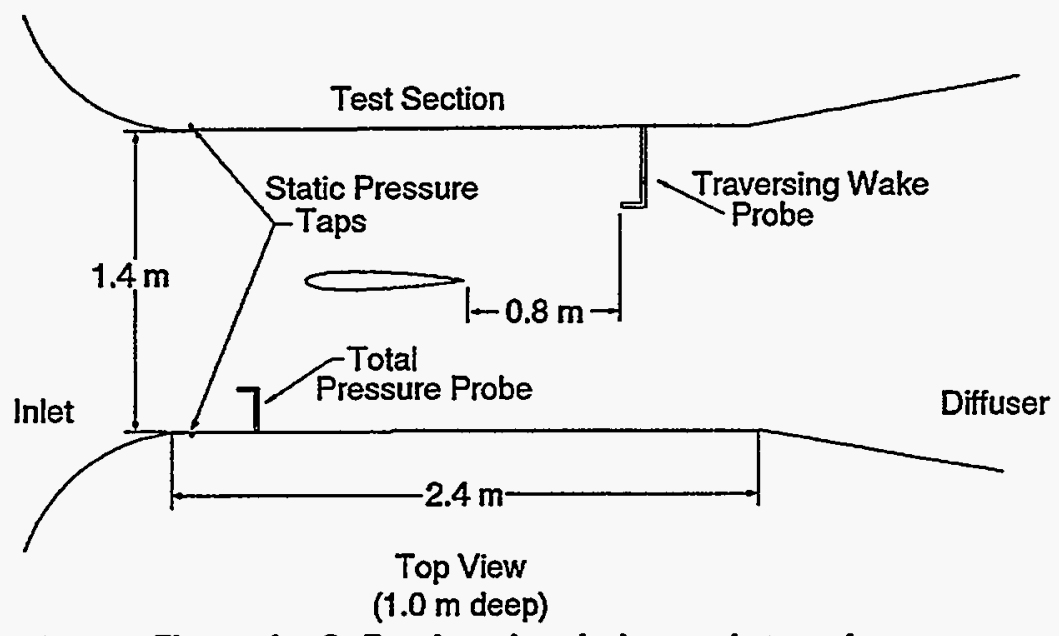

Figure 1. $3 \times 5$ subsonic wind tunnel, top view.

The fan is belt driven by a $93.2-\mathrm{kw}(125-\mathrm{hp})$ three phase a.c. motor connected to a variable frequency motor controller. Nominal test section dimensions are $1.0-\mathrm{m}$ (39-in) high by $1.4-\mathrm{m}$ (55-in) wide by 2.4-m (96-in) long. The 457-mm (18-in) chord airfoil model was mounted vertically in the test section.

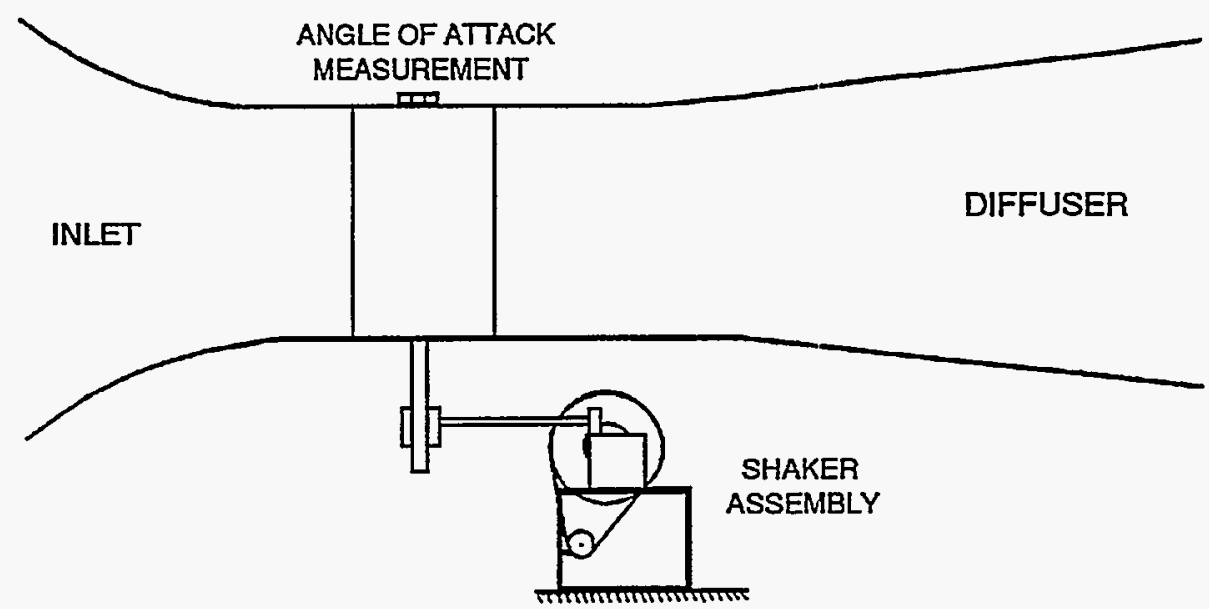

Figure 2. $3 \times 5$ subsonic wind tunnel, side view.

A steel tube through the quarter chord of the model attached the model to the tunnel during testing. An angle of attack potentiometer was fastened to the model at the top of the tunnel as shown in Figure 2. The steady state angle of attack was adjusted with a worm gear drive attached to the model strut below the tunnel floor. 


\section{Oscillation System}

Portions of the airfoil model testing required the use of a reliable pitch oscillation system. The OSU/AARL 'shaker' system incorporated a face cam and follower arm attached to the model support tube below the wind tunnel floor, as shown in Figure 3. The choice of cam governed the type and amplitude of the wave form produced. Sine wave forms with amplitudes of $\pm 5.5^{\circ}$ and $\pm 10^{\circ}$ were used for these tests. The wave form is defined by the equation

$$
\alpha=\alpha_{m}+A \sin (2 \pi f t)
$$

where $\mathrm{A}$ is the respective amplitude. The shaker system was powered by a 5-hp AC motor with variable line frequency controller. The useable oscillating frequency range was $0.1-2.0 \mathrm{~Hz}$, with three frequencies used for this test: $0.6,1.2$, and $1.8 \mathrm{~Hz}$.

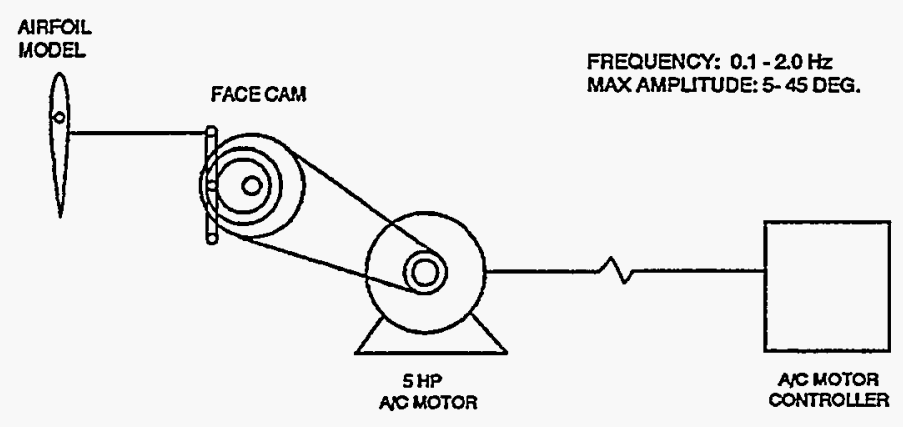

Figure 3. $3 \times 5$ wind tunnel oscillation system. 


\section{Model Details}

A 457-mm (18-in) constant chord NACA 4415 airfoil model was designed by OSU/AARL personnel and manufactured by others. Figure 4 shows the airfoil section; the model measured coordinates are given in Appendix A. The model was made of a carbon composite skin over ribs and foam. The main load

\section{NACA 4415}

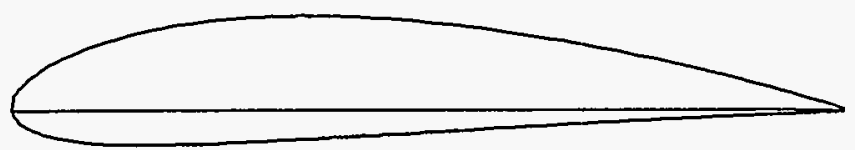

Figure 4. NACA 4415 airfoil section.

bearing member was a 38-mm (1.5-in) diameter steel tube which passed through the model quarter chord station. Ribs and end plates were used to transfer loads from the composite skin to the steel tube. The final surface was hand finished using templates to attain given coordinates within a tolerance of \pm 0.25 -mm ( $\pm 0.01-\mathrm{in})$. The completed model was measured by others using a contact type coordinate measurement machine. Measurements were made in English units and later converted to metric.

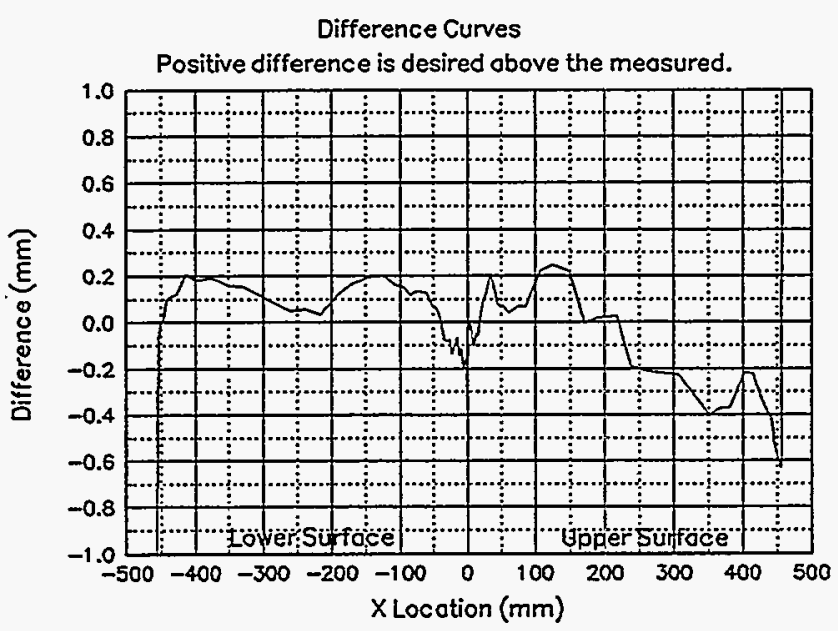

Figure 5. Measured-to-desired model coordinates difference curves.

Figure 5 shows the results of comparing measured-to-desired coordinates by calculating differences normal to the profiled surface at the mid-span station of the model. The spikes apparent near the trailing edge are due to the numerical methods used and are not real.

To minimize pressure response times, which is important for the unsteady testing, the surface pressure tap lead-out lines had to be as short as possible. Consequently, a compartment was built into the model so pressure scanning modules could be installed inside the model. This compartment was accessed through a panel door fitted flush with the model contour on the lower (pressure) surface.

For test cases involving roughness, a standard, repeatable pattern with grit as roughness elements was desired. A roughness pattern was jointly developed by OSU/AARL and KENETECH Windpower personnel from a molded insect pattern taken from a wind turbine in the field by personnel at the 
University of Texas Permian Basin. The particle density was 5 particles per $\mathrm{cm}^{2}$ (32 particles per square inch) in the middle of the pattern, thinning to 1.25 particles per $\mathrm{cm}^{2}$ (8 particles per square inch) at the edge of the pattern. Figure 6 shows the pattern. To make a usable template, the pattern was repeatedly cut into a steel sheet $102-\mathrm{mm}$ (4-in) wide and 91-cm (3-ft) long with holes just large enough for one piece of grit. Based on average particle size from the field specimen, standard \#40 lapidary grit was chosen for the roughness elements, giving $\mathrm{k} / \mathrm{c}=0.0019$ for a $457-\mathrm{mm}$ (18-in) chord model.

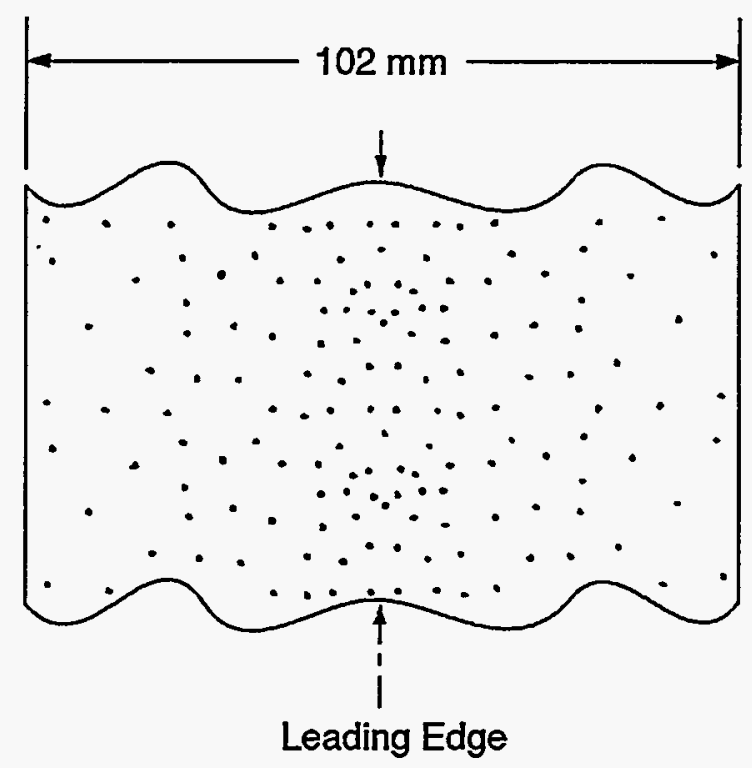

Figure 6. Roughness pattern.

To use the template, 102-mm (4-in) wide double-tack tape was applied to one side of the template and grit was poured and brushed from the opposite side. The tape was then removed from the template and transferred to the model. This method allowed the same roughness pattern to be replicated for any test. 


\section{Test Equipment and Procedures}

\section{Data Acquisition}

Data were acquired and processed from 60 surface pressure taps, four individual tunnel pressure transducers, an angle of attack potentiometer, a wake probe position potentiometer, and a tunnel thermocouple. The data acquisition system included an IBM PC compatible 80486-based computer connected to a Pressure Systems Incorporated (PSI) data scanning system. The PSI system included a 780B Data Acquisition and Control Unit (DACU), 780B Pressure Calibration Unit (PCU), 81-IFC scanning module interface, two 2.5-psid pressure scanning modules (ESPs), one 20-in water column range pressure scanning module, and a 30-channel Remotely Addressed Millivolt Module (RAMM-30). Figure 7 is a schematic the data acquisition system.

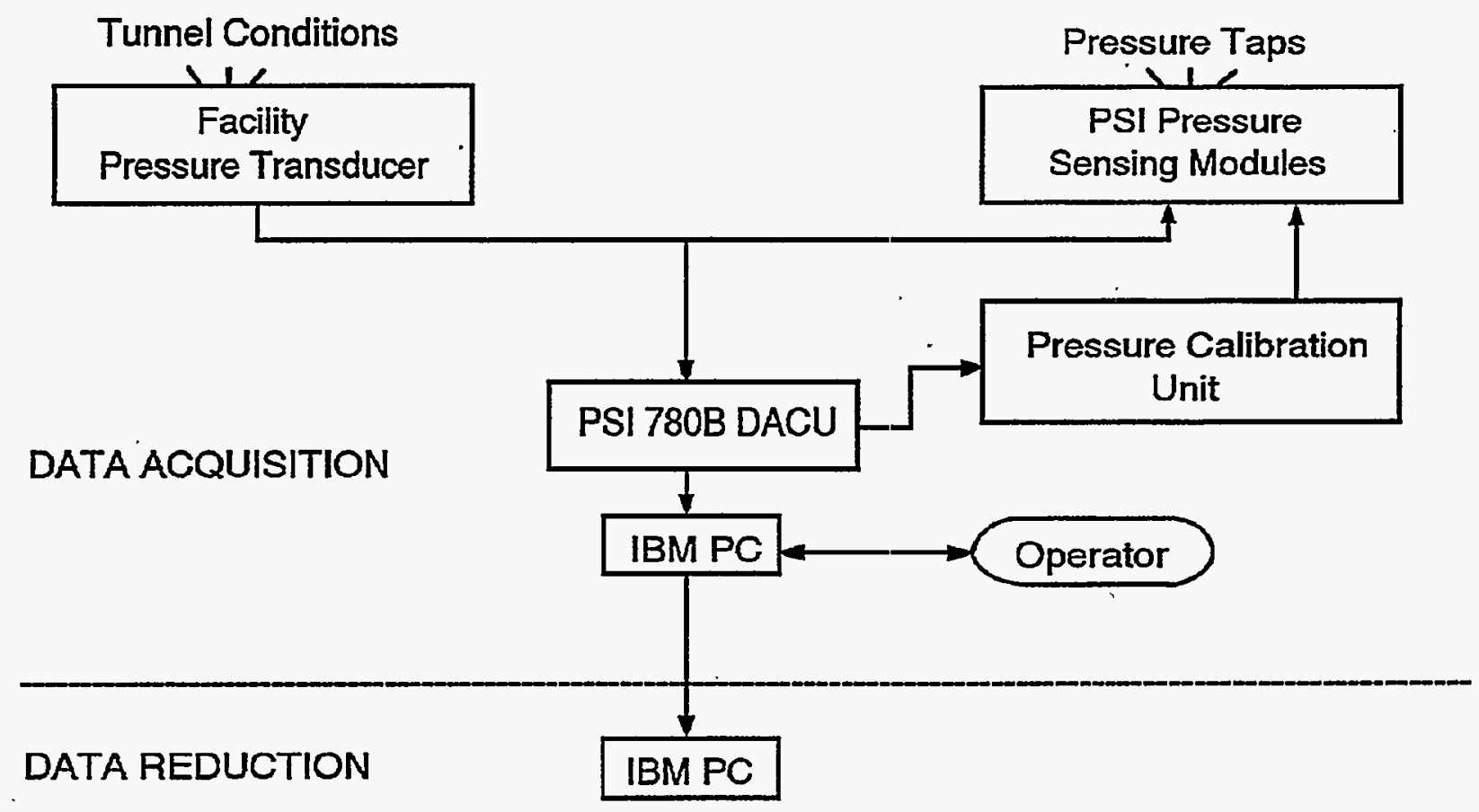

Figure 7. Data acquisition schematic.

Four individual pressure transducers read tunnel total pressure, tunnel north static pressure, tunnel south static pressure, and wake dynamic pressure. Before the test began, these transducers were bench calibrated using a water manometer to determine their sensitivities and offsets. Related values were entered into the data acquisition and reduction program so the transducers could be shunt resistor calibrated before each series of wind tunnel runs.

The rotary angle of attack potentiometer of $0.5 \%$ linearity was regularly calibrated during the tunnel pressure transducers shunt calibration. The angle of attack calibration was accomplished by taking voltage readings at known values of set angle of attack. This calibration method gave angle of attack readings within $\pm 0.25^{\circ}$ over the entire angle range. The wake probe position potentiometer was a linear potentiometer, and it was also regularly calibrated during the shunt calibration of the tunnel pressure transducers.

Calibration of the three ESPs was done simultaneously using the DACU and PCU. At operator request, the DACU commanded the PCU to apply known regulated pressures to the ESPs and read the output 
voltages from each integrated pressure sensor. From these values, the DACU calculated the calibration coefficients and stored them internally until the coefficients were requested by the controlling computer: This calibration was done several times during a run set because the ESPs were installed inside the model and their outputs tended to drift with temperature changes during a test sequence. Frequent on-line calibrations minimized the effect.

For steady state cases, the model would be set to angle of attack and the tunnel conditions were adjusted. At operator request, pressure measurements from the airfoil surface taps and all other channels of information were acquired and stored by the DACU and subsequently passed to the controlling computer for final processing. The angles of attack were always set in the same progression, from negative to positive values.

For model oscillating cases, the tunnel conditions were set while the model was stationary at the desired mean angle of attack. The 'shaker' would be started, and after approximately 10 seconds the model surface pressure and tunnel condition data were acquired. Generally, 120 data scans were acquired over three model oscillation cycles. Since surface pressures were scanned sequentially, the data rate was set so the model rotated through less than $0.50^{\circ}$ during any data burst. Finally, due to the unsteady and complex nature of the pitch oscillation cases, model wake surveys (for drag) were not conducted.

\section{Data Reduction}

The data reduction routine was included as a section of the data acquisition program. This combination of data acquisition and reduction routines allowed data to be reduced on line during a test. By quickly reducing selected runs, integrity checks could be made to ensure the equipment was working properly and to allow timely decisions about the test matrix.

The ambient pressure was manually input into the computer and was updated regularly. This value, along with the measurements from the tunnel pressure transducers and the tunnel thermocouple, were used to calculate tunnel airspeed. As a continuous check of readings, the tunnel total and static pressures were read by both the tunnel individual pressure transducers and the 20 -inch water column ESP.

A typical steady state datum point was derived by acquiring 10 data scans of all channels over a 10 second window at each angle of attack and tunnel condition. The reduction portion of the program processed each data scan to coefficients $\left(\mathrm{C}_{\mathrm{p}}, \mathrm{C}_{1}, \mathrm{C}_{\mathrm{m} / \mathrm{k}}\right.$, and $\left.\mathrm{C}_{\mathrm{dp}}\right)$ using the measured surface pressure voltages, calibration coefficients, tap locations and wind tunnel conditions. All scan sets for a given condition were then ensemble averaged to provide one data set, and that data set was corrected for the effects of solid tunnel walls. All data were saved in electronic form.

Corrections due to solid tunnel sidewalls were applied to the wind tunnel data. As described by Pope and Harper (1966), tunnel conditions are represented by the following equations:

$$
\begin{gathered}
q=q_{u}(1+2 \epsilon) \\
V=V_{u}(1+\epsilon) \\
R_{e}=R_{e_{u}}(1+\epsilon)
\end{gathered}
$$

Airfoil aerodynamic characteristics are then corrected by: 


$$
\begin{gathered}
\alpha=\alpha_{u}+\frac{57.3 \sigma}{2 \pi}\left(C_{l_{u}}+4 C_{m \frac{1}{4}}\right) \\
C_{l}=C_{l_{u}}(1-\sigma-2 \epsilon) \\
C_{m_{\frac{1}{4}}}=C_{m_{\frac{1}{4}}}(1-2 \epsilon)+\frac{\sigma C_{l}}{4} \\
C_{d}=C_{d_{u}}\left(1-3 \epsilon_{s b}-2 \epsilon_{w b}\right)
\end{gathered}
$$

where

$$
\begin{aligned}
& \sigma=\frac{\pi^{2}}{48}\left(\frac{c}{h}\right)^{2} \\
& \epsilon=\epsilon_{s b}+\epsilon_{w b} \\
& \epsilon_{s b}=\Lambda \sigma \\
& \epsilon_{w b}=\frac{c}{h 4} C_{d_{u}}
\end{aligned}
$$

Model wake data were taken for steady state cases when the wake could be completely traversed. Pressures were acquired from a pitot-static probe that was connected to measure incompressible dynamic pressure through the wake. These pressure measurements were used to calculate drag coefficient using a form of the Jones equation derived from Schlichting (1979):

$$
C_{d w}=\frac{2}{c} \int \sqrt{\frac{q_{w}}{q_{\infty}}}\left(1-\sqrt{\frac{q_{w}}{q_{\infty}}}\right) d y
$$

This equation assumes that static pressure at the measurement site is the free-stream value. The integration was done automatically except the computer operator chose the end points of the integration from a plot of the wake survey displayed on the computer screen.

For pitch oscillation cases, model surface pressures were reduced to pressure coefficient form with subsequent integrations and angle of attack considerations giving lift, moment, and pressure drag coefficients. "The wind tunnel was not calibrated for unsteady model pitch conditions; therefore, the unsteady pressure data were not corrected for any possible effects due to time dependent pitching or solid tunnel walls. Also, for these cases, the wind tunnel contraction pressures (used for steady state cases) could not be used to calculate instantaneous freesteam conditions due to slow response. The tunnel conditions were obtained from a total pressure probe and the average of opposing static taps in the test section entrance. This gave nearly instantaneous flow pressure conditions for the pitching frequencies used.

\section{Test Matrix}

The test was designed to study steady state and unsteady pitch oscillation data. Steady state data were acquired at Reynolds numbers of $0.75,1,1.25$, and 1.5 million with and without LEGR. Refer to the tabular data in Appendix B for the actual Reynolds number for each angle of attack for the steady state 
data. The angle of attack increment was two degrees when $-10^{\circ}<\alpha<+10^{\circ}$ or $+20^{\circ}<\alpha<+40^{\circ}$ and one degree when $+10^{\circ}<\alpha<+20^{\circ}$. Wake surveys were conducted to find total airfoil drag over an approximate angle of attack range of $-10^{\circ}$ to $+10^{\circ}$. Unsteady data were taken for Reynolds numbers of $0.75,1,1.25$, and 1.5 million. Sine wave cams with amplitudes $\pm 5.5^{\circ}$ and $\pm 10^{\circ}$ were used for pitch oscillations, and the mean angles for both these amplitudes were $8^{\circ}, 14^{\circ}$, and $20^{\circ}$. For all these conditions, the frequencies were varied to $0.6,1.2$, and $1.8 \mathrm{~Hz}$. All data points for the unsteady cases were acquired for both clean and LEGR cases. 


\section{Results and Discussion}

The NACA 4415 airfoil model was tested under steady state and pitch oscillation conditions. A brief discussion of the results follows, beginning with a comparison of experimental data and computational predictions.

\section{Comparison with Theory}

The wind tunnel steady state data collected in this study were compared with computed predictions made using the North Carolina State Airfoil Analysis Code. This analysis code has proven to be accurate for moderate angles of attack. The analysis was made with specifications set to allow free transition from laminar to turbulent flow, and the pressure distribution comparisons were matched to the same angle of attack as the wind tunnel cases.

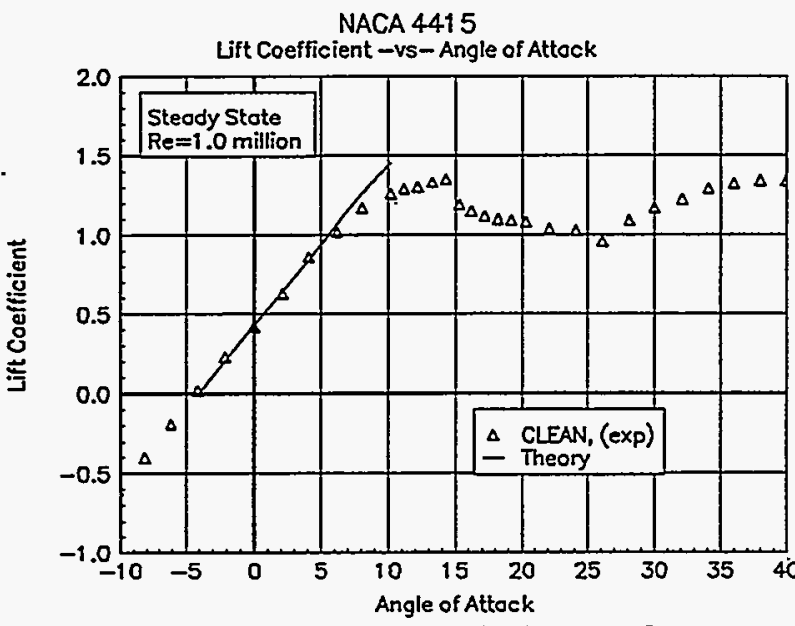

Figure 8. Comparison with theory, $\mathrm{C}_{1}$ vs $a$.

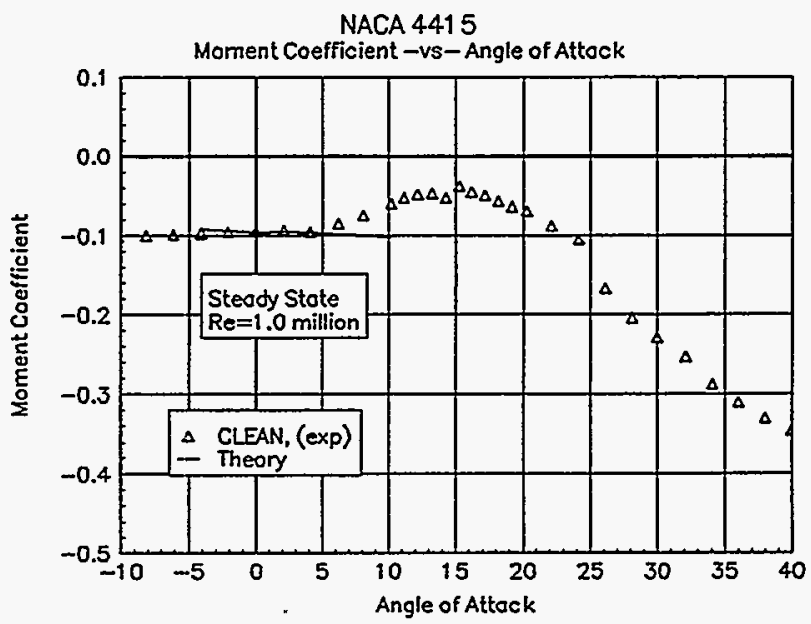

Figure 9. Comparison with theory, $\mathrm{C}_{\mathrm{m}}$ vs $a$.

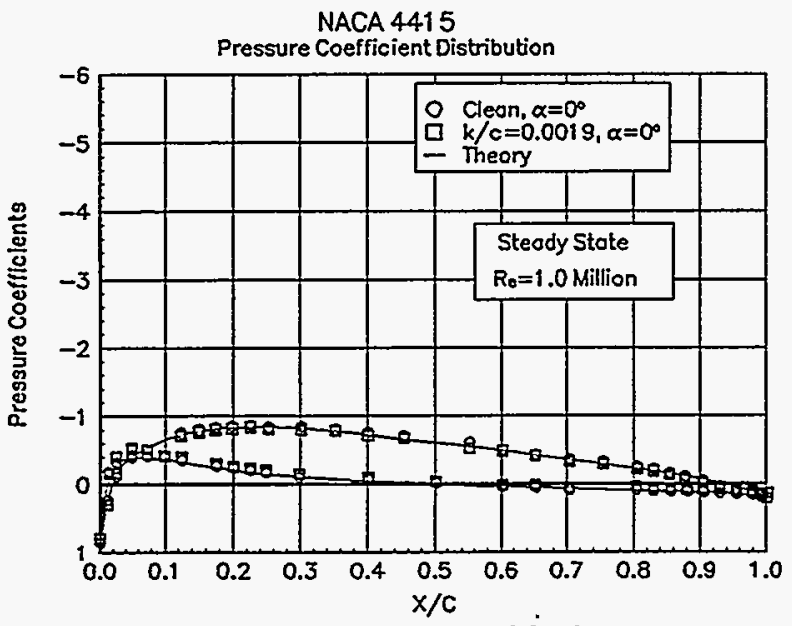

Figure 10. Comparison with theory,. $C_{p}$ vs $x / c, a=0^{\circ}$
NACA 4415

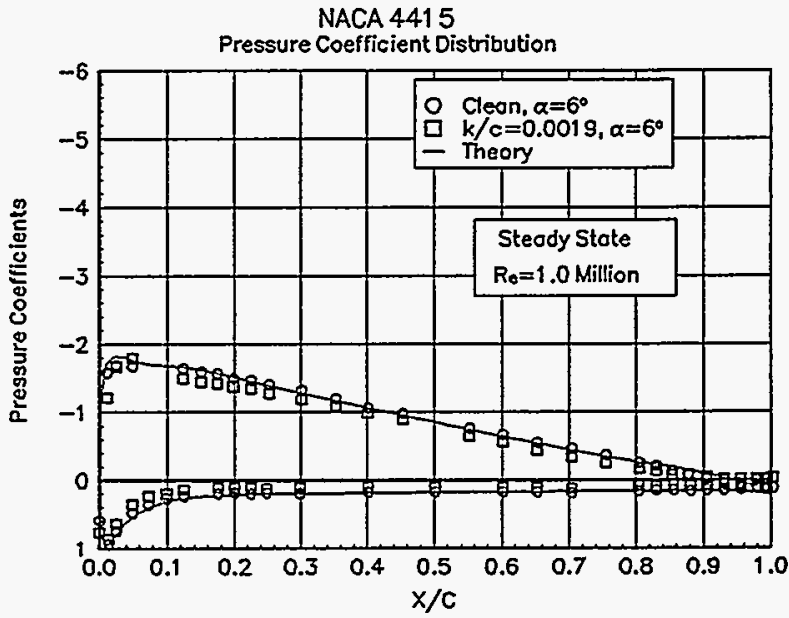

Figure 11. Comparison with theory,. $C_{p}$ vs $x / c, a=6^{\circ}$

Figure 8 shows the lift coefficient versus angle of attack for the 1 million Reynolds number case. For moderate angles of attack, where the analysis code is valid, the comparison shows good agreement. The pitching moment about the quarter chord, Figure 9, also shows good agreement for angles of attack from 
$-5^{\circ}$ to $5^{\circ}$. The pressure distributions shown in Figure 10 and Figure 11 are for angles of attack of $0^{\circ}$ and $6^{\circ}$, respectively, and include clean and LEGR wind tunnel data as compared to computed free transition pressure distributions. For both angles of attack, there is excellent correlation between the experimental and predicted values.

\section{Steady State Data}

The NACA 4415 airfoil model was tested at four Reynolds numbers at nominal angles of attack from $-10^{\circ}$ to $+40^{\circ}$. Figure 12 and Figure 13 show lift coefficients for all the test Reynolds numbers

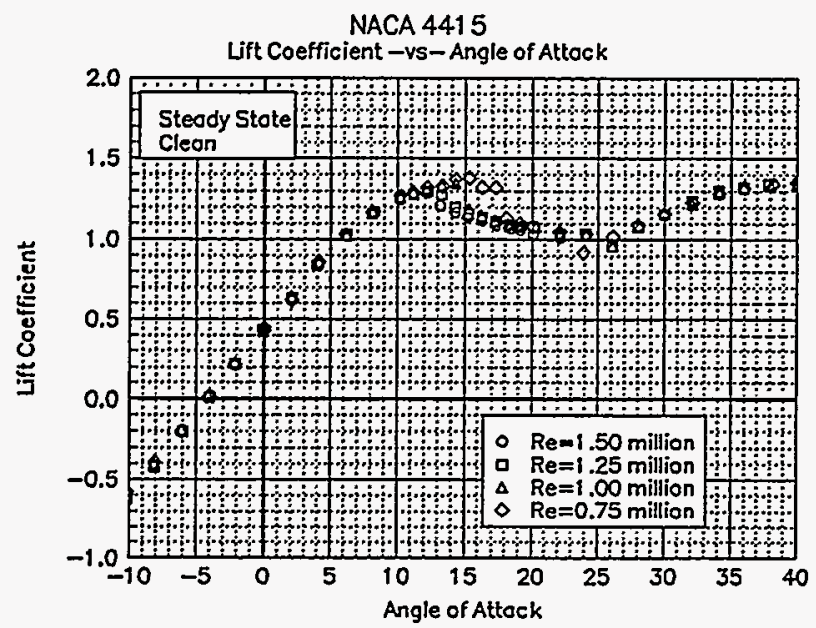

Figure 12. $C_{l}$ vs $a$, clean.

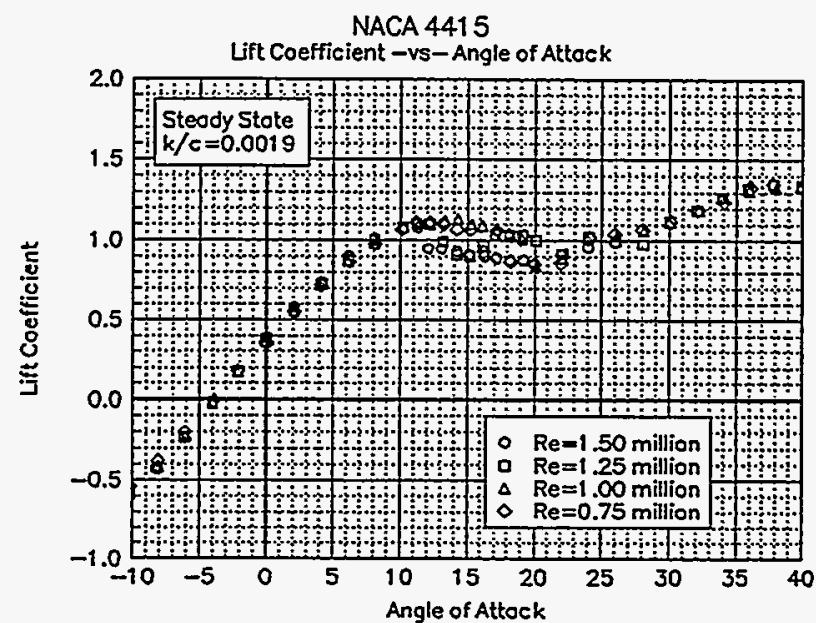

Figure 13. $C_{1}$ vs $a, L E G R, k / c=0.0019$.

for a clean model and with LEGR applied, respectively. The maximum positive lift coefficient for the clean cases is about 1.38 and about 1.11 for the LEGR cases, a $20 \%$ reduction. The stall characteristic is similar for both clean and LEGR cases, with indications of stall occurring at lower angles of attack in

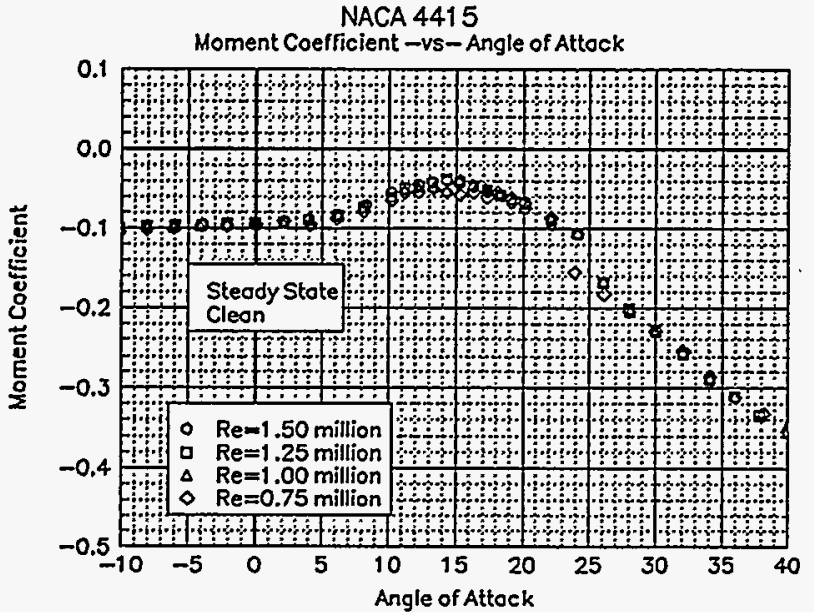

Figure 14. $\mathrm{C}_{\mathrm{m}}$ vs $a$, clean.

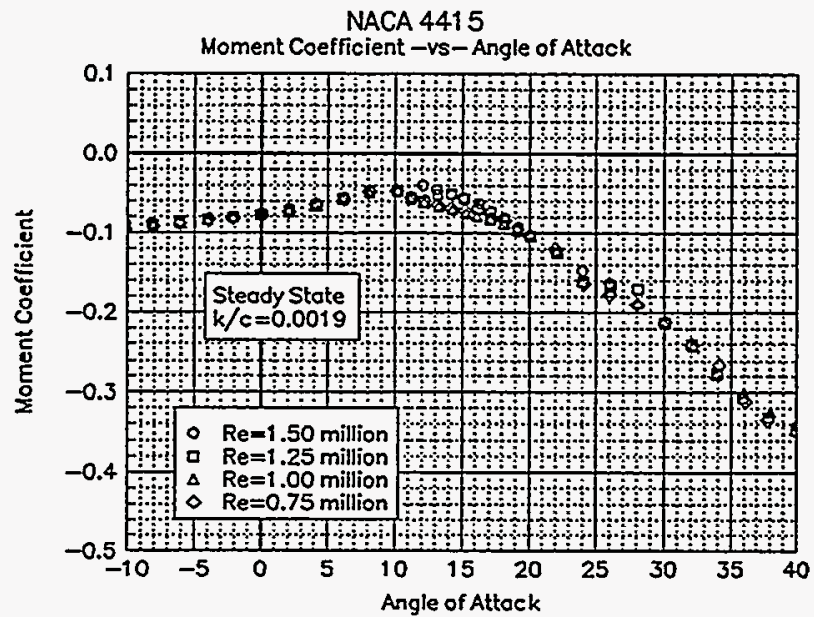

Figure 15. $\mathrm{C}_{\mathrm{m}}$ vs $a, \mathrm{LEGR}, \mathrm{k} / \mathrm{c}=0.0019$.

the higher Reynolds number cases. This was an unexpected result that is not yet understood. For the clean cases, surface pressure taps may be locally affecting the boundary layer, resulting in greater energy losses at the higher Reynolds numbers. Fixed grit roughness size and thinning boundary layer with increasing Reynolds number may explain the effect for LEGR cases. Finally, the average lift curve slope 
for clean data is about 0.104 ; it is slightly lower for the LEGR case at 0.095 . The associated average lift coefficients at zero angle of attack are 0.42 for the clean case and 0.36 for the LEGR case.

Figure 14 shows the pitching moment about the quarter chord for the clean cases, and Figure 15 shows the same for the LEGR cases. The LEGR data have slightly more positive pitching moment at low angles of attack. The moment coefficient about the quarter chord for the 1 million Reynolds number, is -0.0967 for the clean case and -0.0842 for the LEGR case.

Total wake drag data were obtained for both the clean and LEGR cases over an angle of attack range of $-10^{\circ}$ to $10^{\circ}$. A pitot-static probe was used to describe the wake profile. This method is reliable when

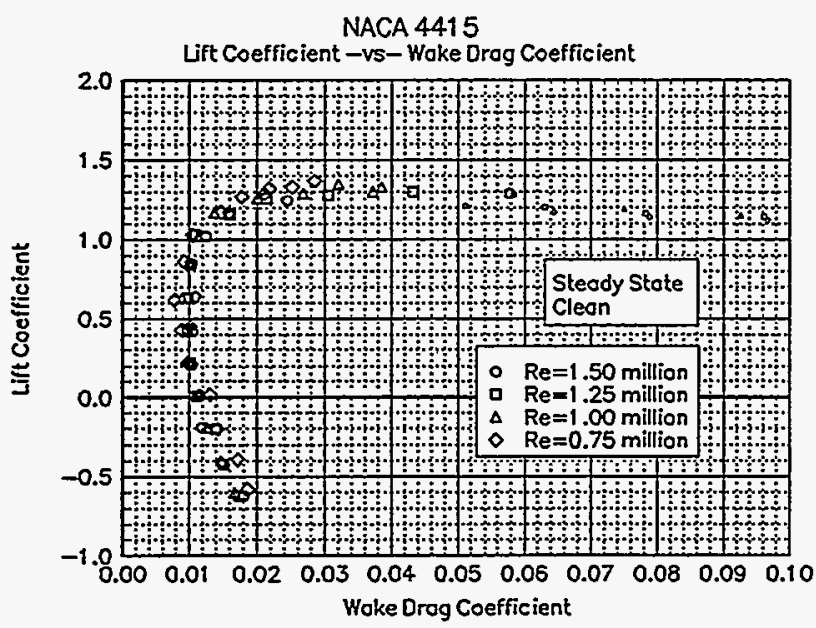

Figure 16. Clean, drag polar.

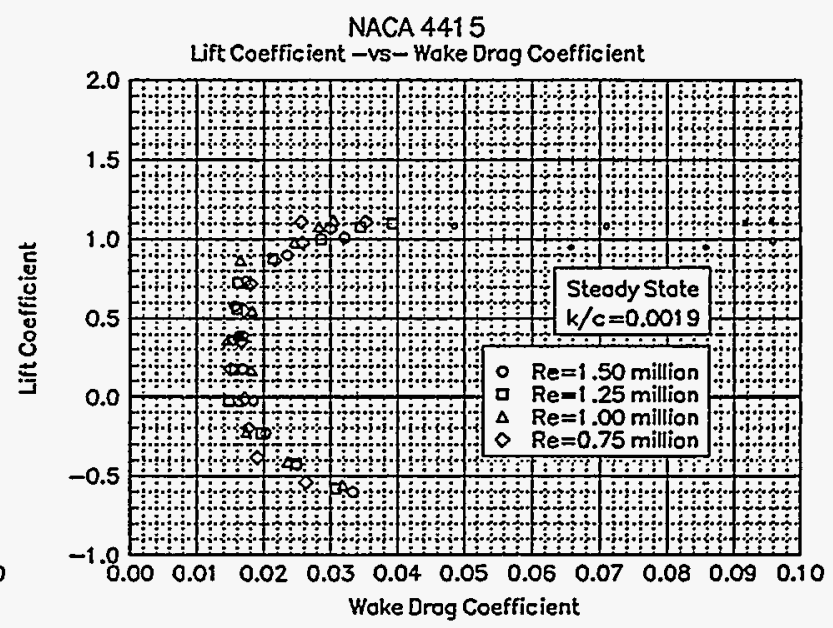

Figure 17. LEGR, drag polar.

there is relatively low turbulence in the wake flow; therefore, only moderate angles of attack have reliable total drag coefficient data. At angles of attack other than $-10^{\circ}$ to $10^{\circ}$, surface pressure data were integrated to give $C_{d p}$ and are shown in the drag polars as small symbols. The model clean drag data are shown in Figure 16, and the LEGR case is shown in Figure 17. At 1 million Reynolds number, minimum drag coefficient for the clean cases was measured as 0.0090 , and 0.0146 for LEGR, a $62 \%$ increase. The general effect of LEGR is to increase drag consistently through most angles of attack.

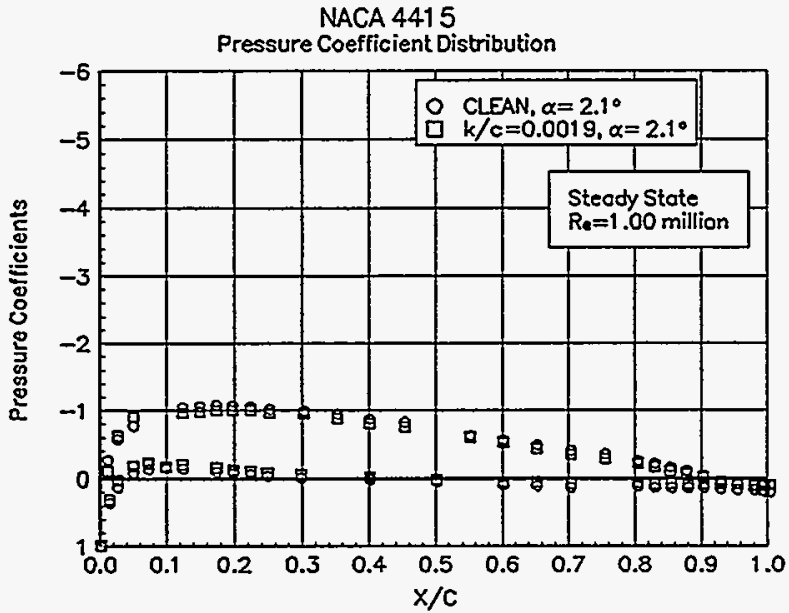

Figure 18. Pressure distribution, $a=2.1^{\circ}$.

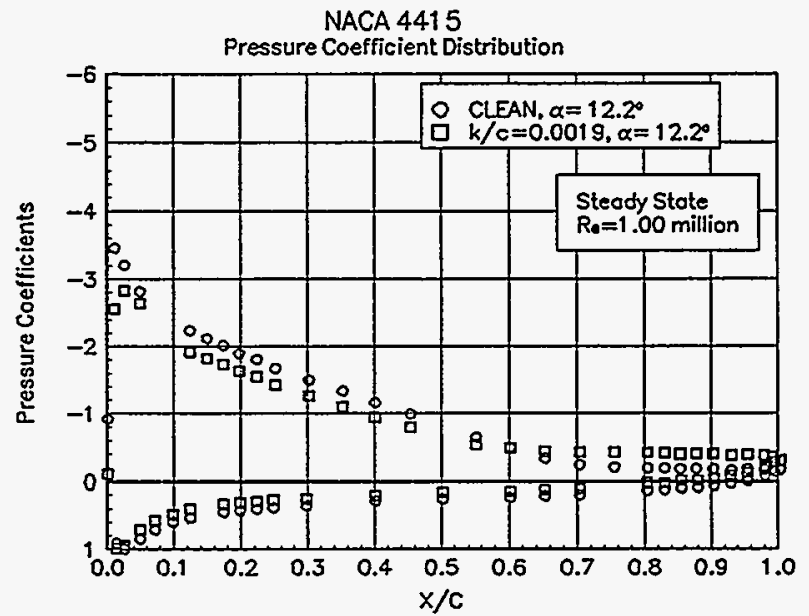

Figure 19. Pressure distribution, $a=12.2^{\circ}$. 
Two examples of the surface pressure distributions are shown in Figure 18 and Figure 19 for $2.1^{\circ}$ and $12.2^{\circ}$, respectively, for 1 million Reynolds number. At the angles of attack close to zero degrees, the effect of LEGR does not appear to significantly affect the pressure distribution compared to the clean case distribution. However, there is an effect apparent in the lift coefficient with values of 0.55 for the LEGR case and 0.63 for the clean case. For the higher angle of attack case, Figure 19, the effect of LEGR is to reduce the magnitude of the pressure peak from -3.5 to -2.9 and generally bring all surface pressures closer to freestream. Also, flow separation occurs earlier in the LEGR case. The net effect is a reduction in lift coefficient from 1.35 to 1.13 , a $16 \%$ decrease.

\section{Unsteady Data}

Unsteady experimental data were obtained for the NACA 4415 airfoil model undergoing sinusoidal pitch oscillations. As mentioned earlier, no attempt was made to calibrate the wind tunnel for the unsteady oscillating model conditions; the steady state tunnel calibration was used to set the flow conditions while the model .was stationary at its mean angle of attack. The use of the unsteady data should be limited to comparisons with other models tested in this same facility and can be used to detect possible trends. A comprehensive set of test conditions was used to describe unsteady behavior of an airfoil, including two angle of attack amplitudes, $\pm 5.5^{\circ}$ and $\pm 10^{\circ}$; four Reynolds numbers, $0.75,1,1.25$, and 1.5 million; three pitch oscillation frequencies, $0.6,1.2$, and 1.8; and three mean angles of attack, $8^{\circ}, 14^{\circ}$, and $20^{\circ}$.
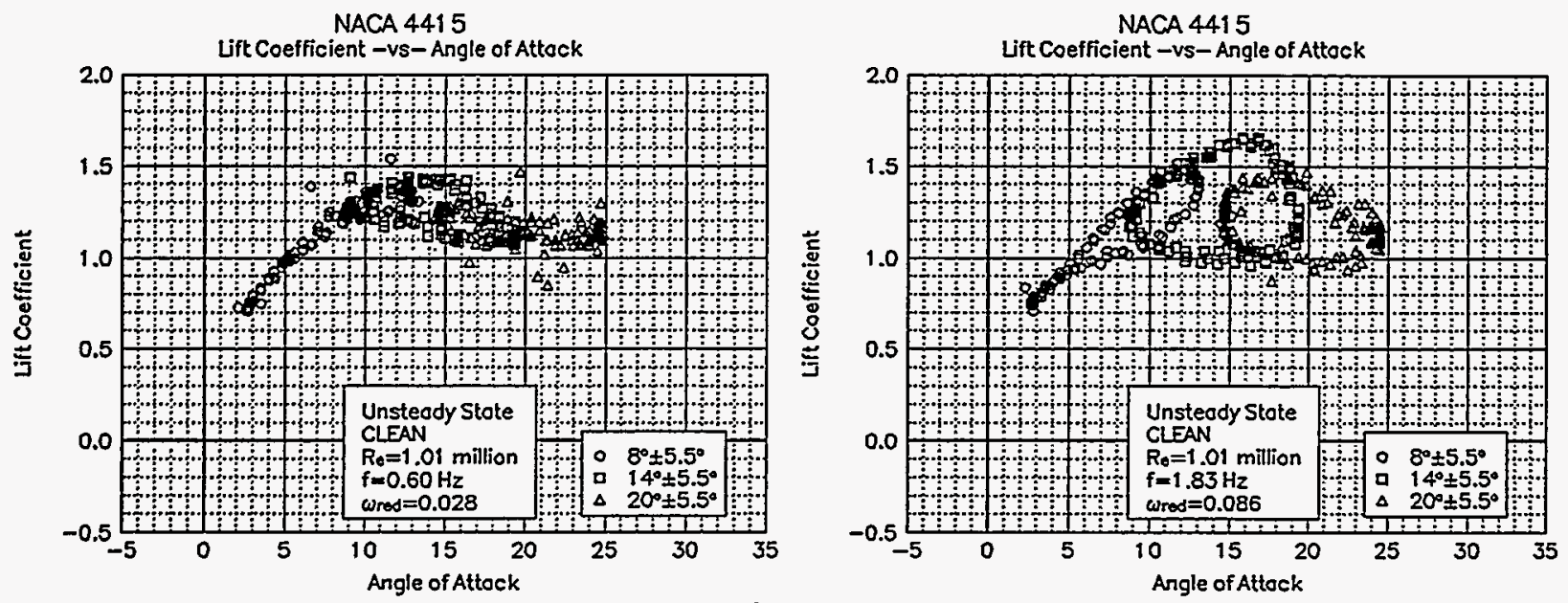

Figure 20. Clean, $C_{1}$ vs $a, \omega_{\text {red }}=0.028, \pm 5.5^{\circ}$.

Figure 21. Clean, $C_{1}$ vs $a, \omega_{\text {red }}=0.086, \pm 5.5^{\circ}$.

Figure 20 shows the lift coefficient versus angle of attack for the $\pm 5.5^{\circ}$ amplitude, model clean case, at reduced frequency of 0.028 and 1 million Reynolds number. Note that all three mean angles of attack are plotted on the same figure. The maximum pre-stall lift coefficient for this case is near 1.44 and occurs when the airfoil is traveling with the angle of attack increasing. In contrast, when the model is traveling through decreasing angles of attack, the stall recovery is delayed and a hysteresis behavior is exhibited in the lift coefficient that can be seen throughout all the unsteady data. To obtain some measure of this hysteresis behavior, the lift coefficient on the "return" portion of the curve, at the angle of attack where maximum lift coefficient occurs, can be used. For the case discussed here the hysteresis lift coefficient is 1.21 , a $16 \%$ decrease from the 1.44 unsteady maximum value. By comparison, the steady state maximum lift coefficient is 1.35. At higher reduced frequency of 0.086 , the hysteresis behavior is more pronounced, as seen in Figure 21. In addition to greater hysteresis, the maximum lift coefficient is increased to about 1.66 , a $23 \%$ increase over the steady state value. The corresponding hysteresis lift coefficient is 1.08 . This significant difference between steady state behavior and unsteady hysteresis 
behavior is a main reason that unsteady testing should be required for airfoils used in wind turbine applications.
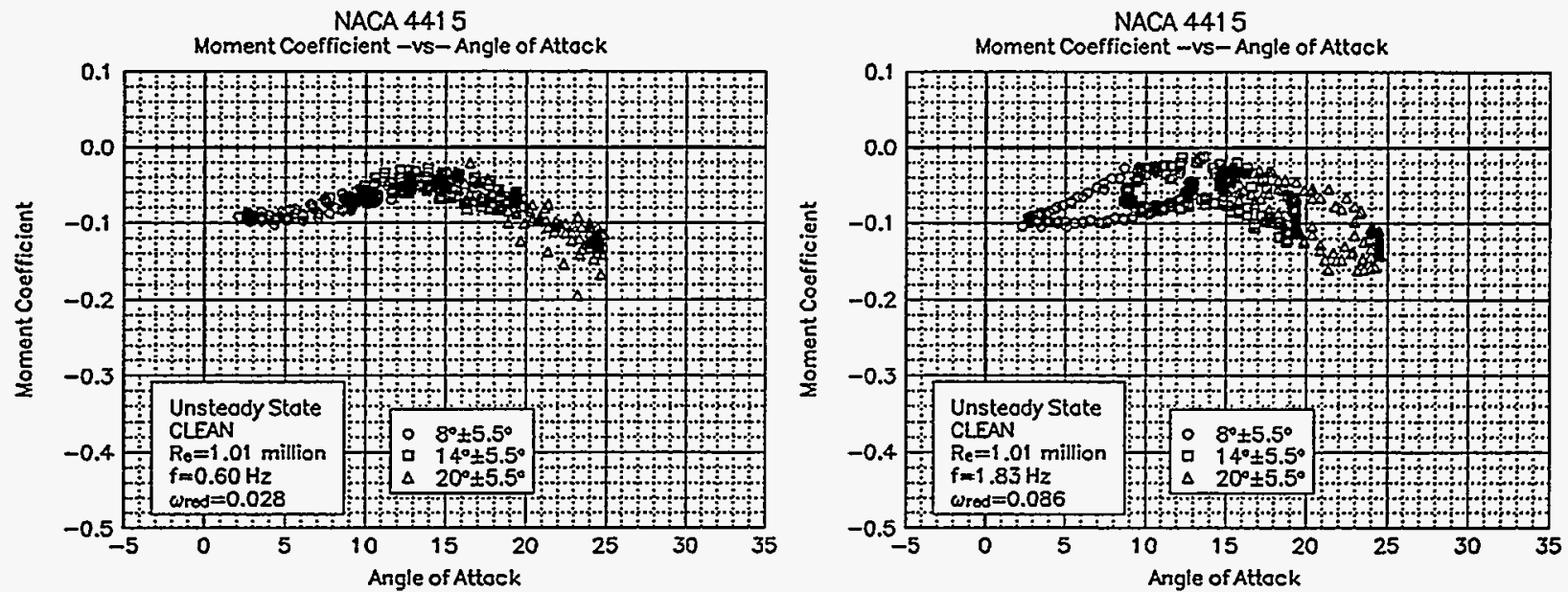

Figure 22. Clean, $C_{m}$ vs $a, \omega_{\text {red }}=0.028, \pm 5.5^{\circ}$. Figure 23. Clean, $C_{m}$ vs $a, \omega_{\text {red }}=0.086, \pm 5.5^{\circ}$.

The pitching moment shown in Figure 22 and Figure 23 corresponds to the same conditions as the two lift coefficient plots previously discussed. Hysteresis behavior is indicated but it is not as apparent as in the lift coefficient plots. However, the higher reduced frequency case does show more hysteresis than the lower reduced frequency case. For reference, the steady state maximum lift occurs near $14^{\circ}$ angle of attack, and the steady state pitching moment at this maximum lift point is -0.0526. In comparison, when the airfoil is undergoing pitch oscillation for the lower frequency, pitching moment varies from -0.0593 to -0.0310 (at the angle of attack where maximum lift occurs); a $13 \%$ increase to a $41 \%$ decrease in magnitude from the steady state value. Note the angle of attack where the maximum lift coefficient occurs does not necessarily show the greatest hysteresis behavior but does give a relative indication of the effect.

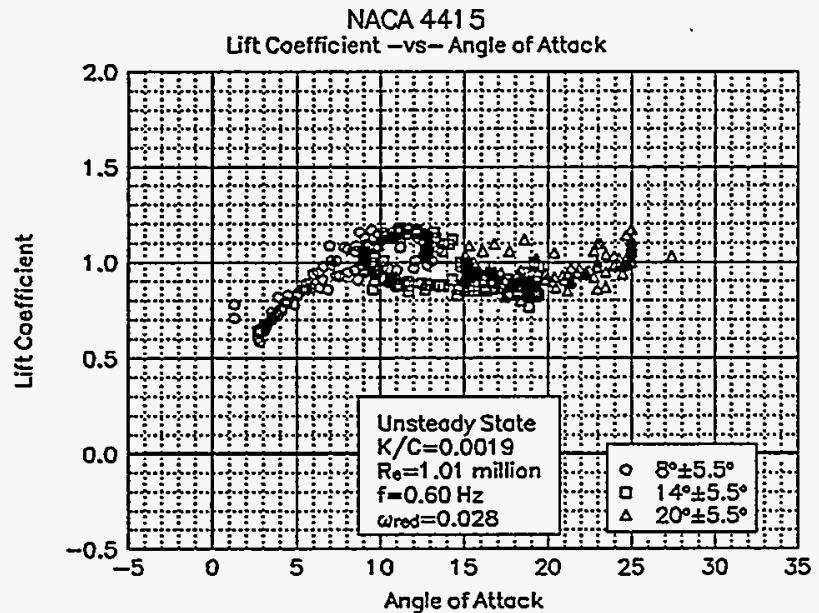

Figure 24. LEGR, $C_{1}$ vs $a, \omega_{\mathrm{red}}=0.028, \pm 5.5^{\circ}$.

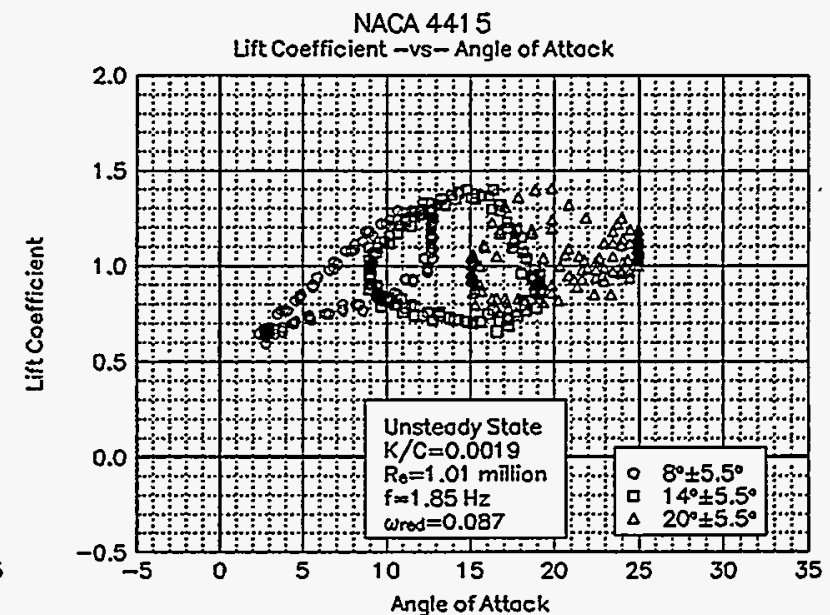

Figure 25. LEGR, $C_{1}$ vs $a, \omega_{\text {red }}=0.087, \pm 5.5^{\circ}$.

Compared to the clean data, the application of LEGR reduces the maximum lift coefficient in the pitch oscillation cases. Lift coefficient versus angle of attack with LEGR applied is shown in Figure 24 for the 0.028 reduced frequency case. The 0.087 reduced frequency case is shown in ?. Both correspond to the same run conditions that were described earlier for the clean cases. For the lower reduced 
frequency, the maximum unsteady lift coefficient is reduced to 1.17 from the corresponding clean case of 1.44 , a $19 \%$ decrease. Hysteresis behavior is apparent at this frequency and is of similar order to the clean case; the corresponding hysteresis lift coefficient is 0.88 when LEGR is applied. In contrast, the higher frequency LEGR case has a maximum lift coefficient of 1.39 while the model is increasing in angle of attack, and the corresponding decreasing angle of attack lift coefficient is 0.72 . In this case, the application of LEGR gives a.greater hysteresis loop behavior than the clean case at the same run conditions.
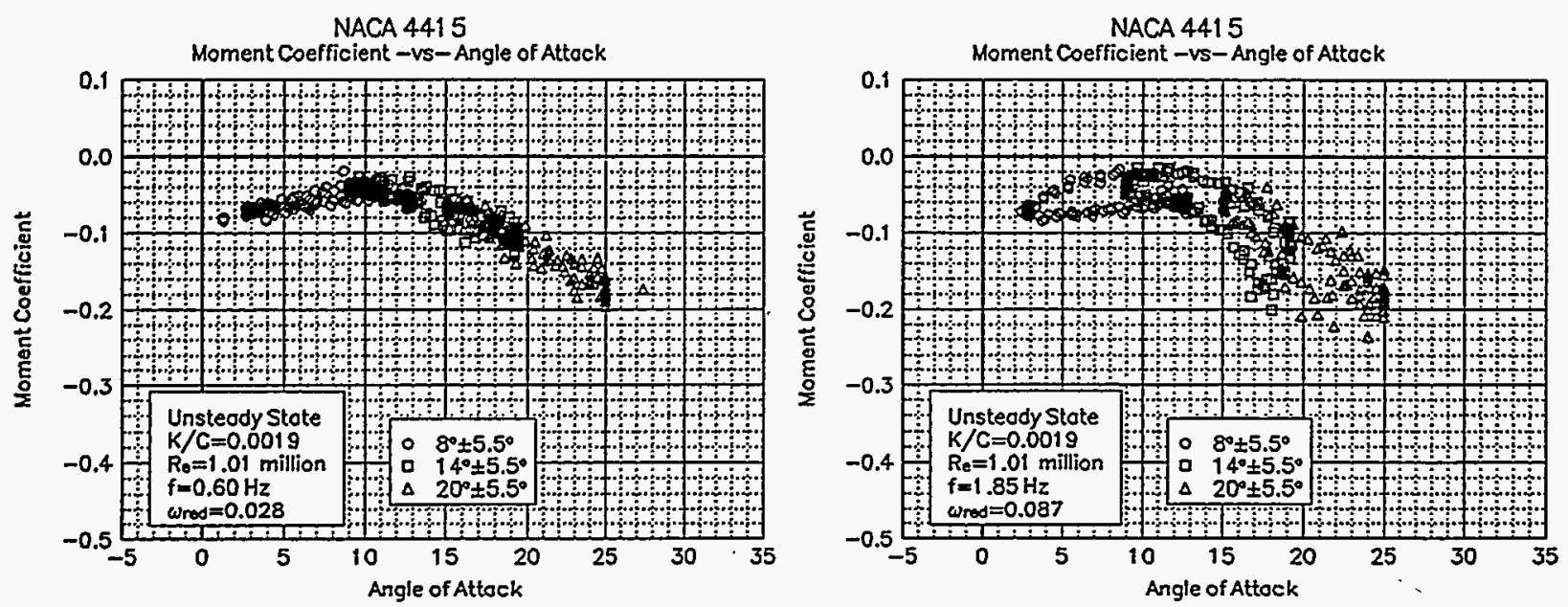

Figure 26. LEGR, $\mathrm{C}_{\mathrm{m}}$ vs $a, \omega_{\text {red }}=0.028, \pm 5.5^{\circ}$. Figure 27. $L E G R, \mathrm{C}_{\mathrm{m}}$ vs $a, \omega_{\text {red }}=0.087, \pm 5.5^{\circ}$.

The pitching moment coefficient shown in Figure 26 is for 0.028 reduced frequency with LEGR applied. At the angle of unsteady maximum lift, the pitching moment ranges from -0.0508 to -0.0267 , while the steady state LEGR pitching moment is -0.0617 at the steady state stall angle of attack $\left(12.2^{\circ}\right)$. The higher reduced frequency of 0.087 with LEGR applied is shown in Figure 27. As was seen with the lift coefficient, pitching moment hysteresis is more apparent at the higher reduced frequency than in the corresponding clean case (shown in Figure 23). Unsteady maximum lift angle of attack for this reduced frequency occurs at $14.3^{\circ}$, and the pitching moment ranges from -0.0841 to -0.0341 at that angle. Throughout the higher angle of attack range, the magnitude of the unsteady pitching moment can be much different than that resulting from steady state clean conditions (steady state pitching moment at maximum lift is -0.0526). It seems these differences can have an impact on the fatigue life predictions of a wind turbine system.

In addition to the $\pm 5.5^{\circ}$ unsteady experimental data, $\pm 10^{\circ}$ unsteady data were obtained with and without LEGR. The data were taken at 1 million Reynolds number using the same mean angles and frequencies as the $5.5^{\circ}$ amplitude cases. Figure 28 and Figure 29 show the $\pm 10^{\circ}$, unsteady, clean, lift coefficient for the reduced frequencies of 0.029 and 0.089 , respectively. The maximum lift coefficient for the lower frequency is 1.55 and occurs, as expected, when the airfoil is traveling through increasing angles of attack. The hysteresis lift coefficient (at $14.9^{\circ}$ ) is 1.07 . At the higher reduced frequency, the maximum lift coefficient occurs at a higher angle of attack, $19.4^{\circ}$, and is 1.95 . The corresponding hysteresis lift coefficient is 0.92 . The difference between the maximum lift coefficient and the hysteresis lift coefficient indicates a much greater hysteresis response than experienced for the lower reduced frequency. The steady state, clean, maximum lift coefficient is 1.35 ; therefore, the unsteady behavior created lift coefficients up to $44 \%$ higher that the steady state conditions.

The quarter chord pitching moments with the same reduced frequencies as the lift coefficient cases are shown in Figure 30 and Figure 31. The hysteresis behavior observed in the lift coefficient plots is also 


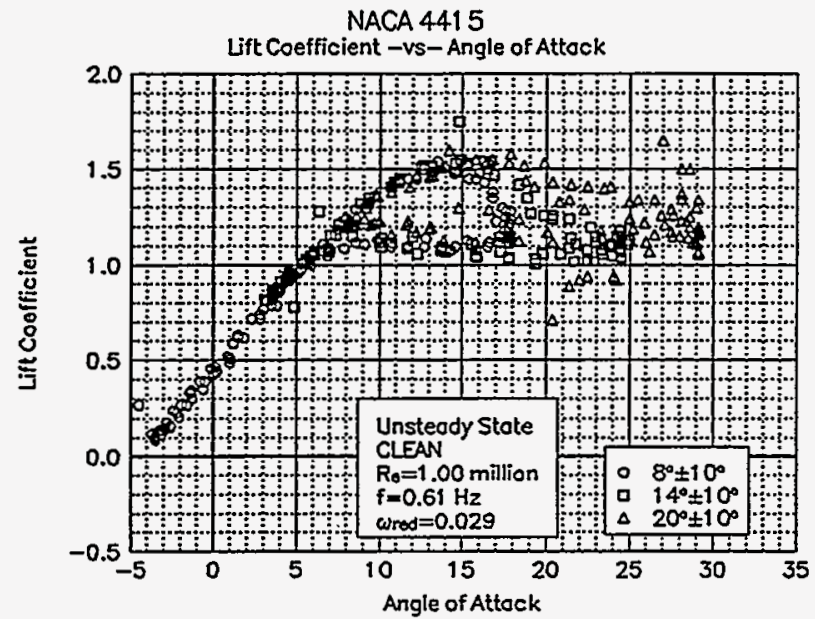

Figure 28. Clean, $C_{1}$ vs $\alpha_{2} \omega_{\text {red }}=0.029, \pm 10^{\circ}$.

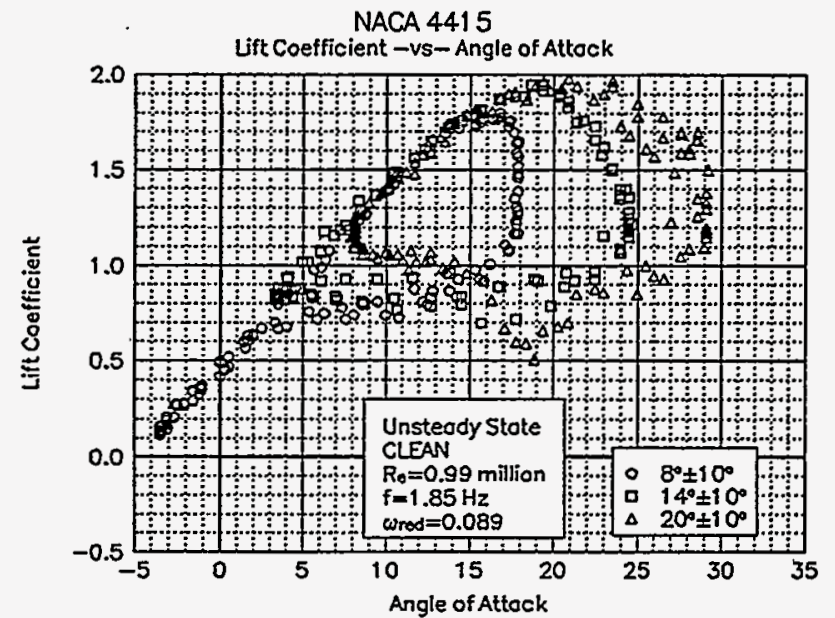

Figure 29. Clean, $c_{l}$ vs $a, \omega_{\text {red }}=0.089, \pm 10^{\circ}$.

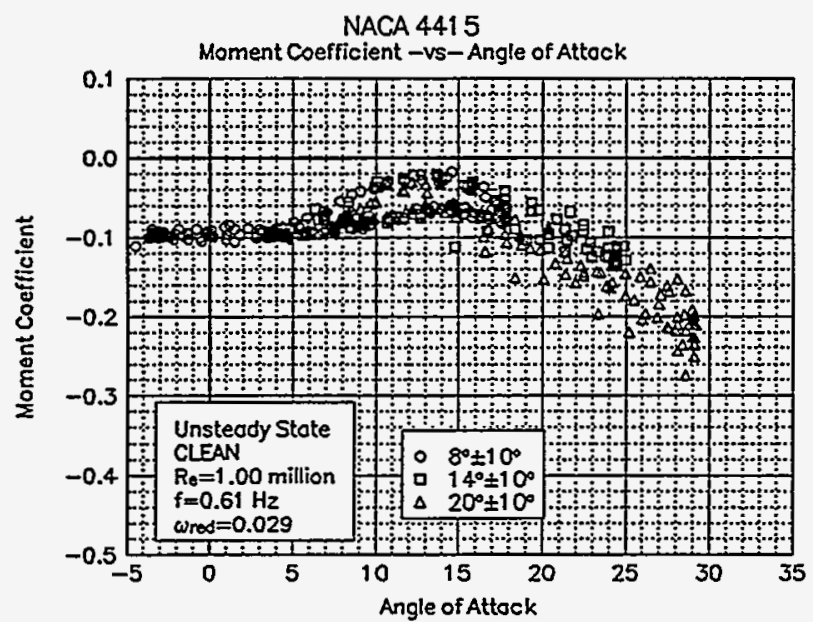

Figure 30. Clean, $\mathrm{C}_{\mathrm{m}}$ vs $a, \omega_{\mathrm{red}}=0.029, \pm 10^{\circ}$.

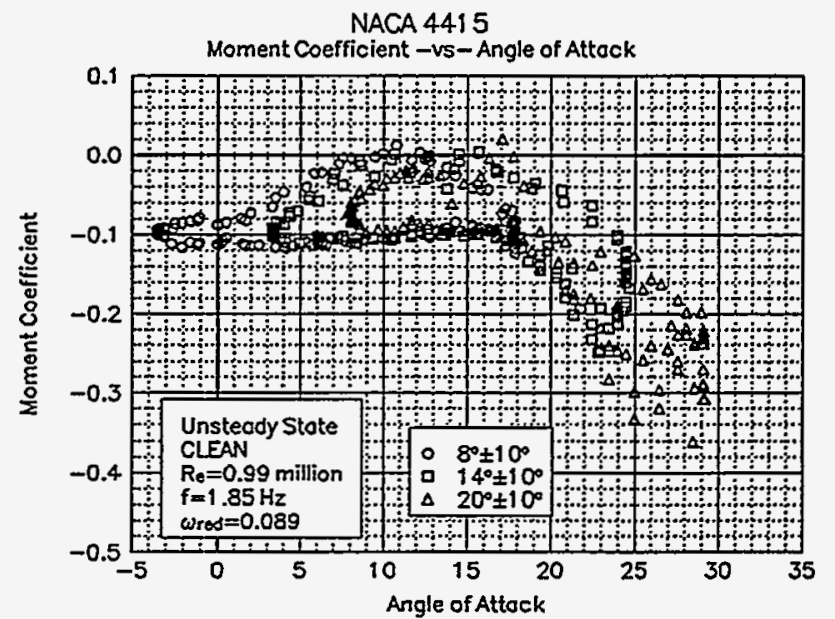

Figure 31. Clean, $C_{m}$ vs $a, \omega_{\text {red }}=0.089, \pm 10^{\circ}$.

reflected in this pitching moment data. Near the maximum lift angle, $14.9^{\circ}$ for the lower frequency, the pitching moment coefficient ranges from -0.0743 to -0.0276 ; the 0.089 reduced frequency case has maximum lift near $19.4^{\circ}$ and pitching moment ranges from -0.1399 to -0.0358 . The higher reduced frequency again shows large hysteresis loops for all three mean angles of attack. In comparison, the steady state pitching moment is -0.0526 near the steady state maximum lift coefficient angle of attack of $14^{\circ}$.

The application of LEGR degrades the lift performance of the airfoil, as would be expected from the results discussed previously. The LEGR lift coefficient data for reduced frequencies of 0.028 and 0.087 are shown in Figure 32 and Figure 33, respectively. The maximum lift coefficient is reduced to 1.34 from 1.55 for the low frequency clean case. Although there is a reduction, this value is still significantly higher than the LEGR steady state case, which has a maximum lift coefficient of 1.13 at $14.3^{\circ}$ angle of attack. The higher reduced frequency has a maximum lift coefficient of 1.80 , which occurs near $19^{\circ}$ angle of attack. The corresponding lift coefficient at $19^{\circ}$ for the airfoil traveling with decreasing angle of attack is 0.71 , a $60 \%$ reduction from the maximum.

Figure 34 and Figure 35 show the corresponding pitching moment coefficients for the reduced frequencies of 0.028 and 0.087 . For the 0.028 reduced frequency case, the pitching moment varies from -0.1119 

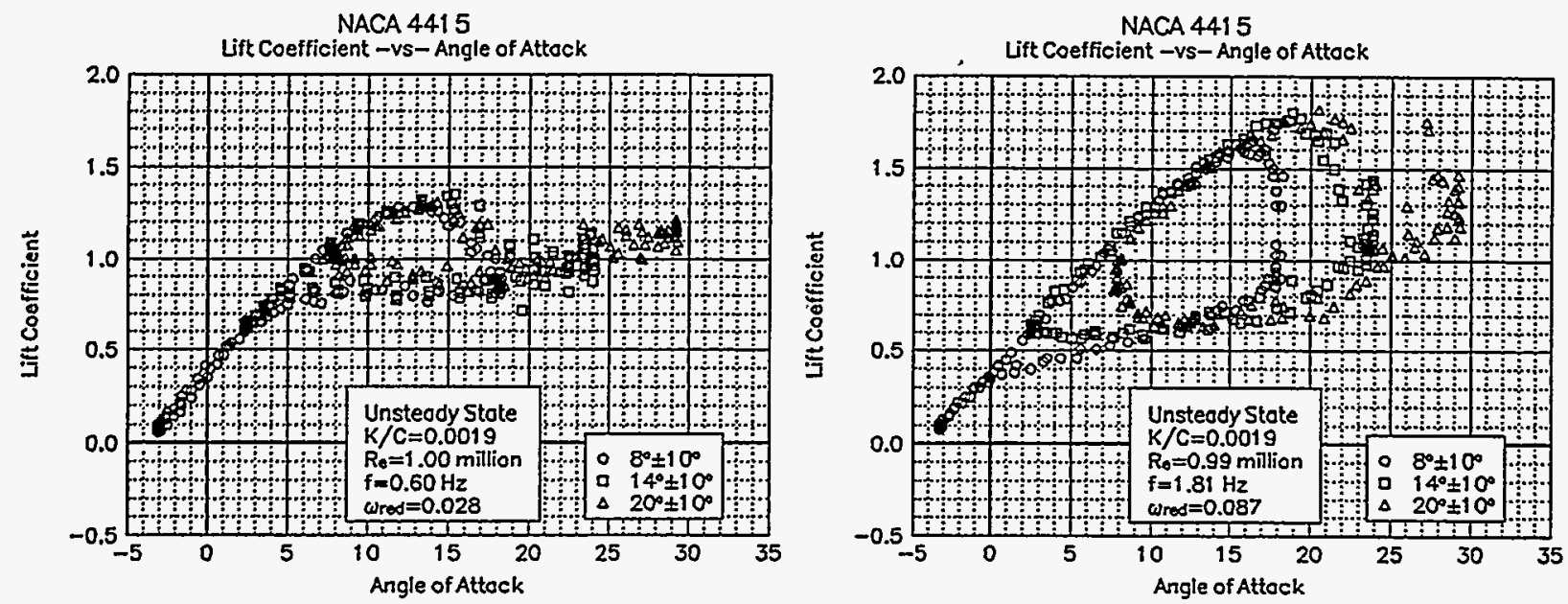

Figure 32. $\mathrm{LEGR}, \mathrm{C}_{\mathrm{l}}$ vs $a, \omega_{\text {red }}=0.028, \pm 10^{\circ}$.

Figure 33. LEGR, $C_{1}$ vs $a, \omega_{\text {red }}=0.087, \pm 10^{\circ}$.
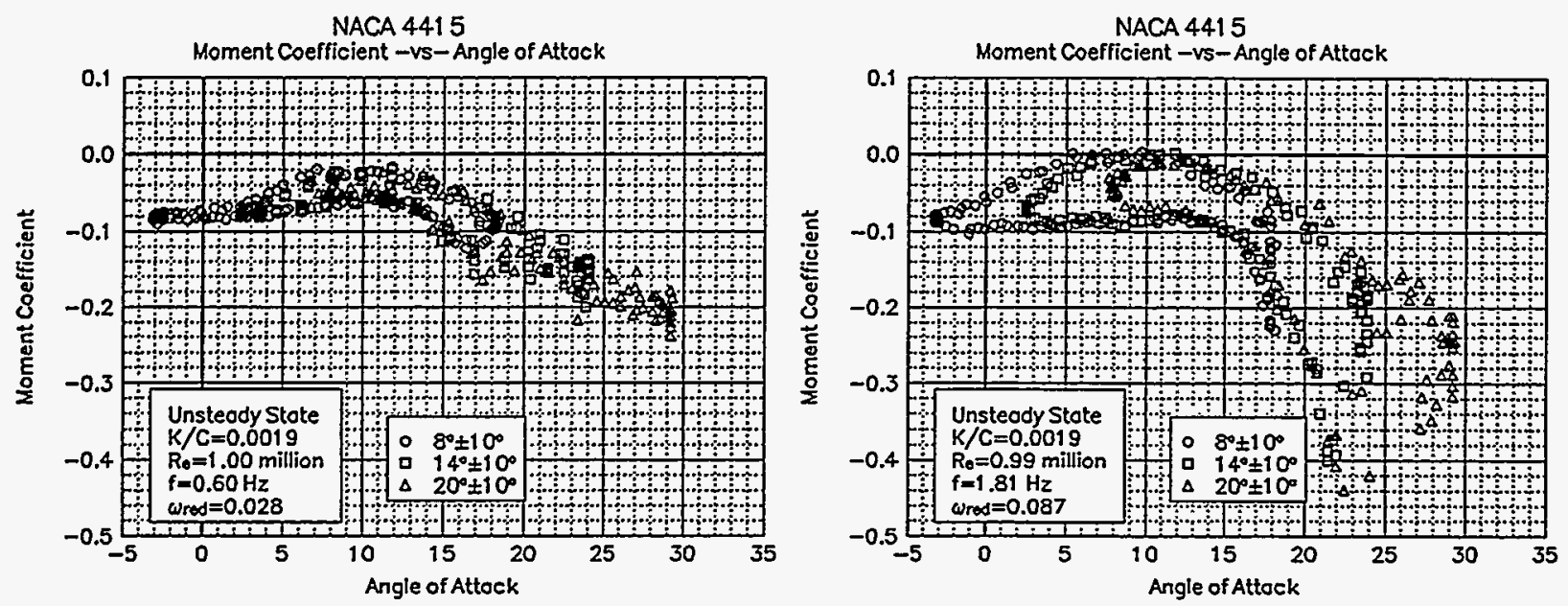

Figure 34. LEGR, $C_{\mathrm{m}}$ vs $a, \omega_{\text {red }}=0.028, \pm 10^{\circ}$.

Figure 35. $L E G R, C_{m}$ vs $a, \omega_{\text {red }}=0.087, \pm 10^{\circ}$.

to -0.0488 at $14.9^{\circ}$ (where the maximum lift occurs). The hysteresis behavior is more pronounced for the higher reduced frequency case, where the range of pitching moments at the maximum lift angle of $18.9^{\circ}$ is from -0.2082 to -0.0625 . These values can then be compared to the steady state LEGR value of -0.0617 .

Although all the unsteady data have not been discussed here, the previous discussion included typical examples of the wind tunnel data. The remaining cases of the $\pm 5.5^{\circ}$ and $\pm 10^{\circ}$ oscillation data for all the Reynolds numbers are included in Appendix C.

The following four unsteady pressure distributions show examples of the data used to calculate the lift, pressure drag, and pitching moment coefficients. Figure 36 shows the distribution for a clean model with a reduced frequency of 0.028 , mean angle of attack of $8^{\circ}$, and $\pm 10^{\circ}$ pitch oscillation. For plotting clarity, the model pressures were 'unwrapped' about the trailing edge. The upper surface pressures are depicted on the right side of the surface plot; lower surface values are on the left. The trailing edge is at the midpoint of the $\mathrm{x}$-axis with the leading edge at each extreme. The time scale corresponds to angle of attack. For this case, the separated flow area is defined by the irregular, rough areas of the upper surface portion of the plot. The lower surface stays attached through all airfoil oscillations. Figure 37 shows the LEGR case for the same test conditions as the previous figure. In this case, the pressure peaks 
were not as high as for the clean case, and the stall behavior is more pronounced. Also, each case shows the effect of a bad tap on the lower surface near the trailing edge; it is indicated by the line of pressure irregularity. This lower response tap did not significantly affect the integrated results and remained in the reduction process.

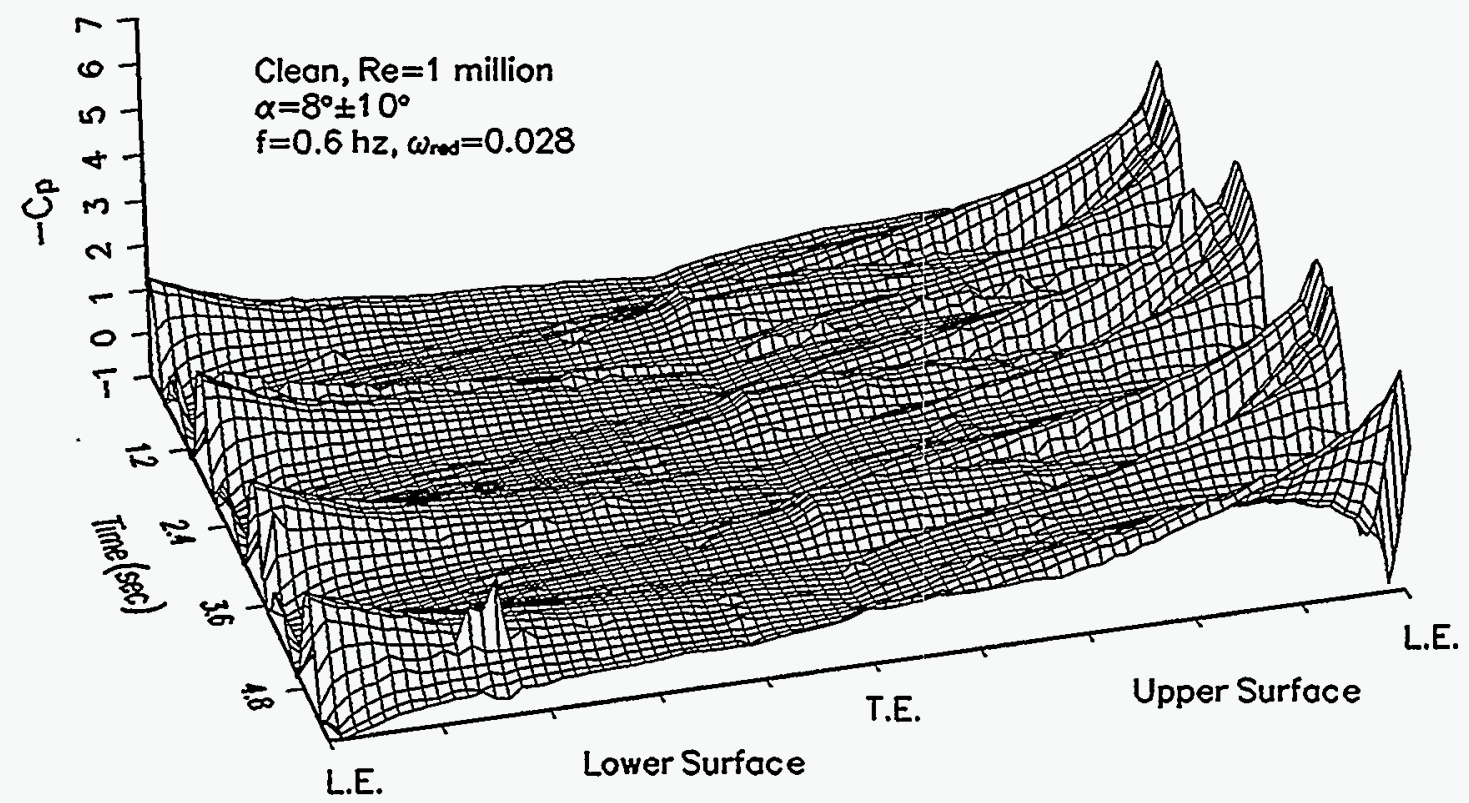

Figure 36. Clean, unsteady pressure distribution, $\pm 10^{\circ}$.

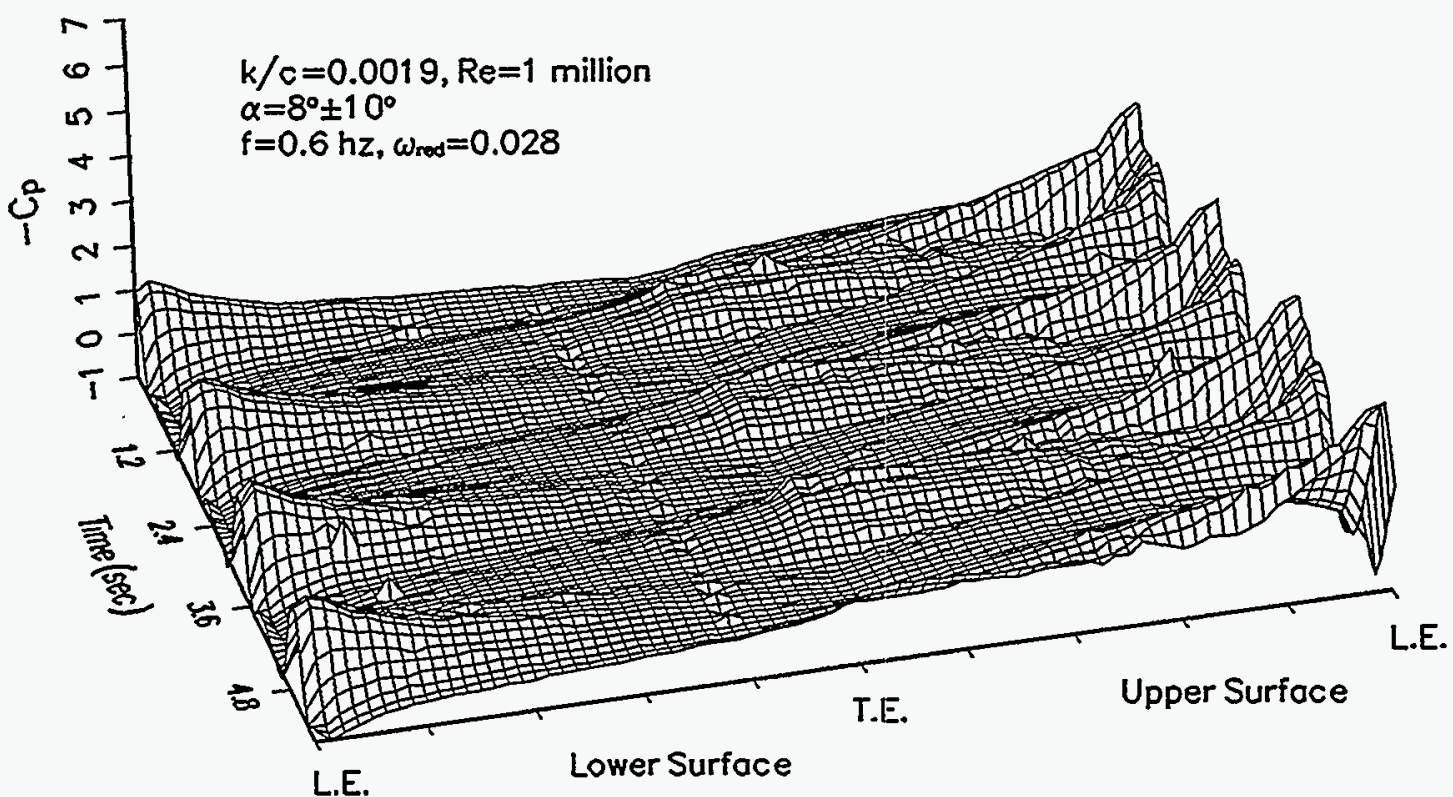

Figure 37. LEGR, unsteady pressure distribution, $\pm 10^{\circ}$.

Figure 38 shows the same clean run conditions at a higher frequency of pitch oscillation. At this higher frequency, the character of the flow is similar to the previous clean case. Noticeably different, however, are the larger magnitude pressure peaks. This is reflected in the maximum lift coefficient results, with values of 1.95 for this case and only 1.52 for the lower frequency case. 


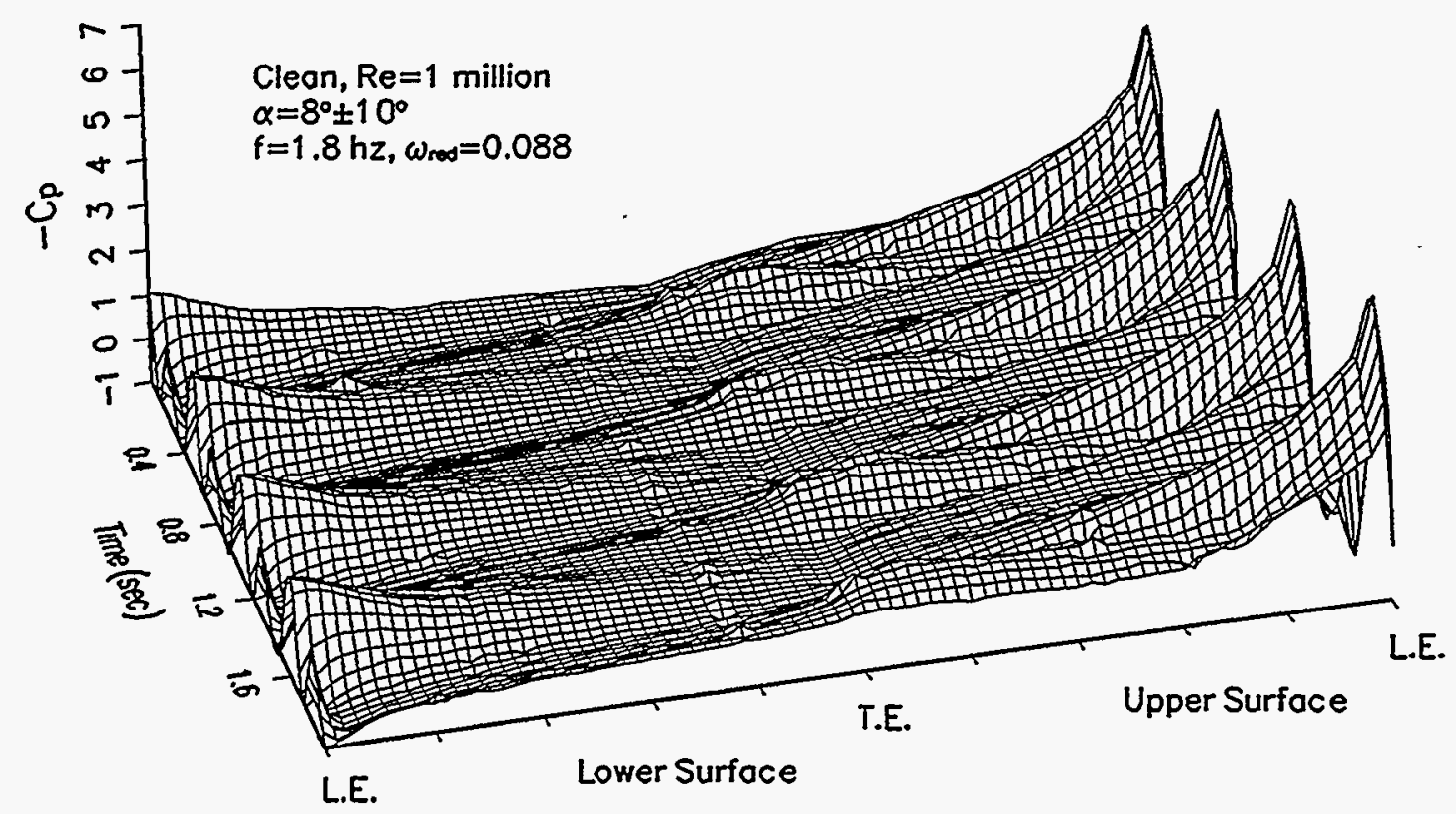

Figure 38. Clean, unsteady pressure distribution, $\pm 10^{\circ}$.

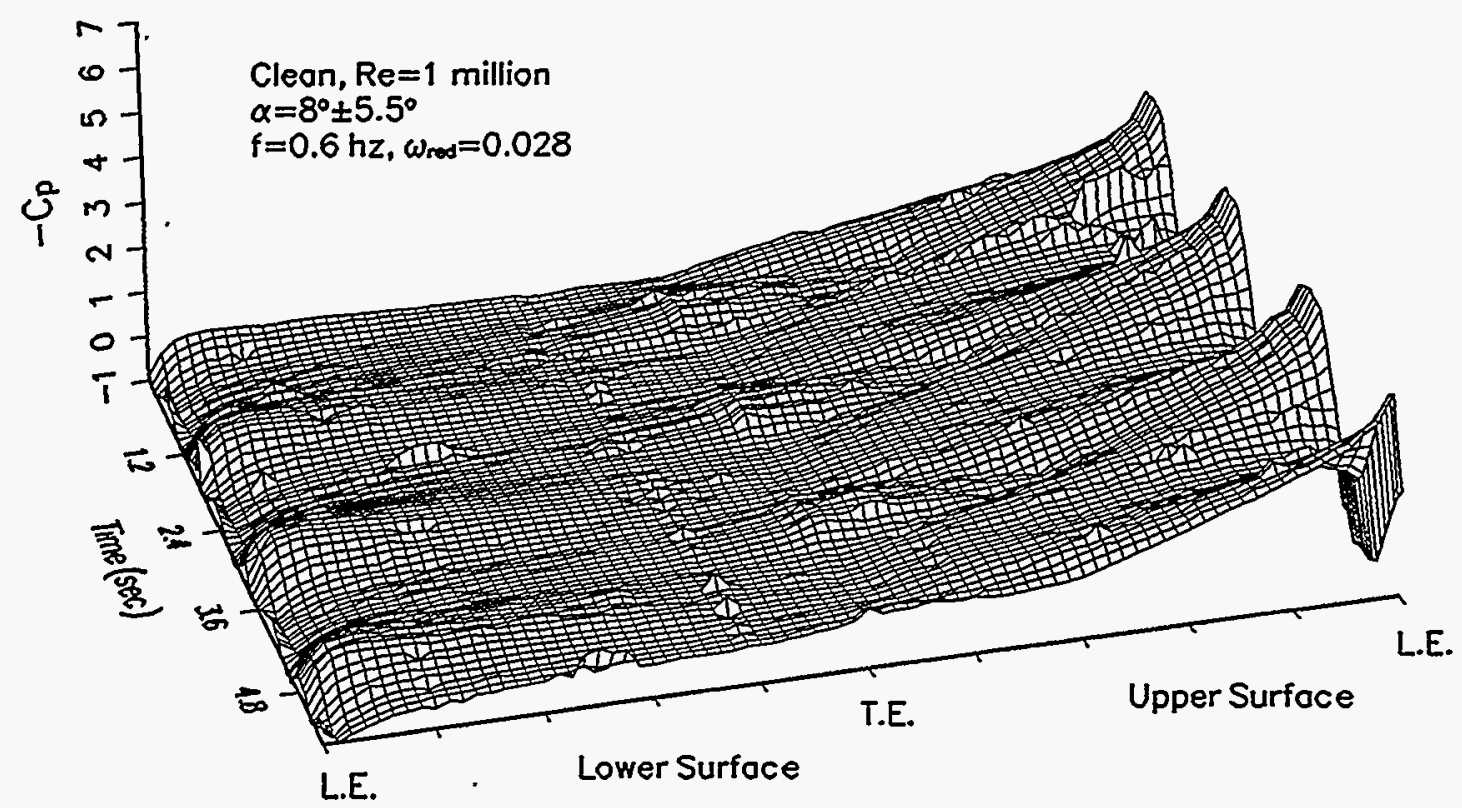

Figure 39. Clean, unsteady pressure distribution, $\pm 5.5^{\circ}$.

Figure 39 shows the smaller mean angle for the clean case at the same conditions indicated above. The structure is different from the previous figure because less of the upper surface flow is separated, the consequence of lower angles of attack. 


\section{Summary of Results}

A NACA 4415 airfoil model was tested under steady state and pitch oscillation conditions. Baseline tests were made while the model was clean, and then corresponding tests were conducted with LEGR applied.

A summary of the steady state aerodynamic parameters is shown in Table 1. As observed, the application of LEGR reduced the maximum lift of the airfoil up to $19 \%$, and the minimum drag coefficient on average increased more than $50 \%$ on average. LEGR also affects the zero lift pitching moment coefficient by reducing the magnitude by an average of $13 \%$.

Table 1. NACA $\mathbf{4 4 1 5}$ Steady State Parameters Summary.

\begin{tabular}{ccccc}
\hline Grit Pattern & $\operatorname{Re} \times 10^{-6}$ & $\mathrm{C}_{\operatorname{lmax}}$ & $\mathrm{C}_{\mathrm{dmin}}$ & $\mathrm{C}_{\mathrm{mo}}$ \\
\hline Clean & 0.75 & $1.38 @ 15.3^{\circ}$ & 0.0078 & -0.0962 \\
$\mathrm{k} / \mathrm{c}=0.0019$ & 0.75 & $1.11 @ 11.2^{\circ}$ & 0.0150 & -0.0835 \\
Clean & 1.00 & $1.35 @ 14.3^{\circ}$ & 0.0090 & -0.0967 \\
$\mathrm{k} / \mathrm{c}=0.0019$ & 1.00 & $1.13 @ 14.3^{\circ}$ & 0.0146 & -0.0842 \\
Clean & 1.25 & $1.30 @ 12.3^{\circ}$ & 0.0097 & -0.0962 \\
$\mathrm{k} / \mathrm{c}=0.0019$ & 1.25 & $1.10 @ 11.2^{\circ}$ & 0.0153 & -0.0844 \\
Clean & 1.50 & $1.29 @ 12.2^{\circ}$ & 0.0105 & -0.0947 \\
$\mathrm{k} / \mathrm{c}=0.0019$ & 1.50 & $1.08 @ 10.2^{\circ}$ & 0.0163 & -0.0827 \\
\hline
\end{tabular}

Table 2. NACA 4415, Unsteady, Clean, $\pm 5.5^{\circ}$.

\begin{tabular}{cccccccc}
\hline$\omega_{\text {red }}$ & $\operatorname{Re} \times 10^{-6}$ & $\mathrm{f}$ & $\mathrm{C}_{\max }$ & $\alpha_{\max }$ & $\mathrm{C}_{1 \text { dec }}$ & $\mathrm{C}_{\mathrm{m} \text { inc }}$ & $\mathrm{C}_{\mathrm{m} \mathrm{dec}}$ \\
\hline 0.037 & 0.75 & 0.59 & 1.52 & 16.8 & 1.11 & -0.0941 & -0.0338 \\
0.076 & 0.75 & 1.21 & 1.65 & 16.5 & 1.00 & -0.0744 & -0.0202 \\
0.116 & 0.75 & 1.85 & 1.75 & 15.7 & 1.05 & -0.0899 & -0.0301 \\
\hline 0.028 & 1.01 & 0.60 & 1.44 & 12.7 & 1.21 & -0.0593 & -0.0310 \\
0.056 & 1.01 & 1.21 & 1.57 & 16.3 & 1.05 & -0.0897 & -0.0381 \\
0.086 & 1.01 & 1.83 & 1.66 & 15.8 & 1.08 & -0.0833 & -0.0459 \\
\hline 0.022 & 1.26 & 0.61 & 1.45 & 12.7 & 1.22 & -0.0632 & -0.0402 \\
0.044 & 1.26 & 1.18 & 1.54 & 14.8 & 1.09 & -0.0748 & -0.0341 \\
0.069 & 1.26 & 1.85 & 1.61 & 16.3 & 1.05 & -0.0942 & -0.0395 \\
\hline 0.019 & 1.51 & 0.60 & 1.43 & 14.3 & 1.13 & -0.0645 & -0.0338 \\
0.037 & 1.50 & 1.19 & 1.50 & 14.3 & 1.14 & -0.0610 & -0.0370 \\
0.056 & 1.51 & 1.81 & 1.57 & 14.8 & 1.03 & -0.0705 & -0.0321 \\
\hline
\end{tabular}

The pitch oscillation data can be divided into two groups, the $\pm 5.5^{\circ}$ amplitude and $\pm 10^{\circ}$ amplitude oscillations, which show similar trends. For both $\pm 5.5^{\circ}$ and $\pm 10^{\circ}$, the unsteady test conditions and the maximum lift coefficients are listed in Tables 2, 3, 4, and 5. As the reduced frequency, which takes oscillation and tunnel speed into account, is increased, the maximum lift coefficient also increases. In addition, the hysteresis behavior becomes increasingly apparent with increased reduced frequency. 
Table 3. NACA 4415, Unsteady, LEGR, $\pm 5.5^{\circ}$.

\begin{tabular}{cccccccc}
\hline$\omega_{\text {red }}$ & $\operatorname{Re} \times 10^{-6}$ & $\mathrm{f}$ & $\mathrm{C}_{\operatorname{lmax}}$ & $\alpha_{\max }$ & $\mathrm{C}_{1 \text { dec }}$ & $\mathrm{C}_{\mathrm{m} \text { inc }}$ & $\mathrm{C}_{\mathrm{m} \text { dec }}$ \\
\hline 0.038 & 0.76 & 0.61 & 1.23 & 14.3 & 0.83 & -0.0991 & -0.0400 \\
0.073 & 0.76 & 1.17 & 1.37 & 14.3 & 0.72 & -0.0971 & -0.0334 \\
0.116 & 0.76 & 1.85 & 1.50 & 16.2 & 0.80 & -0.1274 & -0.0556 \\
\hline 0.028 & 1.01 & 0.61 & 1.17 & 11.1 & 0.88 & -0.0508 & -0.0267 \\
0.056 & 1.01 & 1.19 & 1.26 & 13.7 & 0.81 & -0.0793 & -0.0340 \\
0.087 & 1.01 & 1.85 & 1.39 & 14.3 & 0.72 & -0.0841 & -0.0341 \\
\hline 0.023 & 1.26 & 0.61 & 1.21 & 11.7 & 0.97 & -0.0700 & -0.0403 \\
0.046 & 1.25 & 1.21 & 1.30 & 13.8 & 0.87 & -0.0907 & -0.0388 \\
0.068 & 1.25 & 1.83 & 1.39 & 13.8 & 0.82 & -0.0899 & -0.0212 \\
\hline 0.019 & 1.51 & 0.61 & 1.18 & 11.8 & 0.98 & -0.0705 & -0.0350 \\
0.038 & 1.50 & 1.21 & 1.21 & 13.3 & 0.86 & -0.0764 & -0.0258 \\
0.057 & 1.50 & 1.83 & 1.25 & 13.2 & 0.76 & -0.0766 & -0.0307 \\
\hline
\end{tabular}

Table 4. NACA 4415, Unsteady, Clean, $\pm 10^{\circ}$.

\begin{tabular}{cccccccc}
\hline$\omega_{\text {red }}$ & $\operatorname{Re} \times 10^{-6}$ & $\mathrm{f}$ & $\mathrm{C}_{\max }$ & $\alpha_{\max }$ & $\mathrm{C}_{1 \text { dec }}$ & $\mathrm{C}_{\mathrm{m} \text { inc }}$ & $\mathrm{C}_{\mathrm{m} \mathrm{dec}}$ \\
\hline 0.039 & 0.74 & 0.61 & 1.66 & 15.4 & 1.18 & -0.0812 & -0.0679 \\
0.076 & 0.74 & 1.18 & 1.91 & 17.9 & 0.54 & -0.1018 & -0.0692 \\
0.118 & 0.74 & 1.83 & 2.05 & 18.4 & 0.73 & -0.1168 & -0.0899 \\
\hline 0.029 & 1.00 & 0.61 & 1.55 & 14.9 & 1.07 & -0.0743 & -0.0276 \\
0.057 & 0.99 & 1.18 & 1.77 & 16.6 & 0.88 & -0.0831 & -0.0495 \\
0.089 & 0.99 & 1.85 & 1.95 & 19.4 & 0.92 & -0.1399 & -0.0358 \\
\hline 0.023 & 1.24 & 0.61 & 1.51 & 14.5 & 1.09 & -0.0747 & -0.0257 \\
0.046 & 1.24 & 1.21 & 1.67 & 16.8 & 0.95 & -0.0893 & -0.0241 \\
0.070 & 1.23 & 1.83 & 1.88 & 17.9 & 0.97 & -0.1064 & -0.0265 \\
\hline 0.019 & 1.49 & 0.60 & 1.51 & 14.8 & 1.06 & -0.0709 & -0.0364 \\
0.038 & 1.49 & 1.21 & 1.65 & 17.0 & 1.01 & -0.0895 & -0.0348 \\
0.058 & 1.49 & 1.83 & 1.77 & 18.4 & 0.96 & -0.1129 & -0.0448 \\
\hline
\end{tabular}

As expected, the application of LEGR reduces the aerodynamic performance of the airfoil. The maximum lift coefficient is reduced by $15 \%-20 \%$ for the $\pm 5.5^{\circ}$ case and $10 \%-15 \%$ for the $\pm 10^{\circ}$ case. In addition to following the same trends as the clean, unsteady data discussed previously, the LEGR causes the hysteresis behavior to persist into lower angles of attack than in the clean cases. Overall, the unsteady wind tunnel data show hysteresis behavior that becomes more apparent with increased reduced frequency. The maximum unsteady lift coefficient can be up to $25 \%$ higher for the $\pm 5.5^{\circ}$ amplitude and up to $50 \%$ higher for the $\pm 10^{\circ}$ amplitude than the steady state maximum lift coefficient. Variation in the quarter chord pitching moment coefficient can be $40 \%$ greater than that indicated by steady state results. These findings indicate that it is important to consider the unsteady 
loading that will occur in wind turbine operation because steady state results can greatly underestimate the forces.

Table 5. NACA 4415, Unsteady, LEGR, $\pm 10^{\circ}$.

\begin{tabular}{cccccccc}
\hline$\omega_{\text {red }}$ & $\operatorname{Re} \times 10^{-6}$ & $\omega$ & $\mathrm{C}_{\max }$ & $\alpha_{\max }$ & $\mathrm{C}_{1 \text { dec }}$ & $\mathrm{C}_{\mathrm{m} \text { inc }}$ & $\mathrm{C}_{\mathrm{m} \mathrm{dec}}$ \\
\hline 0.038 & 0.75 & 0.60 & 1.44 & 14.3 & 0.86 & -0.0903 & -0.0360 \\
0.076 & 0.75 & 1.19 & 1.72 & 17.1 & 0.76 & -0.1634 & -0.0615 \\
0.119 & 0.74 & 1.85 & 1.92 & 18.4 & 0.87 & -0.1829 & -0.0851 \\
\hline 0.028 & 1.00 & 0.60 & 1.34 & 14.9 & 0.79 & -0.1119 & -0.0488 \\
0.058 & 0.99 & 1.21 & 1.52 & 16.9 & 0.81 & -0.1468 & -0.0464 \\
0.087 & 0.99 & 1.81 & 1.80 & 18.9 & 0.71 & -0.2082 & -0.0625 \\
\hline 0.023 & 1.25 & 0.61 & 1.30 & 13.1 & 0.85 & -0.0784 & -0.0340 \\
0.046 & 1.24 & 1.19 & 1.48 & 15.1 & 0.73 & -0.1061 & -0.0276 \\
0.070 & 1.24 & 1.83 & 1.63 & 17.8 & 0.77 & -0.1713 & -0.0469 \\
\hline 0.019 & 1.50 & 0.60 & 1.27 & 12.8 & 0.97 & -0.0717 & -0.0313 \\
0.037 & 1.49 & 1.18 & 1.39 & 12.8 & 0.81 & -0.0674 & -0.0190 \\
0.058 & 1.49 & 1.85 & 1.58 & 15.9 & 0.66 & -0.1151 & -0.0394 \\
\hline
\end{tabular}




\section{References}

Pope, A., Harper, J.J. 1966. Low Speed Wind Tunnel Testing. New York, NY: John Wiley \& Sons, Inc.

Schlichting, H. 1979. Boundary Layer Theory. New York, NY: McGraw-Hill Inc.

Smetana, F., Summey, D., et-al. 1975. Light Aircraft Lift, Drag, Moment Prediction - a Review and Analysis. North Carolina State University. NASA-CR2523. 



\section{Appendix A: Model and Surface Pressure Tap Coordinates}




\section{List of Tables}

A1. NACA 4415 Measured Model Coordinates, 18 inch desired chord . . . . . . . . . A-3

A2. NACA 4415, Surface Pressure Taps, Non-Dimensional Coordinates 


\begin{tabular}{|c|c|c|c|}
\hline $\begin{array}{l}\text { Chord Station } \\
\text { (in) }\end{array}$ & $\begin{array}{l}\text { Upper Ordinate } \\
\text { (in) }\end{array}$ & $\begin{array}{l}\text { Chord Station } \\
\text { (in) }\end{array}$ & $\begin{array}{l}\text { Lower Ordinate } \\
\text { (in) }\end{array}$ \\
\hline-0.002 & 0.091 & -0.002 & 0.091 \\
\hline 0.000 & 0.138 & 0.000 & 0.039 \\
\hline 0.002 & 0.151 & 0.002 & 0.028 \\
\hline 0.005 & 0.174 & 0.004 & 0.012 \\
\hline 0.009 & 0.196 & 0.009 & -0.008 \\
\hline 0.018 & 0.234 & 0.016 & -0.035 \\
\hline 0.050 & 0.320 & 0.045 & -0.108 \\
\hline 0.077 & 0.369 & 0.070 & -0.155 \\
\hline 0.135 & 0.450 & 0.131 & -0.232 \\
\hline 0.214 & 0.541 & 0.205 & -0.297 \\
\hline 0.315 & 0.641 & 0.304 & -0.364 \\
\hline 0.390 & 0.705 & 0.378 & -0.405 \\
\hline 0.478 & 0.772 & 0.466 & -0.447 \\
\hline 0.613 & 0.864 & 0.600 & -0.499 \\
\hline 0.746 & 0.945 & 0.731 & -0.540 \\
\hline 0.901 & 1.030 & 0.886 & -0.580 \\
\hline 1.052 & 1.103 & 1.035 & -0.612 \\
\hline 1.169 & 1.158 & 1.152 & -0.633 \\
\hline 1.363 & 1.240 & 1.345 & -0.664 \\
\hline 1.574 & 1.325 & 1.555 & -0.693 \\
\hline 1.740 & 1.386 & 1.721 & -0.711 \\
\hline 1.904 & 1.442 & 1.887 & -0.725 . \\
\hline 2.037 & 1.486 & 2.018 & -0.734 \\
\hline 2.417 & 1.600 & 2.398 & -0.752 \\
\hline 2.969 & 1.725 & 2.950 & -0.759 \\
\hline 3.349 & 1.799 & 3.330 & -0.757 \\
\hline 3.808 & 1.872 & 3.789 & -0.747 \\
\hline 4.213 & 1.924 & 4.196 & -0.734 \\
\hline 4.891 & 1.987 & 4.876 & -0.707 \\
\hline
\end{tabular}




\begin{tabular}{|c|c|c|c|}
\hline $\begin{array}{l}\text { Chord Station } \\
\text { (in) }\end{array}$ & $\begin{array}{l}\text { Upper Ordinate } \\
\text { (in) }\end{array}$ & $\begin{array}{l}\text { Chord Station } \\
\text { (in) }\end{array}$ & $\begin{array}{l}\text { Lower Ordinate } \\
\text { (in) }\end{array}$ \\
\hline 5.836 & 2.031 & 5.821 & -0.662 \\
\hline 6.724 & 2.035 & 6.711 & -0.616 \\
\hline 7.503 & 2.010 & 7.492 & -0.575 \\
\hline 8.515 & 1.944 & 8.505 & -0.520 \\
\hline 9.368 & 1.863 & 9.360 & -0.471 \\
\hline 10.299 & 1.752 & 10.293 & -0.417 \\
\hline 12.066 & 1.479 & 12.937 & -0.266 \\
\hline 13.845 & 1.138 & 13.844 & -0.219 \\
\hline 14.531 & 0.984 & 14.535 & -0.186 \\
\hline 14.997 & 0.874 & 14.999 & -0.164 \\
\hline 15.863 & 0.653 & 15.503 & -0.141 \\
\hline 16.335 & 0.526 & 15.867 & -0.124 \\
\hline 16.828 & 0.391 & 16.308 & -0.106 \\
\hline 17.172 & 0.296 & 16.835 & -0.081 \\
\hline 17.384 & 0.235 & 17.302 & -0.061 \\
\hline 17.526 & 0.190 & 17.462 & -0.053 \\
\hline 17.694 & 0.147 & 17.620 & -0.044 \\
\hline 17.896 & 0.087 & 17.703 & -0.041 \\
\hline 17.946 & 0.071 & 17.782 & -0.037 \\
\hline 18.052 & 0.039 & 17.834 & -0.033 \\
\hline & & 17.905 & -0.030 \\
\hline & & 18.052 & -0.019 \\
\hline \multicolumn{4}{|c|}{ End of Table A1 } \\
\hline
\end{tabular}




\begin{tabular}{|c|c|c|}
\hline \multicolumn{3}{|c|}{$\begin{array}{l}\text { Table A2. NACA 4415, Surface Pressure Taps } \\
\text { Non-Dimensional Coordinates }\end{array}$} \\
\hline Tap Number & Chord Station & Ordinate \\
\hline 1 & 1.0035 & -0.0001 \\
\hline 2 & 0.9958 & -0.0015 \\
\hline 3 & 0.9807 & -0.0032 \\
\hline 4 & 0.9549 & -0.0044 \\
\hline 5 & 0.9298 & -0.0056 \\
\hline 6 & 0.9047 & -0.0067 \\
\hline 7 & 0.8809 & -0.0077 \\
\hline 8 & 0.8559 & -0.0087 \\
\hline 9 & 0.8296 & -0.0099 \\
\hline 10 & $0.8039^{\circ}$ & -0.0109 \\
\hline 11 & 0.7537 & -0.0132 \\
\hline 12 & 0.7041 & -0.0159 \\
\hline 13 & 0.6533 & -0.0188 \\
\hline 14 & 0.6024 & -0.0217 \\
\hline 15 & 0.5545 & -0.0244 \\
\hline 16 & 0.5021 & -0.0274 \\
\hline 17 & 0.4024 & -0.0327 \\
\hline 18 & 0.2989 & -0.0379 \\
\hline 19 & 0.2490 & -0.0400 \\
\hline 20 & 0.2250 & -0.0408 \\
\hline 21 & 0.2000 & -0.0413 \\
\hline 22 & 0.1755 & -0.0418 \\
\hline 23 & 0.1493 & -0.0417 \\
\hline 24 & 0.1252 & -0.0411 \\
\hline 25 & 0.1001 & -0.0395 \\
\hline 26 & 0.0735 & -0.0363 \\
\hline 27 & 0.0496 & -0.0319 \\
\hline 28 & 0.0256 & -0.0243 \\
\hline
\end{tabular}




\begin{tabular}{|c|c|c|}
\hline \multicolumn{3}{|c|}{$\begin{array}{l}\text { Table A2. NACA 4415, Surface Pressure Taps, } \\
\text { Non-Dimensional Coordinates }\end{array}$} \\
\hline Tap Number & Chord Station & Ordinate \\
\hline 29 & 0.0138 & -0.0178 \\
\hline 30 & 0.0010 & 0.0001 \\
\hline 31 & 0.0119 & 0.0306 \\
\hline 32 & 0.0257 & 0.0423 \\
\hline 33 & 0.0498 & 0.0572 \\
\hline 34 & 0.0749 & 0.0689 \\
\hline 35 & 0.1010 & 0.0787 \\
\hline 36 & 0.1242 & 0.0859 \\
\hline 37 & 0.1502 & 0.0926 \\
\hline 38 & 0.1741 & 0.0977 \\
\hline 39 & 0.1981 & 0.1021 \\
\hline 40 & 0.2254 & 0.1057 \\
\hline 41 & 0.2523 & 0.1086 \\
\hline 42 & 0.3016 & 0.1119 \\
\hline 43 & 0.3528 & 0.1130 \\
\hline 44 & 0.4007 & 0.1122 \\
\hline 45 & 0.4538 & 0.1091 \\
\hline 46 & 0.5027 & 0.1049 \\
\hline 47 & 0.5534 & 0.0993 \\
\hline 48 & 0.6016 & 0.0927 \\
\hline 49 & 0.6533 & 0.0844 \\
\hline 50 & 0.7040 & 0.0755 \\
\hline 51 & 0.7548 & 0.0655 \\
\hline 52 & 0.8046 & 0.0546 \\
\hline 53 & 0.8299 & 0.0486 \\
\hline 54 & 0.8538 & 0.0426 \\
\hline 55 & 0.8783 & 0.0363 \\
\hline 56 & 0.9041 & 0.0294 \\
\hline 57 & 0.9309 & 0.0219 \\
\hline
\end{tabular}




\begin{tabular}{|c|c|c||}
\hline \multicolumn{3}{|c||}{$\begin{array}{c}\text { Table A2. NACA 4415, Surface Pressure Taps, } \\
\text { Non-Dimensional Coordinates }\end{array}$} \\
\hline \hline Tap Number & Chord Station & Ordinate \\
\hline 58 & 0.9551 & 0.0152 \\
60 & 0.9800 & 0.0081 \\
& 0.9908 & 0.0043 \\
\hline \multicolumn{3}{|c|}{ End of Table A2 } \\
\hline
\end{tabular}





\section{Appendix B: Steady State Data Integrated Coefficients and Pressure Distributions}




\section{List of Tables}

B1. NACA 4415 , Clean, $\operatorname{Re}=0.75 \times 10^{6} \ldots \ldots \ldots \ldots \ldots \ldots \ldots \ldots \ldots$

B2. NACA 4415 , Clean, $\operatorname{Re}=1.0 \times 10^{6} \ldots \ldots \ldots \ldots \ldots \ldots \ldots \ldots \ldots \ldots$

B3. NACA 4415 , Clean, $\operatorname{Re}=1.25 \times 10^{6} \ldots \ldots \ldots \ldots \ldots \ldots \ldots \ldots \ldots \ldots \ldots$

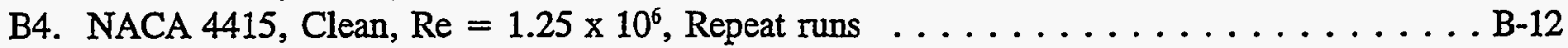

B5. NACA 4415 , Clean, $\operatorname{Re}=1.5 \times 10^{6} \ldots \ldots \ldots \ldots \ldots \ldots \ldots \ldots \ldots \ldots \ldots$

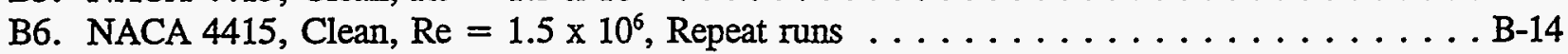

B7. NACA $4415, \mathrm{k} / \mathrm{c}=0.0019, \mathrm{Re}=0.75 \times 10^{6} \ldots \ldots \ldots \ldots \ldots \ldots \ldots \ldots \ldots \ldots \ldots$

B8. NACA $4415, \mathrm{k} / \mathrm{c}=0.0019, \mathrm{Re}=1.0 \times 10^{6} \ldots \ldots \ldots \ldots \ldots \ldots \ldots \ldots \ldots \ldots$

B9. $\mathrm{NACA} 4415, \mathrm{k} / \mathrm{c}=0.0019, \mathrm{Re}=1.25 \times 10^{6} \ldots \ldots \ldots \ldots \ldots \ldots \ldots \ldots \ldots$

B10. NACA $4415, \mathrm{k} / \mathrm{c}=0.0019, \mathrm{Re}=1.5 \times 10^{6} \ldots \ldots \ldots \ldots \ldots \ldots \ldots \ldots \ldots \ldots$ 


\section{List of Figures}

Pressure Distributions, Steady State, $\operatorname{Re}=0.75$ million $\ldots \ldots \ldots \ldots \ldots \ldots$. . . . . . . . . .

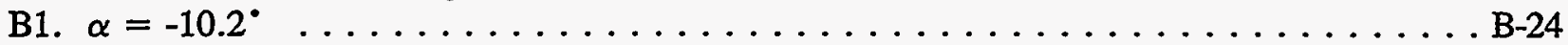

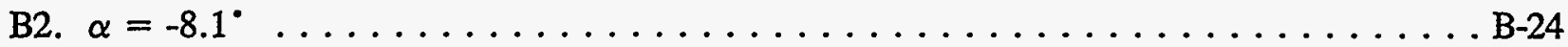

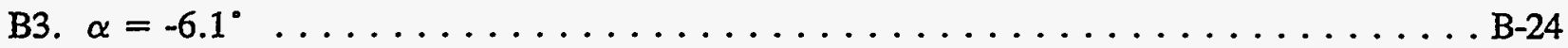

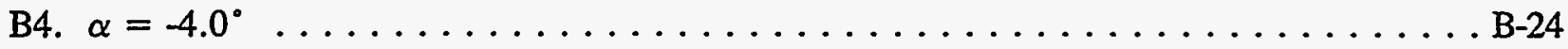

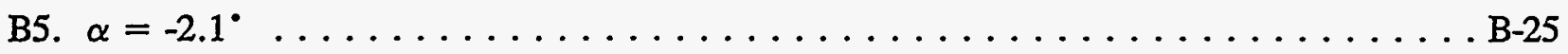

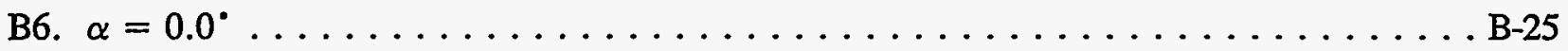

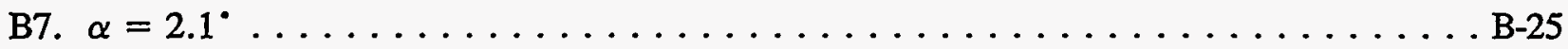

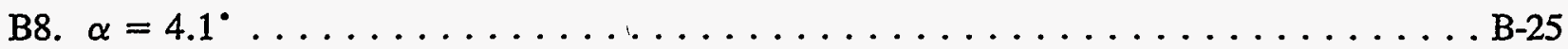

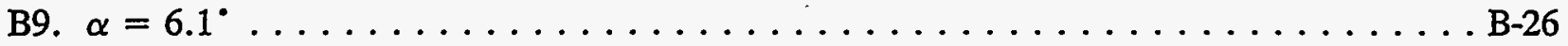

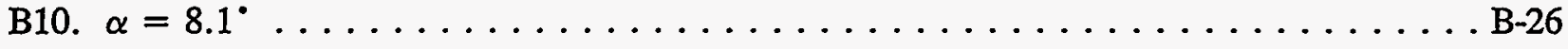

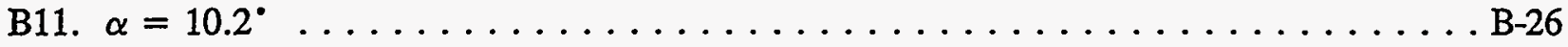

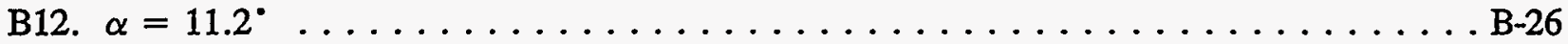

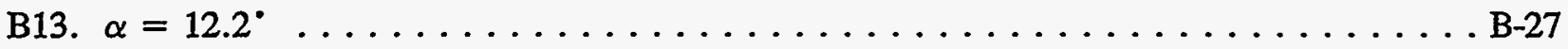

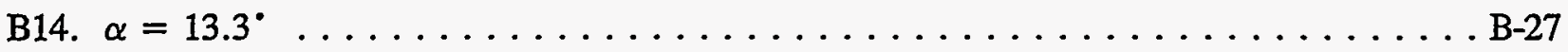

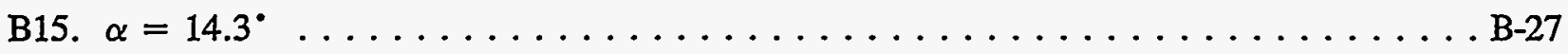

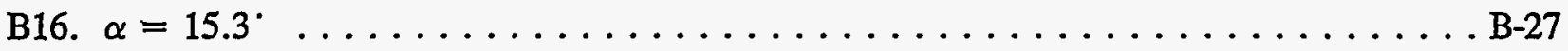

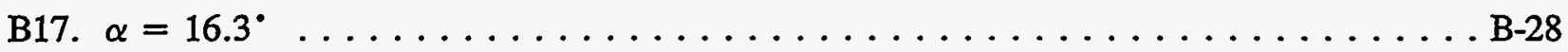

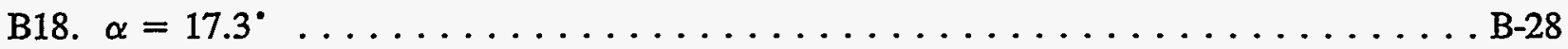

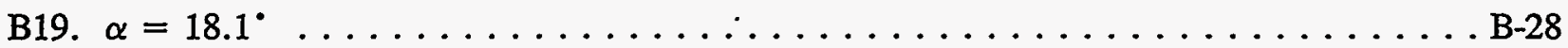

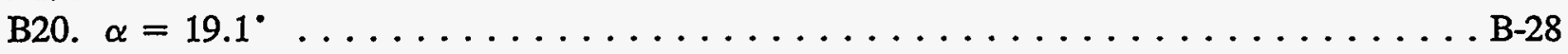

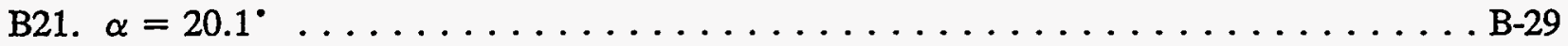

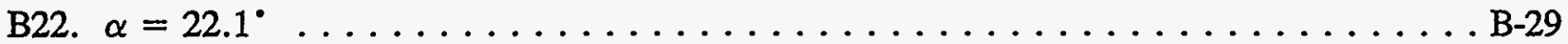

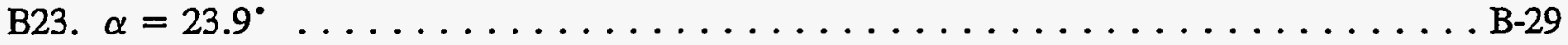

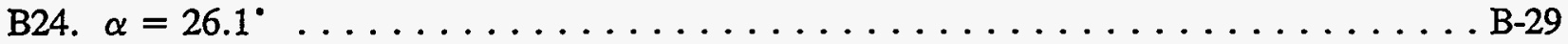

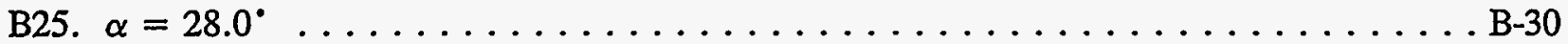

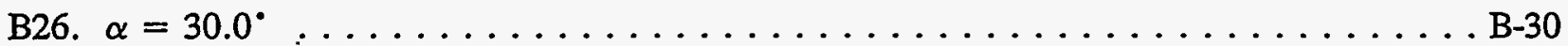

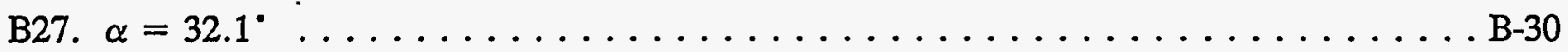

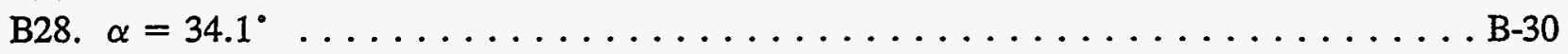

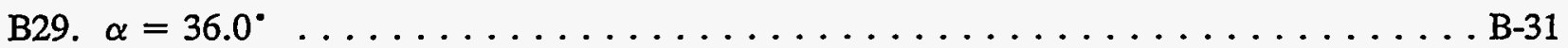

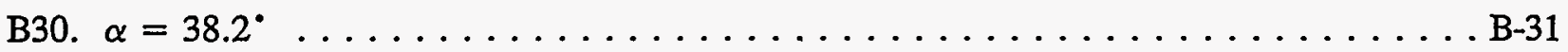

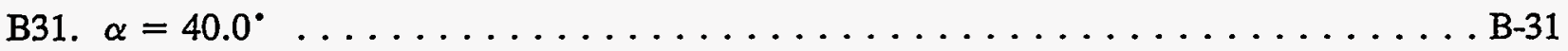

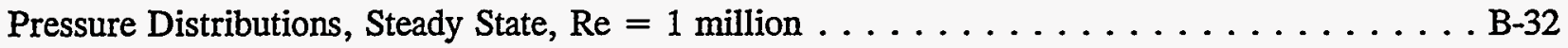

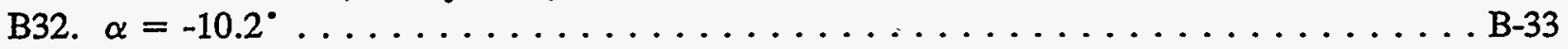

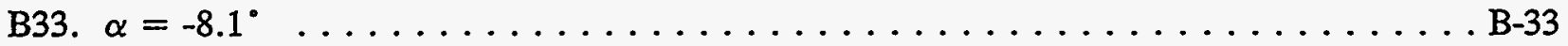

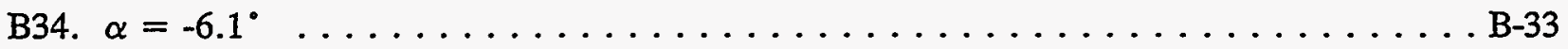

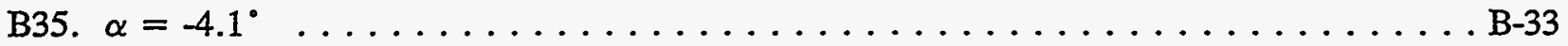

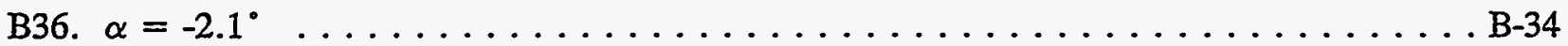

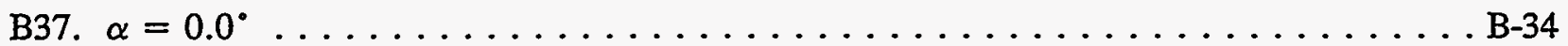

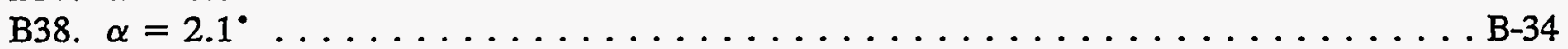

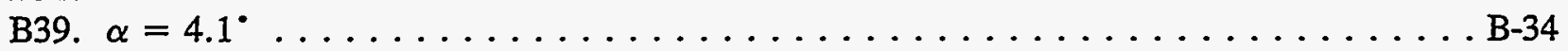

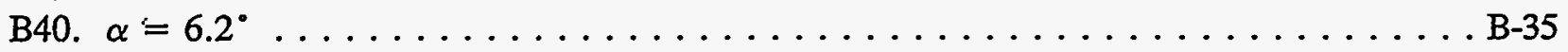

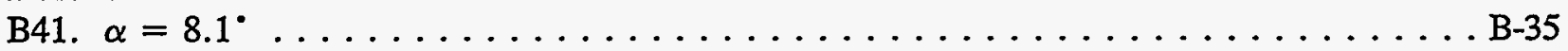

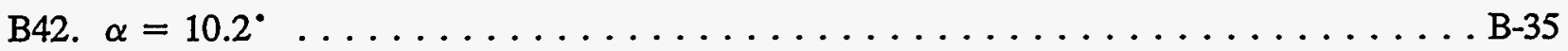

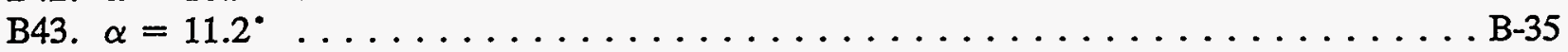

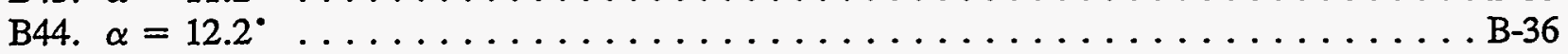

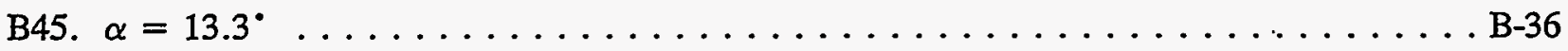


B46. $\alpha=14.3^{\circ}$

B-36

B47. $\alpha=15.3^{\circ}$

$\mathrm{B}-36$

B48. $\alpha=16.2^{\circ}$

B-37

B49. $\alpha=17.2^{\circ}$

B-37

B50. $\alpha=18.2^{\circ}$

B-37

B51. $\alpha=19.2^{\circ}$

B-37

B52. $\alpha=20.3^{\circ}$

B-38

B53. $\alpha=22.1^{\circ}$

B-38

B54. $\alpha=24.1^{\circ}$

B-38

B55. $\alpha=26.1^{\circ}$

B-38

B56. $\alpha=28.1^{\circ}$

B-39

B57. $\alpha=30.0^{\circ}$

B-39

B58. $\alpha=32.1^{\circ}$

B-39

B59. $\alpha=34.1^{\circ}$

B-39

B60. $\alpha=36.0^{\circ}$

B-40

B61. $\alpha=38.0^{\circ}$

B-40

B62. $\alpha=40.0^{\circ}$

B-40

Pressure Distributions, Steady State, $\operatorname{Re}=1.25$ million $\ldots \ldots \ldots \ldots \ldots \ldots \ldots$. . . . B-41

B63. $\alpha=-10.2^{\circ}$

B64. $\alpha=-8.1^{\circ}$

$\mathrm{B}-42$

B65. $\alpha=-6.0^{\circ}$

B-42

B66. $\alpha=-4.0^{\circ}$

$\mathrm{B}-42$

B67. $\alpha=-2.1^{\circ}$

$\mathrm{B}-42$

B68. $\alpha=0.0^{\circ}$

B -43

B69. $\alpha=2.1^{\circ}$

B-43

B70. $\alpha=4.0^{\circ}$

B- 43

B71. $\alpha=6.2^{\circ}$

B-43

B72. $\alpha=8.1^{\circ}$

B-44

B73. $\alpha=10.2^{\circ}$

B-44

B74. $\alpha=11.2^{\circ}$

B-44

B75. $\alpha=12.3^{\circ}$

B-44

B76. $\alpha=13.3^{\circ}$

B-45

B77. $\alpha=14.3^{\circ}$

B-45

B78. $\alpha=15.3^{\circ}$

B-45

B79. $\alpha=16.3^{\circ}$

B-45

B80. $\alpha=17.3^{\circ}$

B-46

B81. $\alpha=18.3^{\circ}$

B -46

B82. $\alpha=19.1^{\circ}$

B-46

B83. $\alpha=20.1^{\circ}$

B-46

B84. $\alpha=22.1^{\circ}$

B-47

B85. $\alpha=24.1^{\circ}$

B-47

B86. $\alpha=26.1^{\circ}$

B87. $\alpha=28.0^{\circ}$

B-47

B88. $\alpha=30.0^{\circ}$

B-48

B89. $\alpha=32.1^{\circ}$

B-48

B90. $\alpha=34.1^{\circ}$

B-48

B91. $\alpha=36.0^{\circ}$

B-48

B92. $\alpha=37.9^{\circ}$

B-49

B93. $\alpha=40.1^{\circ}$ 
Pressure Distributions, Steady State, $\mathrm{Re}=1.5$ million $\ldots \ldots \ldots \ldots \ldots$

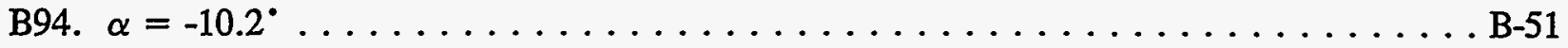

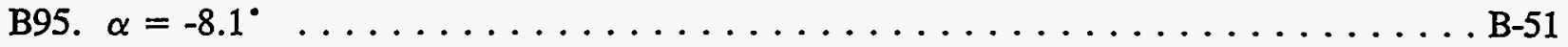

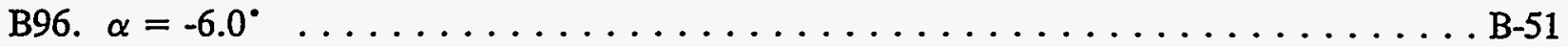

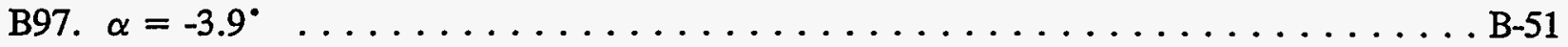

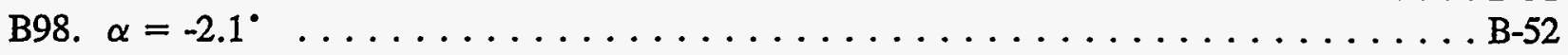

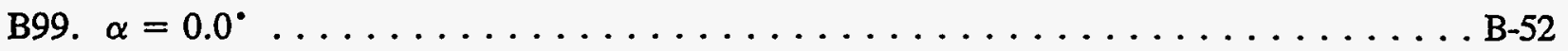

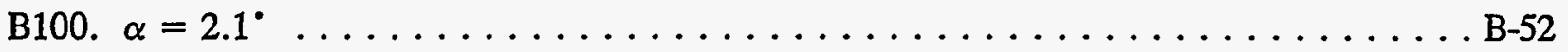

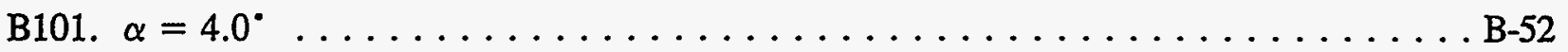

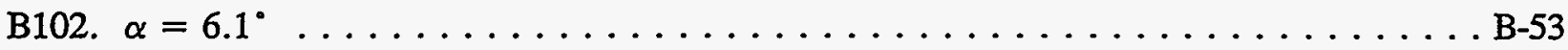

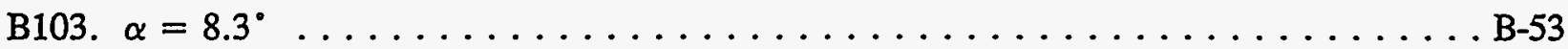

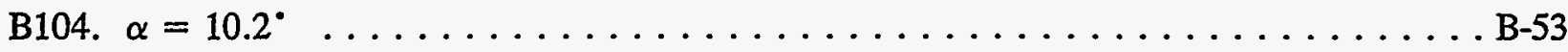

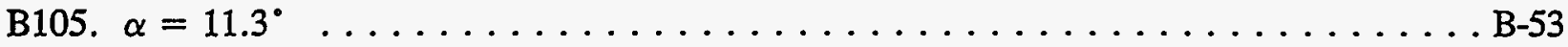

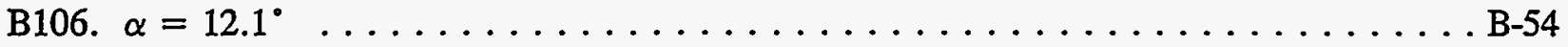

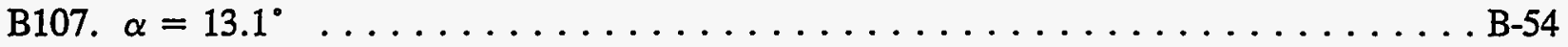

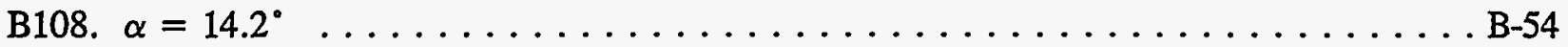

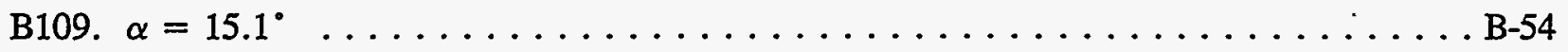

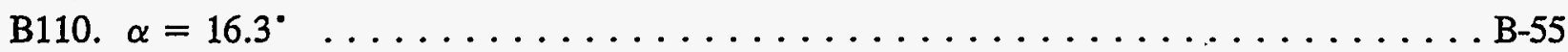

B111. $\alpha=17.2^{\circ} \ldots \ldots \ldots \ldots \ldots \ldots \ldots \ldots \ldots \ldots \ldots \ldots \ldots \ldots \ldots \ldots \ldots$

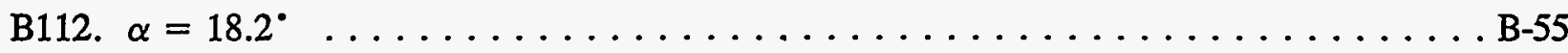

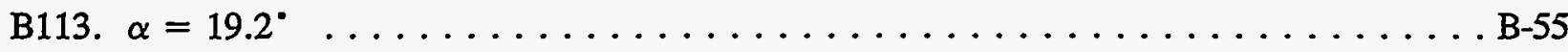

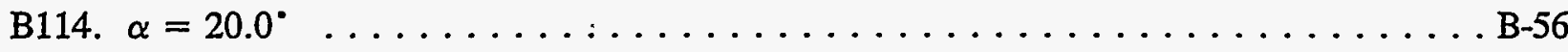

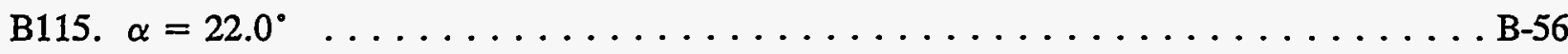

B116. $\alpha=24.0^{\circ}$

B-56 


\begin{tabular}{|c|c|c|c|c|c|c|}
\hline RUN & $\mathrm{AOA}$ & $\mathrm{C}_{1}$ & $\mathrm{C}_{\mathrm{dp}}$ & $\mathrm{C}_{\mathrm{m}^{1 / k}}$ & $\operatorname{Re} \times 10^{-6}$ & $\mathrm{C}_{\mathrm{dw}}$ \\
\hline 76 & -20.1 & -0.39 & 0.2599 & 0.0130 & 0.77 & - \\
\hline $77^{\circ}$ & -18.0 & -0.33 & 0.2208 & 0.0062 & 0.77 & - \\
\hline 78 & -16.0 & -0.26 & 0.1840 & -0.0015 & 0.77 & - \\
\hline 79 & -14.1 & -0.22 & 0.1563 & -0.0038 & 0.76 & - \\
\hline 80 & -12.1 & -0.32 & 0.1501 & 0.0080 & 0.77 & - \\
\hline 81 & -10.2 & -0.58 & -0.0121 & -0.1048 & 0.76 & 0.0187 \\
\hline 82 & -8.1 & -0.39 & -0.0133 & -0.1015 & 0.76 & 0.0172 \\
\hline 83 & -6.1 & -0.20 & -0.0118 & -0.1000 & 0.76 & 0.0142 \\
\hline 84 & -4.0 & 0.02 & -0.0085 & -0.0962 & 0.76 & 0.0132 \\
\hline 85 & -2.1 & 0.22 & -0.0059 & -0.0958 & 0.76 & 0.0097 \\
\hline 86 & 0.0 & 0.43 & -0.0012 & -0.0958 & 0.75 & 0.0089 \\
\hline 87 & 2.1 & 0.62 & 0.0055 & -0.0912 & 0.76 & 0.0078 \\
\hline 88 & 4.1 & 0.86 & 0.0122 & -0.0951 & 0.76 & 0.0093 \\
\hline 89 & 6.1 & 1.03 & 0.0192 & -0.0882 & 0.76 & 0.0105 \\
\hline 90 & 8.1 & 1.17 & 0.0283 & -0.0780 & 0.76 & 0.0148 \\
\hline 91 & 10.2 & 1.27 & 0.0412 & -0.0645 & 0.75 & 0.0178 \\
\hline 92 & 11.2 & 1.29 & 0.0455 & -0.0545 & 0.76 & 0.0212 \\
\hline 93 & 12.2 & 1.32 & 0.0635 & -0.0538 & 0.75 & 0.0218 \\
\hline 94 & 13.3 & 1.33 & 0.0751 & -0.0497 & 0.75 & 0.0252 \\
\hline 95 & 14.3 & 1.37 & 0.0940 & -0.0544 & 0.77 & 0.0284 \\
\hline 96 & 15.3 & 1.38 & 0.1138 & -0.0579 & 0.76 & - \\
\hline 97 & 16.3 & 1.32 & 0.1184 & -0.0545 & 0.77 & - \\
\hline 98 & 17.3 & 1.32 & 0.1395 & -0.0605 & 0.77 & - \\
\hline 99 & 18.1 & 1.13 & 0.1249 & -0.0555 & 0.76 & - \\
\hline 100 & 19.1 & 1.10 & 0.1433 & -0.0614 & 0.76 & - \\
\hline 101 & 20.1 & 1.08 & 0.1638 & -0.0677 & 0.76 & - \\
\hline 102 & 22.1 & 1.05 & 0.2138 & -0.0863 & 0.76 & - \\
\hline 103 & 23.9 & 0.92 & 0.4504 & -0.1558 & 0.74 & - \\
\hline
\end{tabular}


Table B1. NACA 4415, Clean, $R e=0.75 \times 10^{6}$

\begin{tabular}{||c|c|c|c|c|c|c||}
\hline \hline RUN & AOA & $\mathrm{C}_{1}$ & $\mathrm{C}_{\mathrm{dp}}$ & $\mathrm{C}_{\mathrm{m} / \mathrm{k}}$ & $\operatorname{Re} \times 10^{-6}$ & $\mathrm{C}_{\mathrm{dw}}$ \\
\hline 104 & 26.1 & 1.02 & 0.5403 & -0.1826 & 0.80 & - \\
\hline 105 & 28.0 & 1.09 & 0.6147 & -0.2041 & 0.79 & - \\
\hline 106 & 30.0 & 1.16 & 0.7034 & -0.2288 & 0.81 & - \\
\hline 107 & 32.1 & 1.23 & 0.7973 & -0.2546 & 0.81 & - \\
\hline 108 & 34.1 & 1.29 & 0.9007 & -0.2862 & 0.82 & - \\
\hline 109 & 36.0 & 1.32 & 0.9928 & -0.3112 & 0.83 & - \\
\hline 110 & 38.2 & 1.34 & 1.0844 & -0.3323 & 0.85 & - \\
\hline 111 & 40.0 & 1.35 & 1.1643 & -0.3542 & 0.86 & - \\
\hline & & & \multicolumn{7}{|c|}{ End of Table B1 } & \\
\hline
\end{tabular}




\begin{tabular}{|c|c|c|c|c|c|c|}
\hline \multicolumn{7}{|c|}{ Table B2. NACA 4415, Clean, $R e=1.0 \times 10^{6}$} \\
\hline RUN & AOA & $\mathrm{C}_{1}$ & $\mathrm{C}_{\mathrm{dp}}$ & $\mathrm{C}_{\mathrm{m} / 4}$ & $\operatorname{Re} \times 10^{-6}$ & $C_{d w}$ \\
\hline 38 & -20.1 & -0.38 & 0.2555 & 0.0118 & 1.03 & - \\
\hline 39 & -18.0 & -0.32 & 0.2181 & 0.0047 & 1.03 & - \\
\hline 40 & -16.1 & -0.27 & 0.1854 & -0.0002 & 1.02 & - \\
\hline 41 & -14.1 & -0.24 & 0.1613 & 0.0021 & 1.02 & - \\
\hline 42 & -12.1 & -0.47 & 0.1541 & 0.0058 & 1.02 & - \\
\hline 43 & -10.2 & -0.60 & -0.0141 & -0.1014 & 1.01 & 0.0168 \\
\hline 44 & -8.1 & -0.40 & -0.0139 & -0.0990 & 1.01 & 0.0148 \\
\hline 45 & -6.1 & -0.19 & -0.0123 & -0.0981 & 1.01 & 0.0127 \\
\hline 46 & -4.1 & 0.02 & -0.0088 & -0.0967 & 1.01 & 0.0116 \\
\hline 47 & -2.1 & 0.23 & -0.0061 & -0.0954 & 1.00 & 0.0100 \\
\hline 48 & 0.0 & 0.42 & -0.0005 & -0.0939 & 1.01 & 0.0101 \\
\hline 49 & 2.1 & 0.63 & 0.0049 & -0.0931 & 1.00 & 0.0090 \\
\hline 50 & 4.1 & 0.86 & 0.0126 & -0.0947 & 1.01 & 0.0100 \\
\hline 51 & 6.2 & 1.02 & 0.0197 & -0.0846 & 1.01 & 0.0113 \\
\hline 52 & 8.1 & 1.17 & 0.0257 & -0.0745 & 1.01 & 0.0138 \\
\hline 53 & 10.2 & 1.26 & 0.0360 & -0.0598 & 1.01 & 0.0201 \\
\hline 54 & 11.2 & 1.29 & 0.0432 & -0.0519 & 1.01 & 0.0268 \\
\hline 55 & 12.2 & 1.30 & 0.0554 & -0.0477 & 1.00 & 0.0372 \\
\hline 56 & 13.3 & 1.33 & 0.0682 & -0.0467 & 1.01 & 0.0385 \\
\hline 57 & 14.3 & 1.35 & 0.0886 & -0.0526 & 1.01 & 0.0320 \\
\hline 58 & 15.3 & 1.19 & 0.0750 & -0.0378 & 1.02 & - \\
\hline 59 & 16.2 & 1.15 & 0.0925 & -0.0447 & 1.02 & - \\
\hline 60 & 17.2 & 1.12 & 0.1095 & -0.0497 & 1.02 & - \\
\hline 61 & 18.2 & 1.10 & 0.1264 & -0.0568 & 1.02 & - \\
\hline 62 & 19.2 & 1.09 & 0.1469 & -0.0634 & 1.02 & - \\
\hline 63 & 20.3 & 1.08 & 0.1675 & -0.0695 & 1.02 & - \\
\hline 64 & 22.1 & 1.04 & 0.2161 & -0.0877 & 1.03 & - \\
\hline 65 & 24.1 & 1.03 & 0.2705 & -0.1050 & 1.03 & - \\
\hline
\end{tabular}




\begin{tabular}{|c|c|c|c|c|c|c||}
\hline \multicolumn{7}{|c|}{ Table B2. NACA 4415, Clean, Re $=1.0 \times 10^{6}$} \\
\hline \hline RUN & AOA & $C_{1}$ & $C_{d p}$ & $C_{\mathrm{m} / \%}$ & $R e \times 10^{-6}$ & $C_{d w}$ \\
\hline 66 & 26.1 & 0.96 & 0.5087 & -0.1663 & 1.05 & - \\
\hline 67 & 28.1 & 1.09 & 0.6176 & -0.2039 & 1.07 & - \\
\hline 68 & 30.0 & 1.17 & 0.7070 & -0.2294 & 1.07 & - \\
\hline 69 & 32.1 & 1.22 & 0.7936 & -0.2536 & 1.09 & - \\
\hline 70 & 34.1 & 1.29 & 0.9035 & -0.2882 & 1.10 & - \\
\hline 71 & 36.0 & 1.32 & 0.9890 & -0.3101 & 1.10 & - \\
\hline 72 & 38.0 & 1.34 & 1.0748 & -0.3303 & 1.12 & - \\
\hline 73 & 40.0 & 1.34 & 1.1520 & -0.3456 & 1.13 & - \\
\hline
\end{tabular}




\begin{tabular}{|c|c|c|c|c|c|c|}
\hline \multicolumn{7}{|c|}{ Table B3. NACA 4415, Clean, $R e=1.25 \times 10^{6}$} \\
\hline RUN & AOA & $\mathrm{C}_{\mathrm{l}}$ & $\mathrm{C}_{\mathrm{dp}}$ & $\mathrm{C}_{\mathrm{m} / \mathrm{k}}$ & $\operatorname{Re} \times 10^{-6}$ & $C_{d w}$ \\
\hline 2 & -20.1 & -0.39 & 0.2608 & 0.0157 & 1.29 & - \\
\hline 3 & -18.2 & -0.34 & 0.2247 & 0.0085 & 1.28 & - \\
\hline 4 & -16.0 & -0.27 & 0.1852 & 0.0000 & 1.28 & - \\
\hline 5 & -14.1 & -0.30 & 0.1696 & 0.0065 & 1.28 & - \\
\hline 6 & -12.1 & -0.52 & 0.1608 & 0.0201 & 1.28 & - \\
\hline 7 & -10.2 & -0.62 & -0.0145 & -0.0994 & 1.26 & 0.0174 \\
\hline 8 & -8.1 & -0.42 & -0.0132 & -0.0974 & 1.26 & 0.0152 \\
\hline 9 & -6.0 & -0.20 & -0.0117 & -0.0967 & 1.27 & 0.0139 \\
\hline 10 & -4.0 & 0.01 & -0.0090 & -0.0962 & 1.25 & 0.0111 \\
\hline 11 & -2.1 & 0.22 & -0.0053 & -0.0948 & 1.25 & 0.0102 \\
\hline 1 & 0.0 & 0.44 & -0.0019 & -0.0935 & 1.26 & 0.0097 \\
\hline 12 & 0.0 & 0.42 & -0.0001 & -0.0939 & 1.26 & 0.0098 \\
\hline 13 & 2.1 & 0.63 & 0.0052 & -0.0926 & 1.26 & 0.0099 \\
\hline 14 & 4.0 & 0.84 & 0.0105 & -0.0904 & 1.26 & 0.0102 \\
\hline 15 & 6.2 & 1.03 & 0.0187 & -0.0840 & 1.26 & 0.0110 \\
\hline 16 & 8.1 & 1.16 & 0.0261 & -0.0731 & 1.26 & 0.0160 \\
\hline 17 & 10.2 & 1.26 & 0.0377 & -0.0595 & 1.26 & 0.0215 \\
\hline 18 & 11.2 & 1.28 & 0.0412 & -0.0494 & 1.26 & 0.0305 \\
\hline 19 & 12.3 & 1.30 & 0.0520 & -0.0464 & 1.26 & 0.0433 \\
\hline 20 & 13.3 & 1.28 & 0.0583 & -0.0428 & 1.27 & - \\
\hline 21 & 14.3 & 1.20 & 0.0631 & -0.0383 & 1.27 & - \\
\hline 22 & 15.3 & 1.16 & 0.0782 & -0.0409 & 1.26 & - \\
\hline 23 & 16.3 & 1.14 & 0.0961 & -0.0463 & 1.27 & - \\
\hline 24 & 17.3 & 1.11 & 0.1117 & -0.0510 & 1.27 & - \\
\hline 25 & 18.3 & 1.09 & 0.1306 & -0.0580 & 1.27 & - \\
\hline 26 & 19.1 & 1.08 & 0.1469 & -0.0640 & 1.27 & - \\
\hline 27 & 20.1 & 1.08 & 0.1660 & -0.0685 & 1.28 & - \\
\hline 28 & 22.1 & 1.03 & 0.2203 & -0.0900 & 1.28 & - \\
\hline
\end{tabular}




\begin{tabular}{|c|c|c|c|c|c|c||}
\hline \multicolumn{7}{|c|}{ Table B3. NACA 4415, Clean, Re $=1.25 \times 10^{6}$} \\
\hline \hline RUN & AOA & $\mathrm{C}_{1}$ & $\mathrm{C}_{\mathrm{dp}}$ & $\mathrm{C}_{\mathrm{m} 1 / 4}$ & $\operatorname{Re} \times 10^{-6}$ & $\mathrm{C}_{\mathrm{dw}}$ \\
\hline 29 & 24.1 & 1.04 & 0.2732 & -0.1064 & 1.29 & - \\
\hline 30 & 26.1 & 0.96 & 0.5119 & -0.1679 & 1.32 & - \\
\hline 31 & 28.0 & 1.08 & 0.6108 & -0.2004 & 1.32 & - \\
\hline 32 & 30.0 & 1.16 & 0.7014 & -0.2271 & 1.35 & - \\
\hline 33 & 32.1 & 1.24 & 0.8035 & -0.2569 & 1.35 & - \\
\hline 34 & 34.1 & 1.30 & 0.9090 & -0.2893 & 1.36 & - \\
\hline 35 & 36.0 & 1.32 & 0.9899 & -0.3094 & 1.38 & - \\
\hline 36 & 37.9 & 1.34 & 1.0797 & -0.3341 & 1.41 & - \\
\hline 37 & 40.1 & 1.34 & 1.1659 & -0.3549 & 1.41 & - \\
\hline & & & End of Table B3 & & \\
\hline
\end{tabular}




\begin{tabular}{|c|c|c|c|c|c|c|}
\hline RUN & $\mathrm{AOA}$ & $\mathrm{C}_{1}$ & $\mathrm{C}_{\mathrm{dp}}$ & $\mathrm{C}_{\mathrm{m} / \mathrm{k}}$ & $\operatorname{Re} \times 10^{-6}$ & $\mathrm{C}_{\mathrm{dw}}$ \\
\hline 113 & -6.0 & -0.19 & -0.0114 & -0.0968 & 1.26 & 0.0136 \\
\hline 114 & -4.0 & 0.03 & -0.0089 & -0.0958 & 1.26 & 0.0114 \\
\hline 115 & -2.1 & 0.21 & -0.0057 & -0.0956 & 1.26 & 0.0097 \\
\hline 112 & 0.0 & 0.43 & -0.0010 & -0.0955 & 0.75 & 0.0079 \\
\hline 116 & 0.0 & 0.42 & -0.0009 & -0.0932 & 1.26 & 0.0107 \\
\hline 117 & 2.1 & 0.64 & 0.0043 & -0.0923 & 1.25 & 0.0091 \\
\hline 118 & 4.1 & 0.86 & 0.0110 & -0.0917 & 1.25 & 0.0098 \\
\hline 119 & 6.1 & 1.03 & 0.0170 & -0.0847 & 1.27 & 0.0111 \\
\hline 120 & 8.1 & 1.17 & 0.0235 & -0.0717 & 1.27 & 0.0138 \\
\hline 121 & 10.2 & 1.26 & 0.0380 & -0.0596 & 1.26 & .0 .0193 \\
\hline 122 & 11.2 & 1.29 & 0.0440 & -0.0511 & 1.25 & 0.0267 \\
\hline 123 & 12.3 & 1.30 & 0.0524 & -0.0462 & 1.26 & 0.0556 \\
\hline 124 & 13.3 & 1.28 & 0.0585 & -0.0430 & 1.27 & - \\
\hline 125 & 14.3 & 1.19 & 0.0633 & -0.0383 & 1.28 & - \\
\hline 126 & 15.3 & 1.17 & 0.0789 & -0.0407 & 1.27 & - \\
\hline .127 & 16.1 & 1.14 & 0.0905 & -0.0455 & 1.27 & - \\
\hline 128 & 17.3 & 1.12 & 0.1137 & -0.0521 & 1.27 & -- \\
\hline 129 & 18.1 & 1.10 & 0.1293 & -0.0587 & 1.27 & - \\
\hline 130 & 19.1 & 1.08 & 0.1477 & -0.0644 & 1.30 & - \\
\hline 131 & 20.1 & 1.06 & 0.1694 & -0.0720 & 1.30 & - \\
\hline \multicolumn{7}{|c|}{ End of Table B4 } \\
\hline
\end{tabular}




\begin{tabular}{|c|c|c|c|c|c|c|}
\hline \multicolumn{7}{|c|}{ Table B5. NACA 4415, Clean, $R e=1.5 \times 10^{6}$} \\
\hline RUN & $\mathrm{AOA}$ & $\mathrm{C}_{\mathrm{I}}$ & $C_{d p}$ & $\mathrm{C}_{\mathrm{m} / \mathrm{k}}$ & $\operatorname{Re} \times 10^{-6}$ & $C_{d w}$ \\
\hline 132 & -20.1 & -0.39 & 0.2596 & 0.0136 & 1.55 & - \\
\hline 133 & -18.0 & -0.35 & 0.2269 & 0.0104 & 1.53 & - \\
\hline 134 & -15.9 & -0.29 & 0.1895 & 0.0034 & 1.55 & - \\
\hline 135 & -14.1 & -0.32 & 0.1767 & 0.0140 & 1.54 & - \\
\hline 136 & -12.1 & -0.50 & 0.1702 & 0.0265 & 1.53 & - \\
\hline 137 & -10.2 & -0.62 & -0.0142 & -0.0981 & 1.52 & 0.0182 \\
\hline 138 & -8.1 & -0.41 & -0.0137 & -0.0968 & 1.52 & 0.0148 \\
\hline 139 & -6.0 & -0.19 & -0.0106 & -0.0958 & 1.52 & 0.0119 \\
\hline 140 & -3.9 & 0.02 & -0.0086 & -0.0947 & 1.51 & 0.0116 \\
\hline 141 & -2.1 & 0.21 & -0.0056 & -0.0938 & 1.52 & 0.0105 \\
\hline 142 & 0.0 & 0.42 & -0.0008 & -0.0927 & 1.52 & 0.0105 \\
\hline 143 & 2.1 & 0.64 & 0.0039 & -0.0908 & 1.52 & 0.0109 \\
\hline 144 & 4.0 & 0.85 & 0.0089 & -0.0886 & 1.52 & 0.0104 \\
\hline 145 & 6.1 & 1.02 & 0.0165 & -0.0823 & 1.52 & 0.0126 \\
\hline 146 & 8.3 & 1.17 & 0.0270 & -0.0704 & 1.53 & 0.0159 \\
\hline 147 & 10.2 & 1.25 & 0.0319 & -0.0541 & 1.52 & 0.0245 \\
\hline 148 & 12.2 & 1.29 & 0.0470 & -0.0446 & 1.52 & 0.0578 \\
\hline 149 & 13.2 & 1.21 & 0.0511 & -0.0404 & 1.52 & - \\
\hline 150 & 14.3 & 1.17 & 0.0644 & -0.0399 & 1.53 & - \\
\hline 151 & 15.2 & 1.14 & 0.0788 & -0.0431 & 1.52 & - \\
\hline 152 & 16.3 & 1.12 & 0.0966 & -0.0480 & 1.52 & - \\
\hline 153 & 17.3 & 1.09 & 0.1162 & -0.0544 & 1.53 & - \\
\hline 154 & 18.4 & 1.07 & 0.1342 & -0.0600 & 1.53 & -- \\
\hline 155 & 19.1 & 1.06 & 0.1508 & -0.0677 & 1.53 & - \\
\hline 156 & 20.1 & 1.03 & 0.1751 & -0.0758 & 1.54 & - \\
\hline 157 & 22.1 & 1.01 & 0.2280 & -0.0950 & 1.55 & - \\
\hline 158 & 24.2 & 1.03 & 0.2784 & -0.1070 & 1.54 & - \\
\hline
\end{tabular}




\begin{tabular}{||c|c|c|c|c|c|c||}
\hline \multicolumn{7}{|c||}{ Table B6. NACA 4415, Clean, Re $=1.5 \times 10^{6}$, Repeat runs } \\
\hline \hline RUN & AOA & $\mathrm{C}_{1}$ & $\mathrm{C}_{\mathrm{dp}}$ & $\mathrm{C}_{\mathrm{r} / 4}$ & $\operatorname{Re} \times 10^{-6}$ & $\mathrm{C}_{\mathrm{dw}}$ \\
\hline \hline 169 & -17.0 & -0.36 & 0.2181 & 0.0190 & 1.53 & - \\
\hline 168 & -16.0 & -0.36 & 0.2091 & 0.0216 & 1.54 & - \\
\hline 167 & -15.1 & -0.42 & 0.2136 & 0.0387 & 1.54 & - \\
\hline 166 & -14.1 & -0.40 & 0.1939 & 0.0306 & 1.53 & - \\
\hline 165 & -13.3 & -0.91 & -0.0089 & -0.0990 & 1.51 & - \\
\hline 164 & -12.3 & -0.81 & -0.0106 & -0.0993 & 1.51 & - \\
\hline 163 & -11.2 & -0.71 & -0.0124 & -0.0990 & 1.50 & - \\
\hline 162 & -10.2 & -0.62 & -0.0136 & -0.0986 & 1.51 & - \\
\hline 161 & -8.1 & -0.40 & -0.0131 & -0.0972 & 1.50 & - \\
\hline 160 & -3.9 & 0.03 & -0.0087 & -0.0950 & 1.51 & - \\
\hline 159 & 0.0 & 0.44 & -0.0024 & -0.0926 & 1.51 & - \\
\hline & & \multicolumn{7}{|c||}{ End of Table B6 } & \\
\hline
\end{tabular}




\begin{tabular}{|c|c|c|c|c|c|c|}
\hline RUN & $\mathrm{AOA}$ & $\mathrm{C}_{1}$ & $\mathrm{C}_{\mathrm{dp}}$ & $\mathrm{C}_{\mathrm{m} / \mathrm{k}}$ & $\operatorname{Re} \times 10^{-6}$ & $\mathrm{C}_{\mathrm{dw}}$ \\
\hline 180 & -20.1 & -0.40 & 0.2352 & 0.0131 & 0.77 & - \\
\hline 179 & -18.0 & -0.37 & 0.1939 & 0.0065 & 0.77 & - \\
\hline 178 & -16.0 & -0.35 & 0.1594 & 0.0047 & 0.76 & - \\
\hline 177 & -14.1 & -0.33 & 0.1300 & 0.0025 & 0.76 & - \\
\hline 176 & -12.1 & -0.43 & 0.1100 & 0.0093 & 0.76 & - \\
\hline 175 & -10.2 & -0.54 & -0.0132 & -0.0960 & 0.76 & 0.0263 \\
\hline 174 & -8.1 & -0.38 & -0.0175 & -0.0930 & 0.76 & 0.0190 \\
\hline 173 & -6.1 & -0.20 & -0.0161 & -0.0889 & 0.76 & 0.0177 \\
\hline 172 & -3.9 & -0.01 & -0.0113 & -0.0835 & 0.76 & 0.0171 \\
\hline 171 & -2.1 & 0.18 & -0.0083 & -0.0817 & 0.76 & 0.0150 \\
\hline 170 & 0.0 & 0.36 & -0.0031 & -0.0785 & 0.76 & 0.0166 \\
\hline 181 & 0.0 & 0.35 & -0.0029 & -0.0780 & 0.75 & 0.0167 \\
\hline 182 & 2.1 & 0.55 & 0.0002 & -0.0738 & 0.75 & 0.0170 \\
\hline 183 & 4.1 & 0.72 & 0.0063 & -0.0644 & 0.76 & 0.0180 \\
\hline 184 & 6.2 & 0.87 & 0.0152 & -0.0572 & 0.75 & 0.0216 \\
\hline 185 & 8.1 & 0.98 & 0.0264 & -0.0480 & 0.75 & 0.0258 \\
\hline 186 & 10.1 & 1.07 & 0.0485 & -0.0465 & 0.76 & 0.0300 \\
\hline 187 & 11.2 & 1.11 & 0.0686 & -0.0556 & 0.75 & 0.0256 \\
\hline 188 & 12.2 & 1.11 & 0.0897 & -0.0592 & 0.75 & 0.0352 \\
\hline 189 & 13.2 & 1.10 & 0.1101 & -0.0650 & 0.77 & - \\
\hline 190 & 14.2 & 1.07 & 0.1283 & -0.0685 & 0.77 & - \\
\hline 191 & 15.2 & 1.07 & 0.1499 & -0.0723 & 0.76 & - \\
\hline 192 & 16.2 & 0.93 & 0.1547 & -0.0689 & 0.77 & - \\
\hline 193 & 17.2 & 1.06 & 0.1966 & -0.0821 & 0.77 & - \\
\hline 194 & 18.2 & 0.87 & 0.2075 & -0.0849 & 0.77 & - \\
\hline 195 & 19.2 & 1.03 & 0.2461 & -0.0958 & 0.78 & - \\
\hline 196 & 20.0 & 0.85 & 0.2647 & -0.1034 & 0.79 & - \\
\hline 197 & 22.0 & 0.86 & 0.3285 & -0.1204 & 0.76 & - \\
\hline
\end{tabular}




\begin{tabular}{|c|c|c|c|c|c|c||}
\hline \multicolumn{7}{|c|}{ Table B7. NACA 4415, k/c=0.0019, Re $=0.75 \times 10^{6}$} \\
\hline \hline RUN & AOA & $\mathrm{C}_{\mathrm{l}}$ & $\mathrm{C}_{\mathrm{dp}}$ & $\mathrm{C}_{\mathrm{n} 1 \mathrm{k}}$ & $\operatorname{Re} \times 10^{-6}$ & $\mathrm{C}_{\mathrm{dw}}$ \\
\hline 198 & 24.1 & 1.02 & 0.4381 & -0.1639 & 0.78 & - \\
\hline 199 & 26.0 & 1.04 & 0.4994 & -0.1770 & 0.79 & - \\
\hline 200 & 28.0 & 1.07 & 0.5644 & -0.1902 & 0.80 & - \\
\hline 201 & 30.1 & 1.12 & 0.6523 & -0.2121 & 0.80 & - \\
\hline 202 & 32.1 & 1.19 & 0.7493 & -0.2404 & 0.82 & - \\
\hline 203 & 34.1 & 1.24 & 0.8410 & -0.2647 & 0.83 & - \\
\hline 204 & 36.1 & 1.33 & 0.9734 & -0.3110 & 0.83 & - \\
\hline 205 & 37.8 & 1.35 & 1.0589 & -0.3344 & 0.84 & - \\
\hline 206 & 40.1 & 1.33 & 1.1206 & -0.3408 & 0.85 & - \\
\hline & & & End of Table B7 & & - \\
\hline \hline
\end{tabular}




\begin{tabular}{|c|c|c|c|c|c|c|}
\hline RUN & $\mathrm{AOA}$ & $\mathrm{C}_{1}$ & $\mathrm{C}_{\mathrm{dp}}$ & $\mathrm{C}_{\mathrm{m} / \mathrm{k}}$ & $\operatorname{Re} \times 10^{-6}$ & $\mathrm{C}_{\mathrm{dw}}$ \\
\hline 217 & -20.1 & -0.39 & 0.2349 & 0.0109 & 1.03 & - \\
\hline 216 & -18.1 & -0.35 & 0.1999 & 0.0067 & 1.02 & - \\
\hline 215 & -16.0 & -0.33 & 0.1651 & 0.0028 & 1.02 & - \\
\hline 214 & -14.2 & -0.37 & 0.1333 & 0.0027 & 1.02 & - \\
\hline 213 & -12.2 & -0.47 & 0.1017 & -0.0019 & 1.02 & - \\
\hline 212 & -10.2 & -0.56 & -0.0135 & -0.0922 & 1.01 & 0.0318 \\
\hline 211 & -8.1 & -0.41 & -0.0184 & -0.0916 & 1.00 & 0.0236 \\
\hline 210 & -6.0 & -0.22 & -0.0167 & -0.0883 & 1.01 & 0.0174 \\
\hline 209 & -4.0 & -0.02 & -0.0123 & -0.0842 & 1.01 & 0.0164 \\
\hline 208 & -2.1 & 0.17 & -0.0087 & -0.0811 & 1.01 & 0.0182 \\
\hline 207 & 0.0 & 0.36 & -0.0049 & -0.0779 & 1.01 & 0.0146 \\
\hline 218 & 0.0 & 0.36 & -0.0051 & -0.0773 & 1.01 & 0.0152 \\
\hline 219 & 2.1 & 0.55 & 0.0008 & -0.0730 & 1.02 & 0.0183 \\
\hline 220 & 4.0 & 0.72 & 0.0055 & -0.0661 & 1.01 & 0.0178 \\
\hline 221 & 6.1 & 0.87 & 0.0131 & -0.0572 & 1.02 & 0.0165 \\
\hline 222 & 8.1 & 0.98 & 0.0284 & -0.0491 & 1.02 & 0.0247 \\
\hline 223 & 10.2 & 1.08 & 0.0507 & -0.0473 & 1.01 & 0.0283 \\
\hline 224 & 11.2 & 1.12 & 0.0736 & -0.0567 & 1.02 & 0.0304 \\
\hline $225^{\circ}$ & 12.2 & 1.12 & 0.0956 & -0.0617 & 1.02 & - \\
\hline 226 & 13.3 & 1.12 & 0.1152 & -0.0656 & 1.02 & - \\
\hline 227 & 14.3 & 1.13 & 0.1379 & -0.0703 & 1.00 & - \\
\hline 228 & 15.3 & 1.10 & 0.1589 & -0.0753 & 1.04 & - \\
\hline 229 & 16.1 & 1.09 & 0.1774 & -0.0786 & 1.03 & - \\
\hline 230 & 17.1 & 1.07 & 0.1978 & -0.0825 & 1.02 & - \\
\hline 231 & 18.1 & 1.05 & 0.2207 & -0.0881 & 1.03 & - \\
\hline 232 & 19.1 & 1.01 & 0.2417 & -0.0943 & 1.04 & - \\
\hline 233 & 20.1 & 0.84 & 0.2658 & -0.1009 & 1.04 & - \\
\hline 234 & 22.1 & 0.89 & 0.3395 & -0.1240 & 1.06 & - \\
\hline
\end{tabular}




\begin{tabular}{|c|c|c|c|c|c|c||}
\hline \multicolumn{7}{|c||}{ Table B8. NACA 4415, k/c=0.0019, Re $=1.0 \times 10^{6}$} \\
\hline \hline RUN & AOA & $\mathrm{C}_{\mathrm{l}}$ & $\mathrm{C}_{\mathrm{dp}}$ & $\mathrm{C}_{\mathrm{m} / \mathrm{k}}$ & $\operatorname{Re} \times 10^{-6}$ & $\mathrm{C}_{\mathrm{dw}}$ \\
\hline 235 & 24.0 & 1.01 & 0.4355 & -0.1608 & 1.05 & - \\
\hline 236 & 26.1 & 1.03 & 0.4968 & -0.1737 & 1.04 & - \\
\hline 237 & 28.1 & 1.06 & 0.5643 & -0.1875 & 1.05 & - \\
\hline 238 & 30.0 & 1.12 & 0.6480 & -0.2103 & 1.07 & - \\
\hline 239 & 32.2 & 1.19 & 0.7573 & -0.2422 & 1.07 & - \\
\hline 240 & 33.9 & 1.27 & 0.8627 & -0.2770 & 1.09 & - \\
\hline 241 & 36.0 & 1.31 & 0.9549 & -0.3004 & 1.11 & - \\
\hline 242 & 38.0 & 1.33 & 1.0436 & -0.3246 & 1.12 & - \\
\hline 243 & 39.9 & 1.34 & 1.1294 & -0.3462 & 1.12 & - \\
\hline
\end{tabular}




\begin{tabular}{|c|c|c|c|c|c|c|}
\hline RUN & $\mathrm{AOA}$ & $\mathrm{C}_{\mathrm{l}}$ & $\mathrm{C}_{\mathrm{dp}}$ & $\mathrm{C}_{\mathrm{m} / \mathrm{k}}$ & $\operatorname{Re} \times 10^{-6}$ & $\mathrm{C}_{\mathrm{dw}}$ \\
\hline 254 & -20.1 & -0.40 & 0.2384 & 0.0107 & 1.29 & - \\
\hline 253 & -18.1 & -0.34 & 0.2006 & 0.0038 & 1.27 & - \\
\hline 252 & -16.0 & -0.32 & 0.1692 & 0.0014 & 1.28 & - \\
\hline 251 & -14.1 & -0.36 & 0.1394 & 0.0055 & 1.28 & - \\
\hline 250 & -12.2 & -0.49 & 0.1060 & 0.0006 & 1.26 & - \\
\hline 249 & -10.2 & -0.58 & -0.0150 & -0.0926 & 1.26 & 0.0308 \\
\hline 248 & -8.1 & -0.42 & -0.0181 & -0.0900 & 1.27 & 0.0248 \\
\hline 247 & -6.1 & -0.23 & -0.0146 & -0.0868 & 1.27 & 0.0197 \\
\hline 246 & -4.0 & -0.02 & -0.0124 & -0.0844 & 1.28 & 0.0148 \\
\hline 245 & -2.1 & 0.18 & -0.0092 & -0.0807 & 1.27 & 0.0157 \\
\hline 244 & 0.0 & 0.36 & -0.0050 & -0.0775 & 1.28 & 0.0156 \\
\hline 255 & 0.0 & 0.36 & -0.0050 & -0.0773 & 1.26 & 0.0153 \\
\hline 256 & 2.1 & 0.56 & 0.0001 & -0.0723 & 1.26 & 0.0161 \\
\hline 257 & 4.2 & 0.73 & 0.0071 & -0.0662 & 1.26 & 0.0162 \\
\hline 258 & 6.1 & 0.88 & 0.0143 & -0.0569 & 1.26 & 0.0214 \\
\hline 259 & 8.1 & 1.00 & 0.0257 & -0.0473 & 1.26 & 0.0286 \\
\hline 260 & 10.2 & 1.08 & 0.0479 & -0.0458 & 1.26 & 0.0345 \\
\hline 261 & 11.2 & 1.10 & 0.0708 & -0.0559 & 1.27 & 0.0393 \\
\hline 262 & 12.2 & 1.10 & 0.0917 & -0.0604 & 1.26 & - \\
\hline 263 & 13.2 & 0.99 & 0.0958 & -0.0515 & 1.27 & - \\
\hline 264 & 14.2 & 0.91 & 0.1063 & -0.0506 & 1.27 & - \\
\hline 265 & 15.2 & 0.90 & 0.1272 & -0.0567 & 1.27 & - \\
\hline 266 & 16.2 & 0.97 & 0.1630 & -0.0704 & 1.28 & - \\
\hline 267 & 17.1 & 1.04 & 0.1952 & -0.0828 & 1.28 & - \\
\hline 268 & 18.2 & 1.03 & 0.2234 & -0.0891 & 1.29 & - \\
\hline 269 & 19.1 & 1.03 & 0.2469 & -0.0964 & 1.28 & - \\
\hline 270 & 20.1 & 1.00 & 0.2720 & -0.1040 & 1.28 & - \\
\hline 271 & 22.1 & 0.92 & 0.3406 & -0.1251 & 1.30 & - \\
\hline
\end{tabular}




\begin{tabular}{||c|c|c|c|c|c|c||}
\hline \multicolumn{7}{|c|}{ Table B9. NACA 4415, k/c=0.0019, Re $=1.25 \times 10^{6}$} \\
\hline \hline RUN & AOA & $\mathrm{C}_{1}$ & $\mathrm{C}_{\mathrm{dp}}$ & $\mathrm{C}_{\mathrm{m} 1 / /}$ & $\operatorname{Re} \times 10^{-6}$ & $\mathrm{C}_{\mathrm{dw}}$ \\
\hline 272 & 24.1 & 1.02 & 0.4383 & -0.1610 & 1.30 & - \\
\hline 273 & 26.1 & 1.00 & 0.4885 & -0.1674 & 1.31 & - \\
\hline 274 & 28.1 & 0.98 & 0.5311 & -0.1708 & 1.31 & - \\
\hline 275 & 30.1 & 1.12 & 0.6563 & -0.2126 & 1.34 & - \\
\hline 276 & 32.1 & 1.19 & 0.7546 & -0.2403 & 1.34 & - \\
\hline 277 & 34.0 & 1.27 & 0.8638 & -0.2746 & 1.37 & - \\
\hline 278 & 35.9 & 1.32 & 0.9664 & -0.3065 & 1.38 & - \\
\hline 279 & 37.9 & 1.35 & 1.0583 & -0.3315 & 1.40 & - \\
\hline 280 & 40.0 & 1.34 & 1.1341 & -0.3471 & 1.41 & - \\
\hline & & & End of Table B9 & & \\
\hline
\end{tabular}




\begin{tabular}{|c|c|c|c|c|c|c|}
\hline \multicolumn{7}{|c|}{ Table B10. NACA 4415, $\mathrm{k} / \mathrm{c}=0.0019, \mathrm{Re}=1.5 \times 10^{6}$} \\
\hline RUN & AOA & $\mathrm{C}_{1}$ & $\mathrm{C}_{\mathrm{dp}}$ & $\mathrm{C}_{\mathrm{m} / \mathrm{k}}$ & $\operatorname{Re} \times 10^{-6}$ & $C_{d w}$ \\
\hline 291 & -20.1 & -0.39 & 0.2386 & 0.0083 & 1.54 & - \\
\hline 290 & -18.0 & -0.35 & 0.2035 & 0.0049 & 1.53 & - \\
\hline 289 & -16.1 & -0.33 & 0.1743 & 0.0037 & 1.53 & - \\
\hline 288 & -13.9 & -0.38 & 0.1435 & 0.0082 & 1.53 & - \\
\hline 287 & -12.0 & -0.46 & 0.1145 & 0.0101 & 1.52 & - \\
\hline 286 & -10.2 & -0.60 & -0.0130 & -0.0893 & 1.52 & 0.0333 \\
\hline 285 & -8.2 & -0.43 & -0.0164 & -0.0881 & 1.52 & 0.0250 \\
\hline 284 & -6.1 & -0.23 & -0.0155 & -0.0863 & 1.52 & 0.0203 \\
\hline 283 & -4.0 & -0.02 & -0.0124 & -0.0827 & 1.53 & 0.0185 \\
\hline 282 & -2.1 & 0.18 & -0.0095 & -0.0795 & 1.52 & 0.0168 \\
\hline 292 & 0.0 & 0.39 & -0.0070 & -0.0755 & 1.51 & 0.0163 \\
\hline 281 & 0.1 & 0.39 & -0.0065 & -0.0752 & 1.52 & 0.0169 \\
\hline 293 & 2.1 & 0.58 & -0.0038 & -0.0699 & 1.51 & 0.0157 \\
\hline 294 & 4.1 & 0.74 & 0.0039 & -0.0634 & 1.51 & 0.0174 \\
\hline 295 & 6.2 & 0.90 & 0.0121 & -0.0549 & 1.51 & 0.0236 \\
\hline 296 & 8.1 & 1.01 & 0.0224 & -0.0458 & 1.51 & 0.0321 \\
\hline 297 & 10.2 & 1.08 & 0.0485 & -0.0465 & 1.51 & - \\
\hline 298 & 11.3 & 1.08 & 0.0709 & -0.0547 & 1.50 & - \\
\hline 299 & 12.1 & 0.95 & 0.0657 & -0.0396 & 1.51 & - \\
\hline 300 & 13.1 & 0.95 & 0.0858 & -0.0449 & 1.52 & - \\
\hline 301 & 14.2 & 0.93 & 0.1067 & -0.0511 & 1.52 & - \\
\hline 302 & 15.1 & 0.91 & 0.1242 & -0.0556 & 1.52 & - \\
\hline 303 & 16.3 & 0.90 & 0.1516 & -0.0631 & 1.53 & - \\
\hline 304 & 17.2 & 0.89 & 0.1777 & -0.0732 & 1.53 & - \\
\hline 305 & 18.2 & 0.88 & 0.2051 & -0.0811 & 1.53 & - \\
\hline 306 & 19.2 & 0.88 & 0.2381 & -0.0922 & 1.54 & - \\
\hline 307 & 20.0 & 0.86 & 0.2704 & -0.1032 & 1.55 & - \\
\hline 308 & 22.0 & 0.91 & 0.3400 & -0.1234 & 1.56 & - \\
\hline
\end{tabular}




\begin{tabular}{||c|c|c|c|c|c|c||}
\hline \multicolumn{7}{|c||}{ Table B10. NACA 4415, k/c=0.0019, Re $=1.5 \times 10^{6}$} \\
\hline \hline RUN & AOA & $C_{1}$ & $C_{d p}$ & $C_{\mathrm{m} / k}$ & $\operatorname{Re} \times 10^{-6}$ & $C_{d w}$ \\
\hline 309 & 24.0 & 0.96 & 0.4137 & -0.1473 & 1.56 & - \\
\hline 310 & 26.0 & 0.99 & 0.4775 & -0.1627 & 1.54 & - \\
\hline \multicolumn{7}{|c||}{ End of Table B10 } \\
\hline
\end{tabular}




\section{NACA 4415}

Pressure Distributions, Steady State, $R e=0.75$ million 


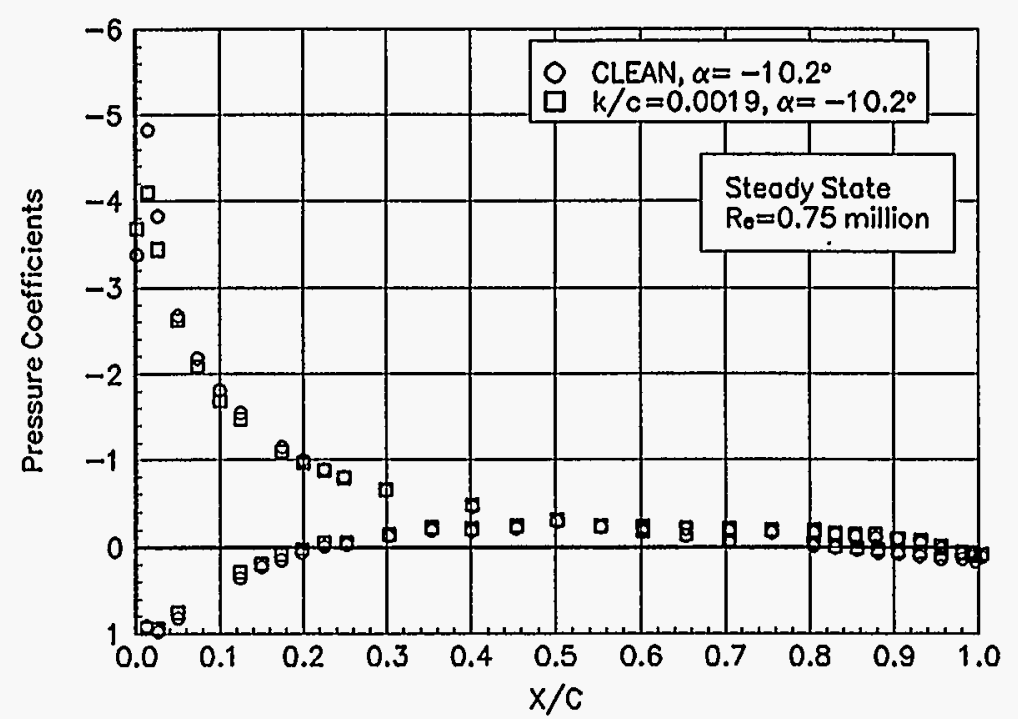

Figure B1. $a=-10.2^{\circ}$

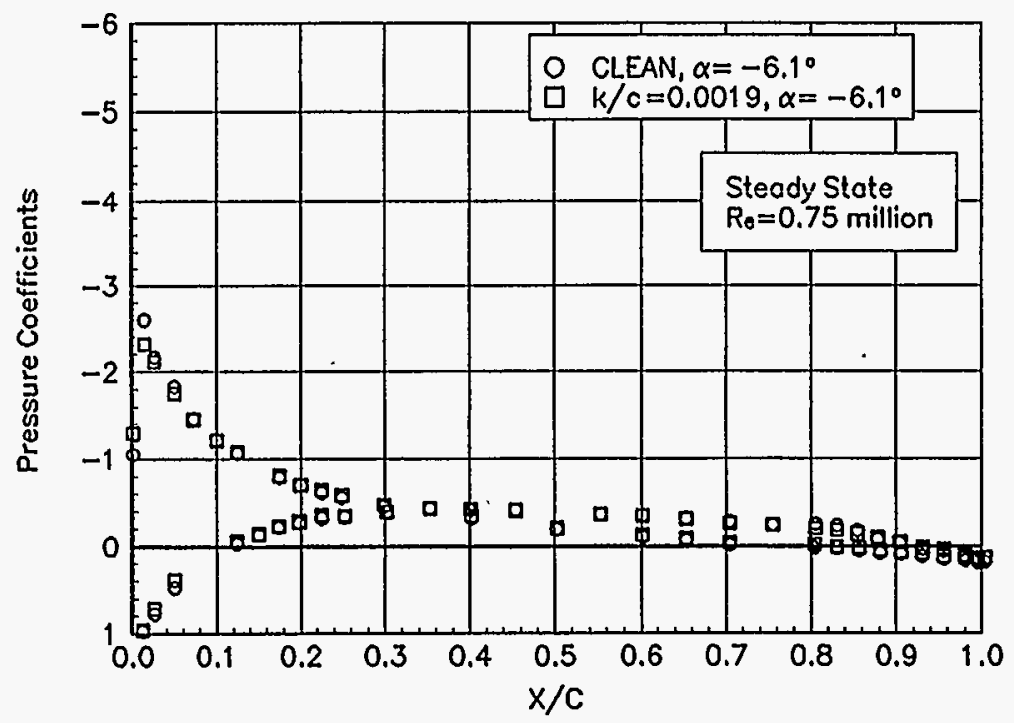

Figure B3. $a=-6.1^{\circ}$

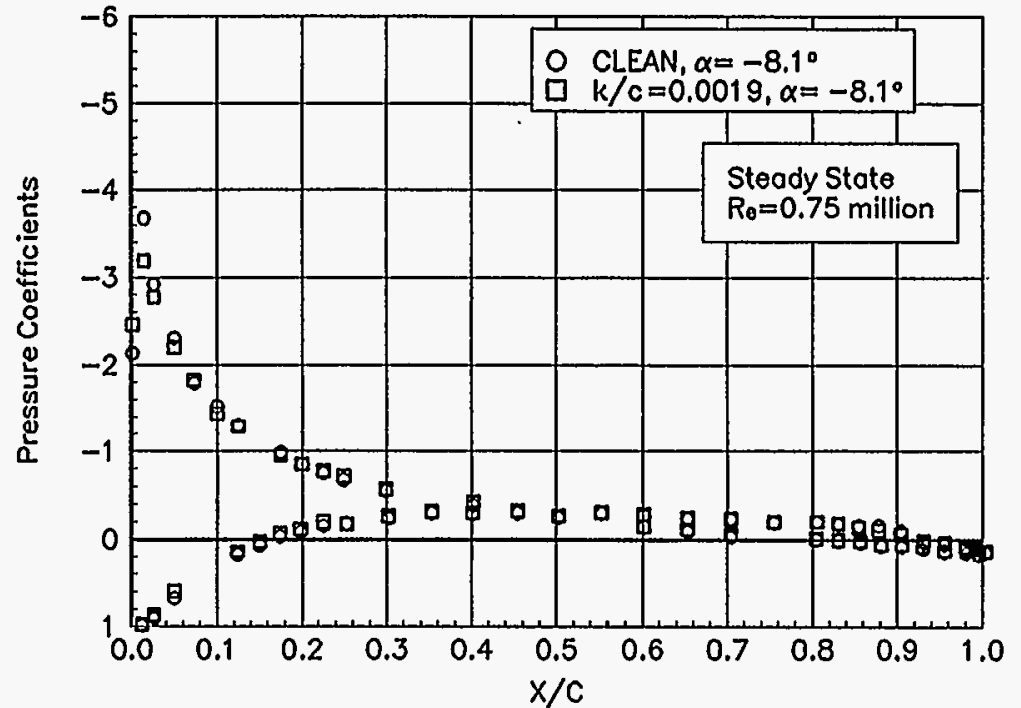

Figure B2. $a=-8.1^{\circ}$

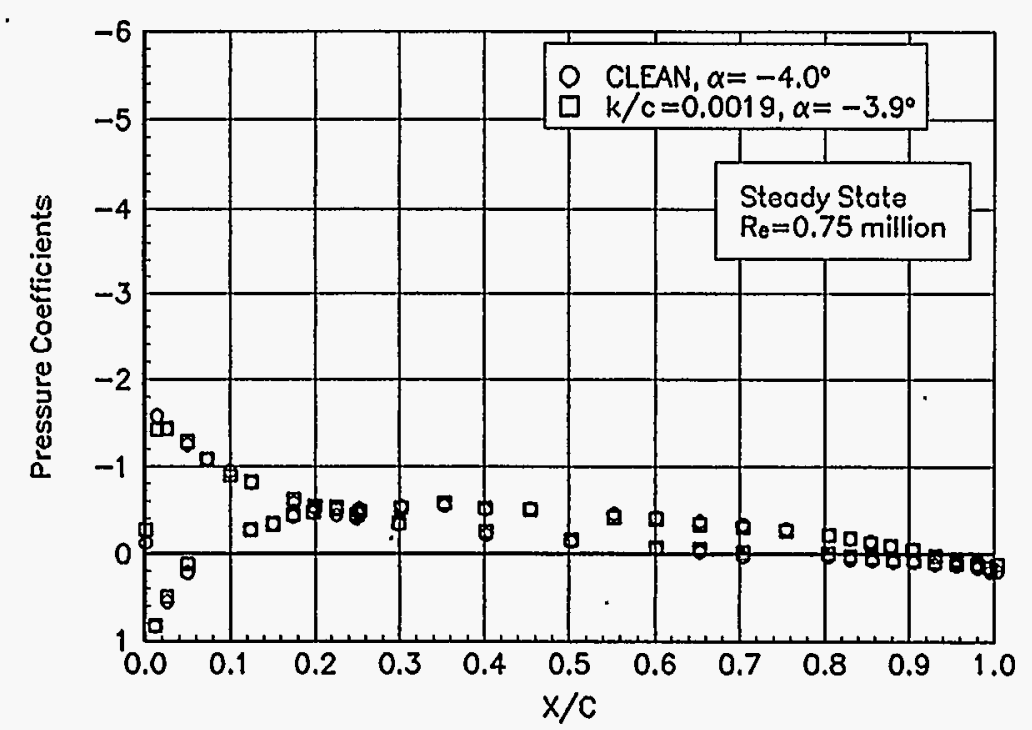

Figure B4. $a=-4.0^{\circ}$ 


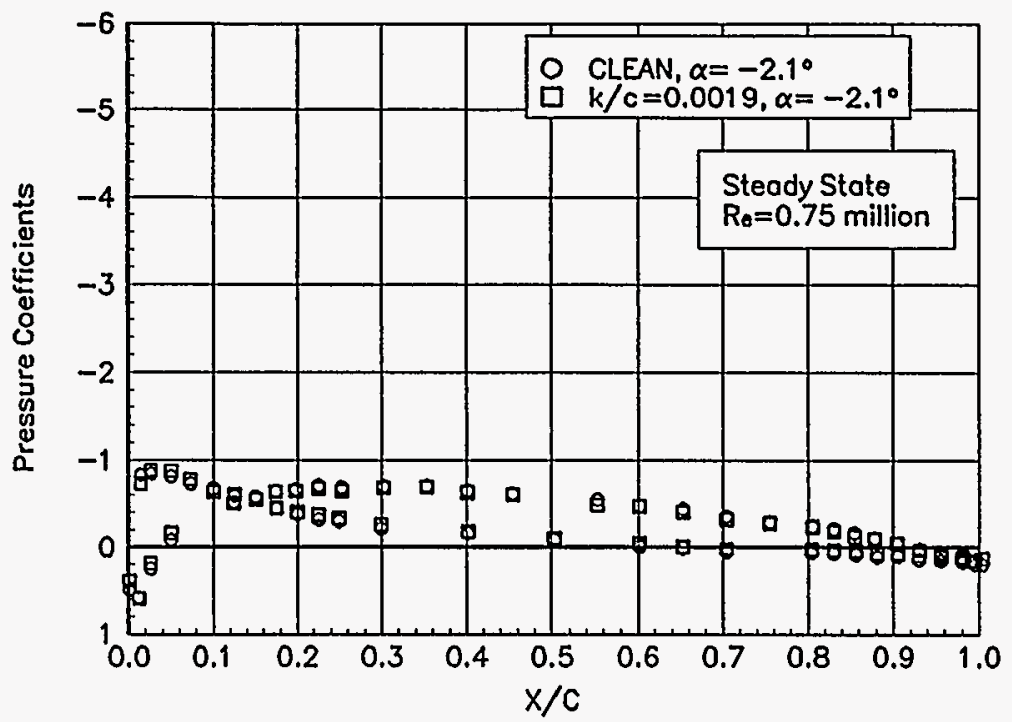

Figure B5. $a=-2.1^{\circ}$

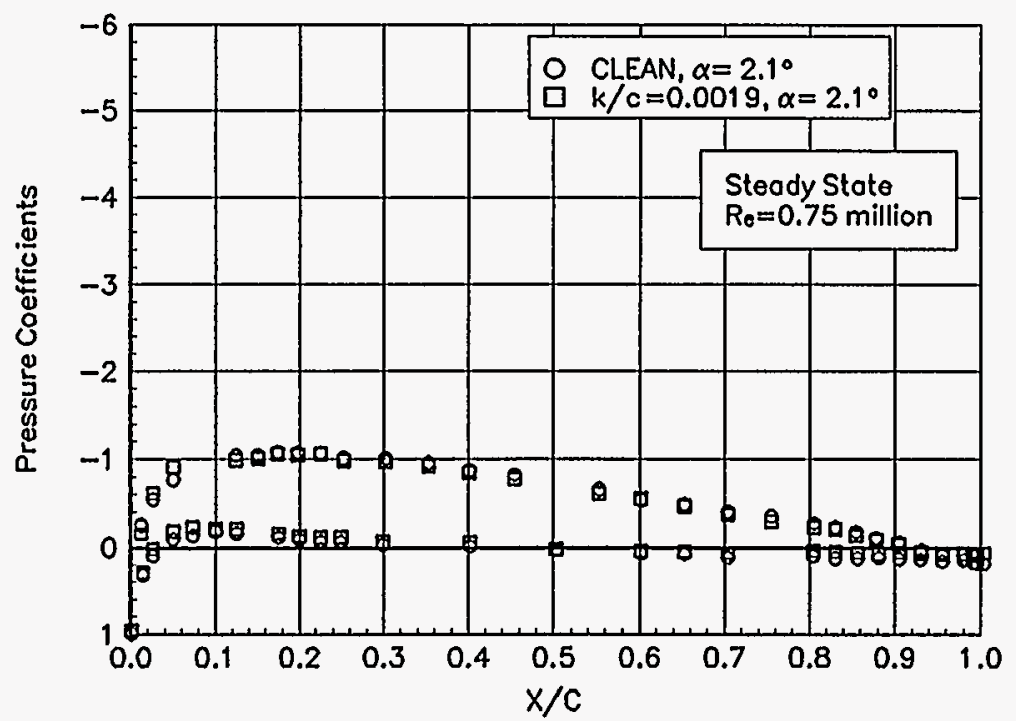

Figure B7. $a=2.1^{\circ}$

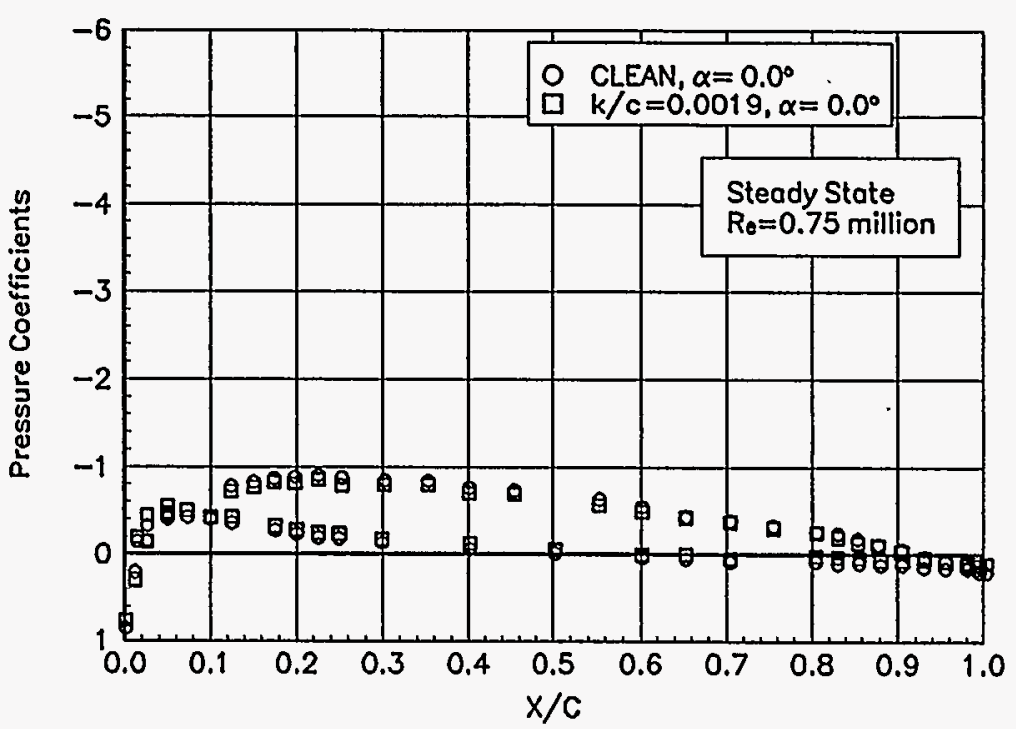

Figure B6. $a=0.0^{\circ}$

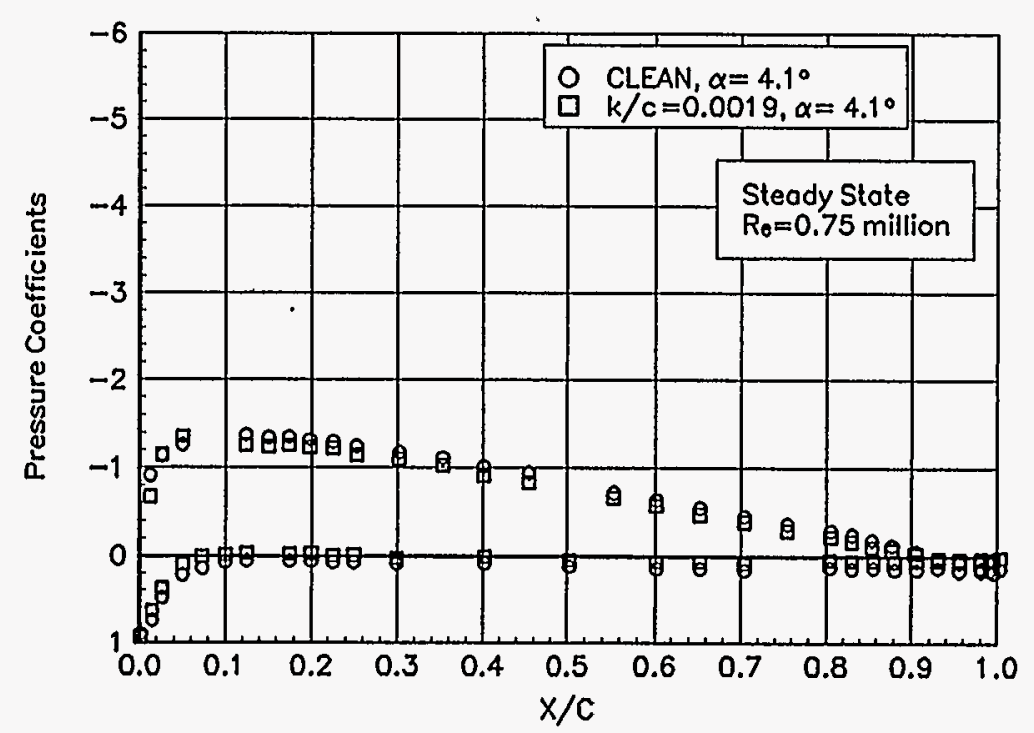

Figure B8. $a=4.1^{\circ}$ 


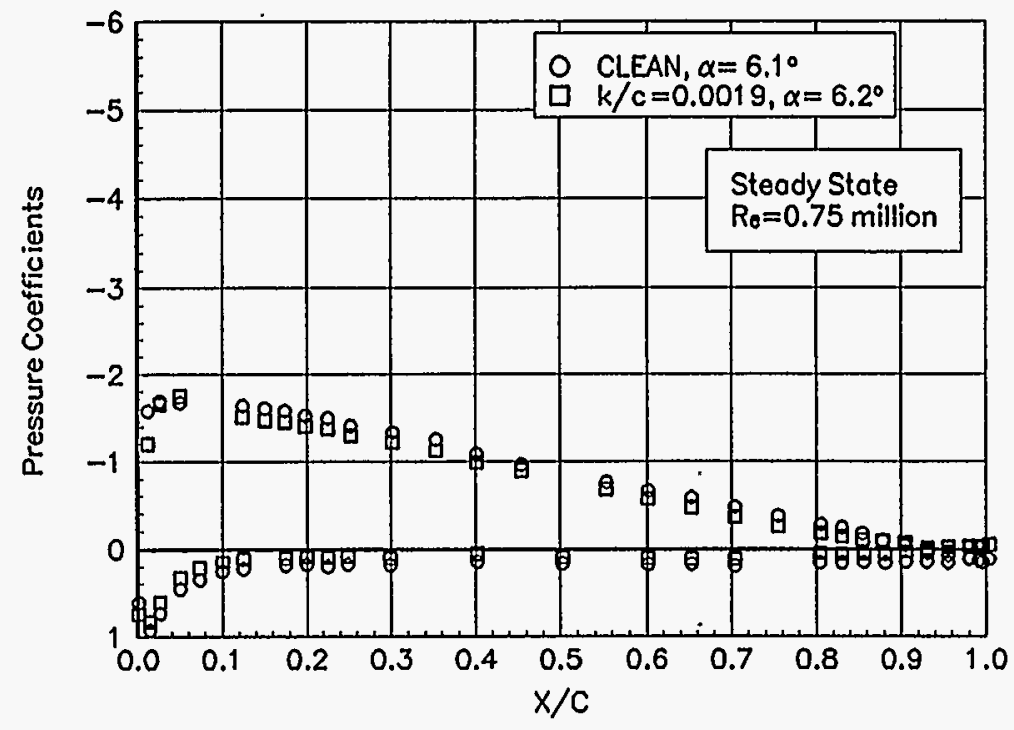

Figure B9. $a=6.1^{\circ}$

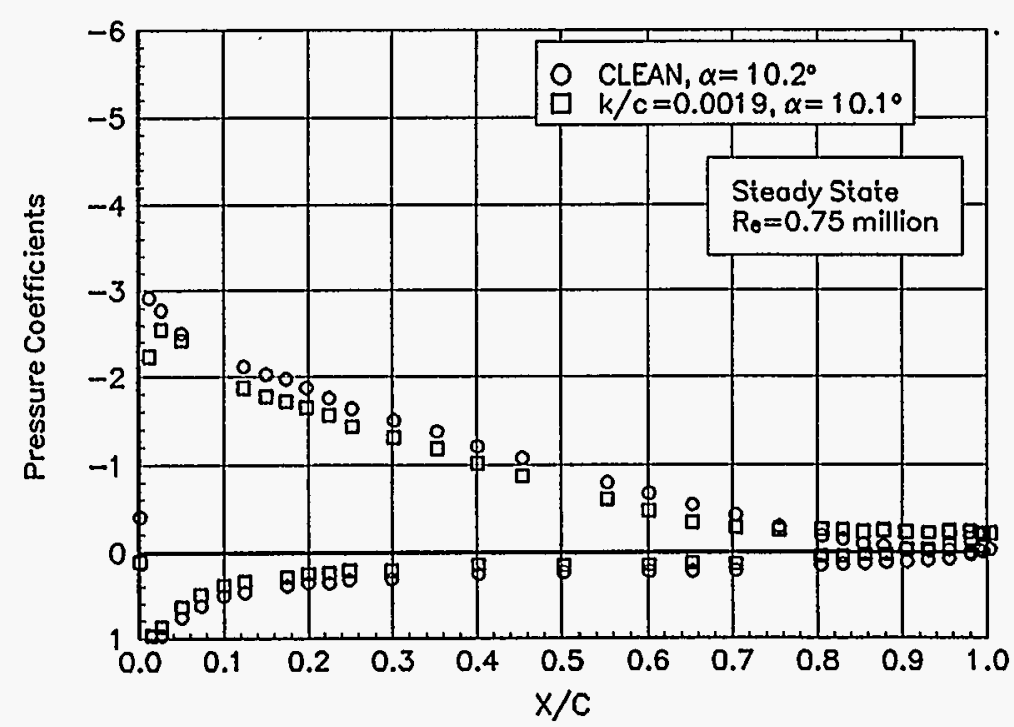

Figure B11. $a=10.2^{\circ}$

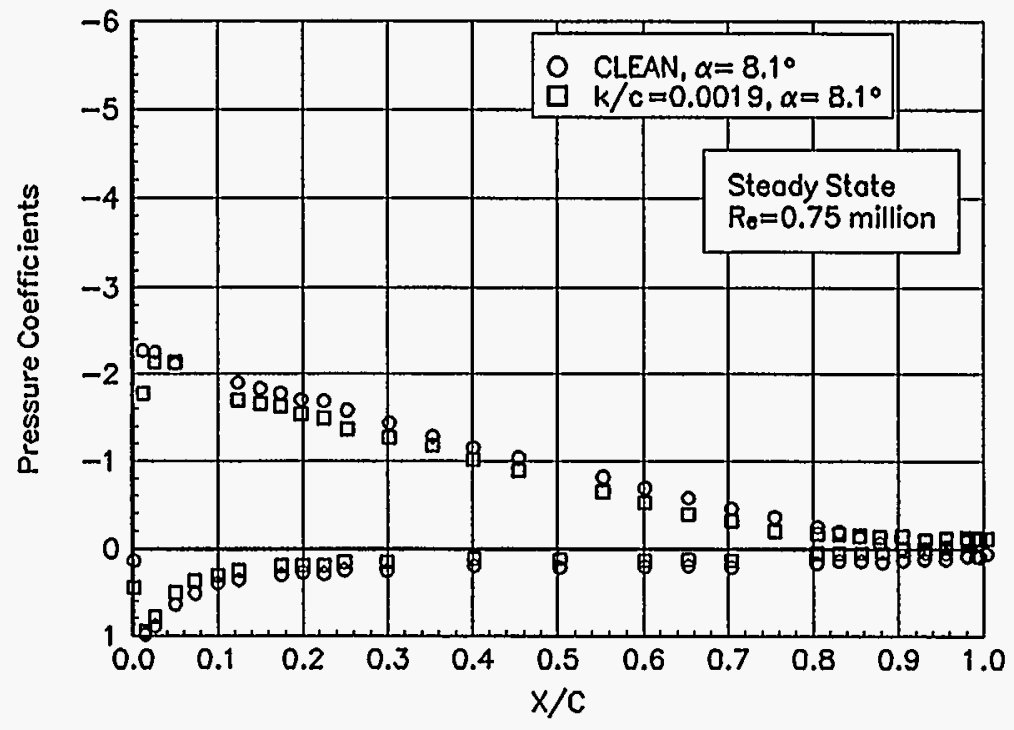

Figure B10. $a=8.1^{\circ}$

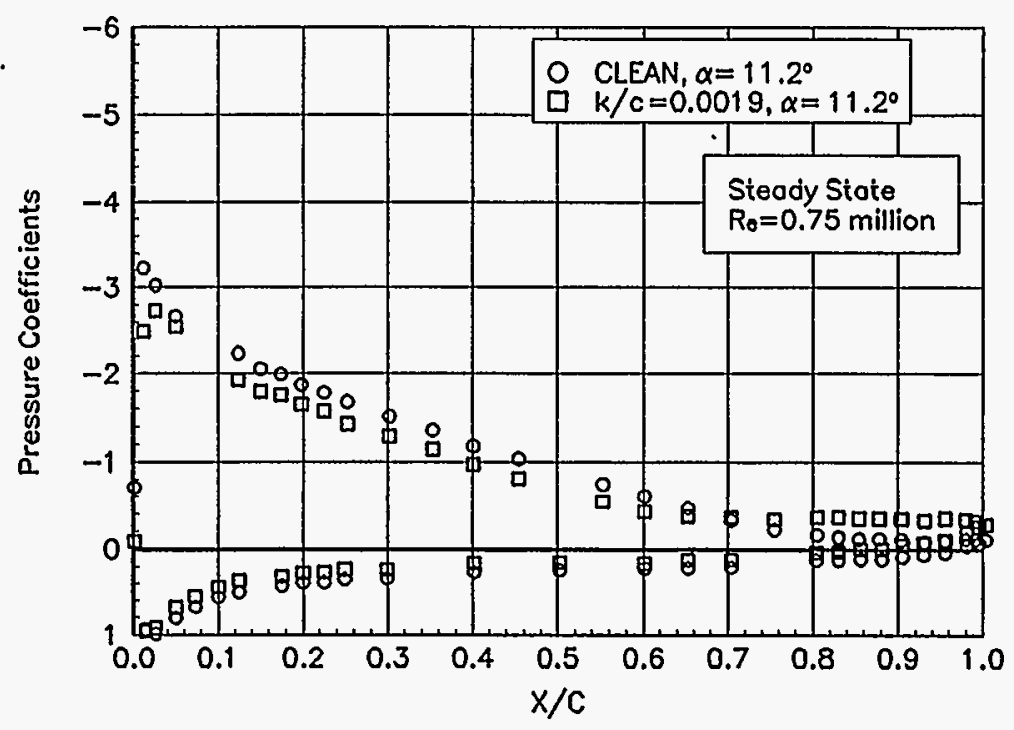

Figure B12. $a=11.2^{\circ}$ 


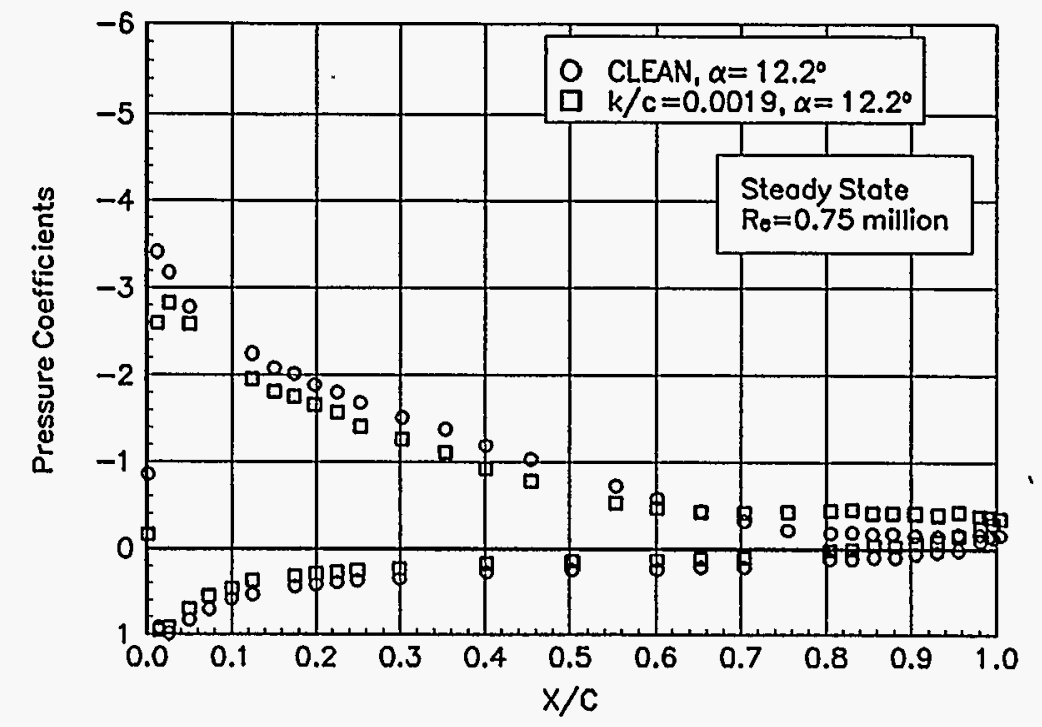

Figure B13. $a=12.2^{\circ}$

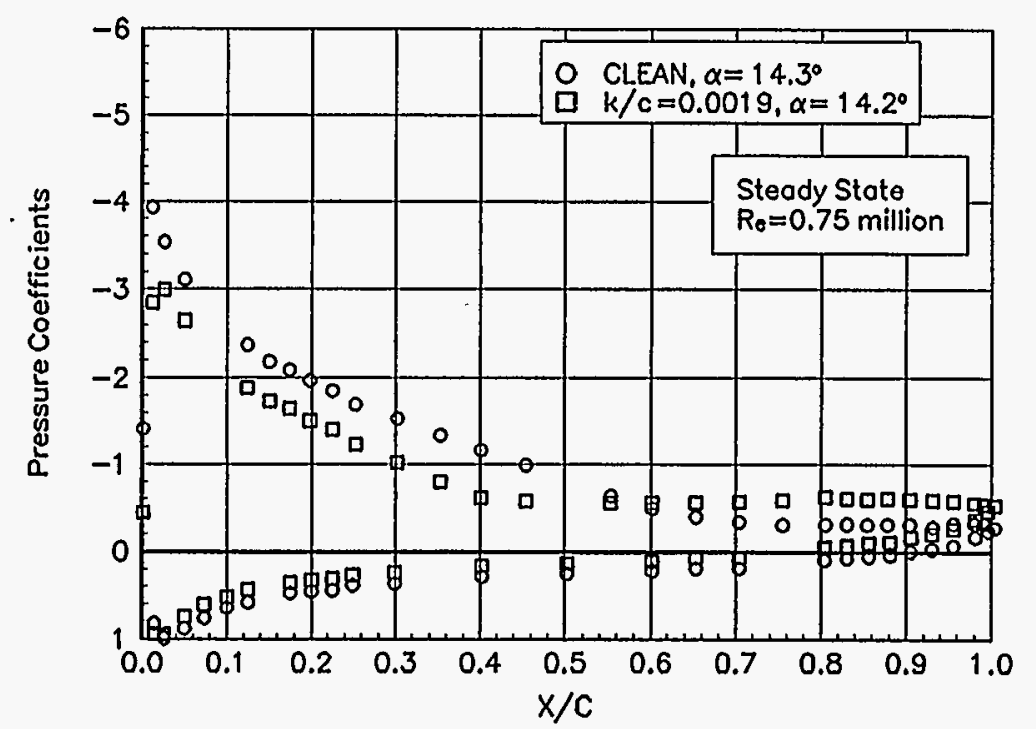

Figure B15. $a=14.3^{\circ}$

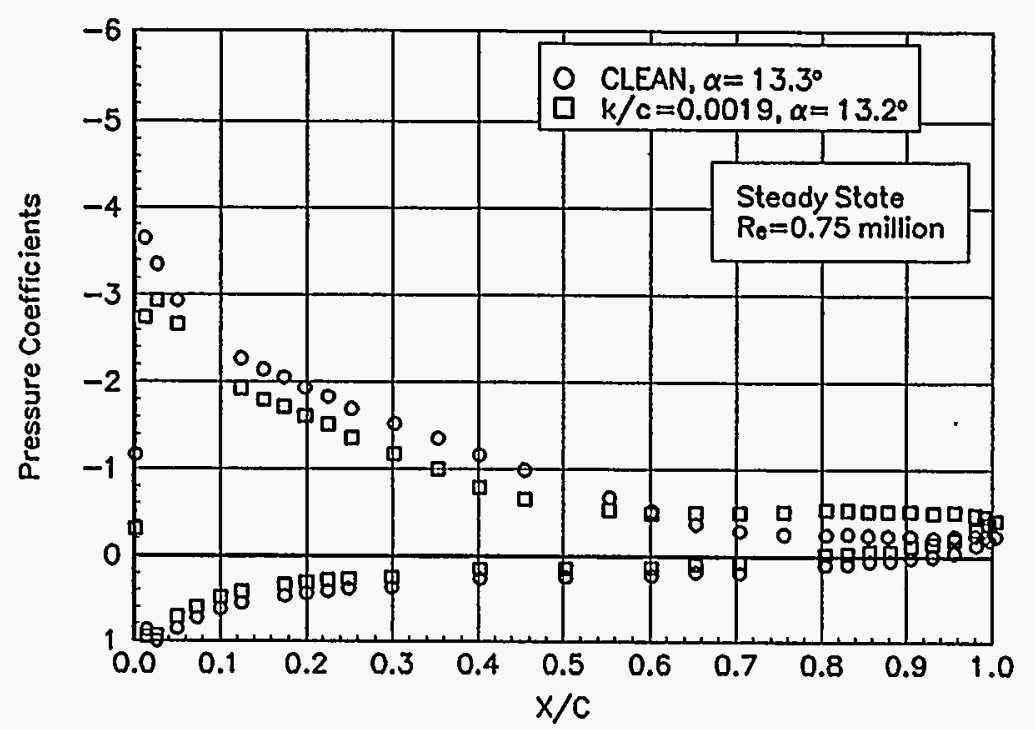

Figure B14. $a=13.3^{\circ}$

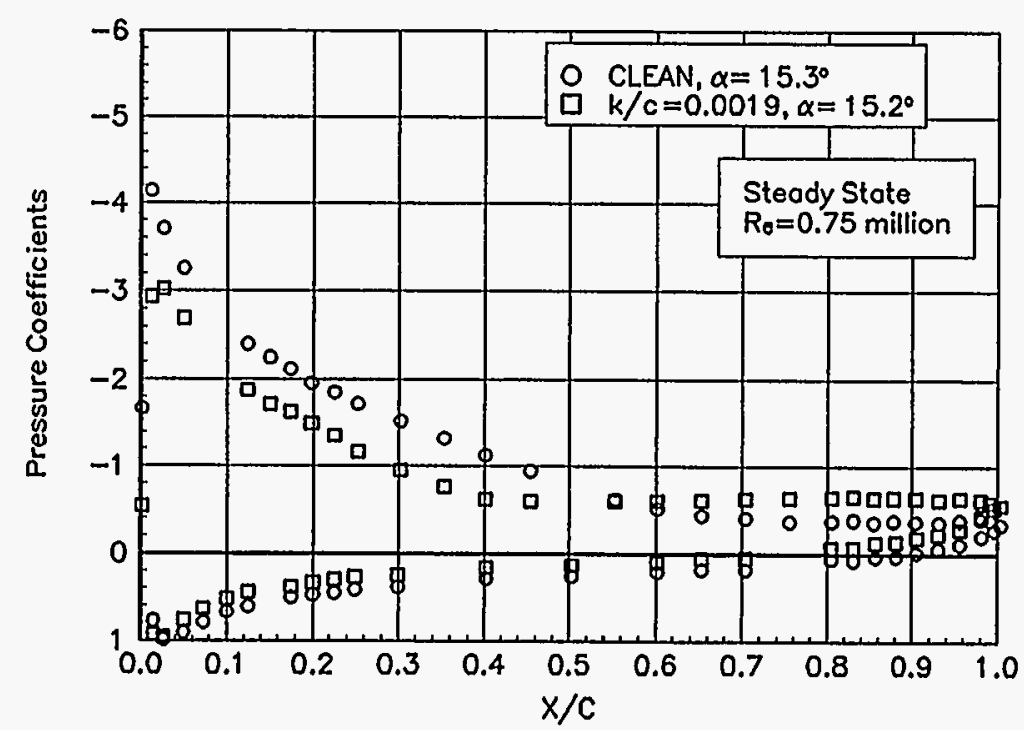

Figure B16. $a=15.3^{\circ}$ 


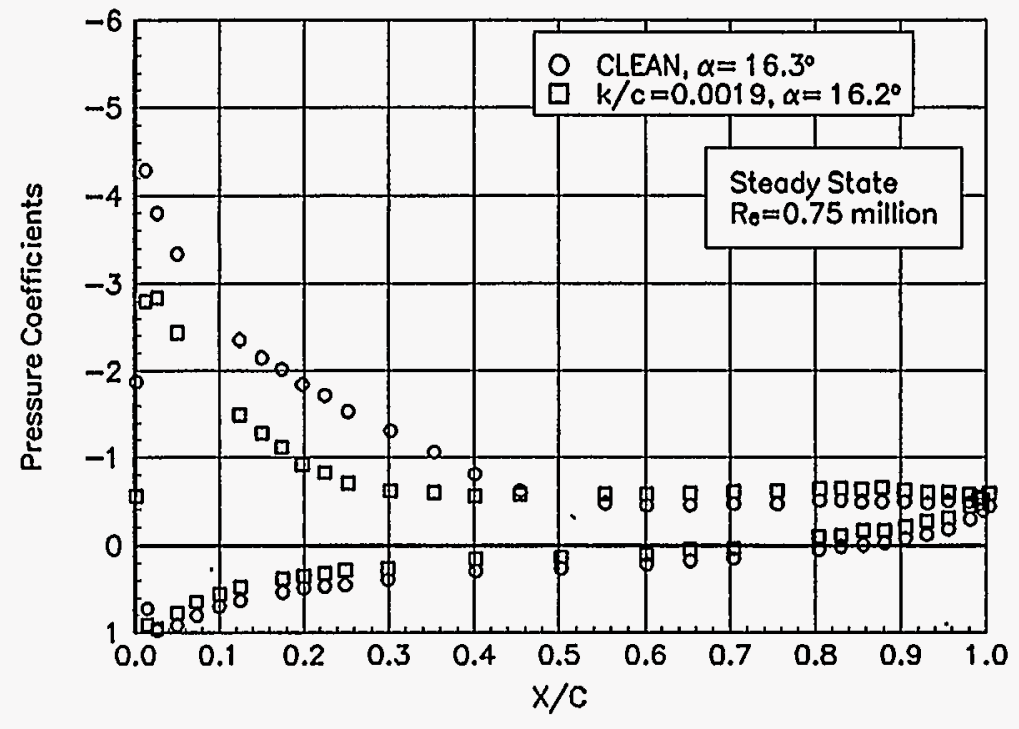

Figure B17. $a=16.3^{\circ}$

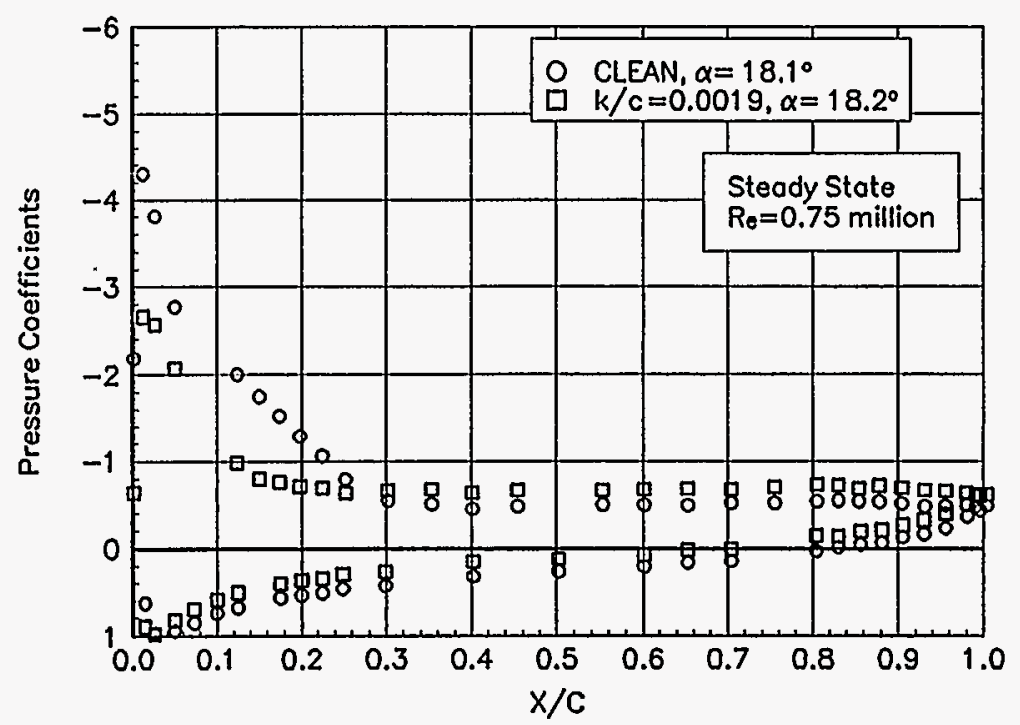

Figure B19. $a=18.1^{\circ}$

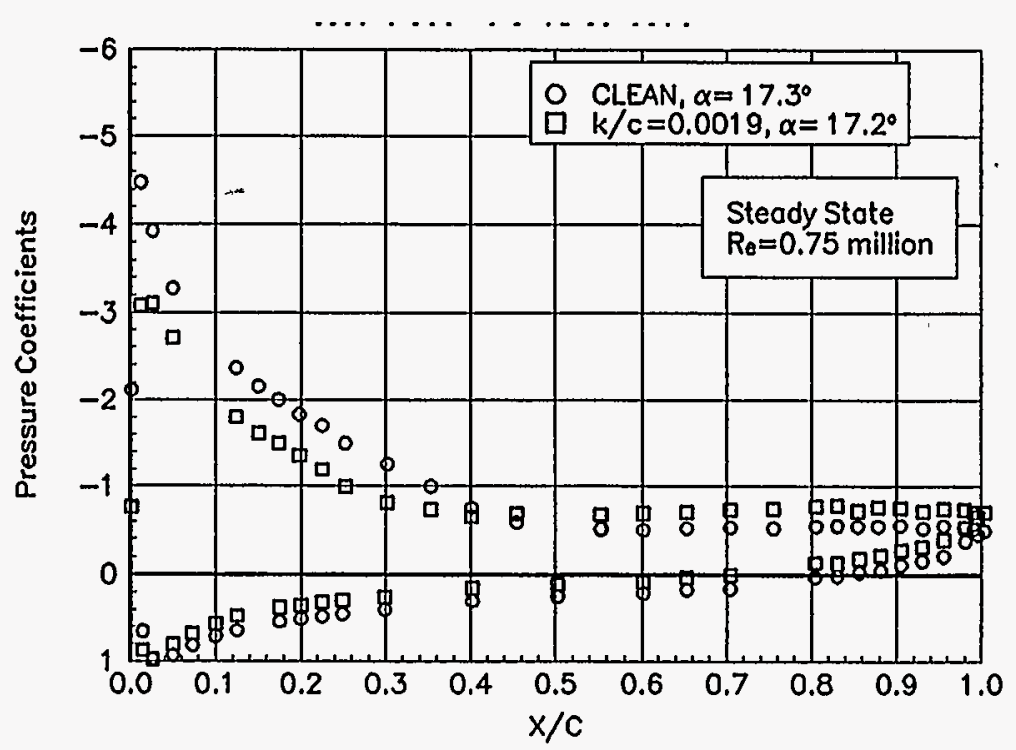

Figure B18. $a=17.3^{\circ}$

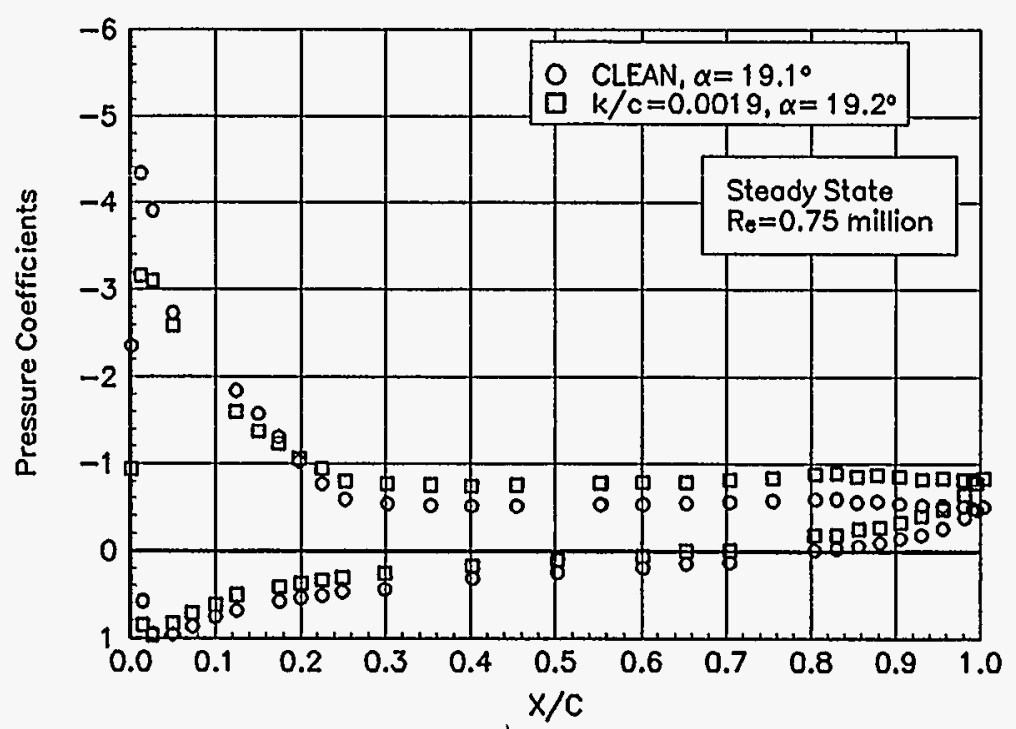

Figure B20. $a=19.1^{\circ}$ 


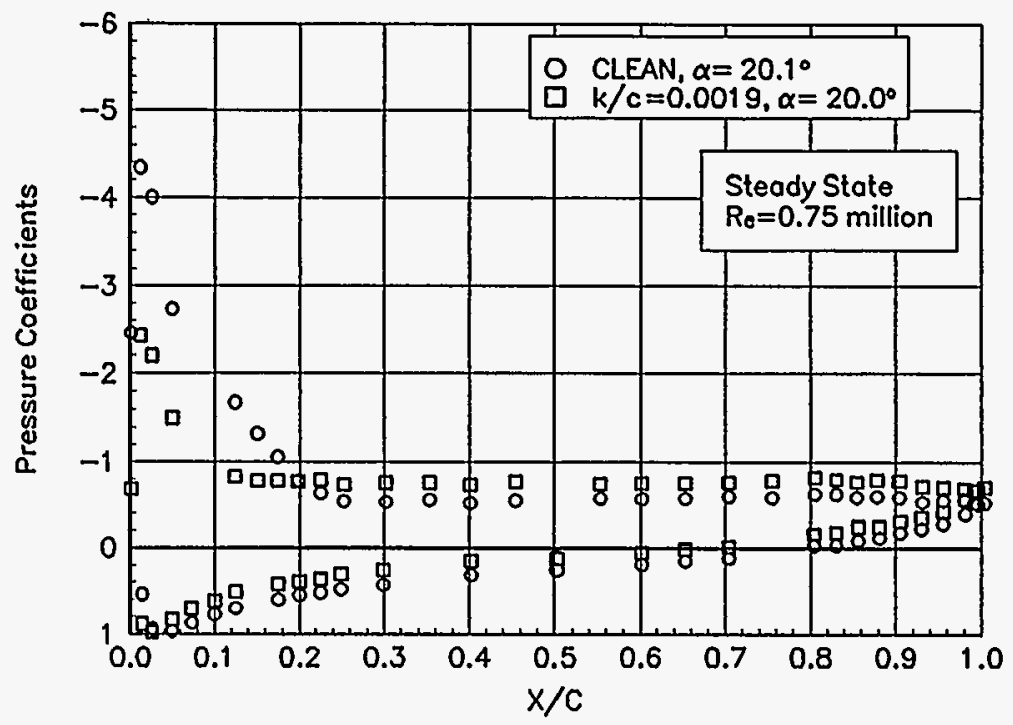

Figure B21. $a=20.1^{\circ}$

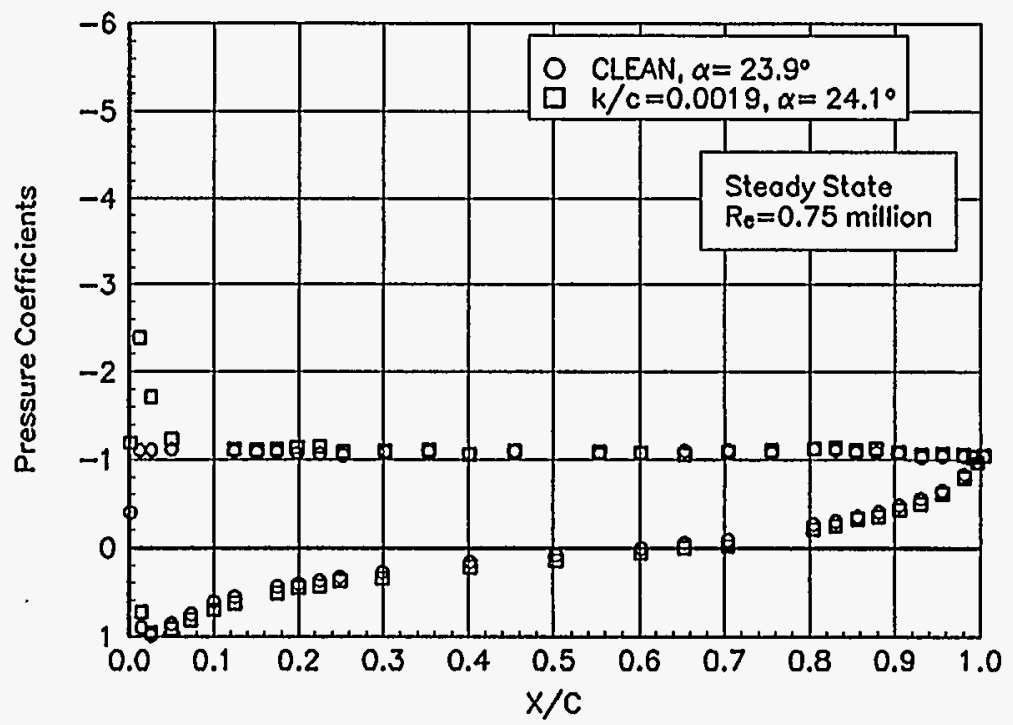

Figure B23. $a=23.9^{\circ}$

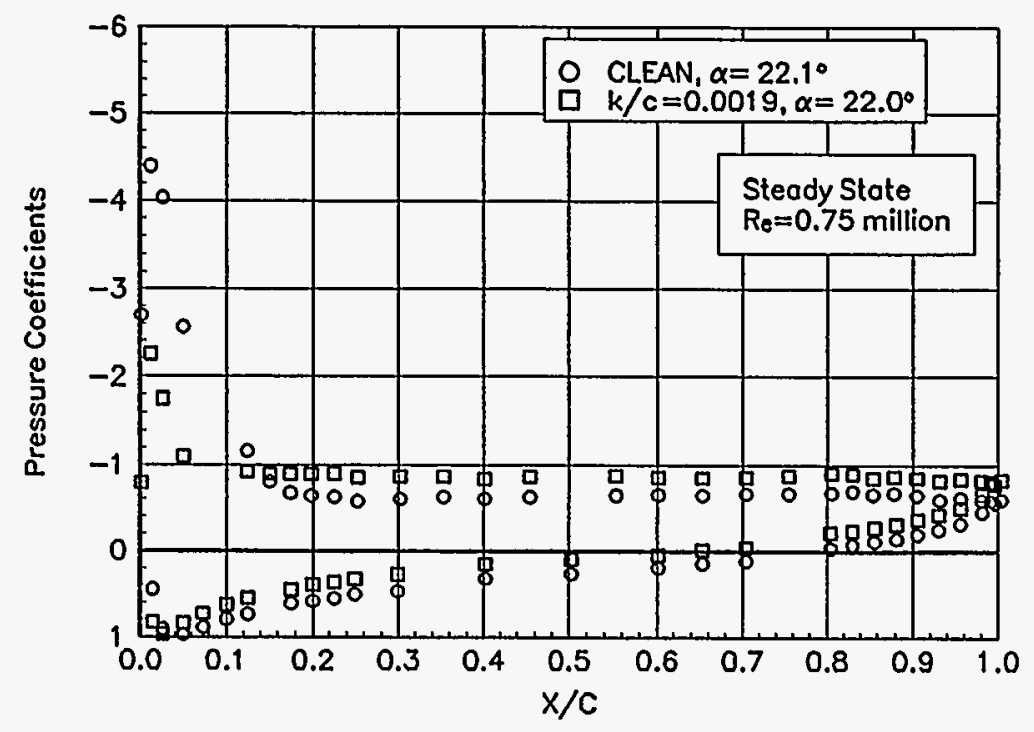

Figure B22. $a=22.1^{\circ}$

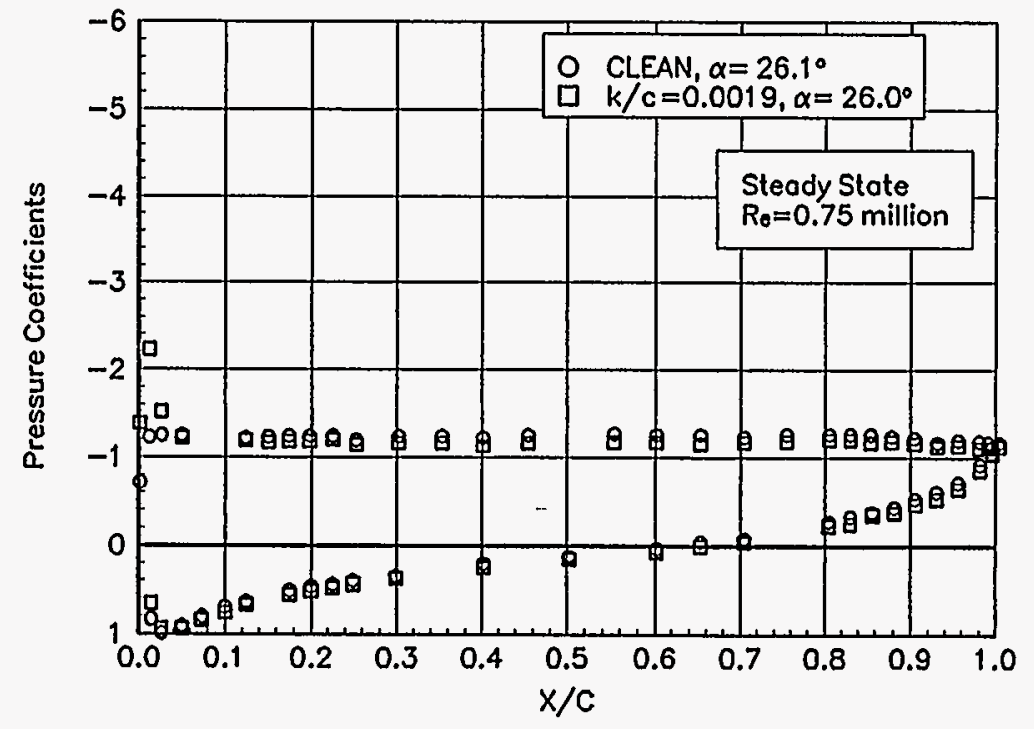

Figure B24. $a=26.1^{\circ}$ 


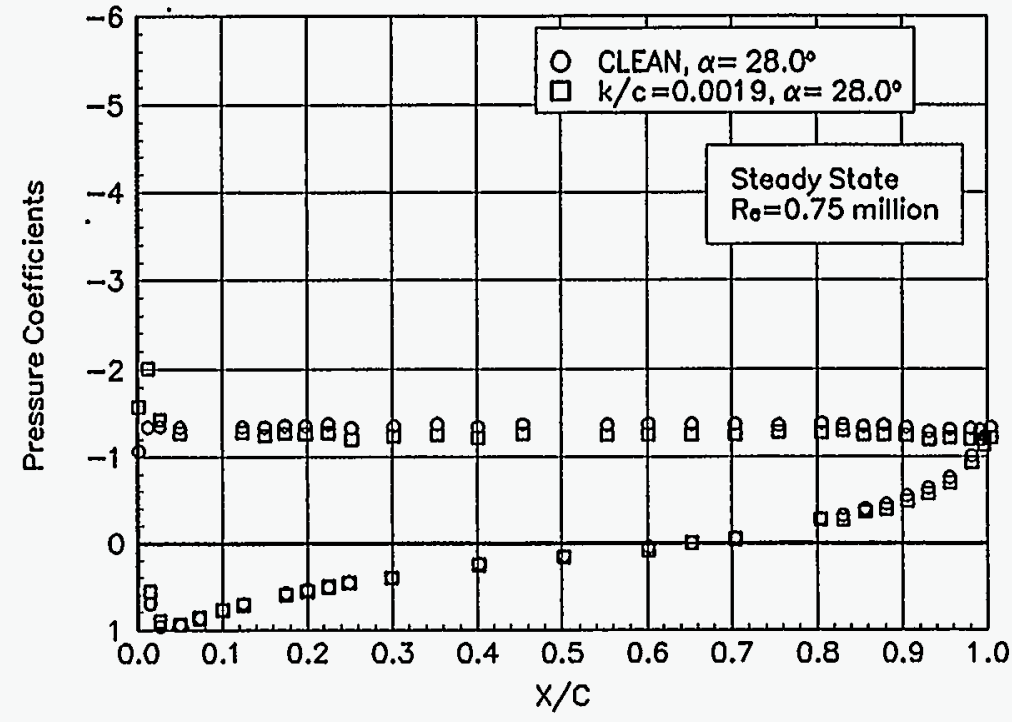

Figure B25. $a=28.0^{\circ}$

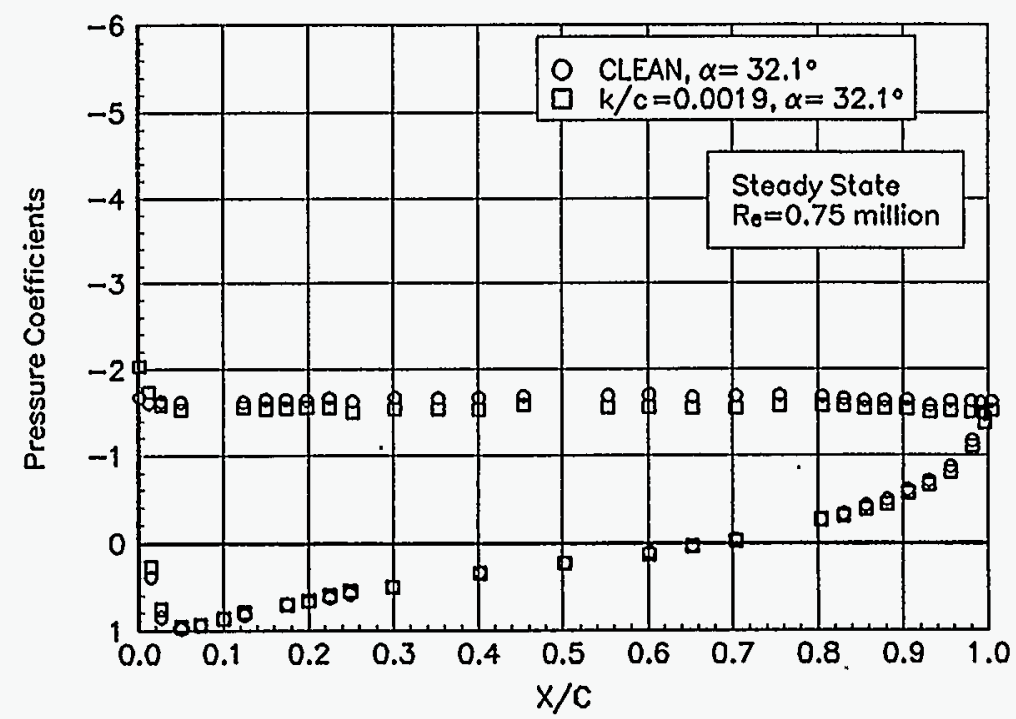

Figure B27. $a=32.1^{\circ}$

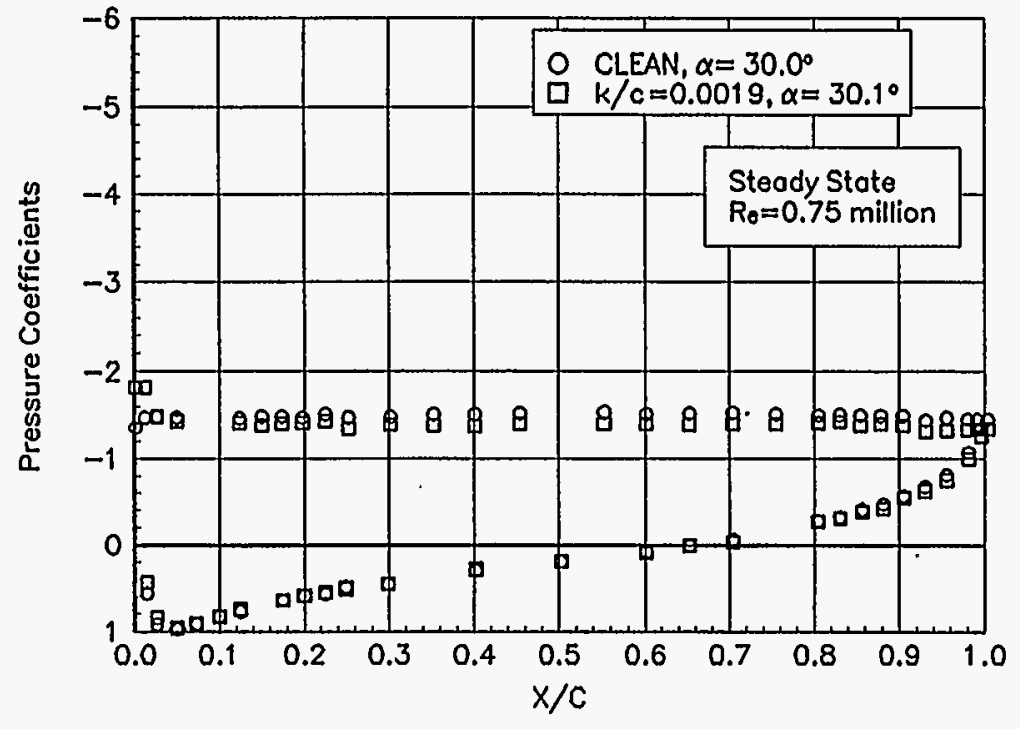

Figure B26. $a=30.0^{\circ}$

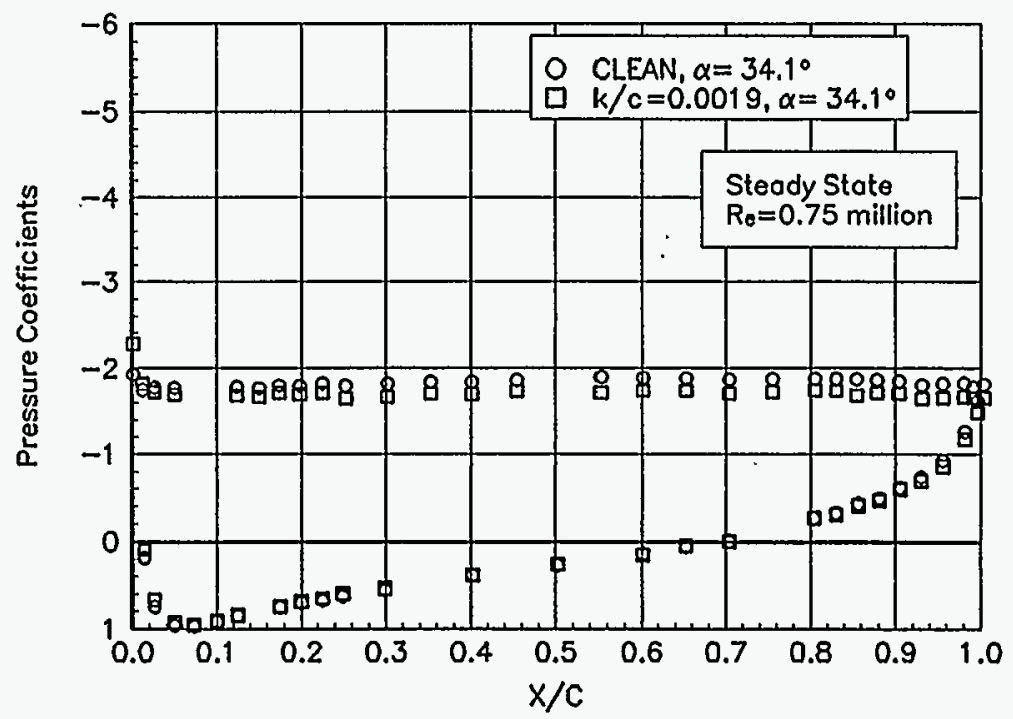

Figure B28, $a=34.1^{\circ}$ 


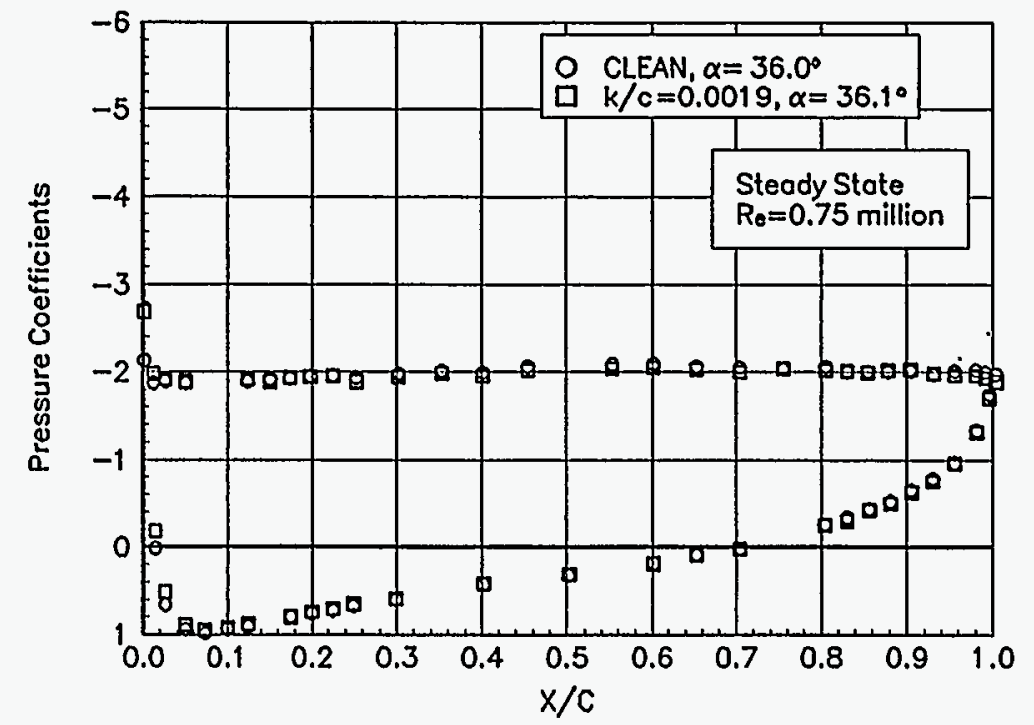

Figure B29. $a=36.0^{\circ}$

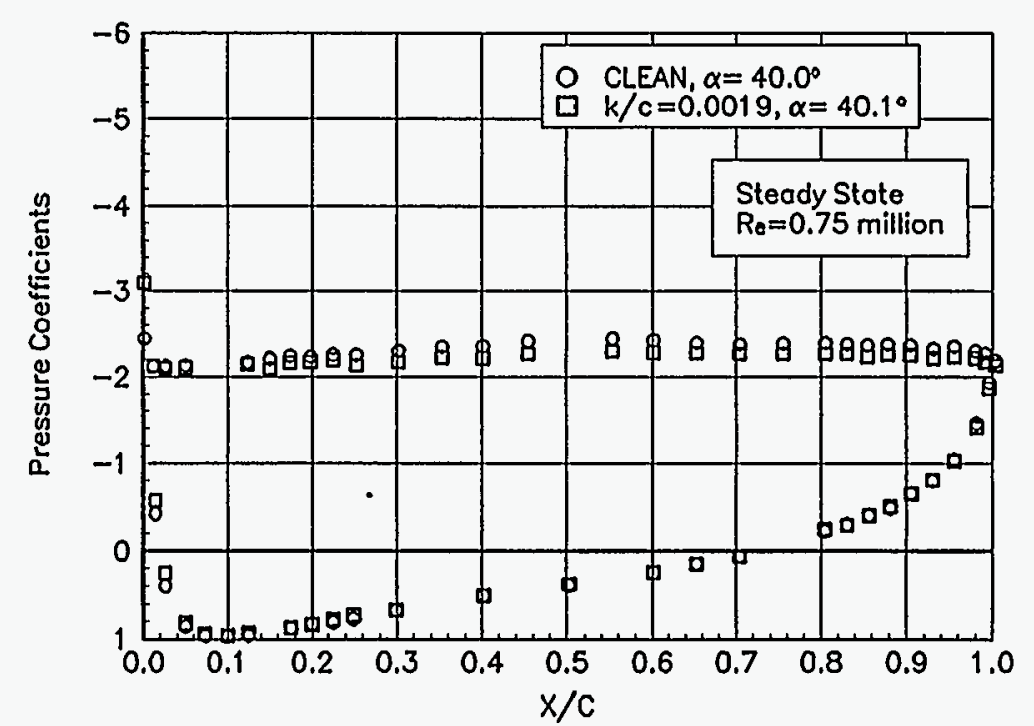

Figure B31. $\alpha=40.0^{\circ}$

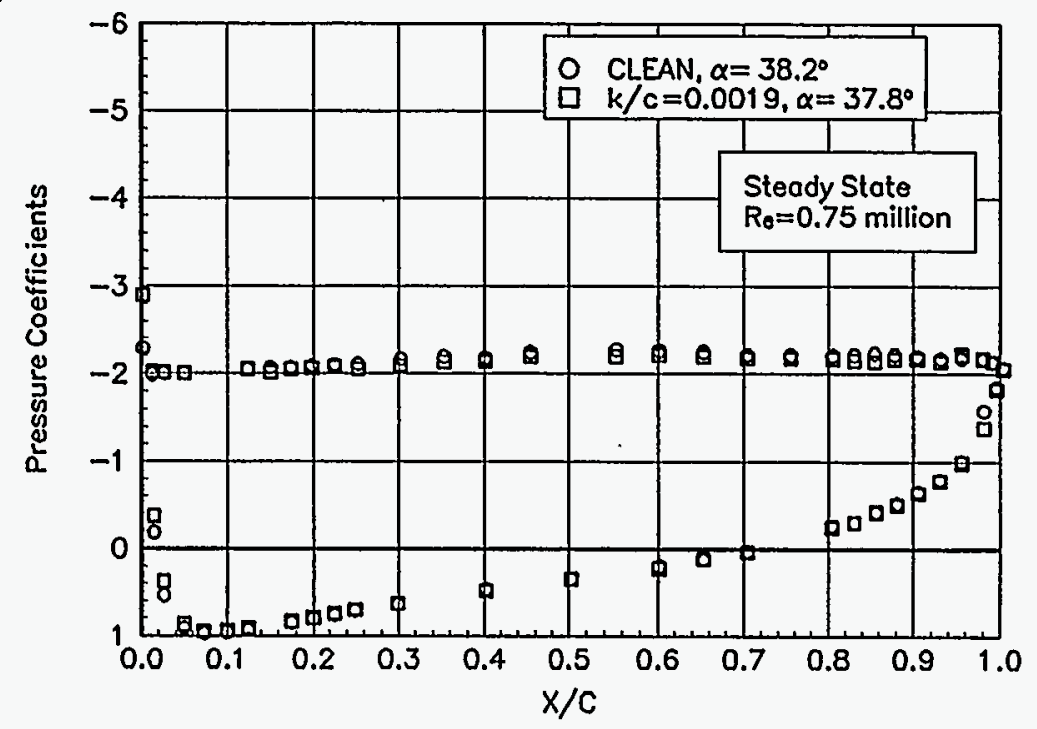

Figure B30: $a=38.2^{\circ}$ 
NACA 4415

Pressure Distributions, Steady State, $R e=1$ million 


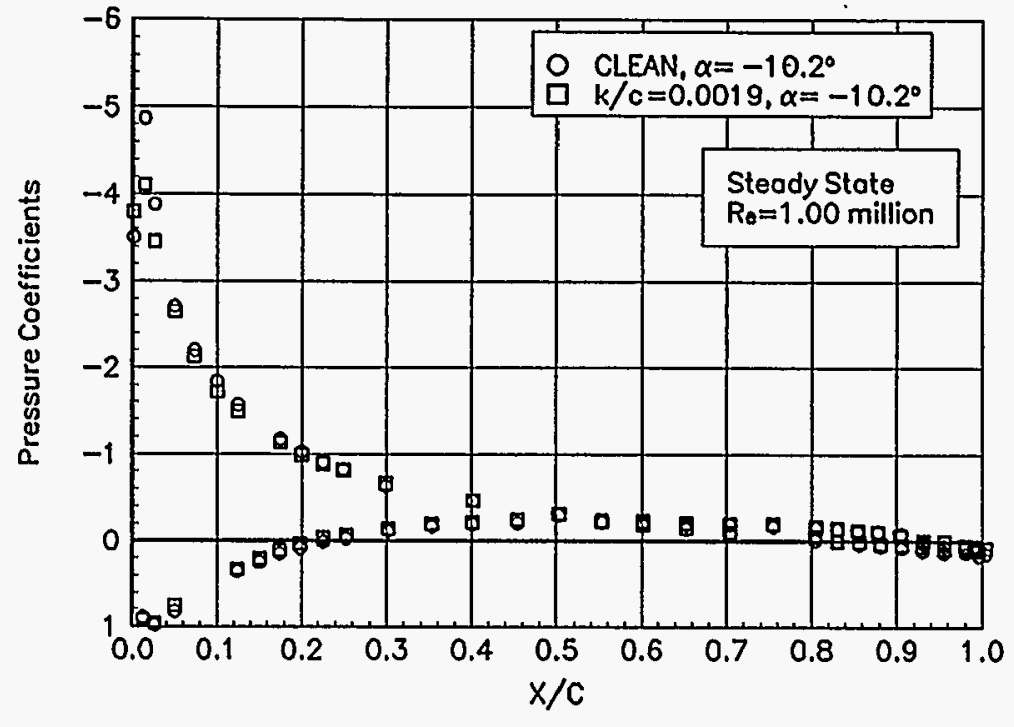

Figure B32. $a=-10.2^{\circ}$

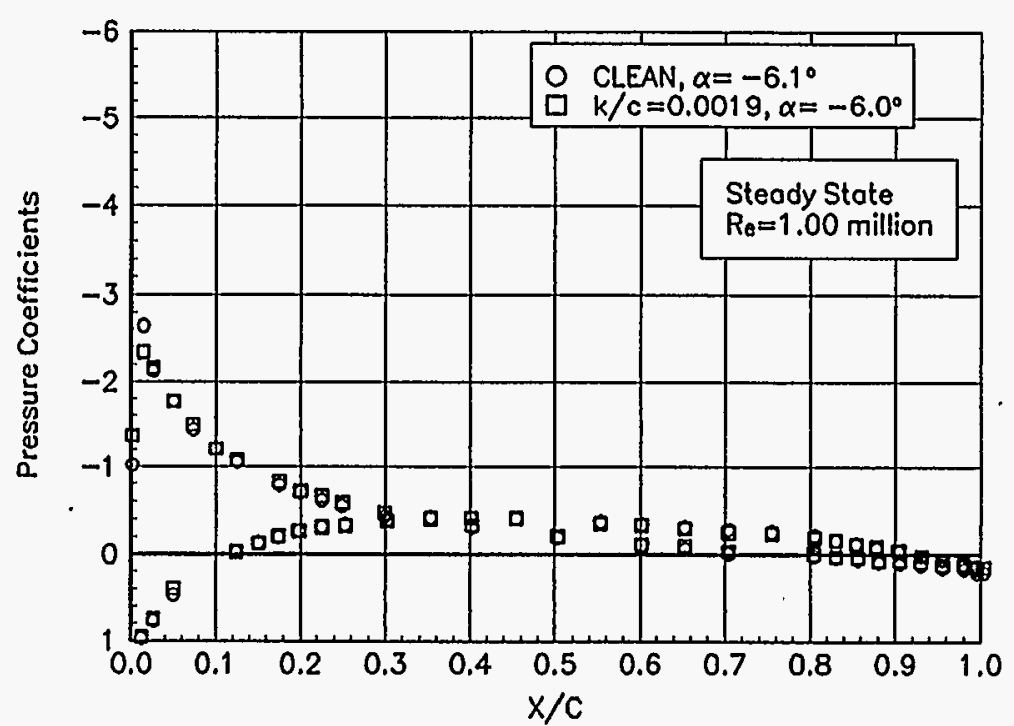

Figure B34. $\alpha=-6.1^{\circ}$

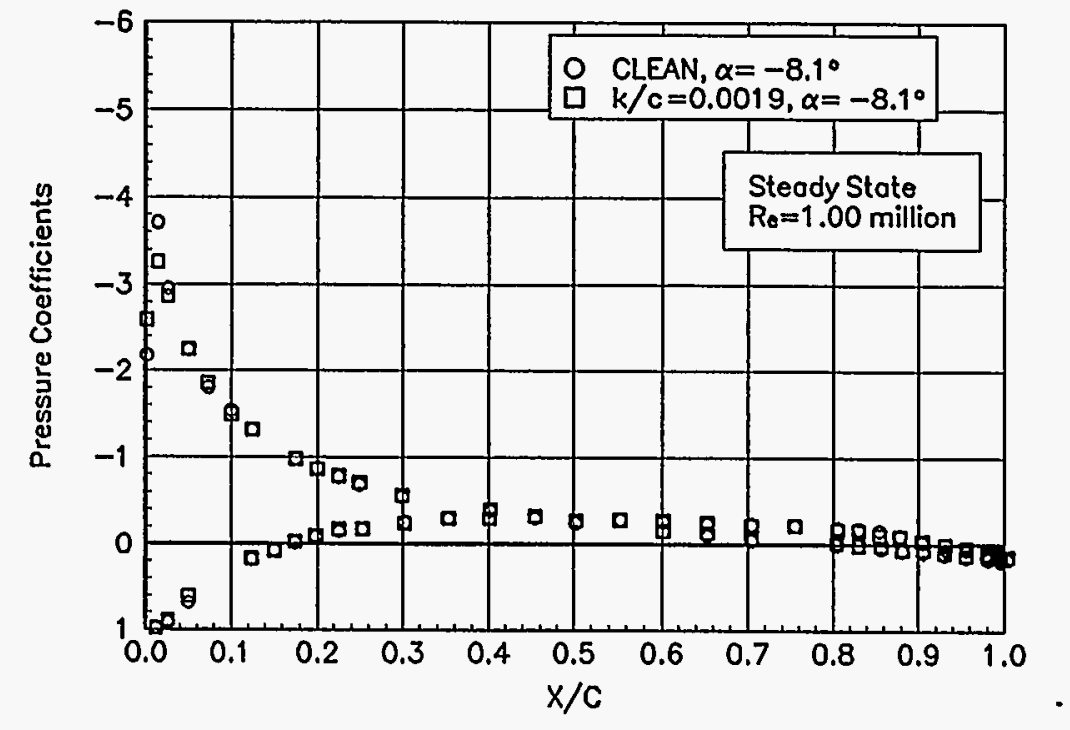

Figure B33. $\alpha=-8.1^{\circ}$

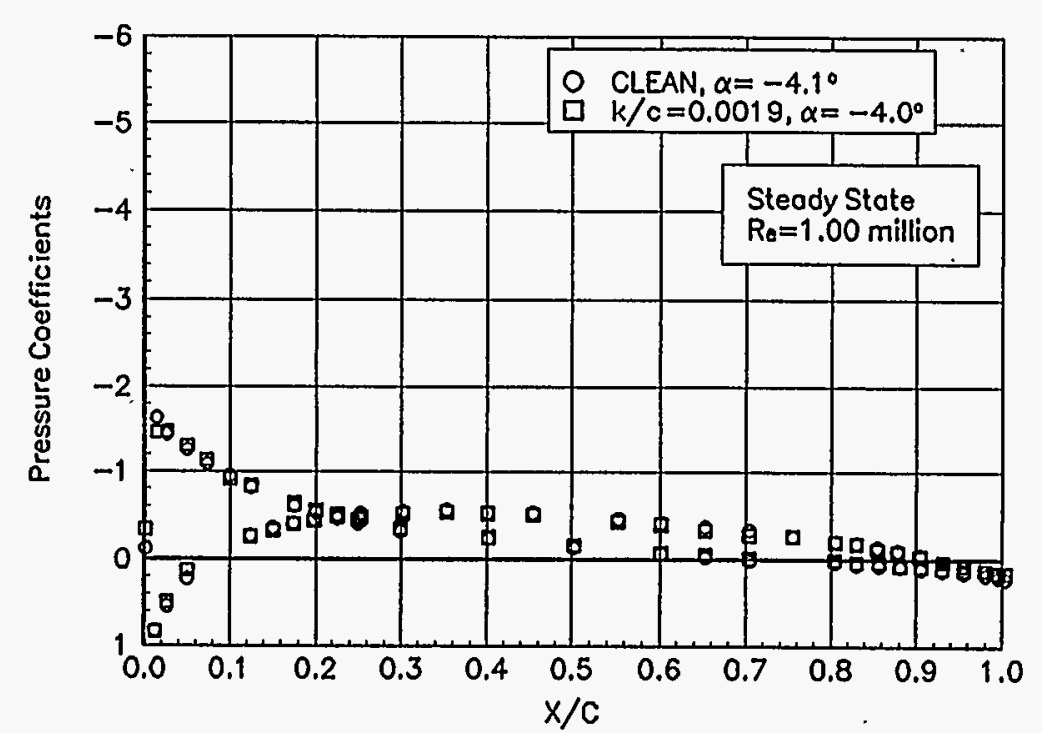

Figure B35. $a=-4.1^{\circ}$ 

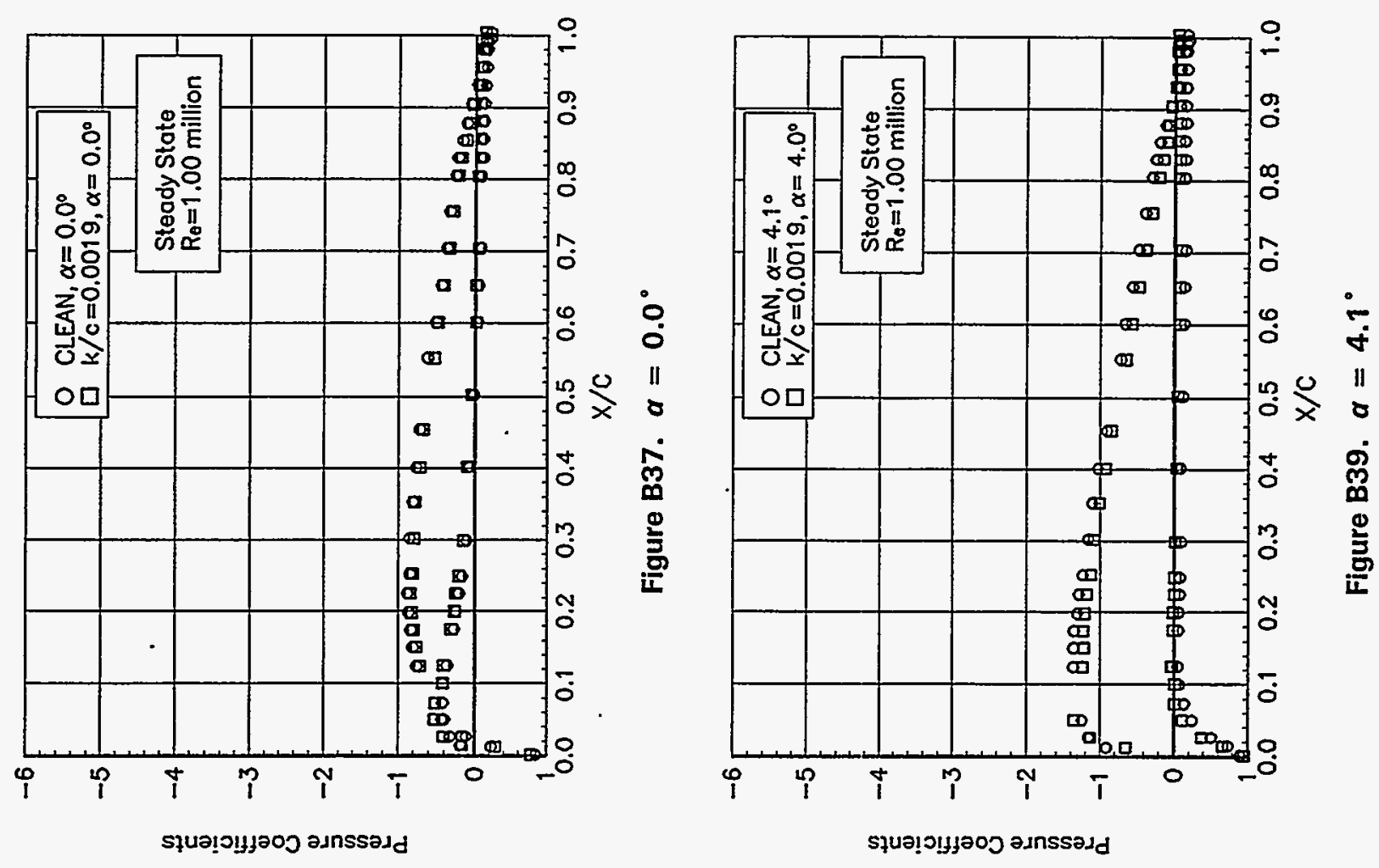

ตै
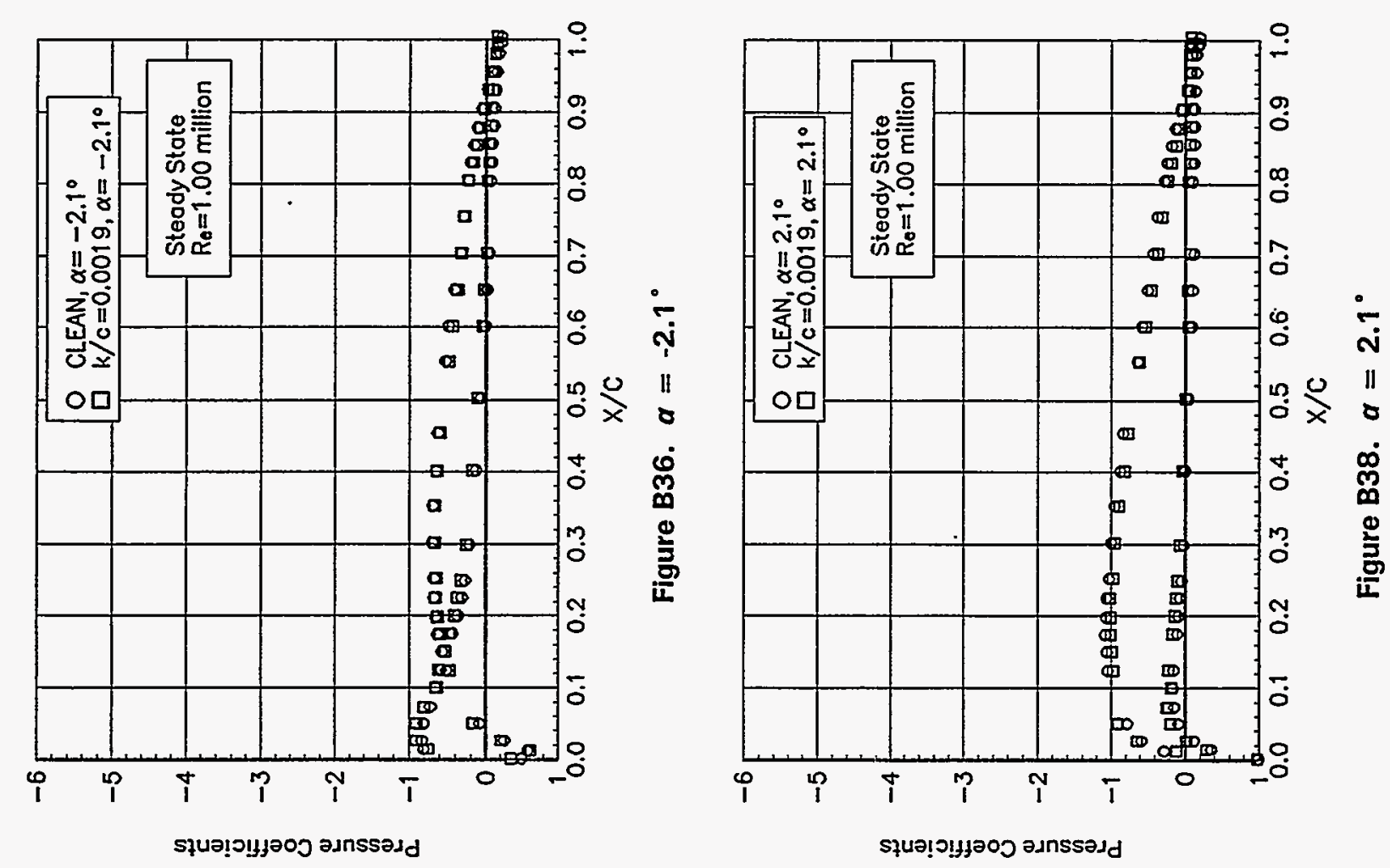


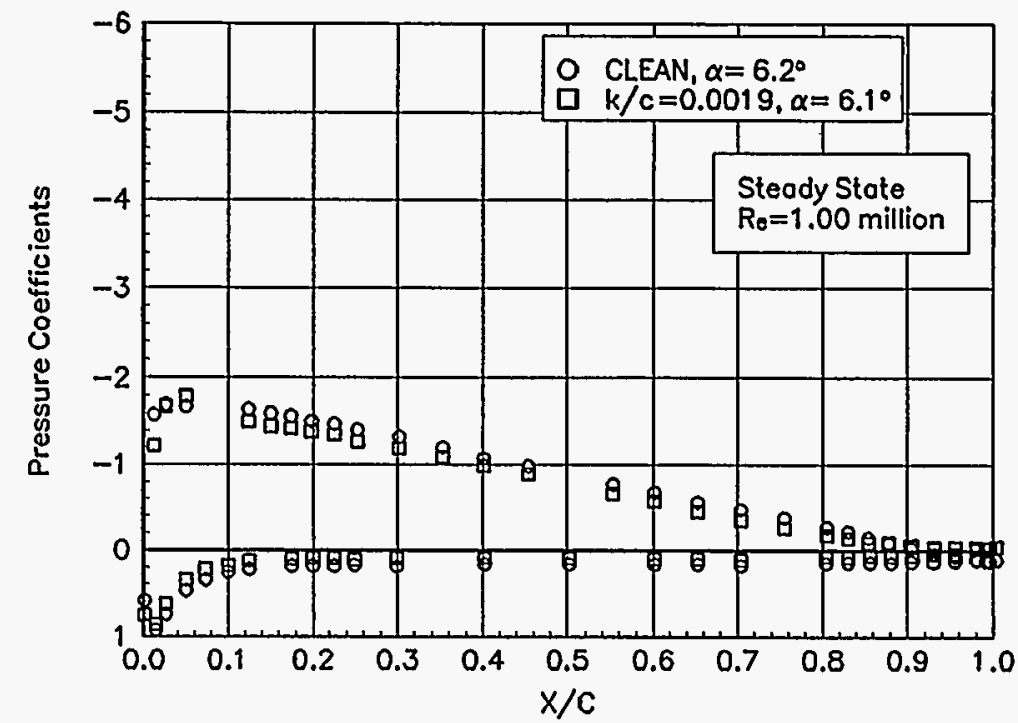

Figure B40. $a=6.2^{\circ}$

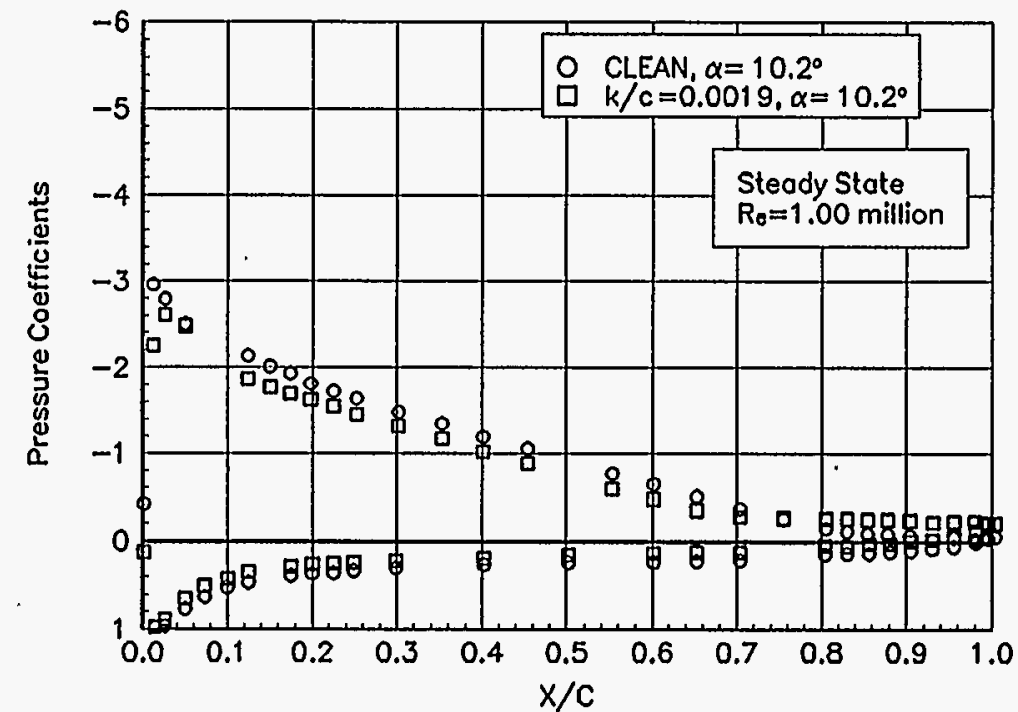

Figure B42. $a=10.2^{\circ}$

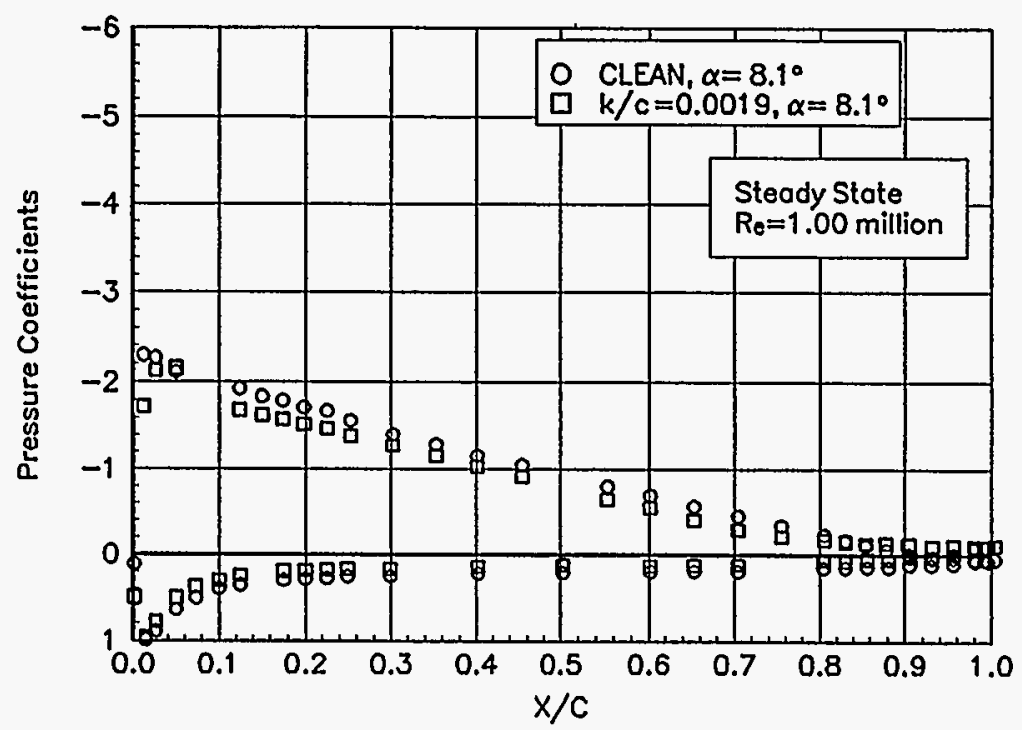

Figure B41. $a=8.1^{\circ}$

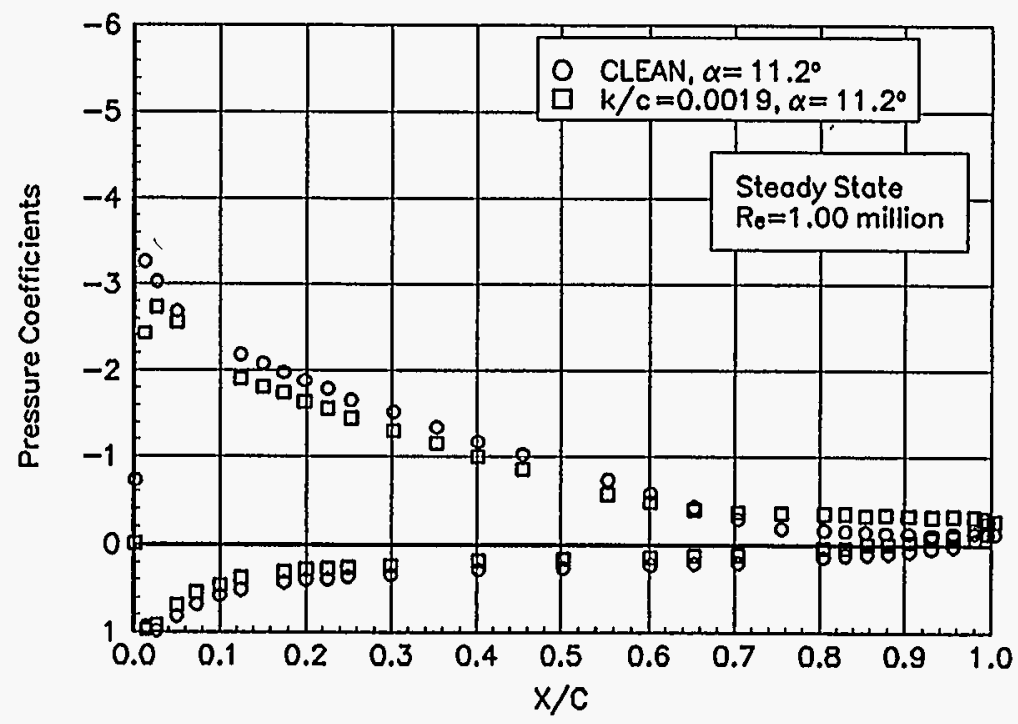

Figure B43. $a=11.2^{\circ}$ 


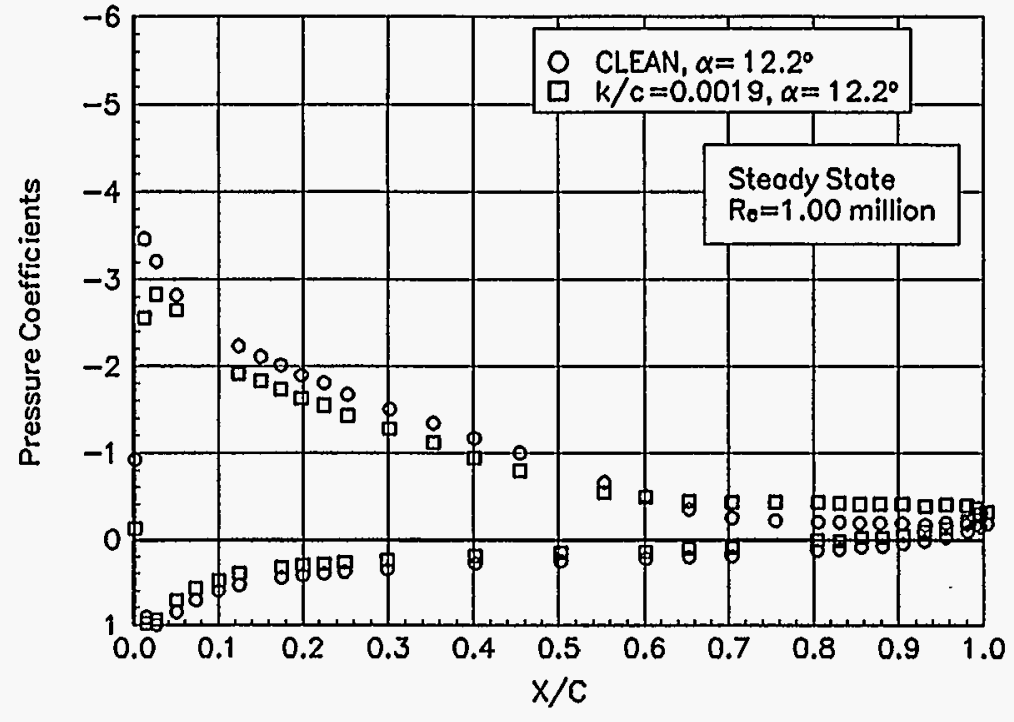

Figure B44. $a=12.2^{\circ}$

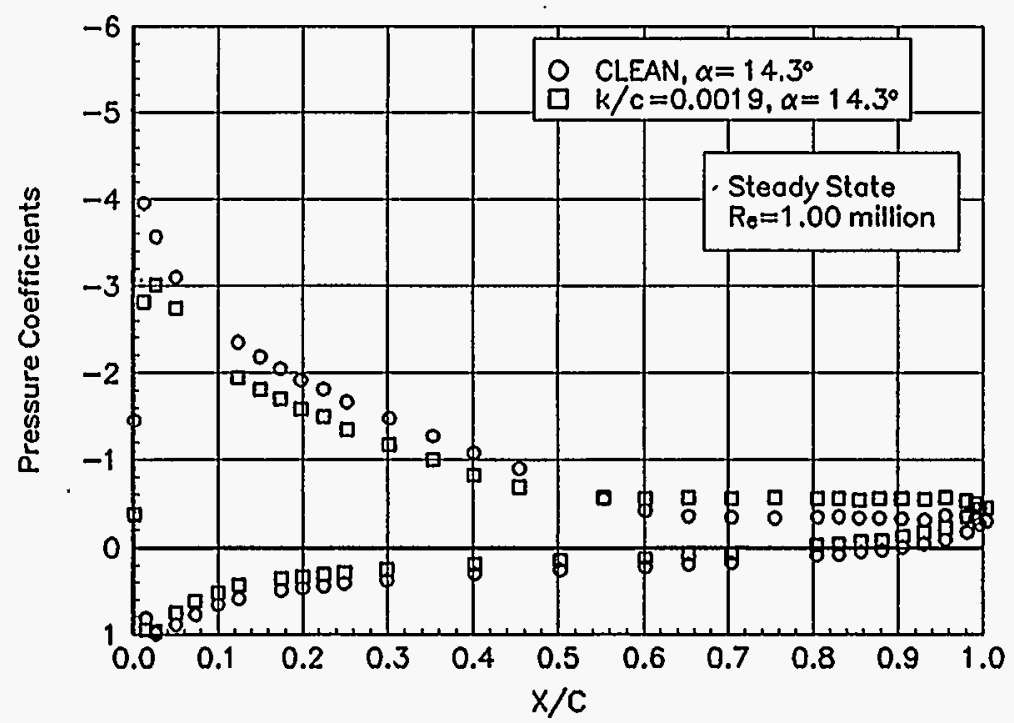

Figure B46. $a=14.3^{\circ}$

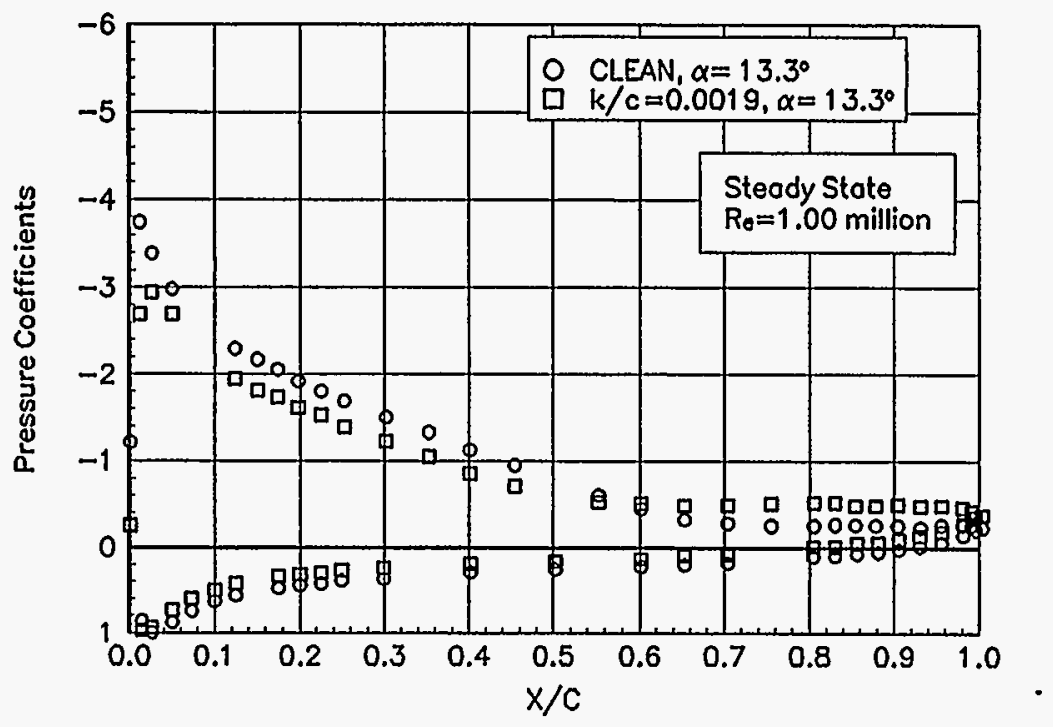

Figure B45. $a=13.3^{\circ}$

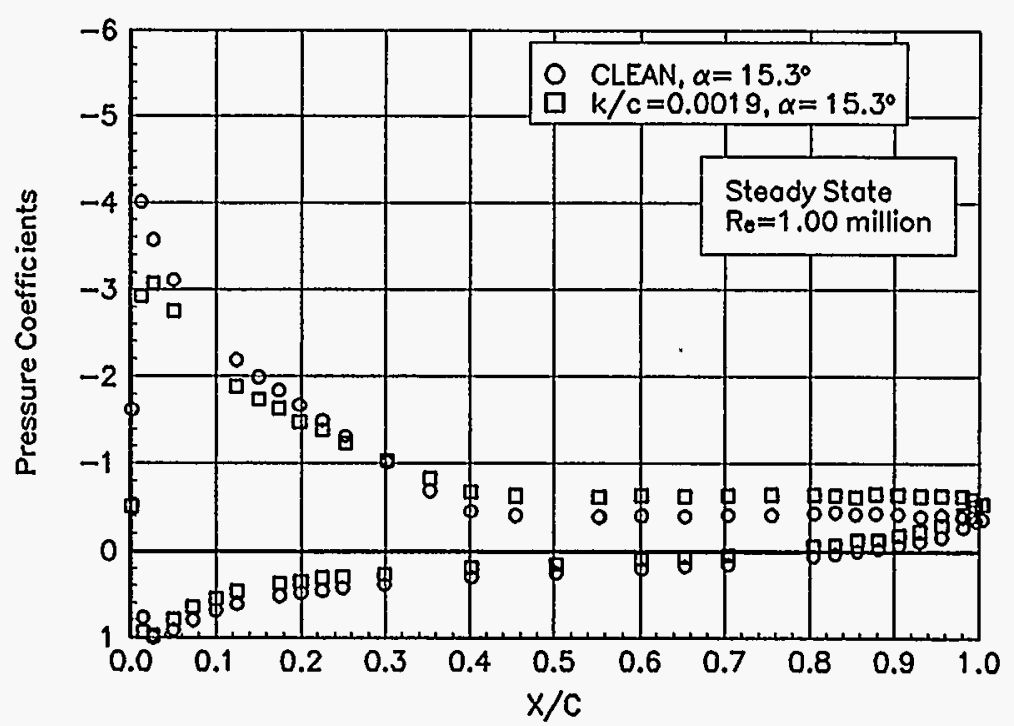

Figure B47. $a=15.3^{\circ}$ 


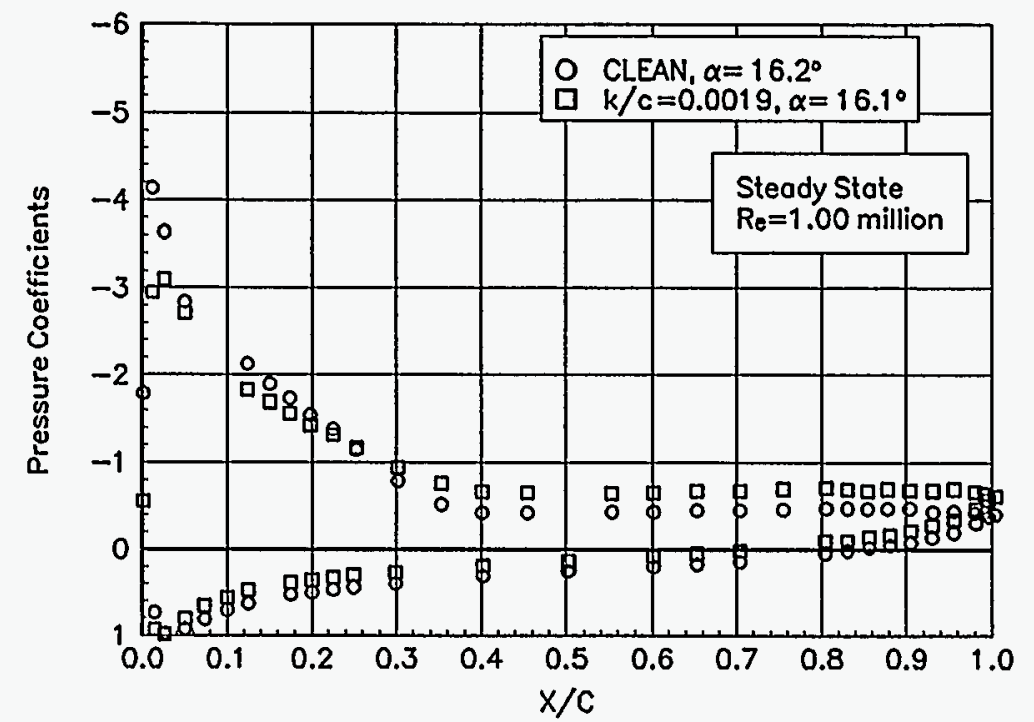

Figure B48. $a=16.2^{\circ}$

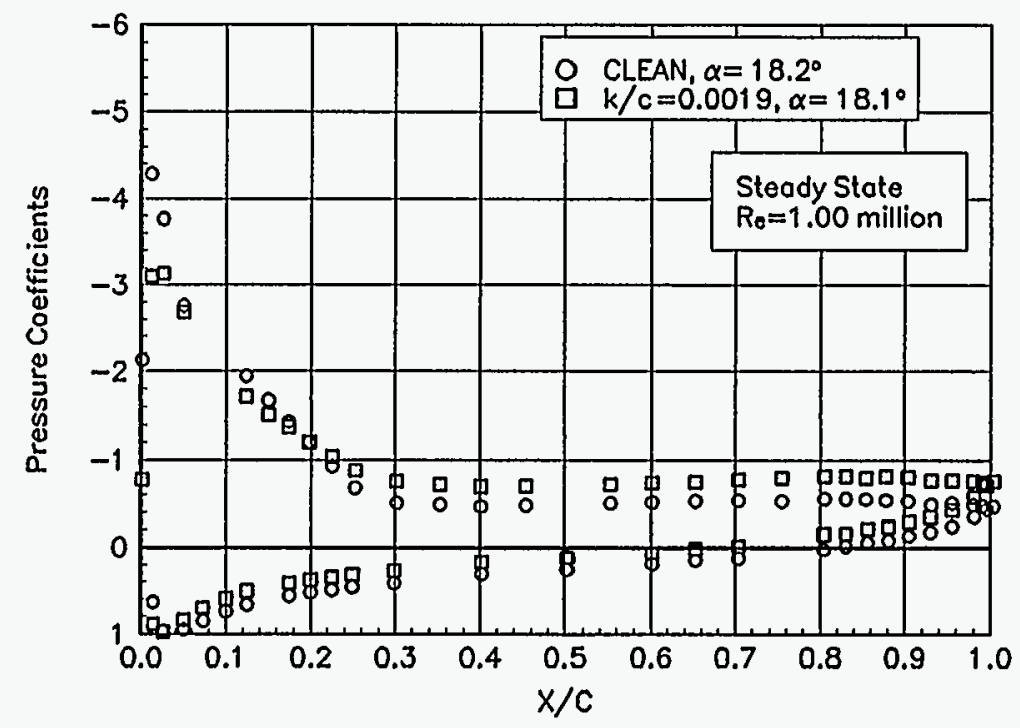

Figure B50. $a=18.2^{\circ}$

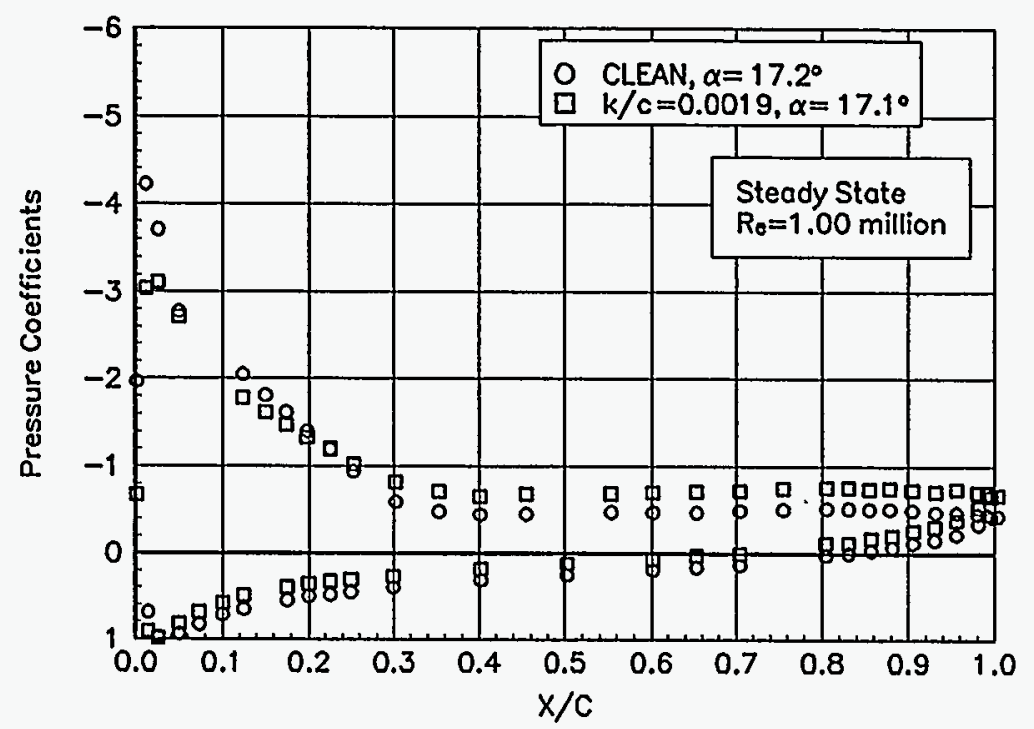

Figure B49. $a=17.2^{\circ}$

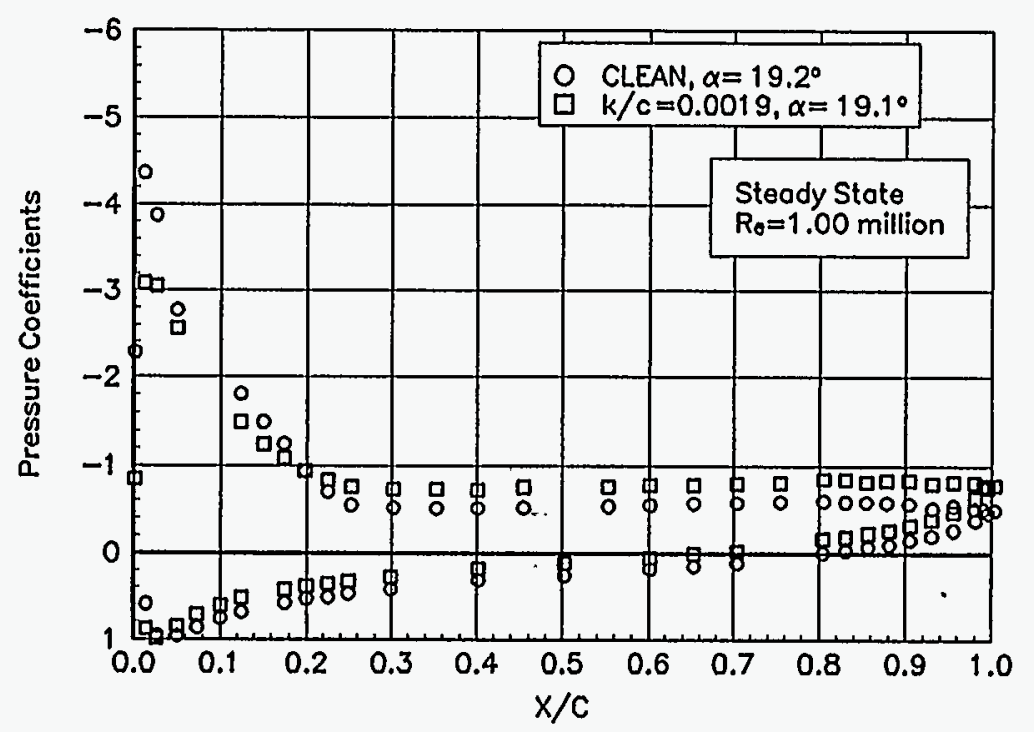

Figure B51. $a=19.2^{\circ}$ 


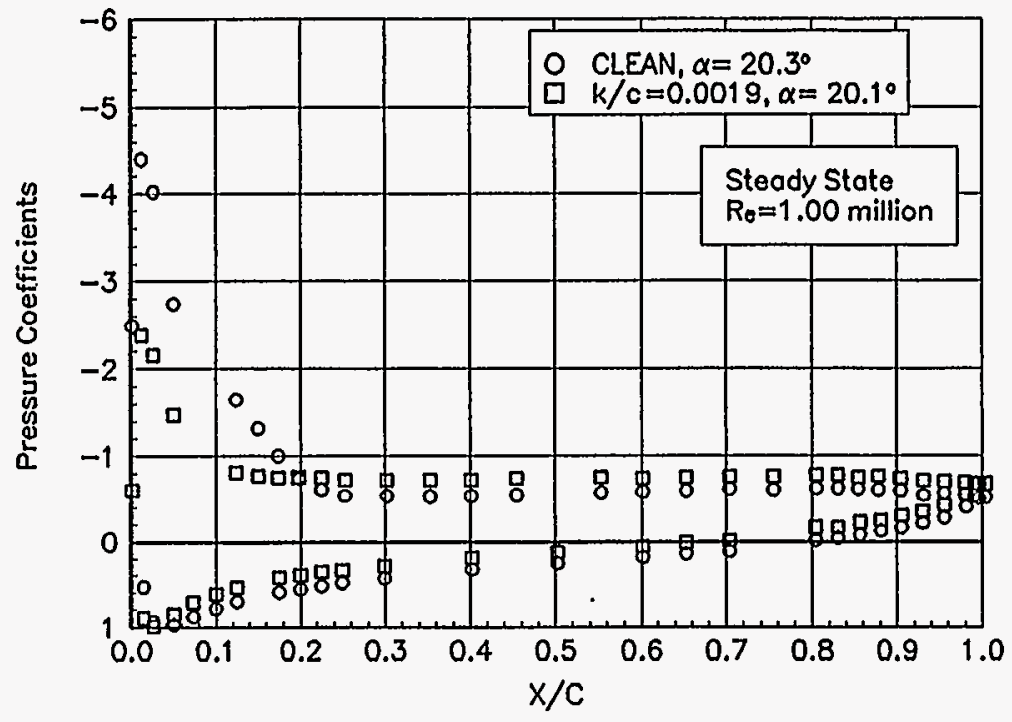

Figure B52. $a=20.3^{\circ}$

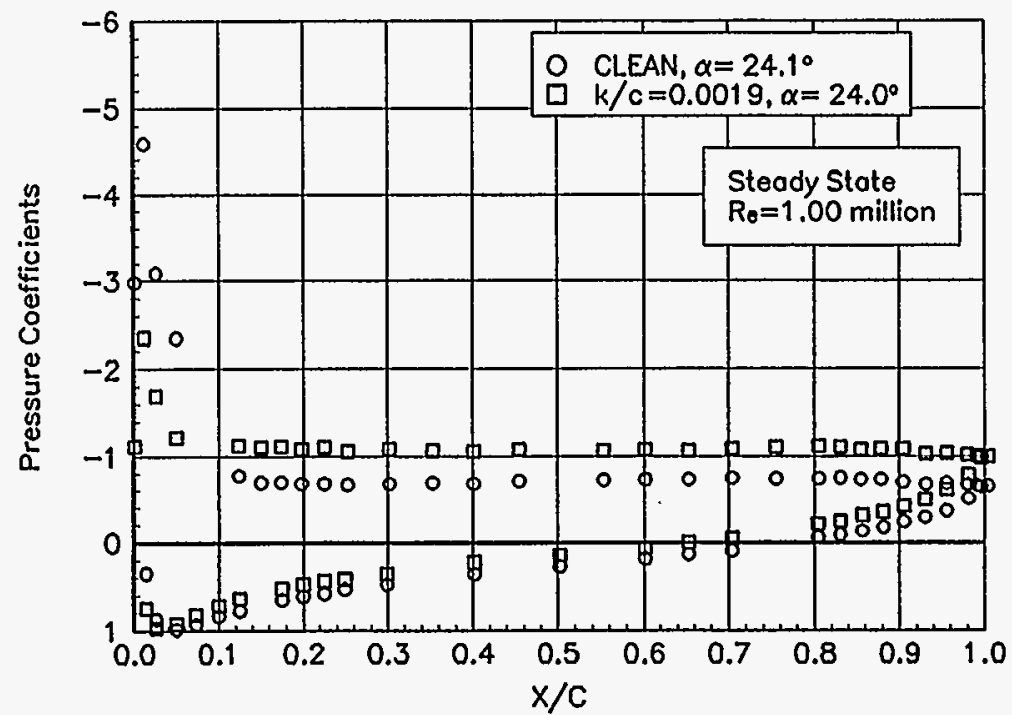

Figure B54. $a=24.1^{\circ}$

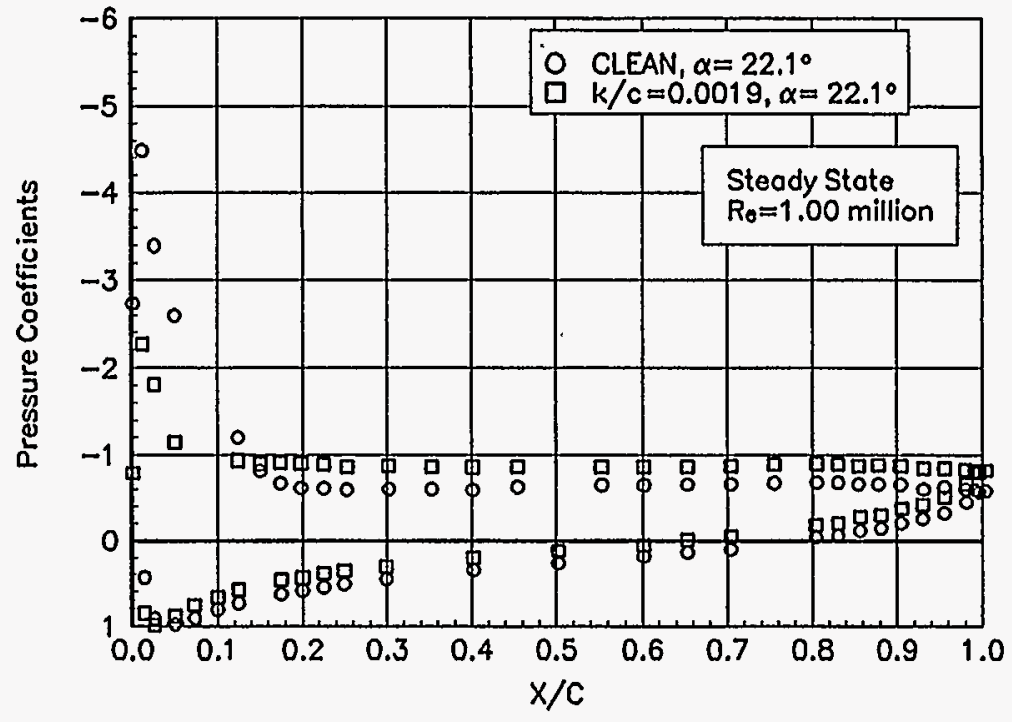

Figure B53, $a=22.1^{\circ}$

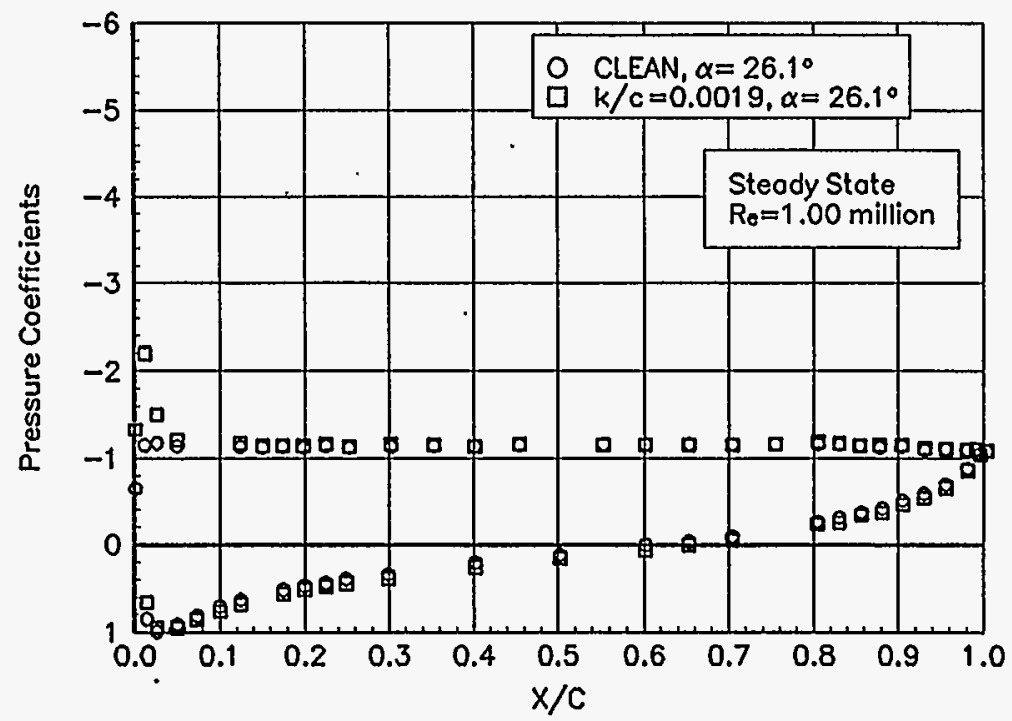

Figure B55. $a=26.1^{\circ}$ 


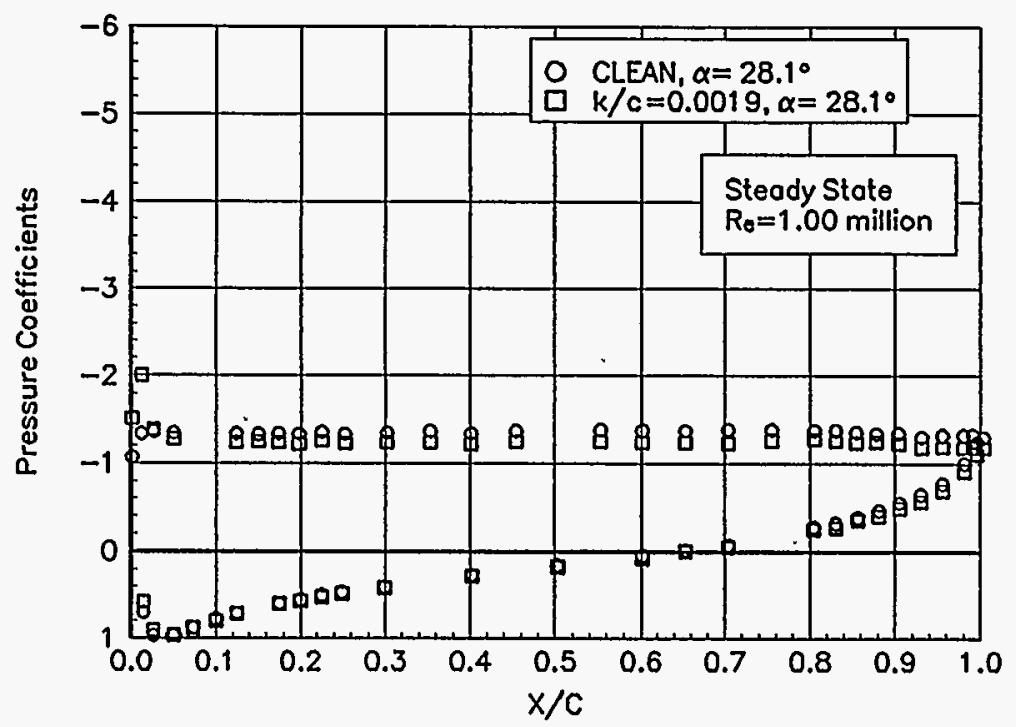

Figure B56. $a=28.1^{\circ}$

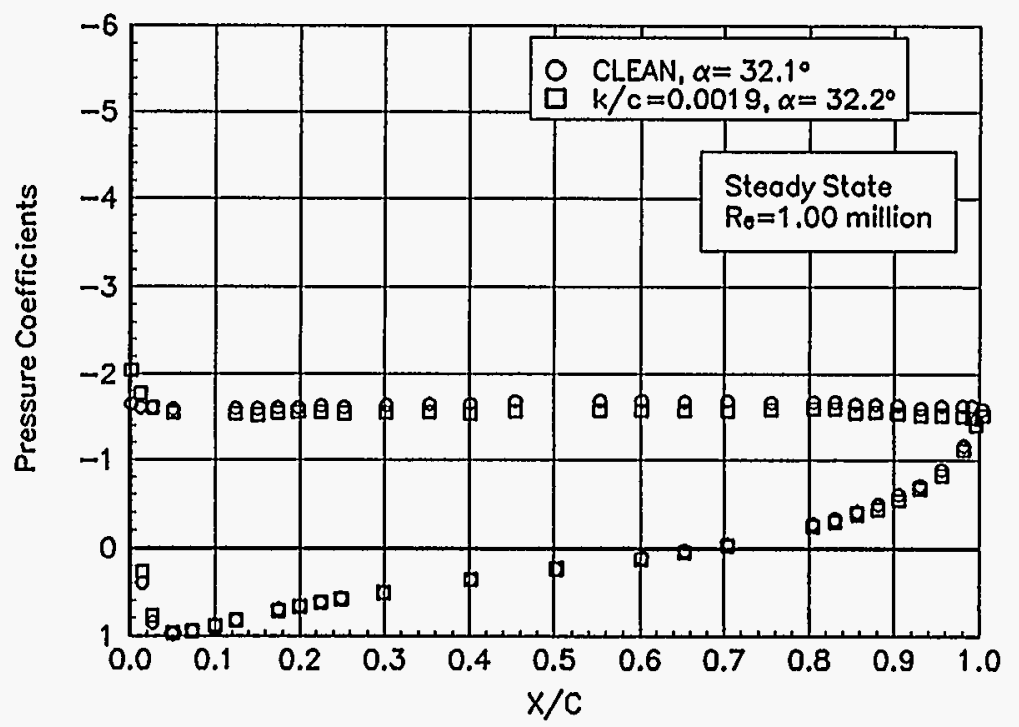

Figure B58. $a=32.1^{\circ}$

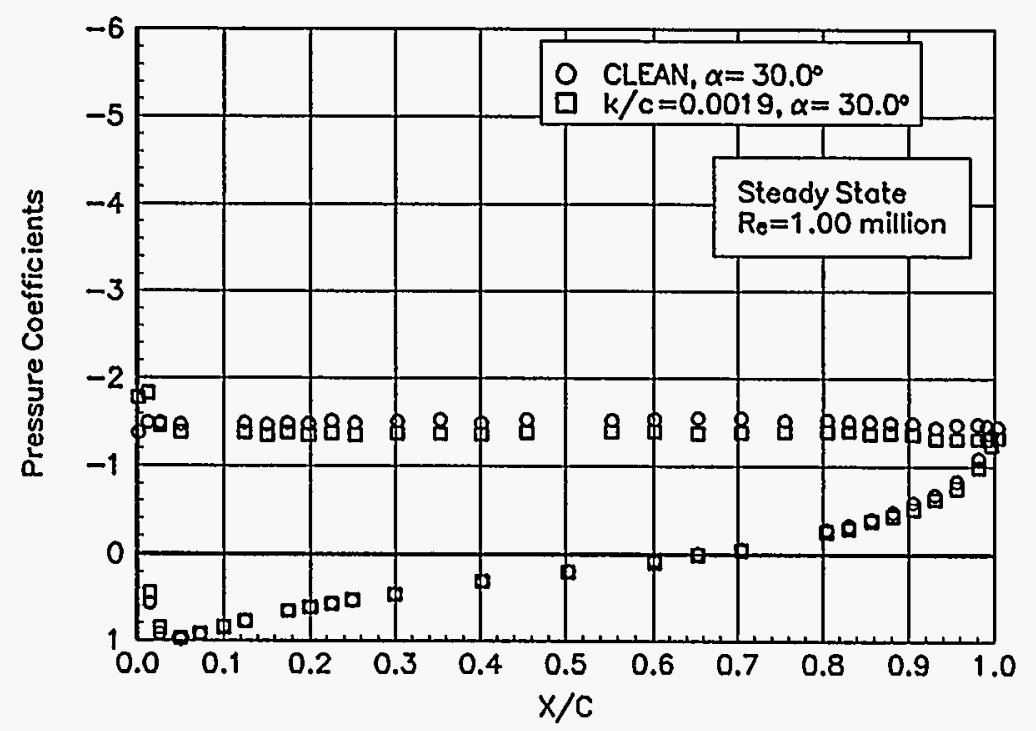

Figure B57. $a=30.0^{\circ}$

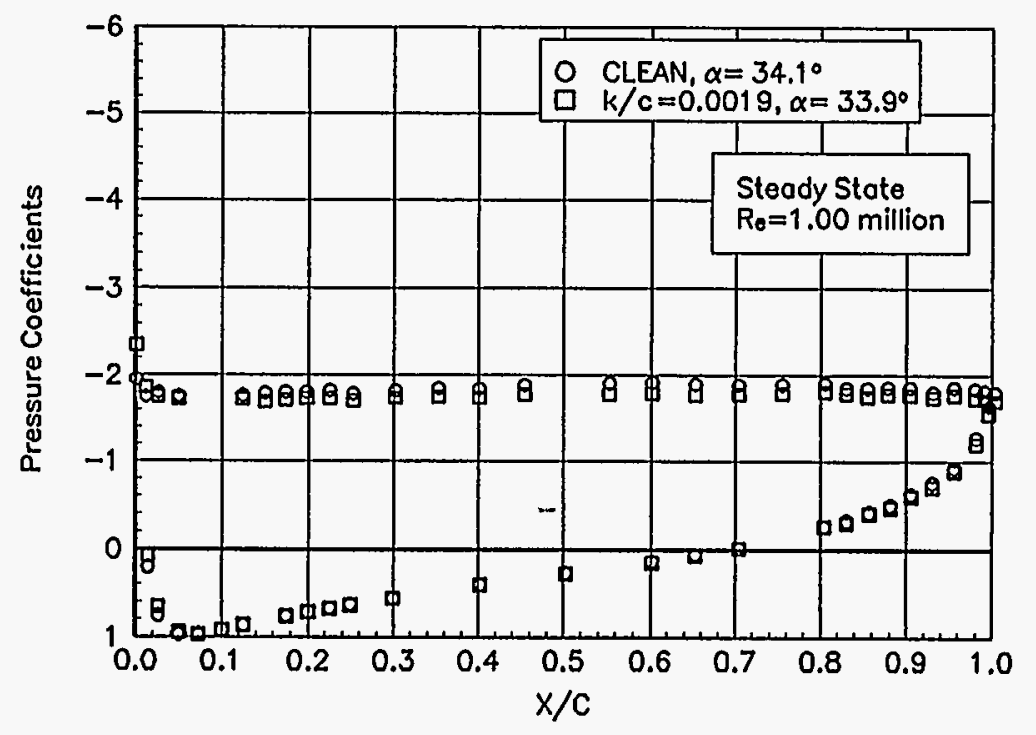

Figure B59. $a=34.1^{\circ}$ 


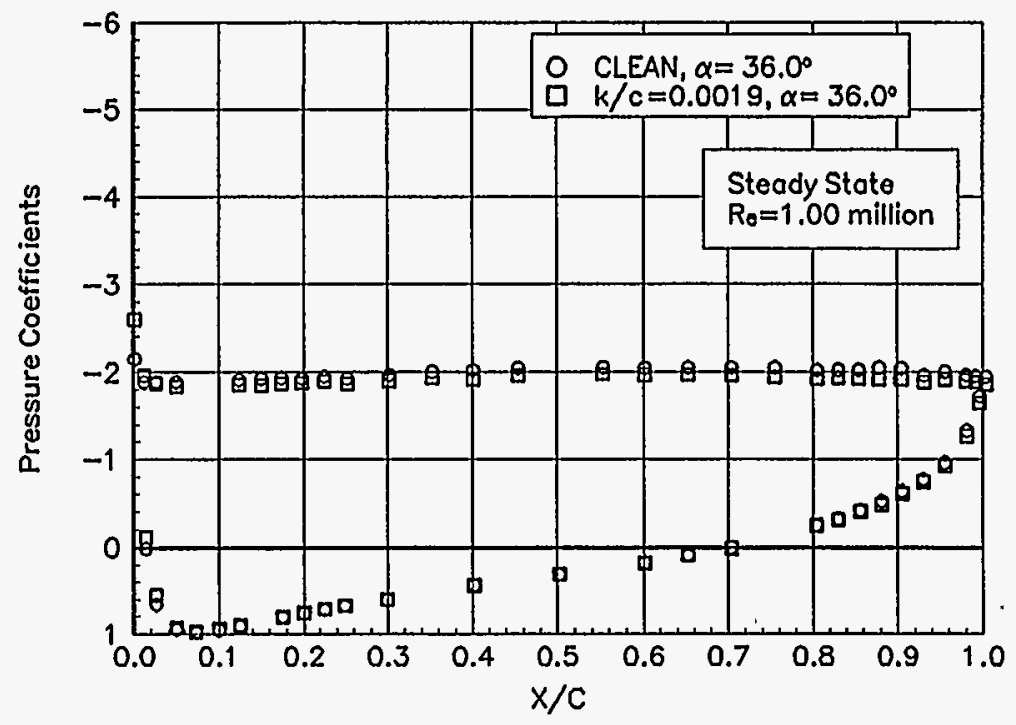

Figure B60. $a=36.0^{\circ}$

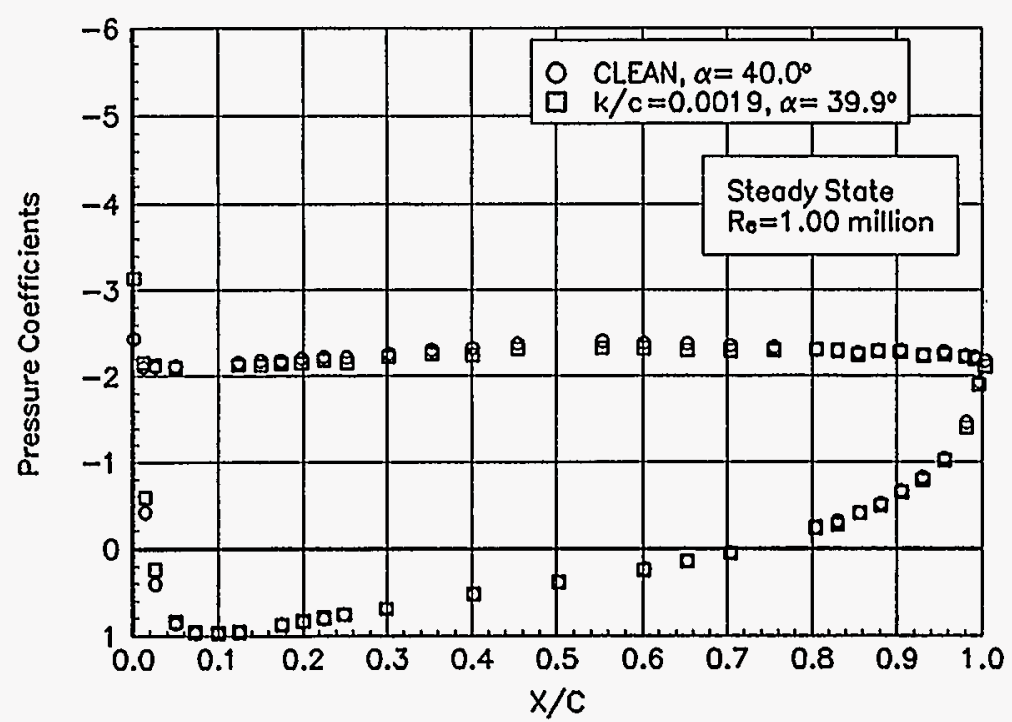

Figure B62. $a=40.0^{\circ}$

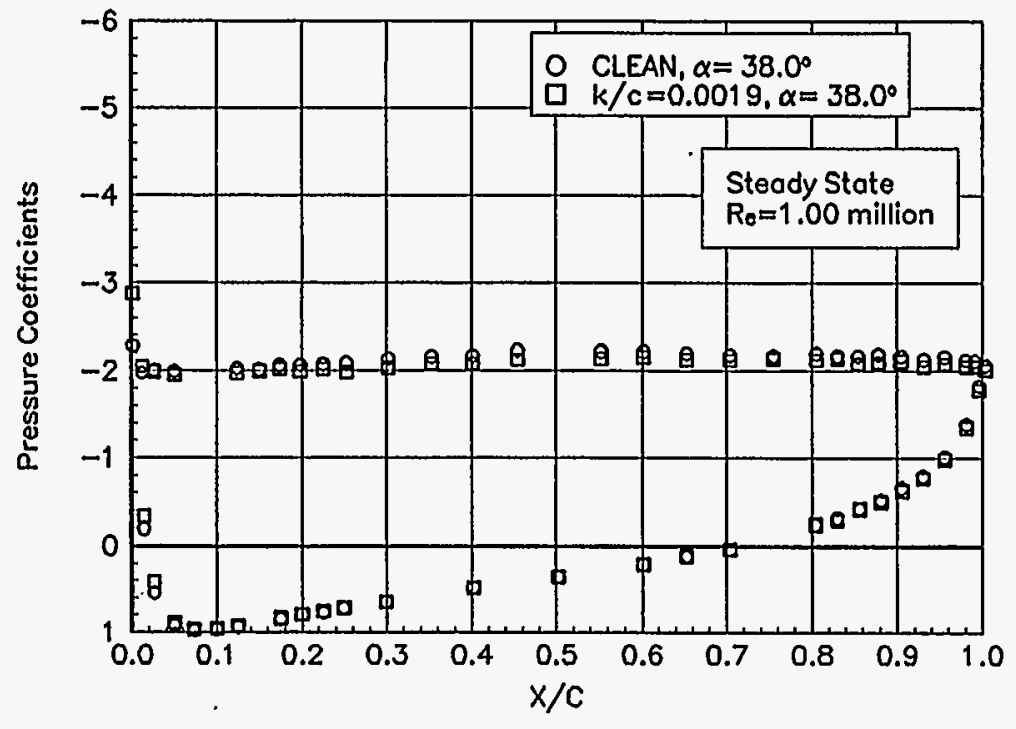

Figure B61. $\alpha=38.0^{\circ}$ 
NACA 4415

Pressure Distributions, Steady State, $R e=1.25$ million 


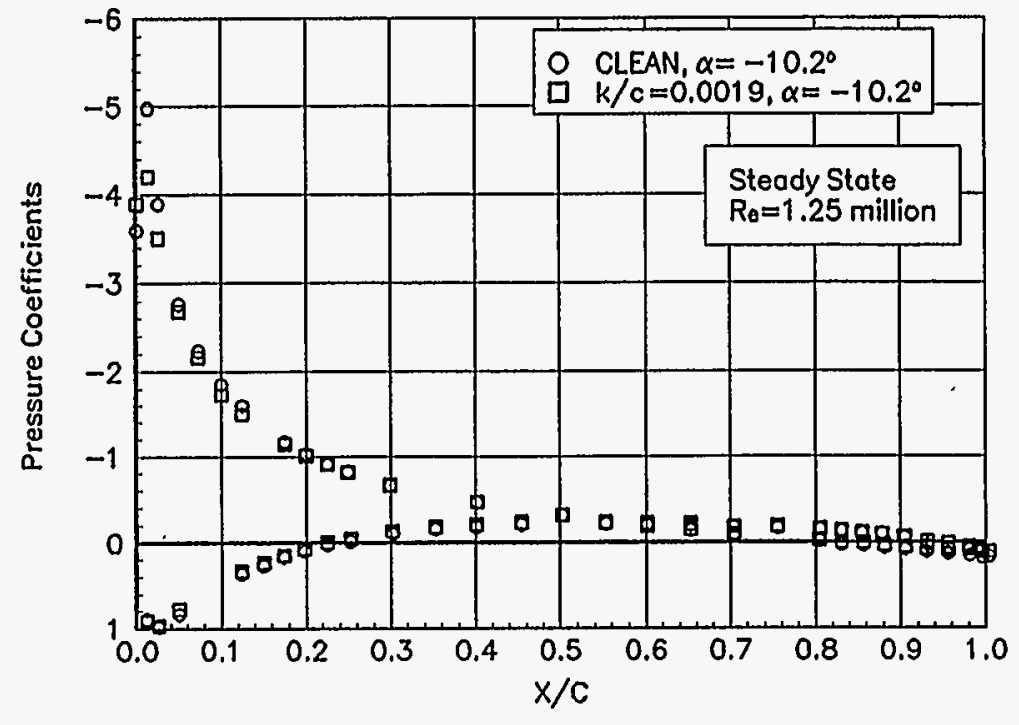

Figure B63. $a=-10.2^{\circ}$

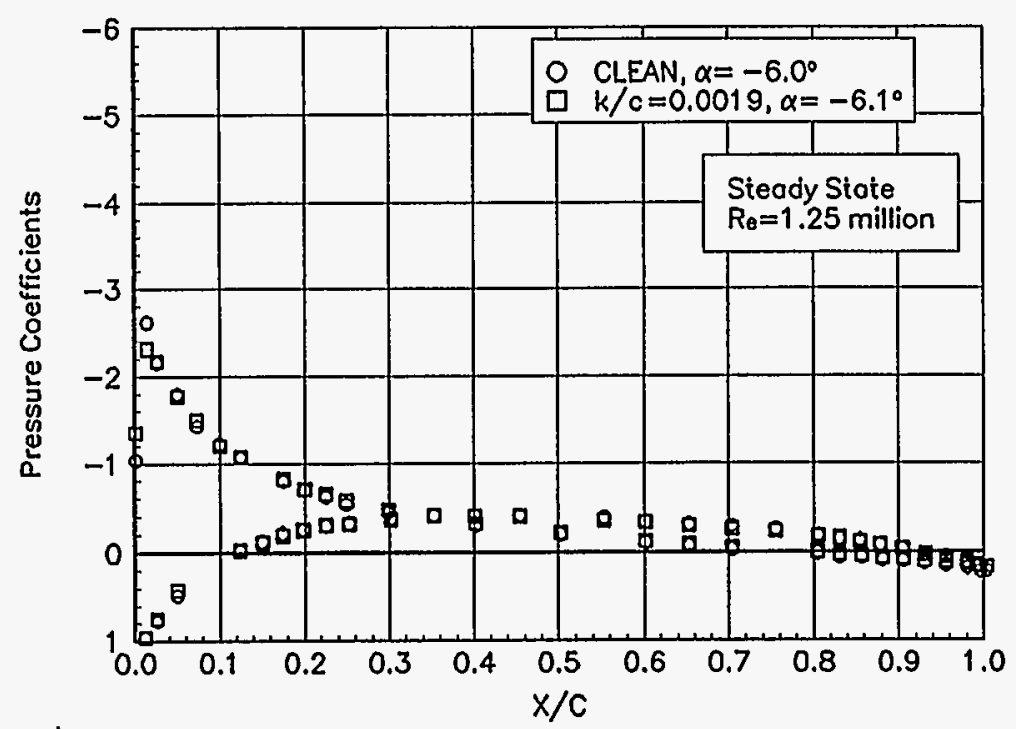

Figure B65. $a=-6.0^{\circ}$

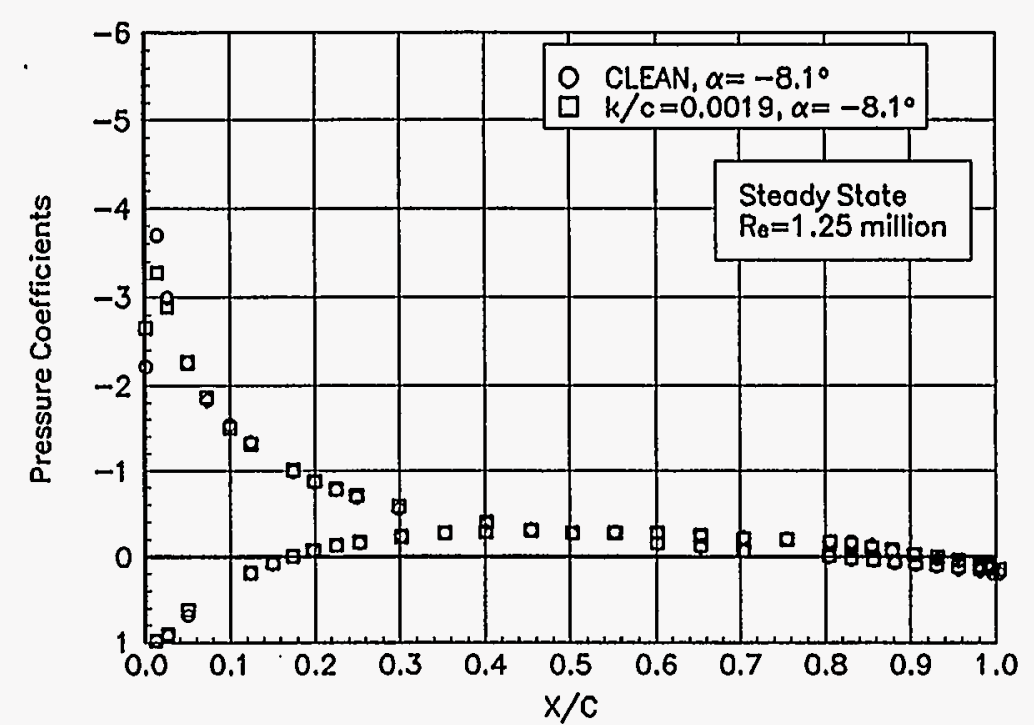

Figure B64. $a=-8.1^{\circ}$

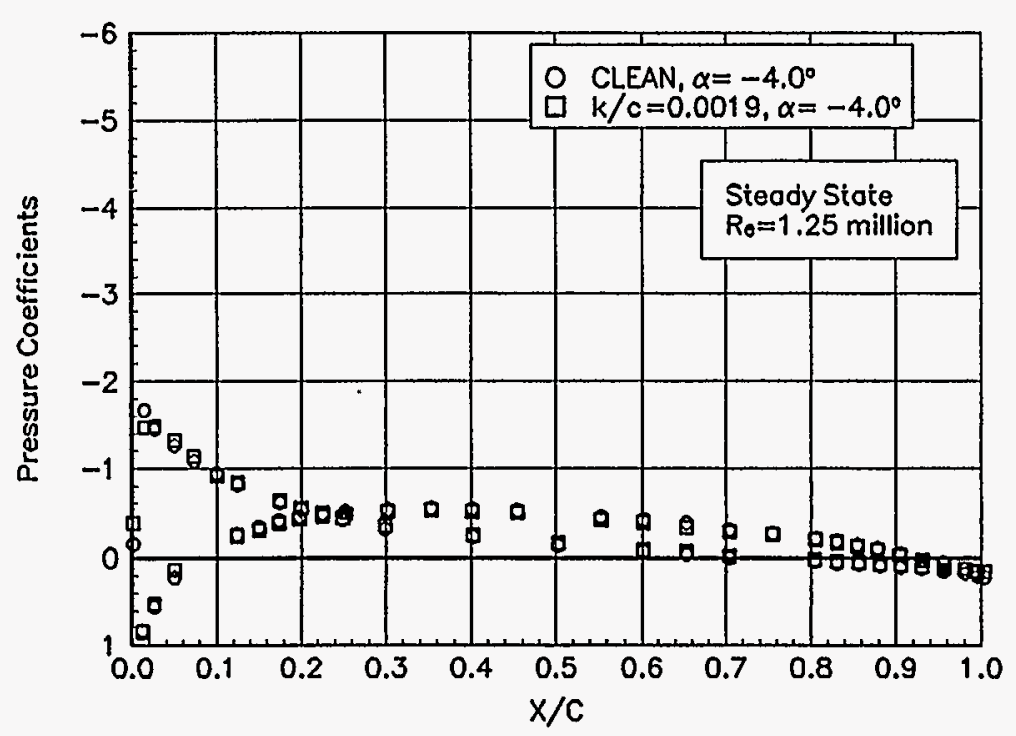

Figure B66. $\alpha=-4.0^{\circ}$ 

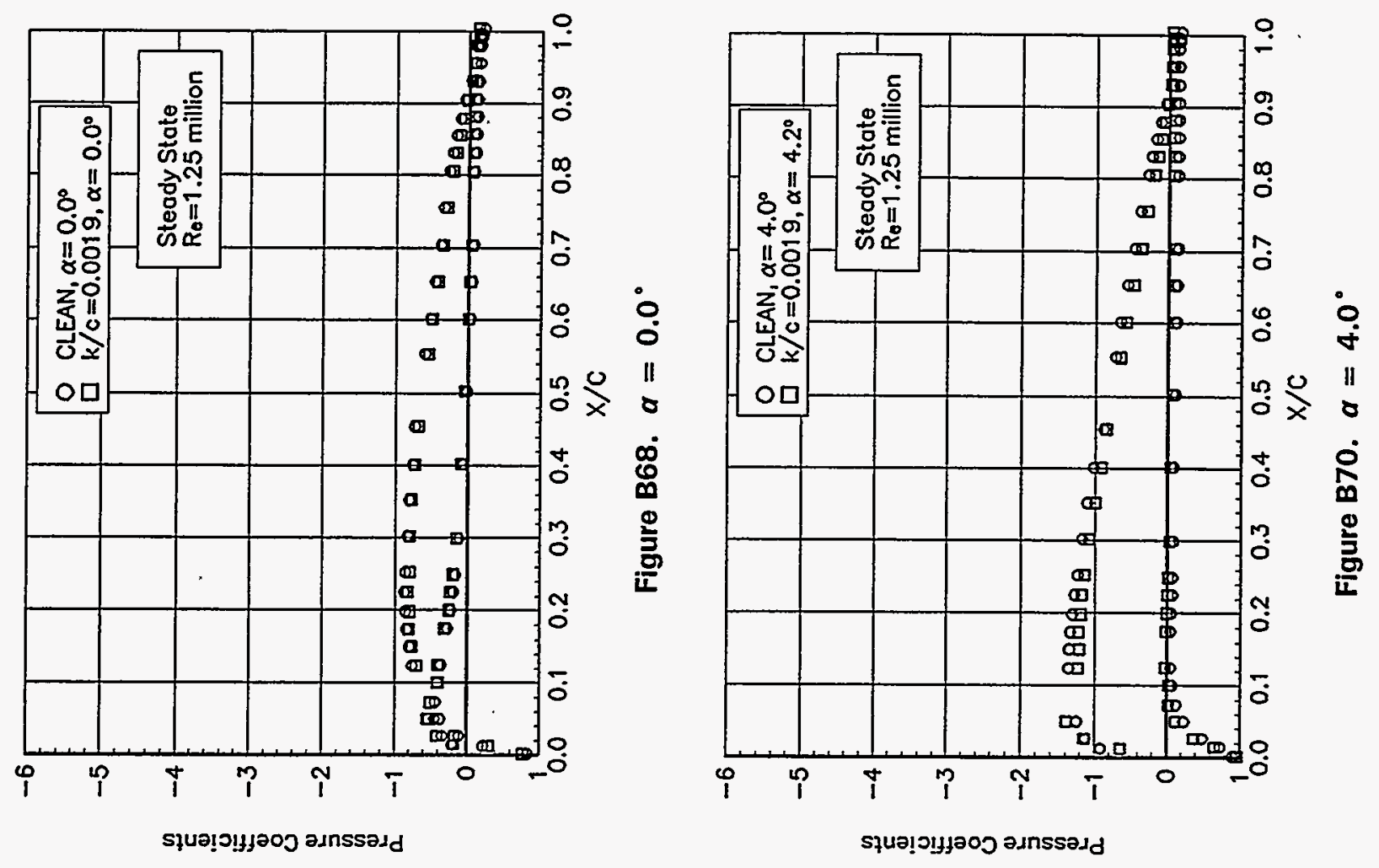

吕
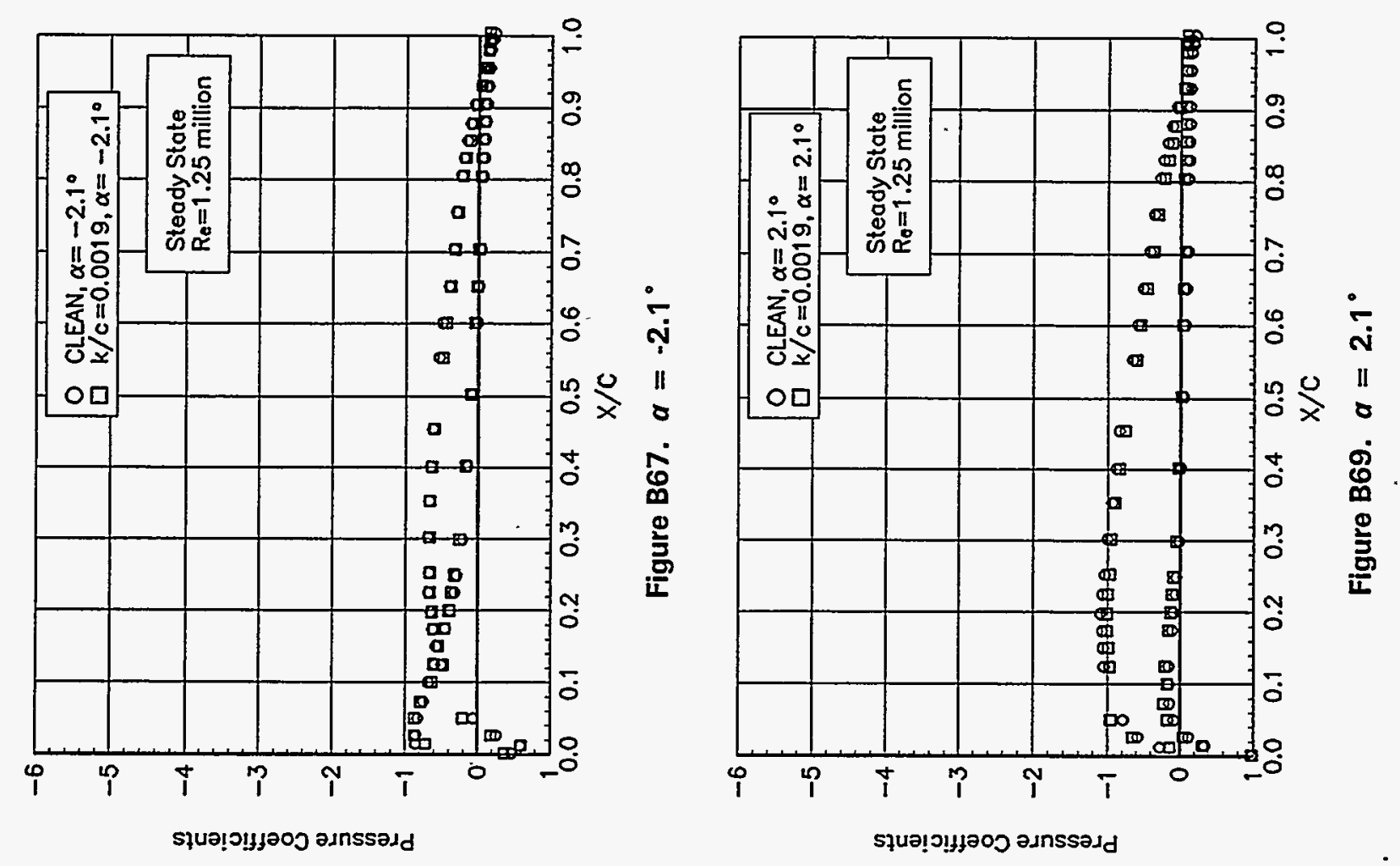

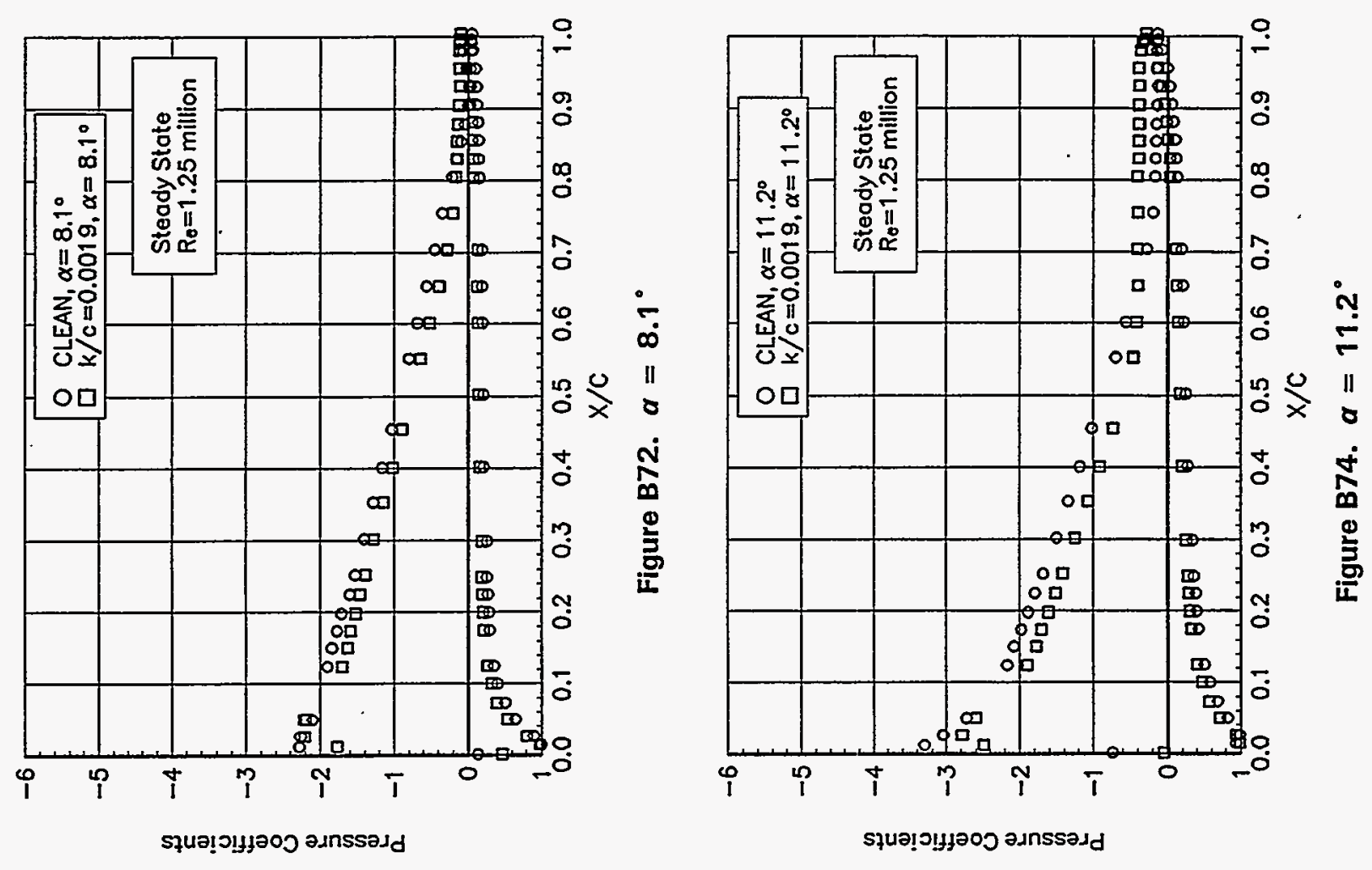

素
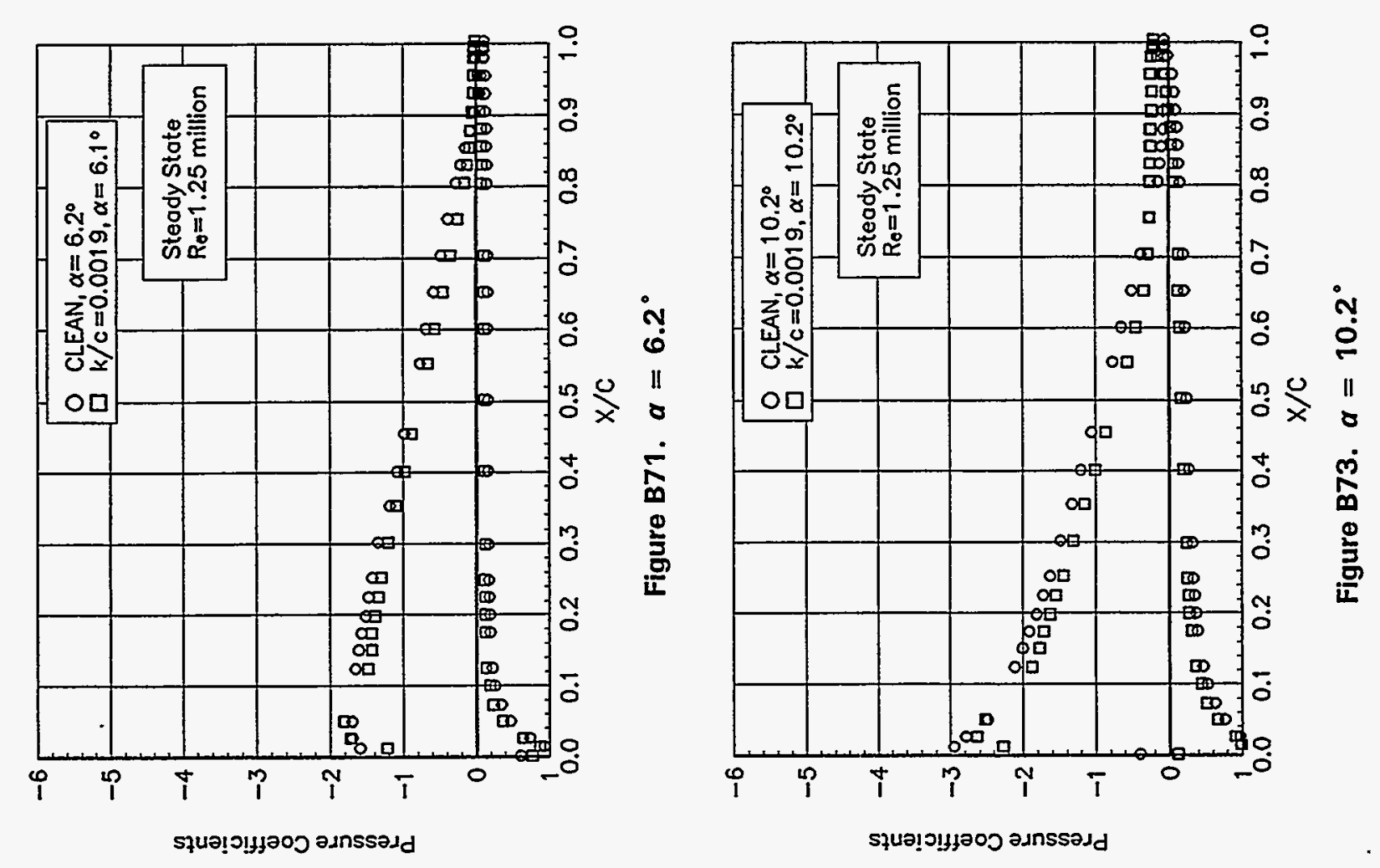


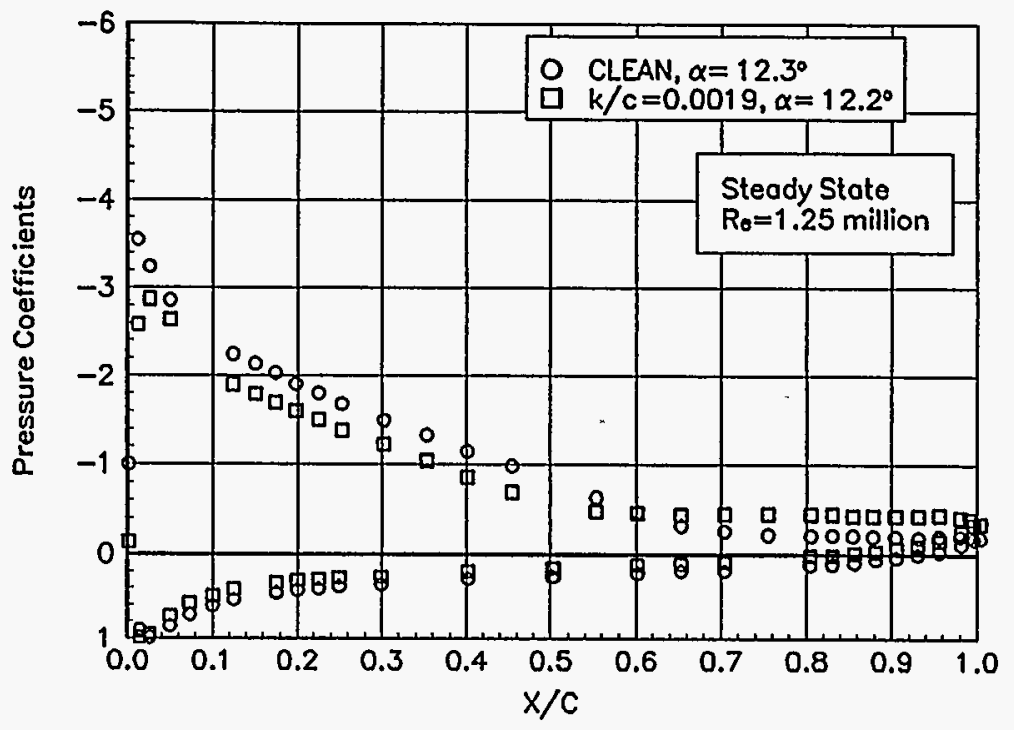

Figure B75. $a=12.3^{\circ}$

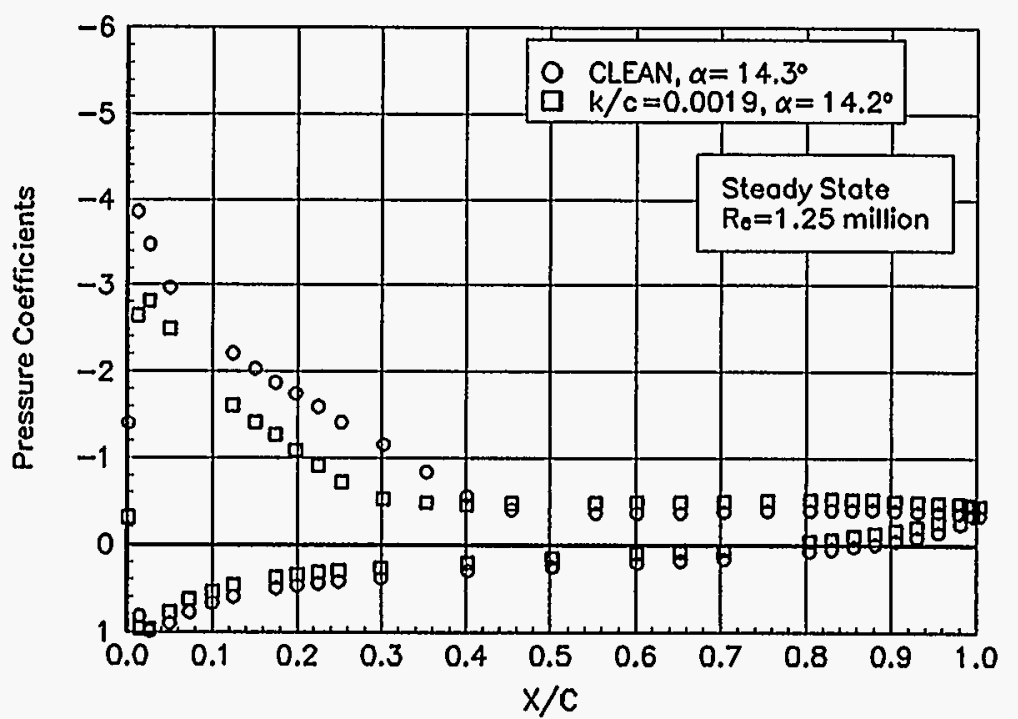

Figure B77. $a=14.3^{\circ}$

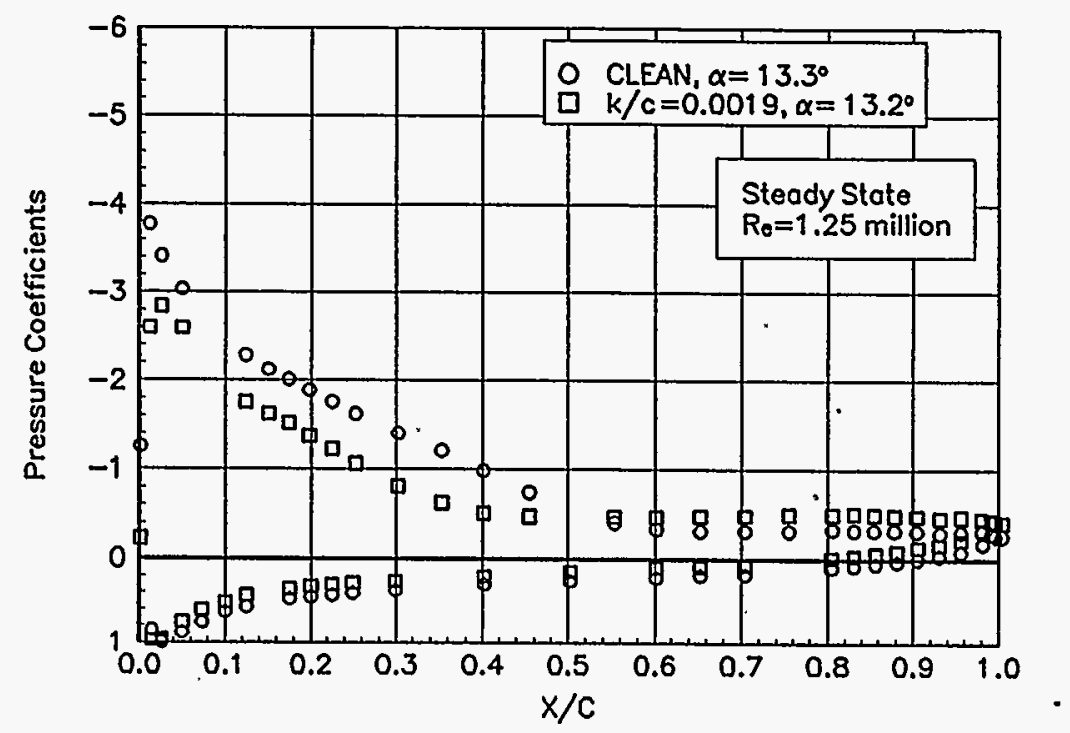

Figure B76. $a=13.3^{\circ}$

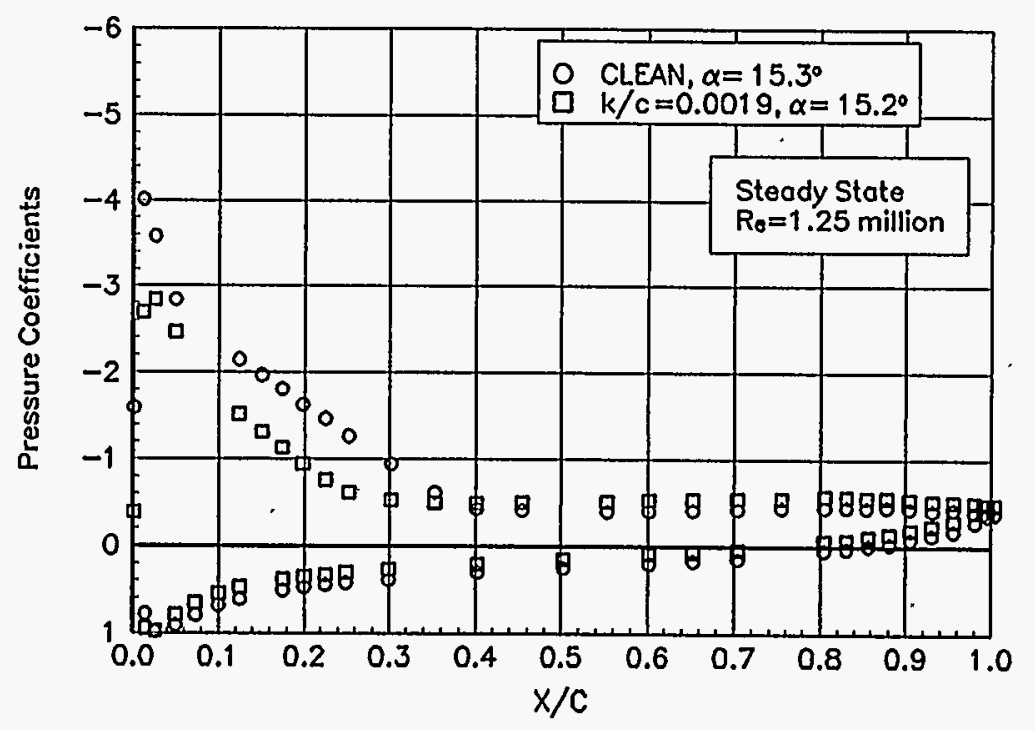

Figure B78. $a=15.3^{\circ}$ 


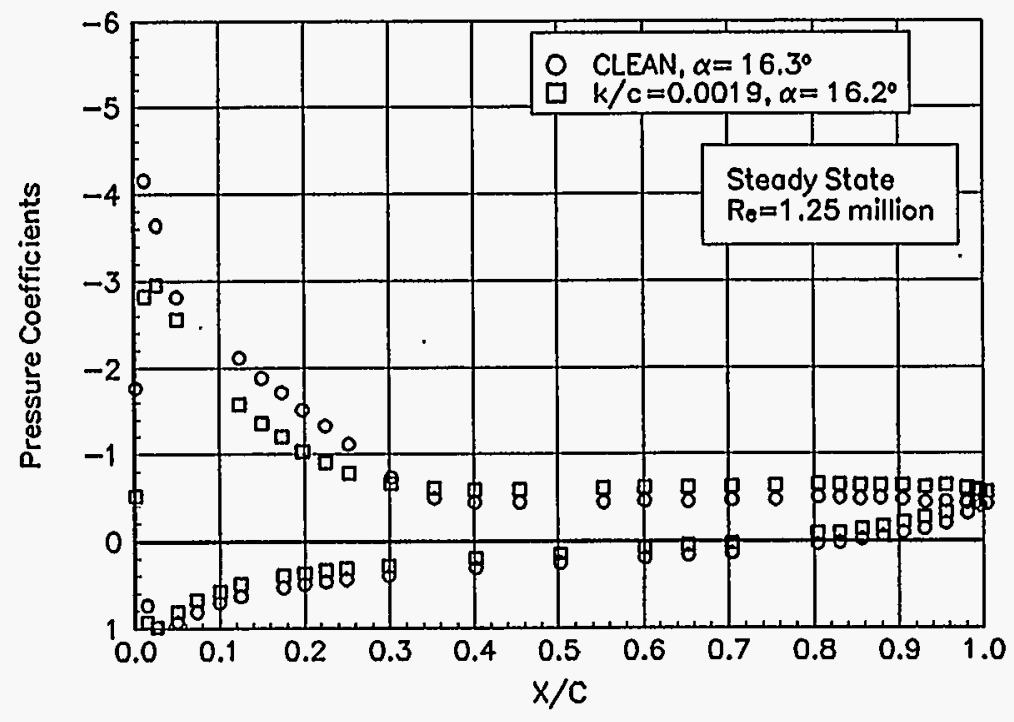

Figure B79. $a=16.3^{\circ}$

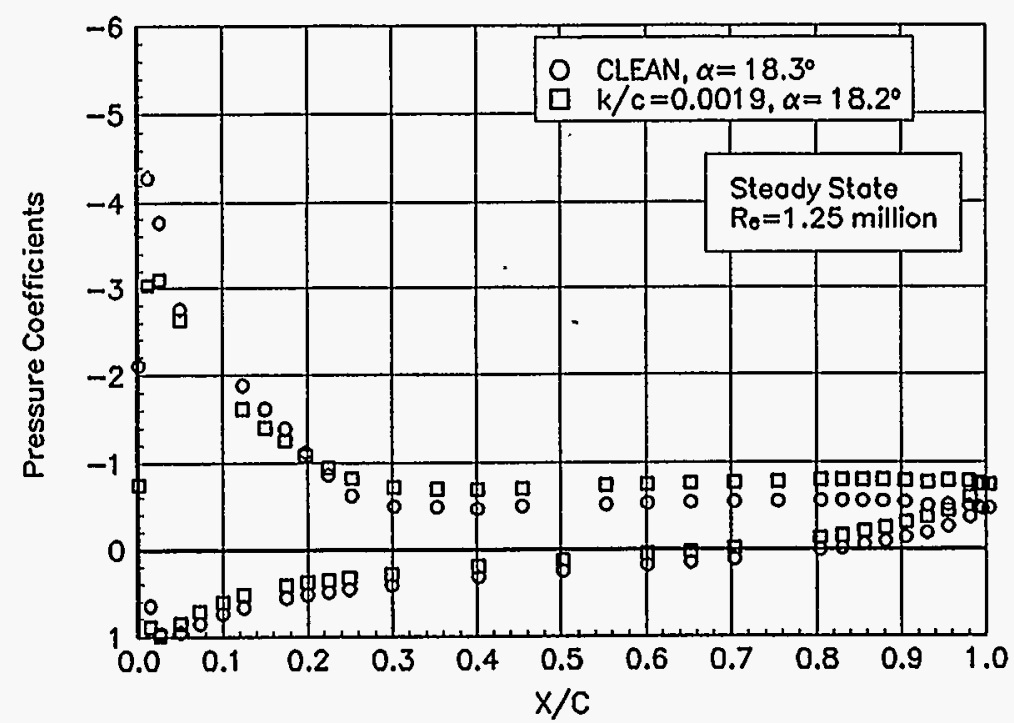

Figure B81. $a=18.3^{\circ}$

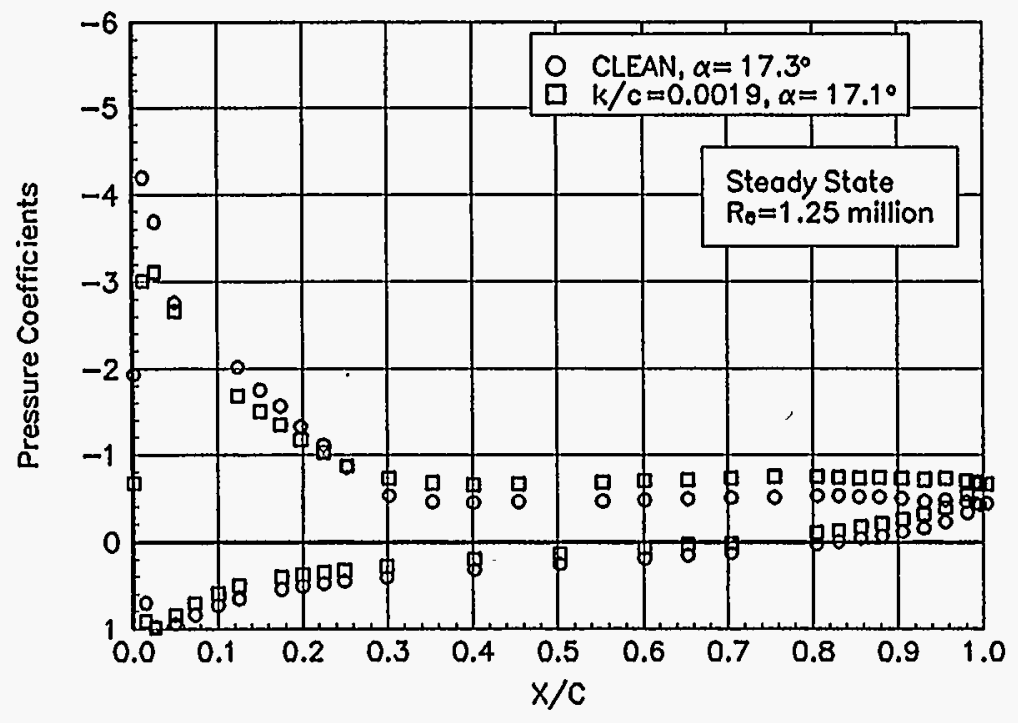

Figure B80. $a=17.3^{\circ}$

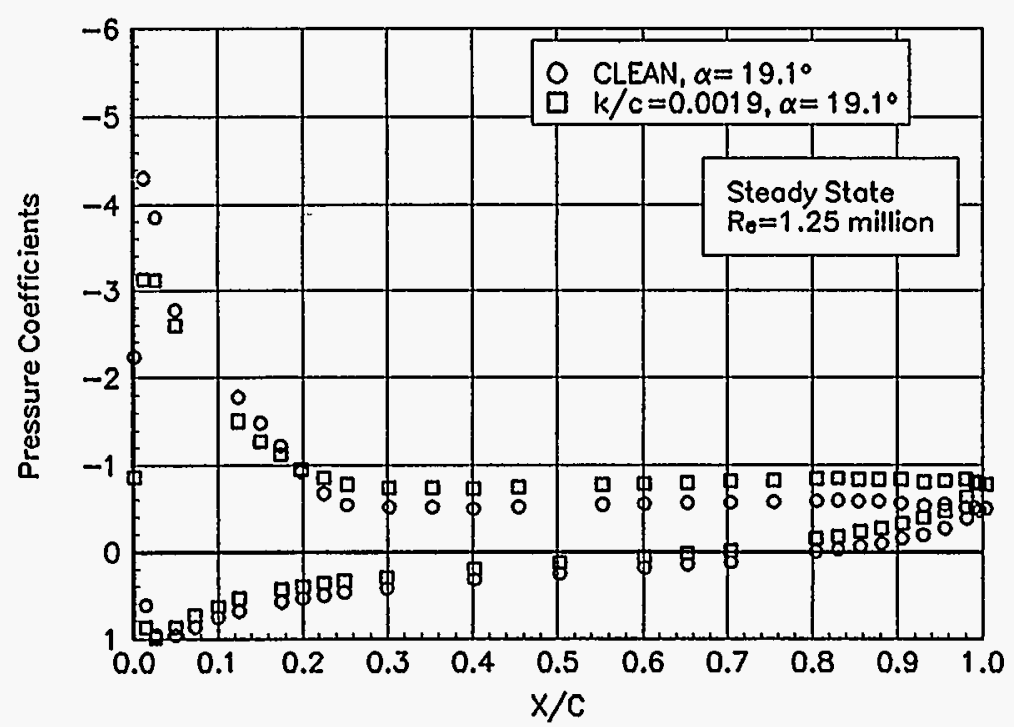

Figure B82. $a=19.1^{\circ}$ 


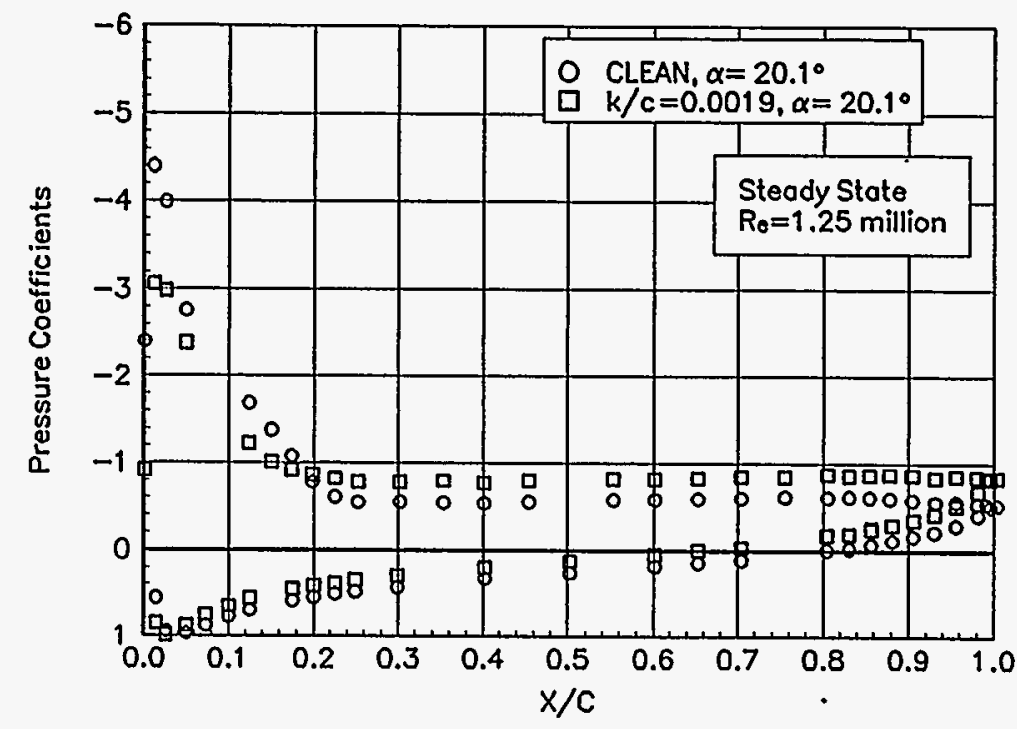

Figure B83. $a=20.1^{\circ}$

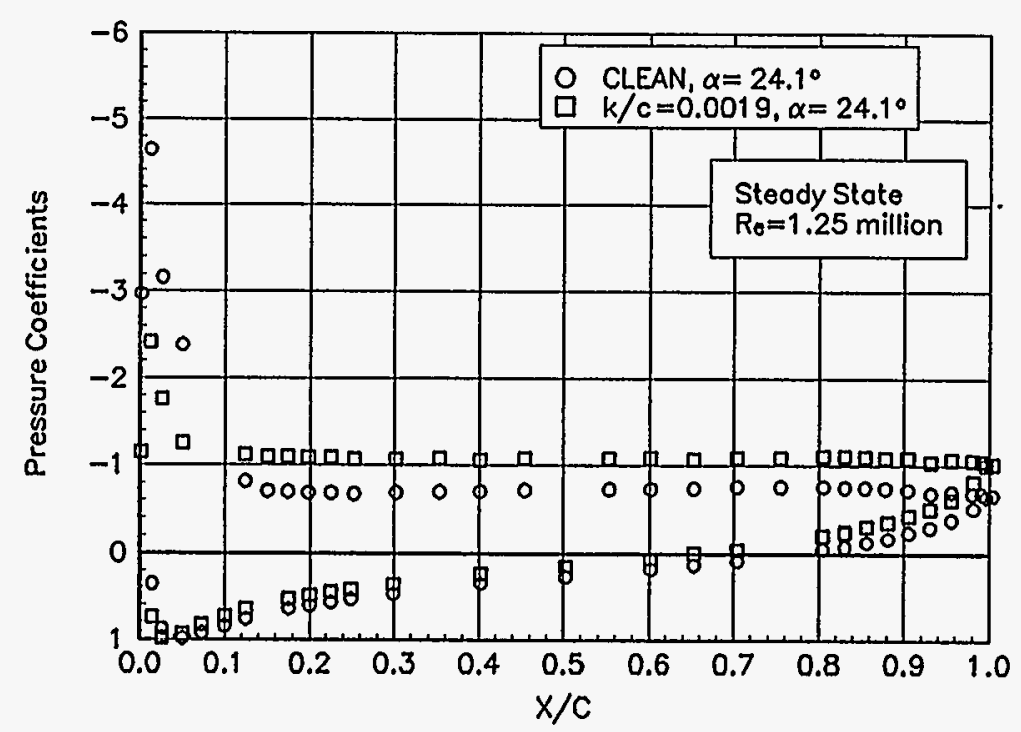

Figure B85. $a=24.1^{\circ}$

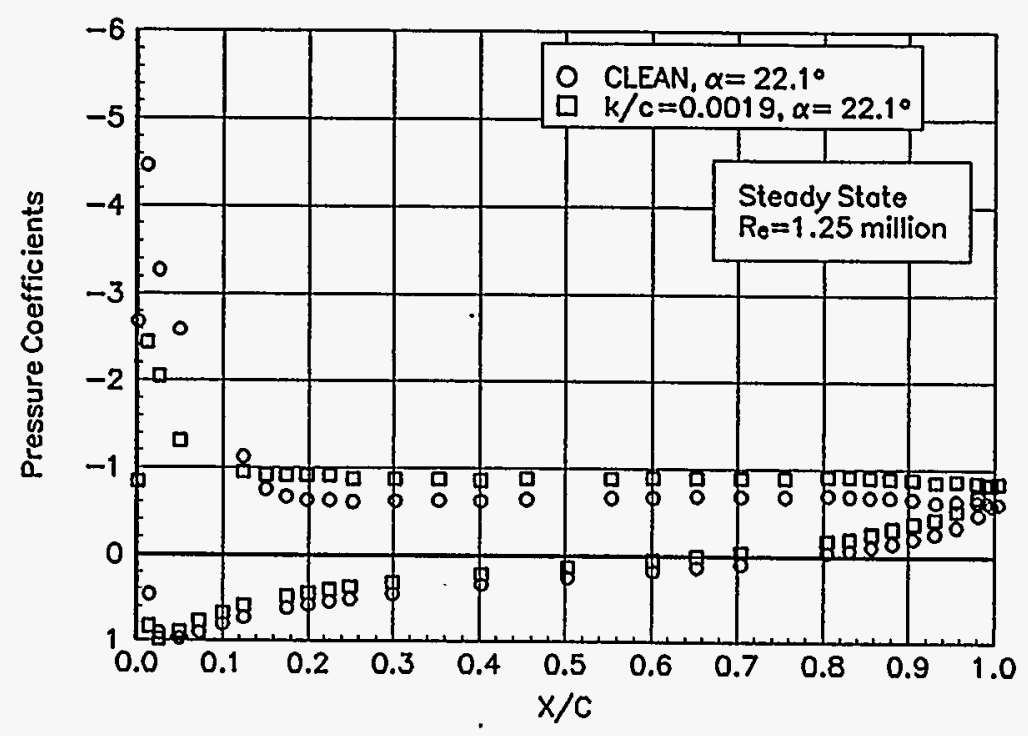

Figure B84. $a=22.1^{\circ}$

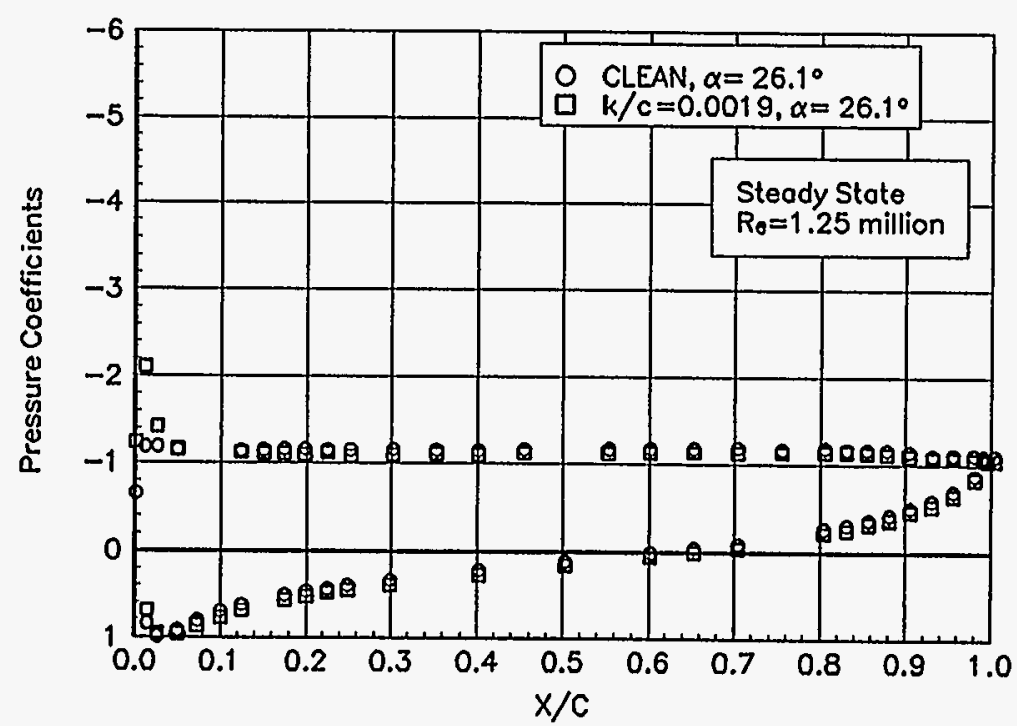

Figure B86. $a=26.1^{\circ}$ 


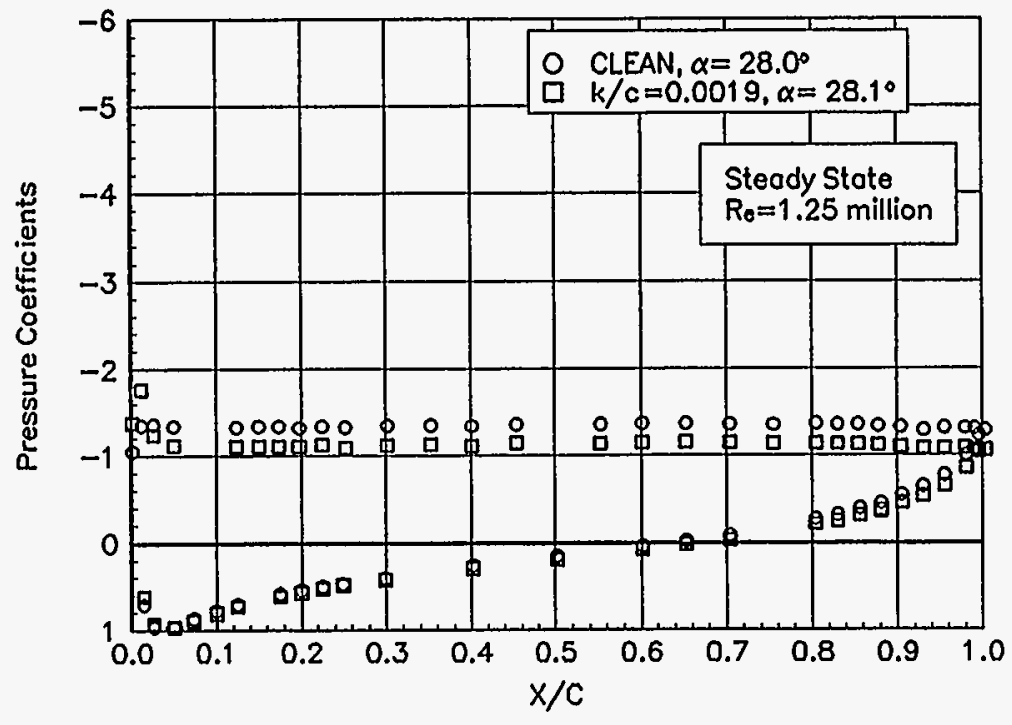

Figure B87. $a=28.0^{\circ}$

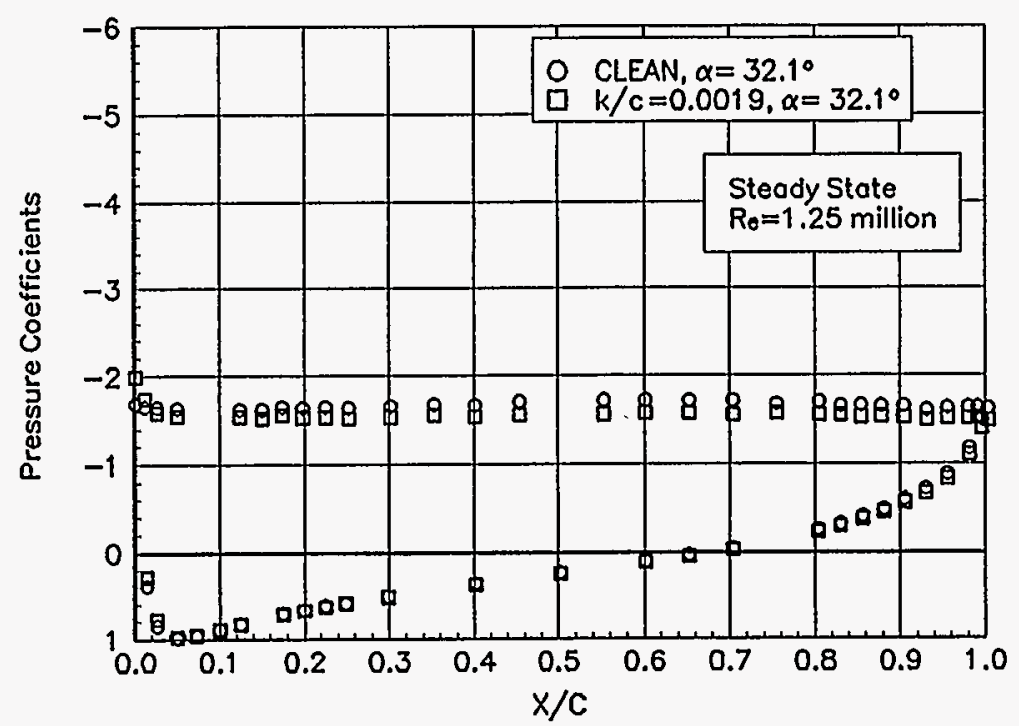

Figure B89. $a=32.1^{\circ}$

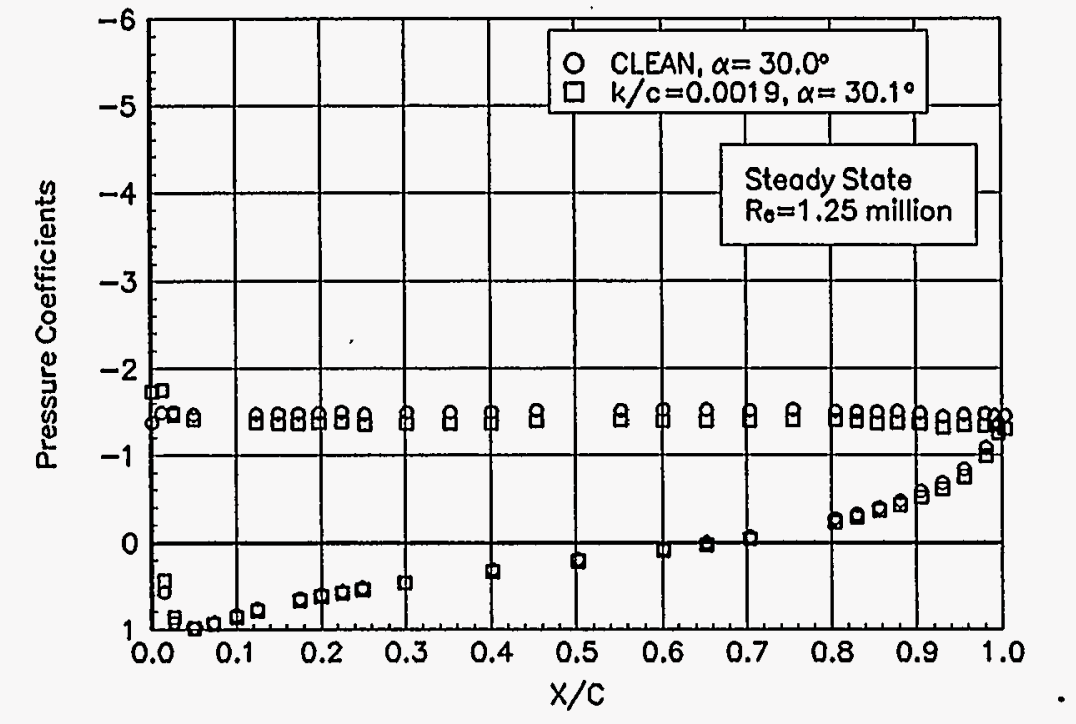

Figure B88. $a=30.0^{\circ}$

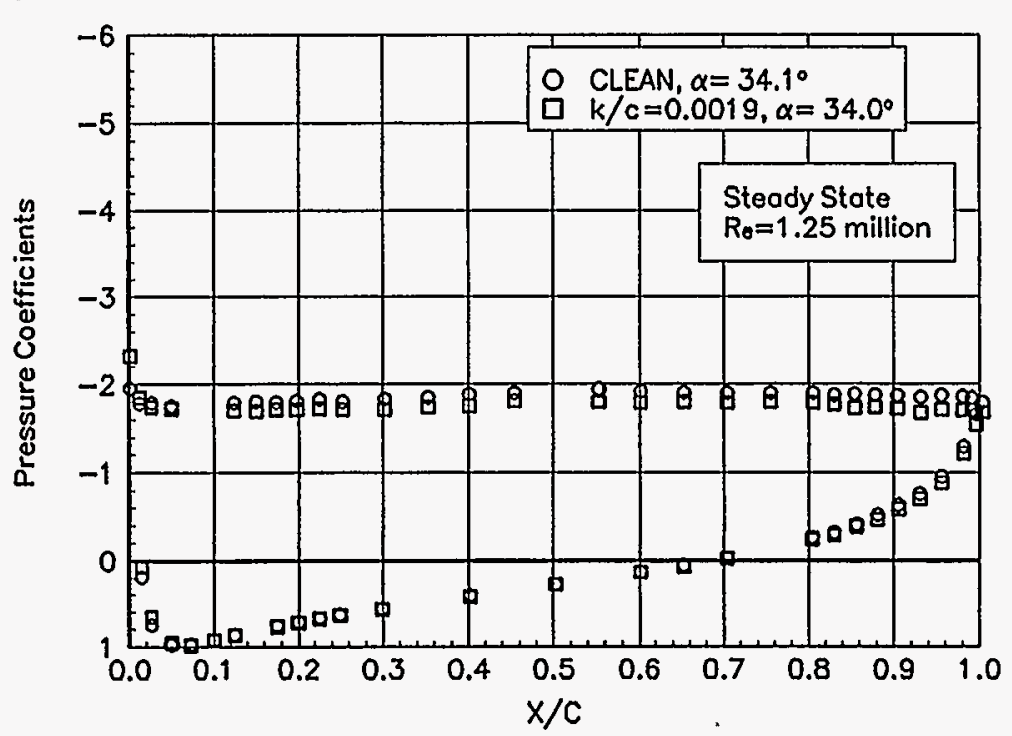

Figure B90. $a=34.1^{\circ}$ 


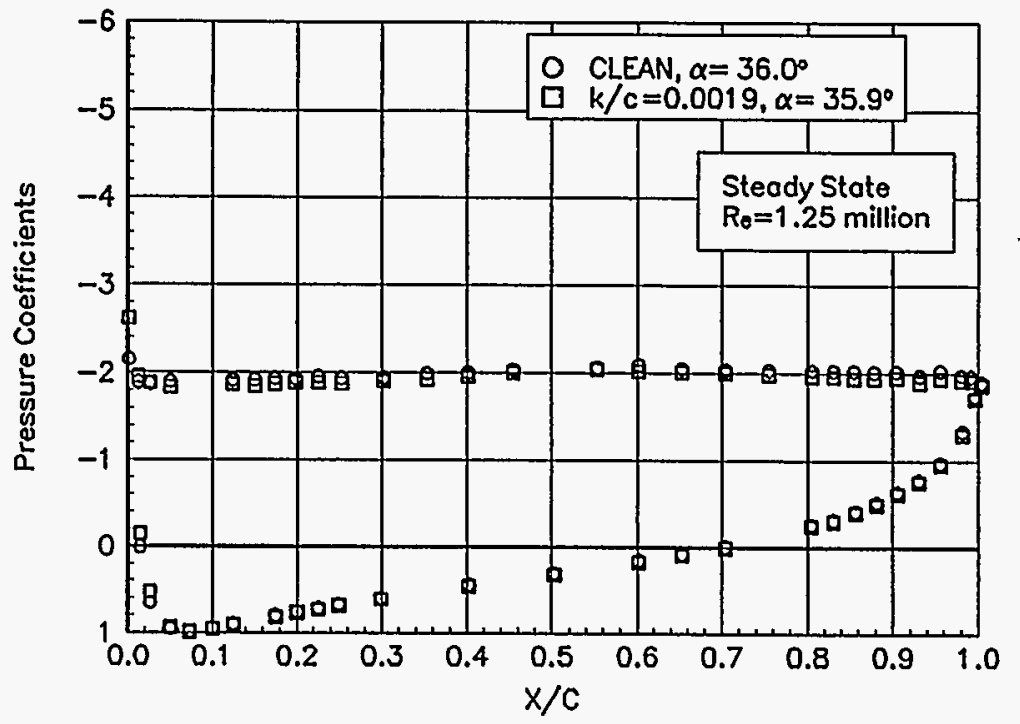

Figure B91. $a=36.0^{\circ}$

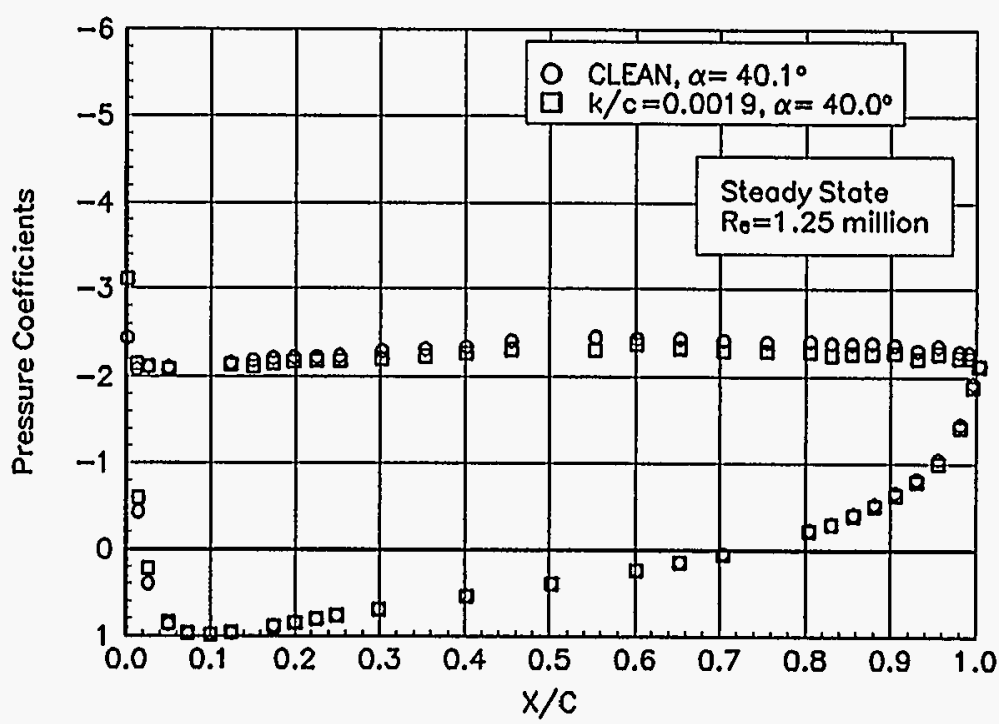

Figure B93. $a=40.1^{\circ}$

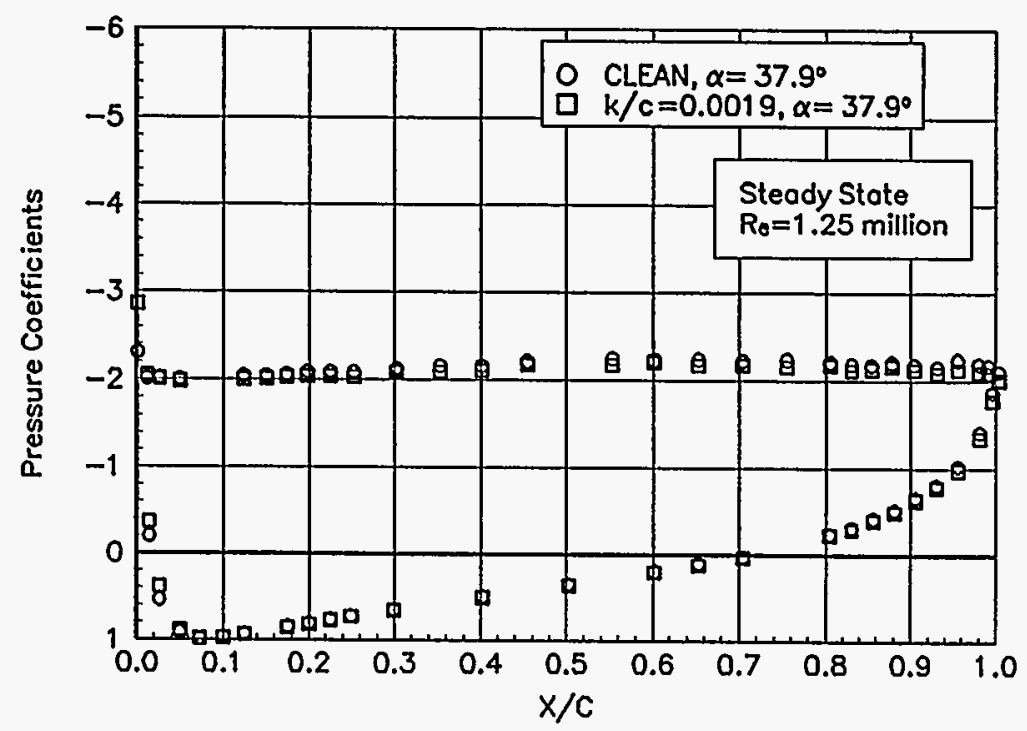

Figure B92. $a=37.9^{\circ}$ 


\section{NACA 4415}

Pressure Distributions, Steady State, $R e=1.5$ million 


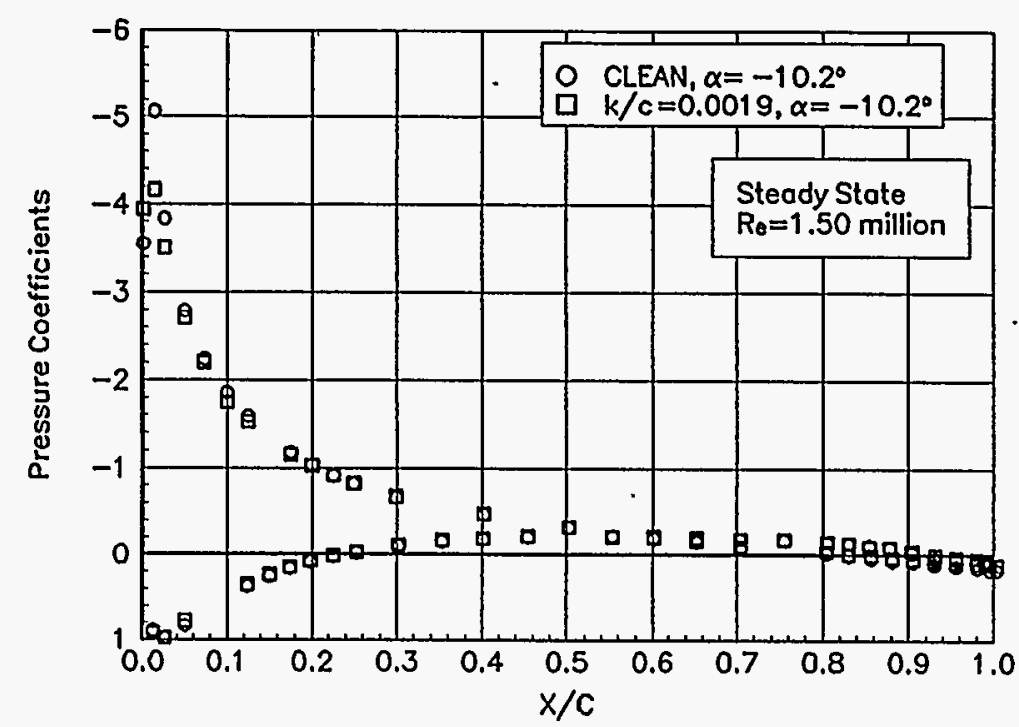

Figure B94. $\alpha=-10.2^{\circ}$

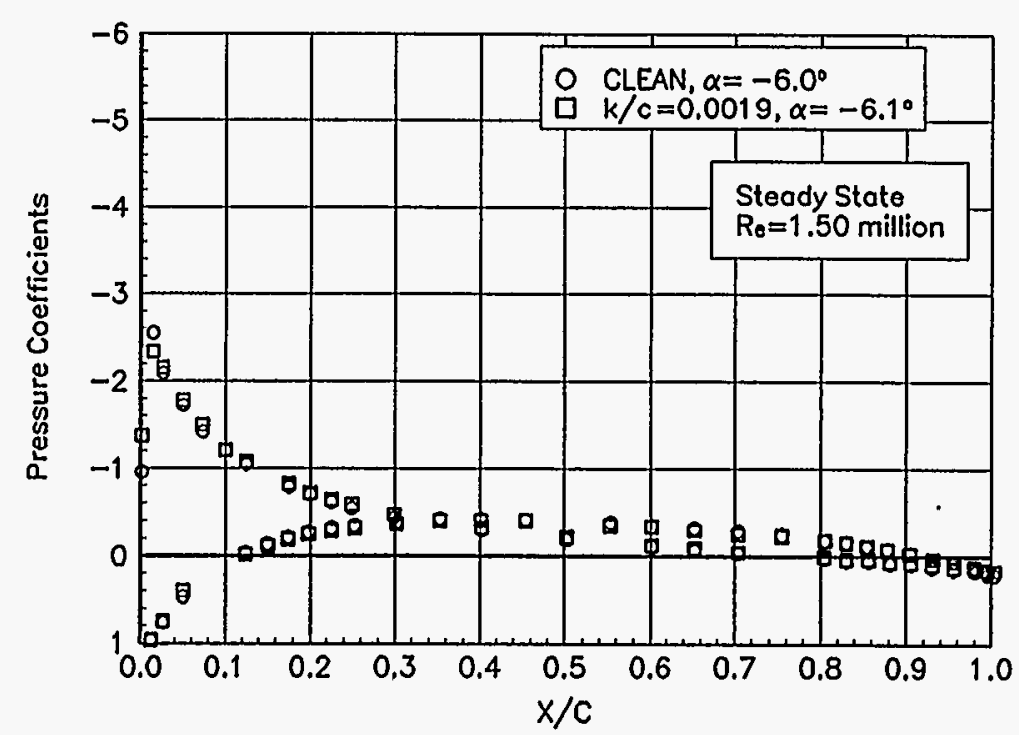

Figure B96. $a=-6.0^{\circ}$

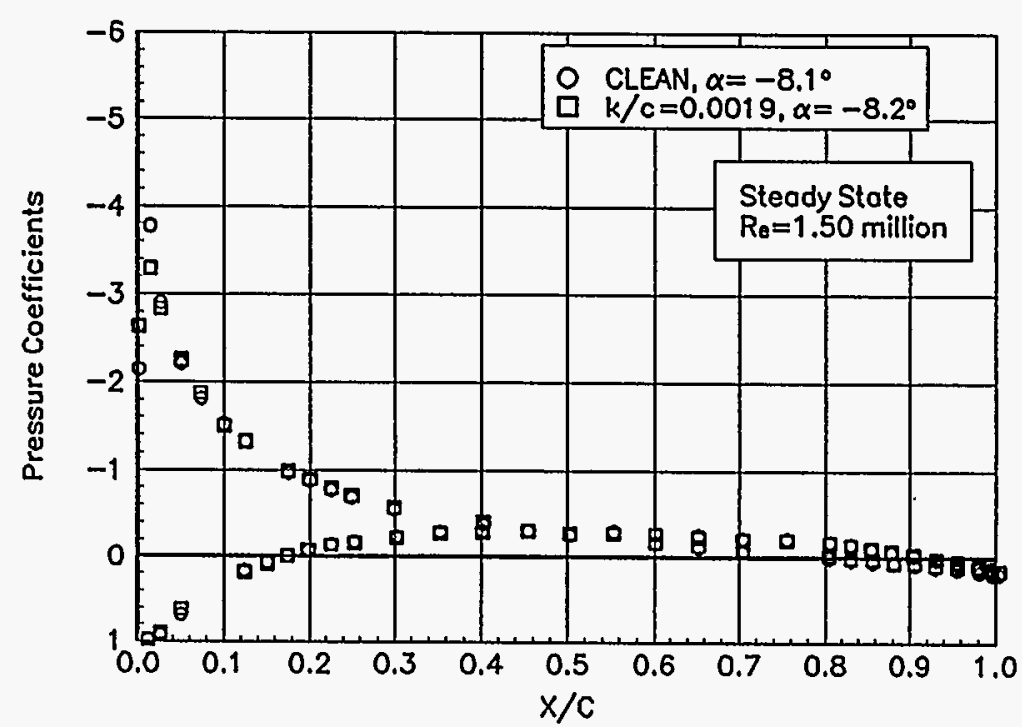

Figure B95. $a=-8.1^{\circ}$

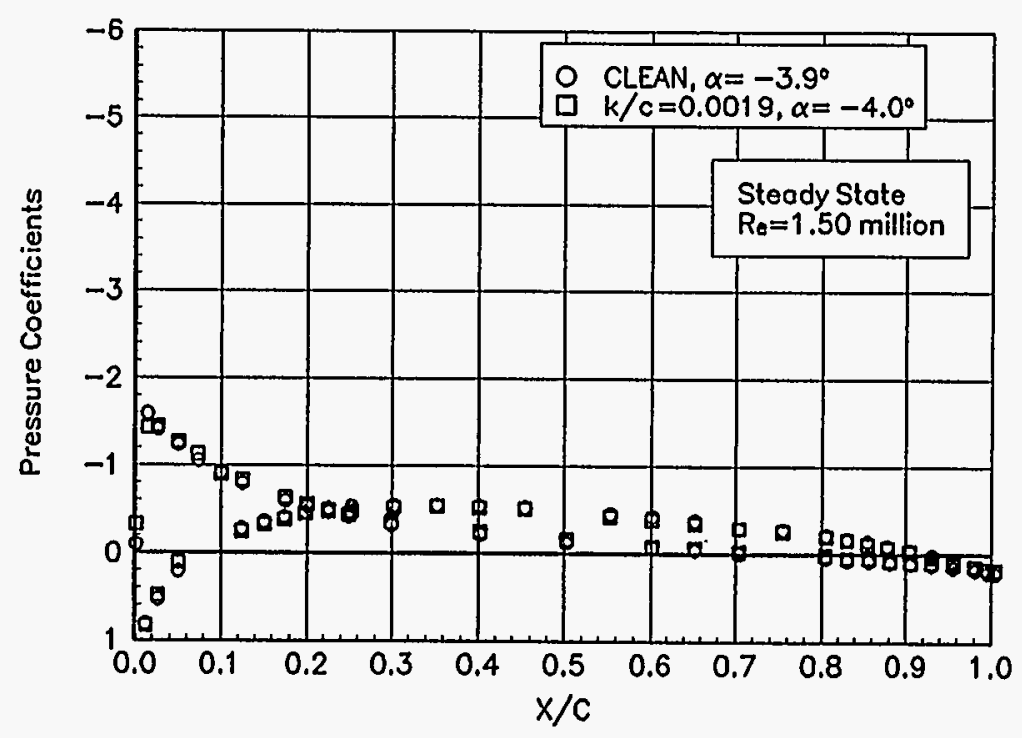

Figure B97. $a=-3.9^{\circ}$ 


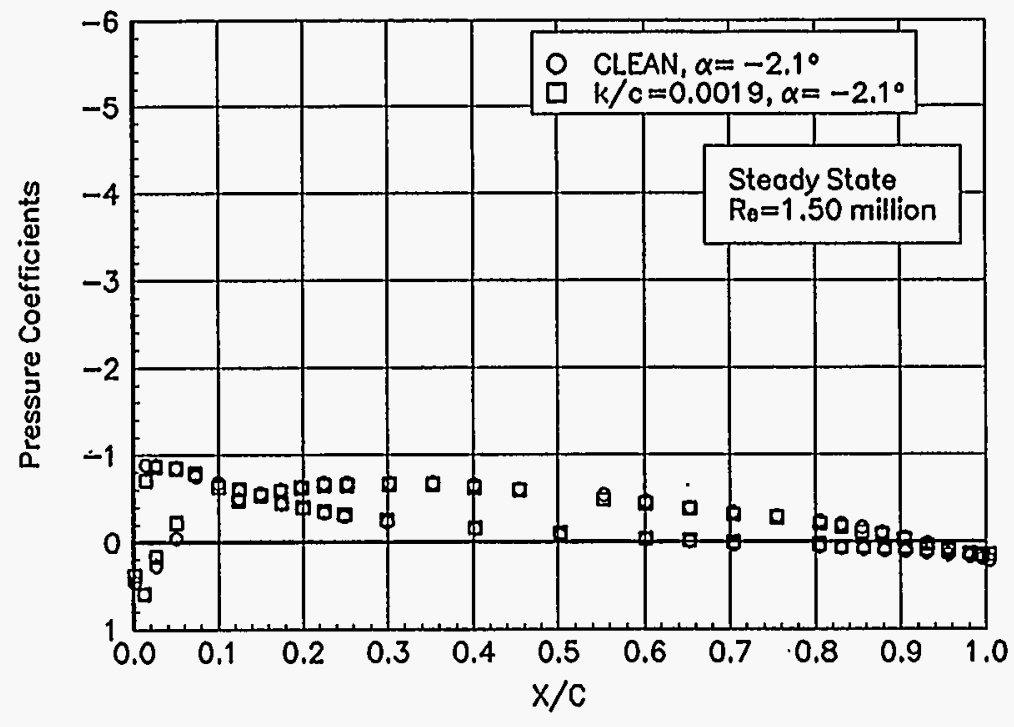

Figure B98. $a=-2.1^{\circ}$

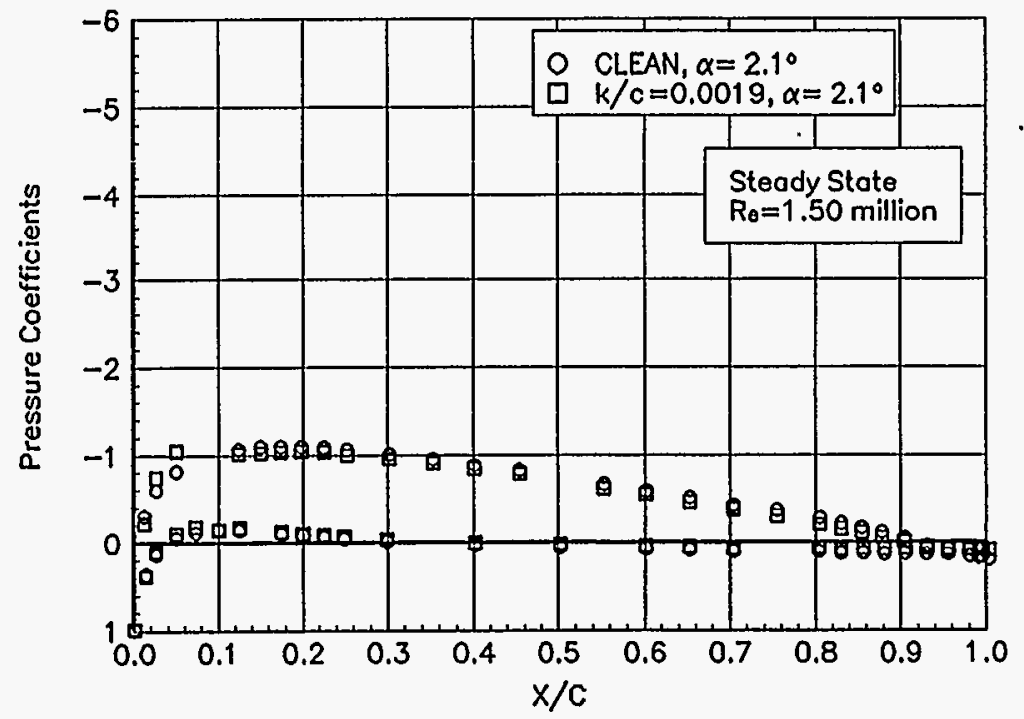

Figure B100. $a=2.1^{\circ}$

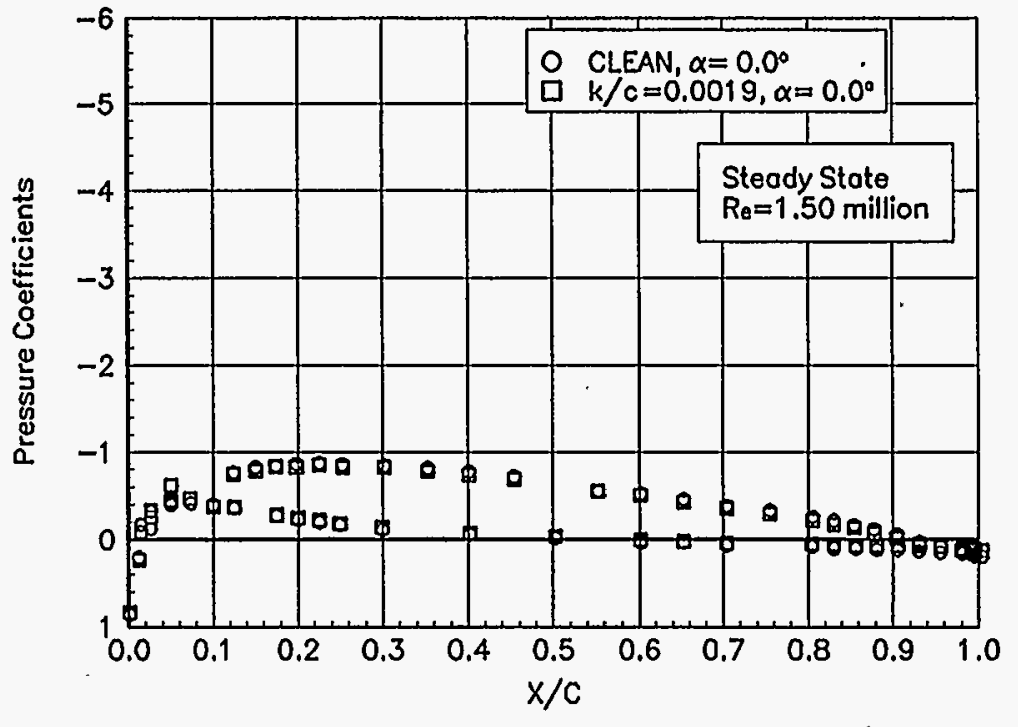

Figure B99. $a=0.0^{\circ}$

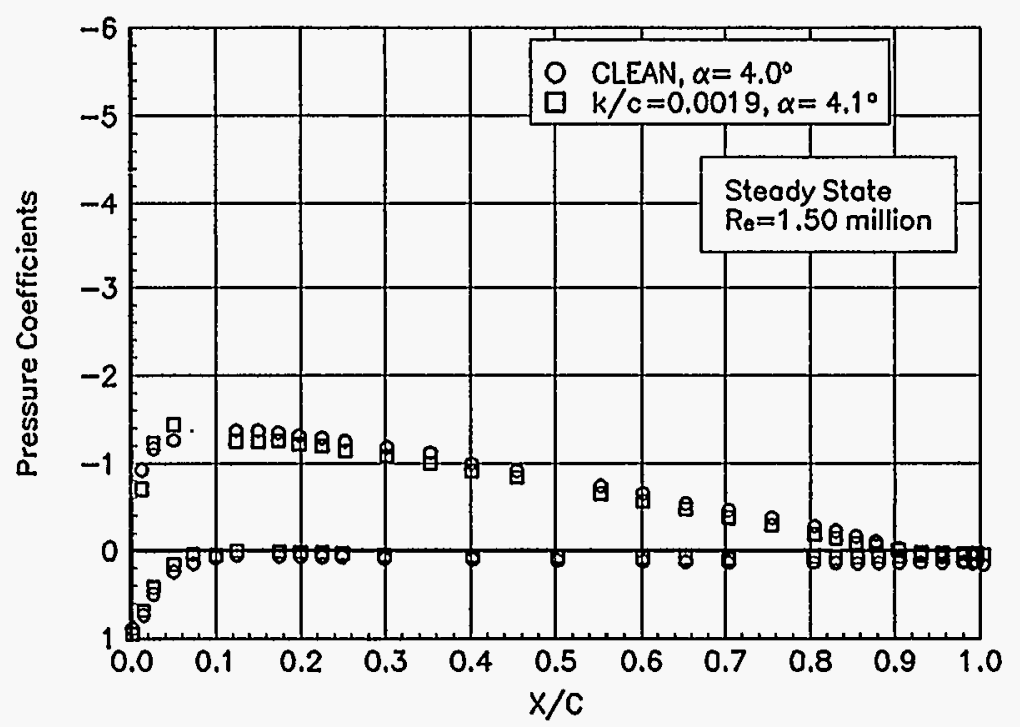

Figure B101. $a=4.0^{\circ}$ 


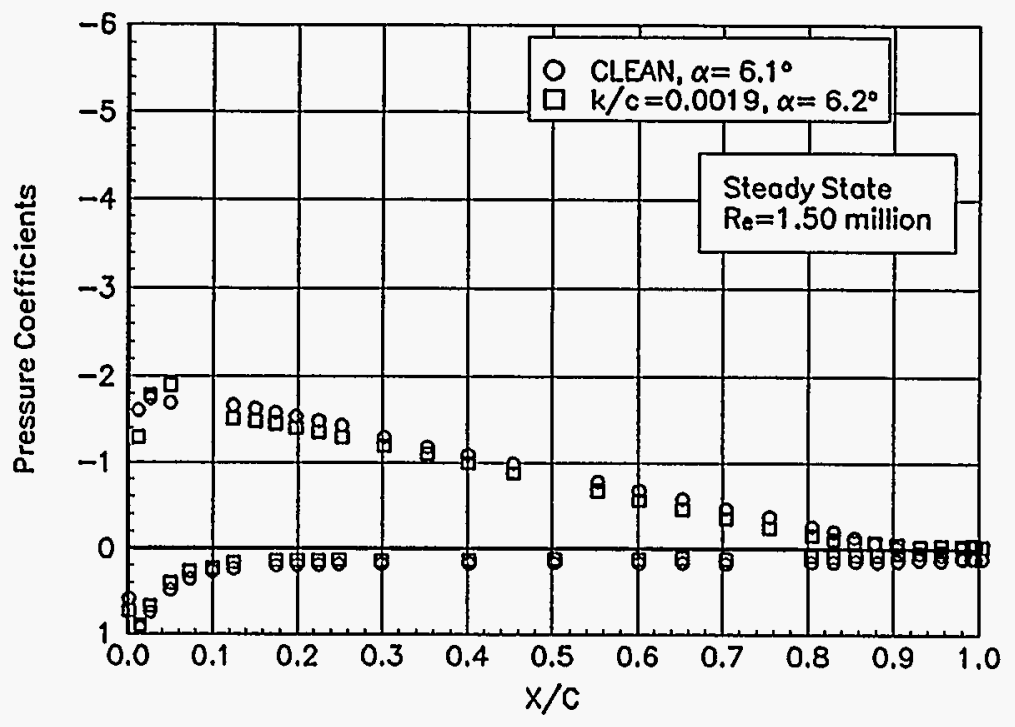

Figure B102. $a=6.1^{\circ}$

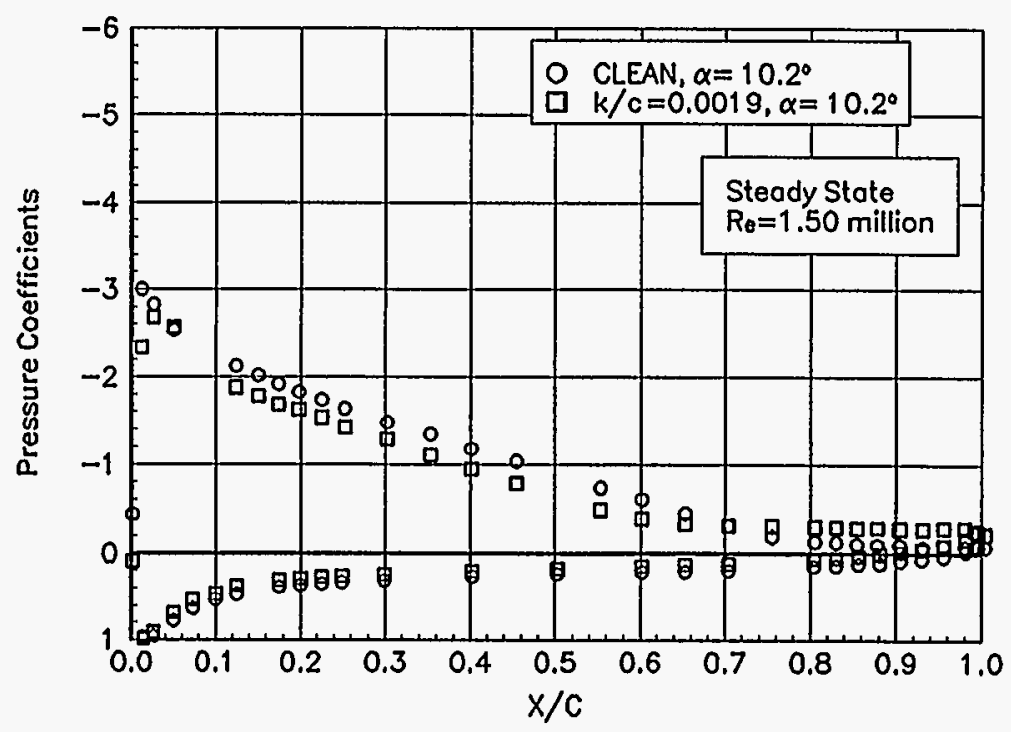

Figure B104. $a=10.2^{\circ}$

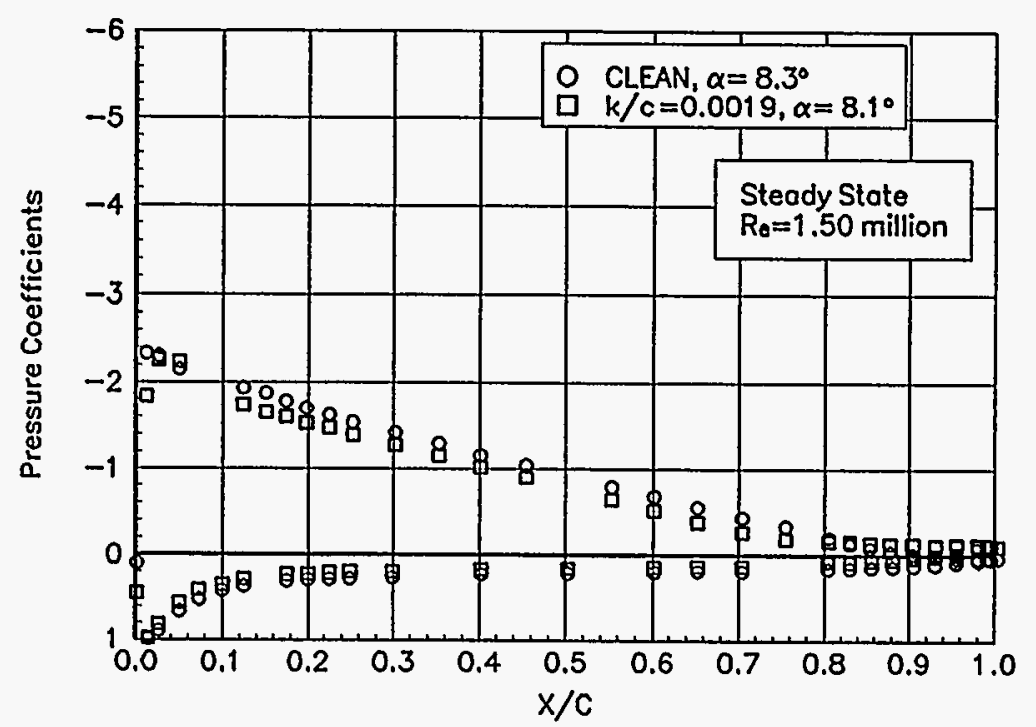

Figure B103. $a=8.3^{\circ}$

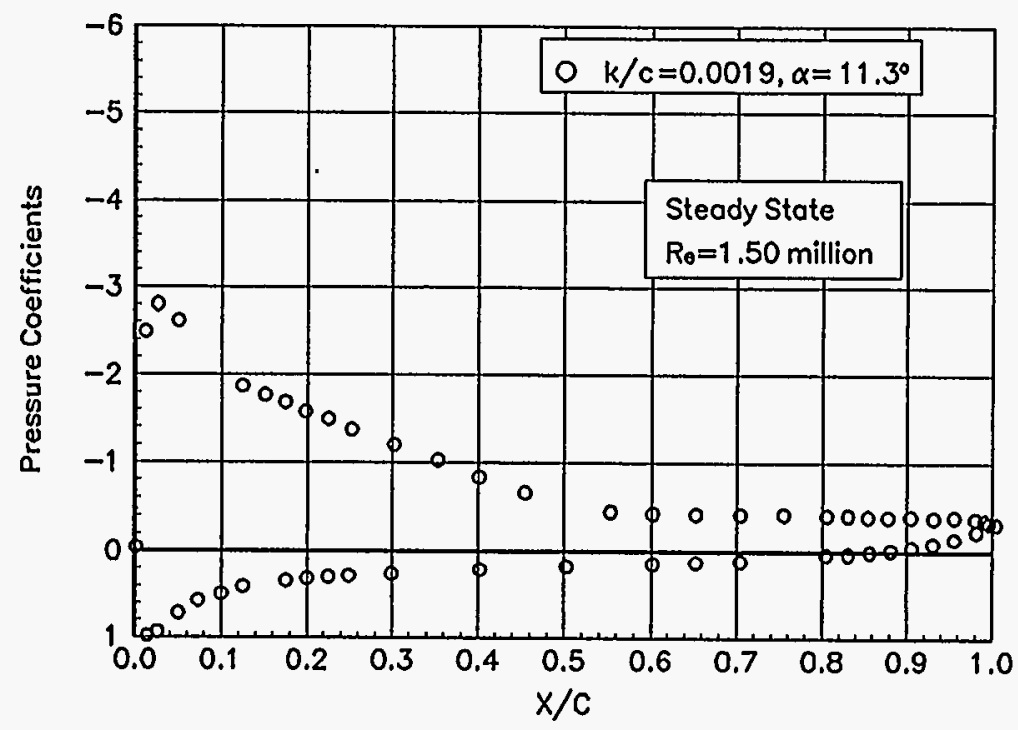

Figure B105. $a=11.3^{\circ}$ 

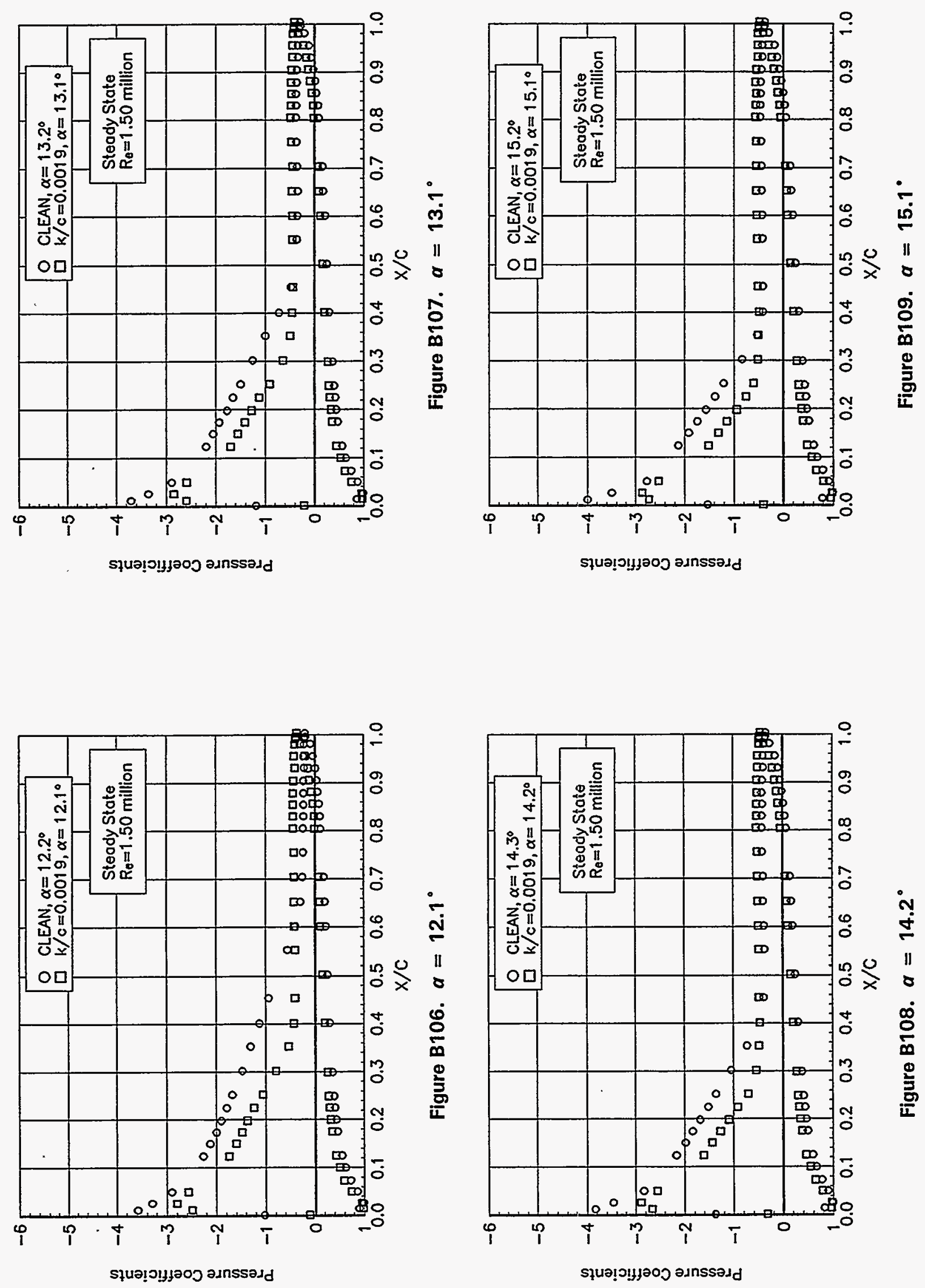


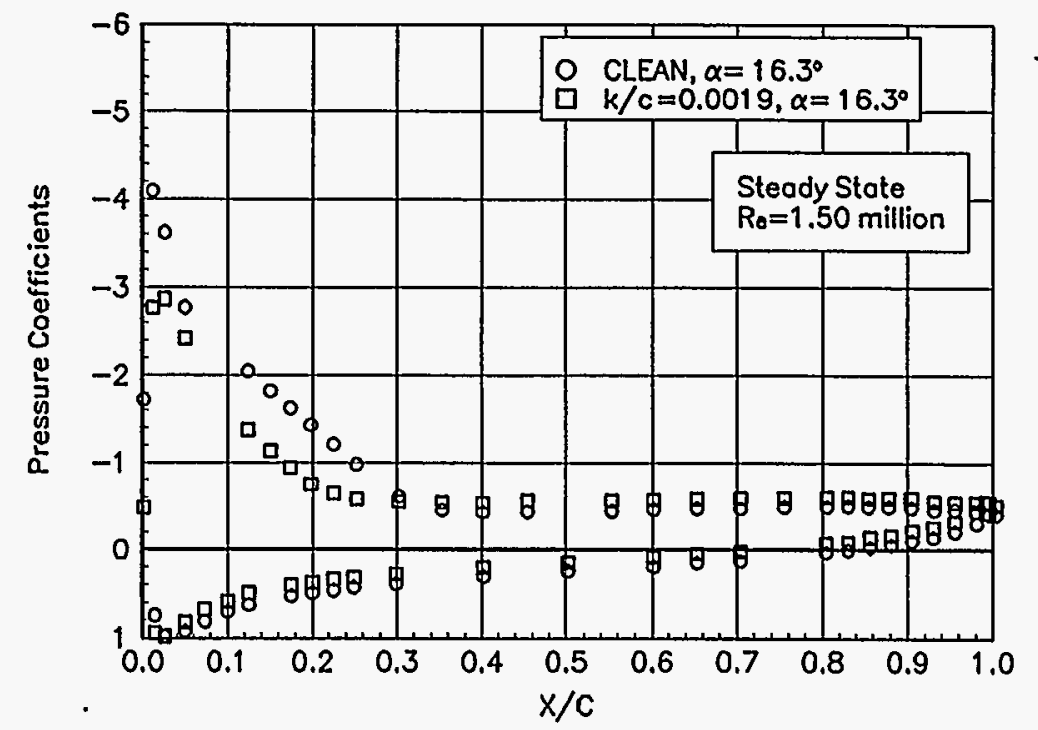

Figure B110. $a=16.3^{\circ}$

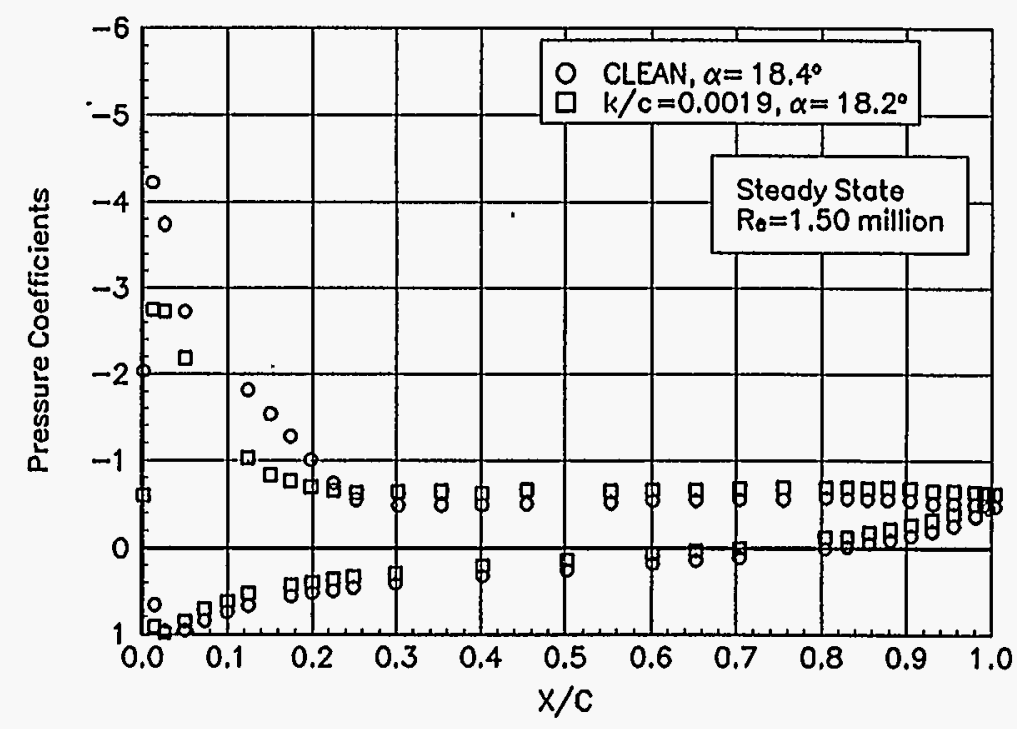

Figure B112. $a=18.2^{\circ}$

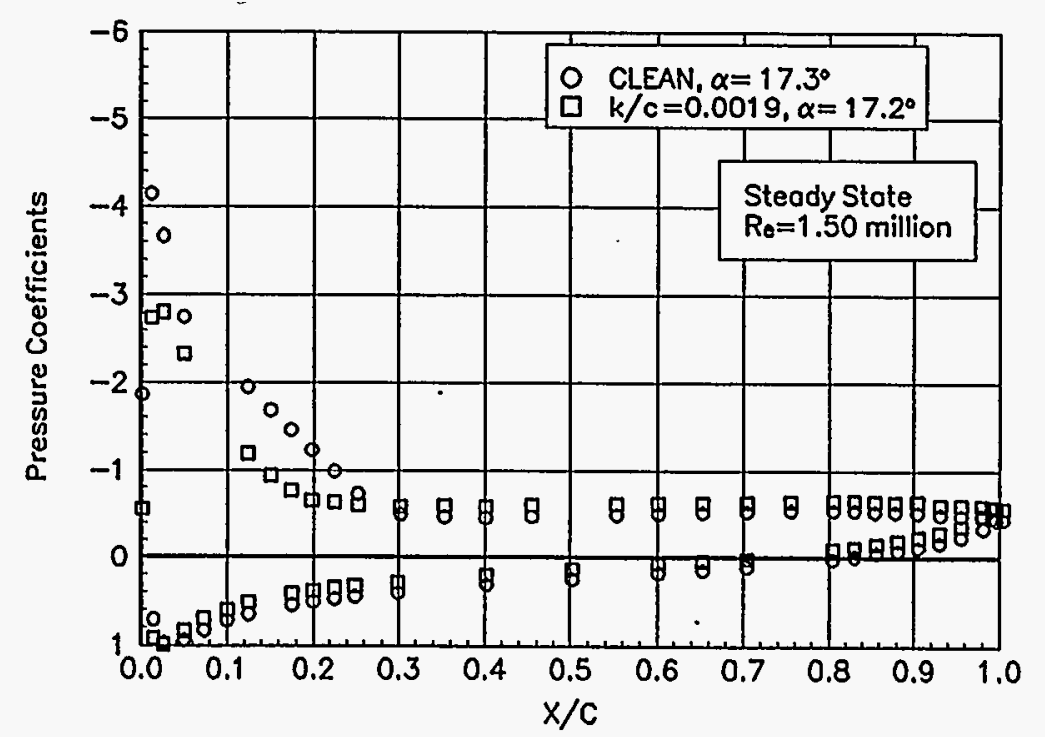

Figure B111. $a=17.2^{\circ}$

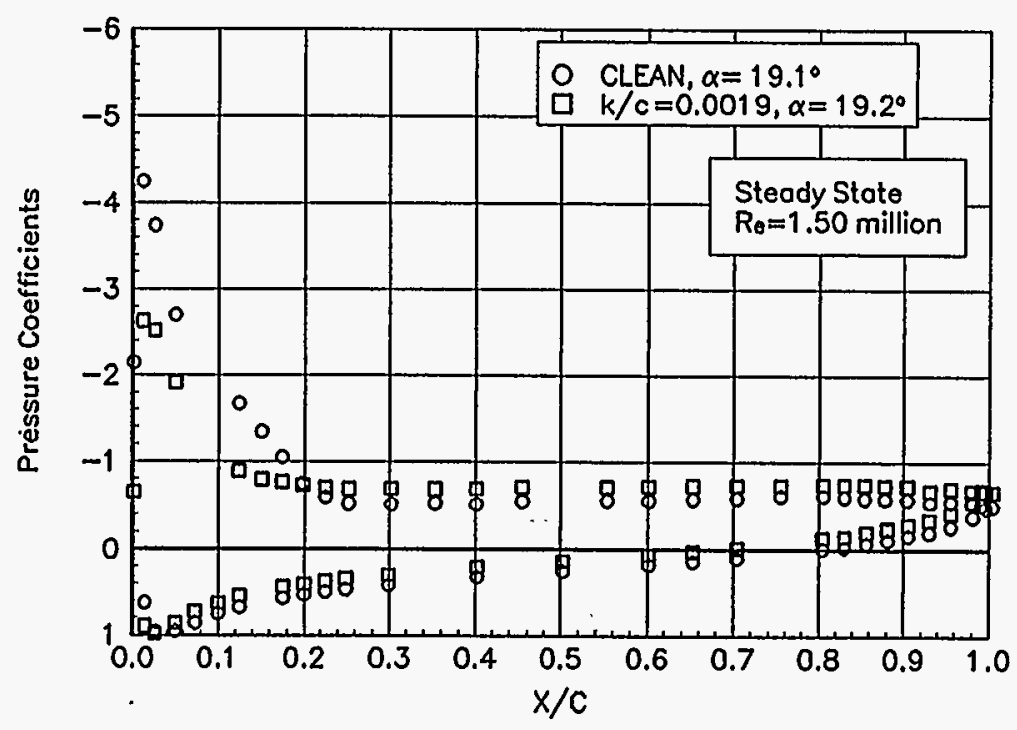

Figure B113. $a=19.2^{\circ}$ 


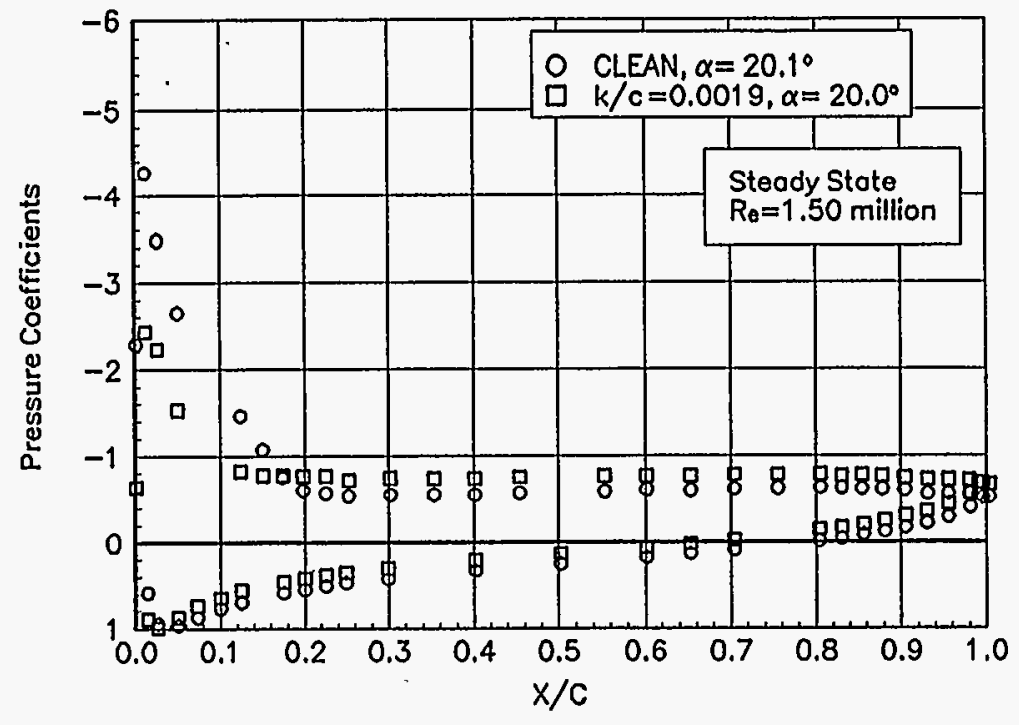

Figure B114. $a=20.0^{\circ}$

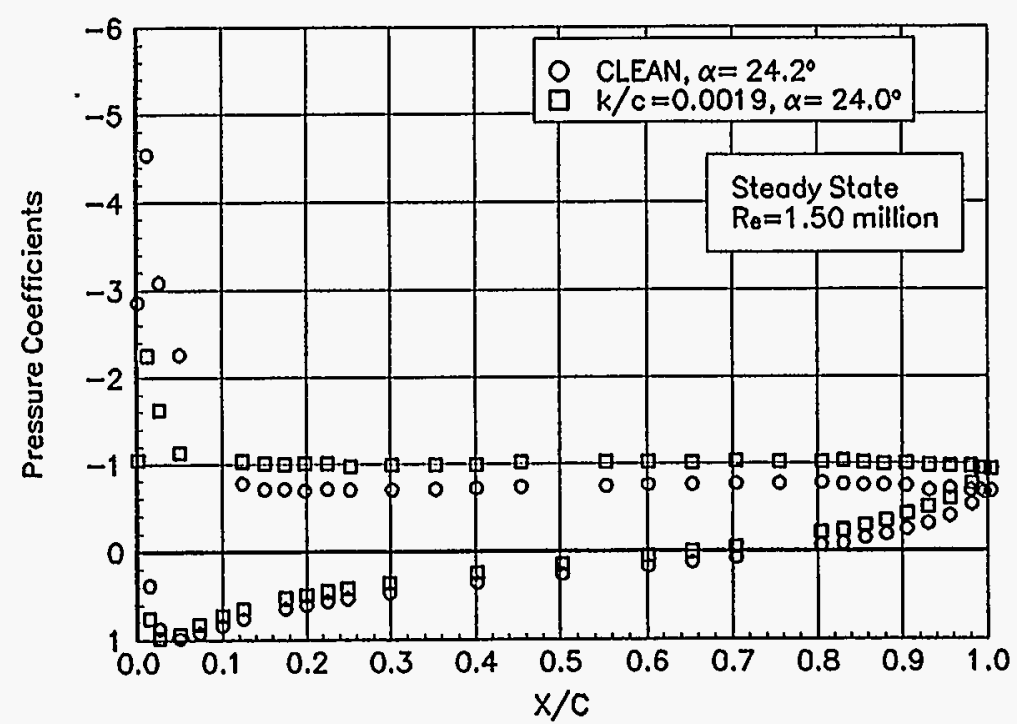

Figure B116. $a=24.0^{\circ}$

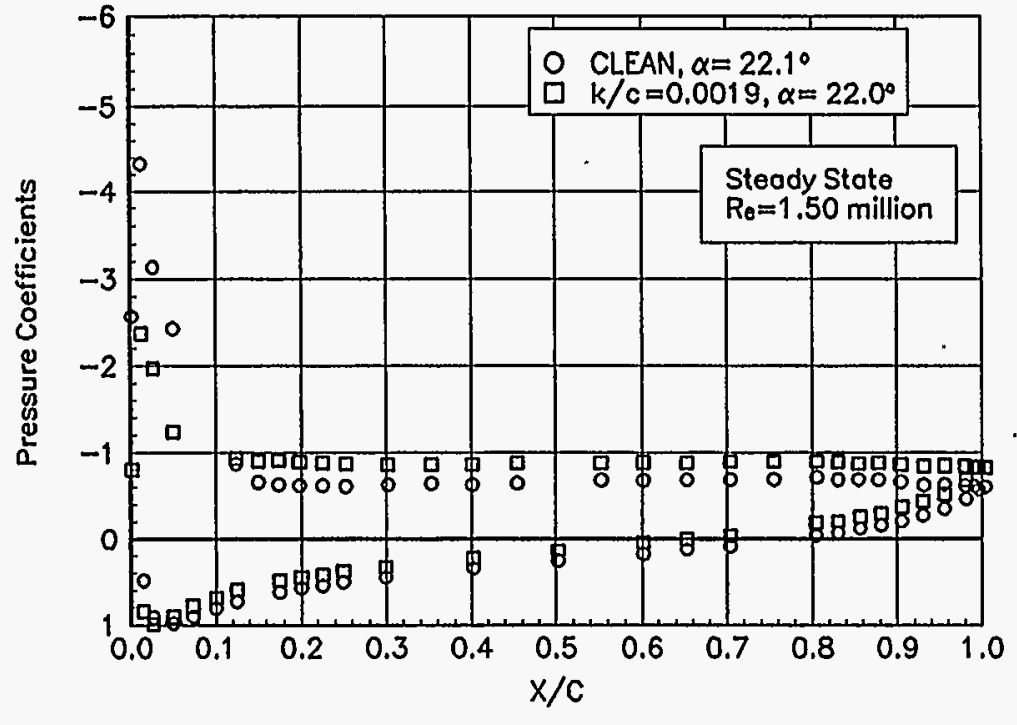

Figure B115. $a=22.0^{\circ}$ 
Appendix C: Unsteady Integrated Coefficients 


\section{List of Figures}

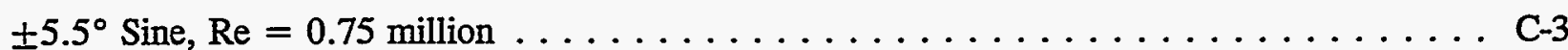

$\pm 5.5^{\circ}$ Sine, $\operatorname{Re}=1$ million $\ldots \ldots \ldots \ldots \ldots \ldots \ldots \ldots \ldots \ldots \ldots \ldots \ldots$

$\pm 5.5^{\circ}$ Sine, $\mathrm{Re}=1.25$ million $\ldots \ldots \ldots \ldots \ldots \ldots \ldots \ldots \ldots \ldots \ldots \ldots$

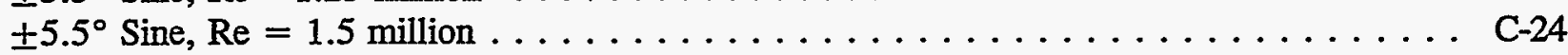

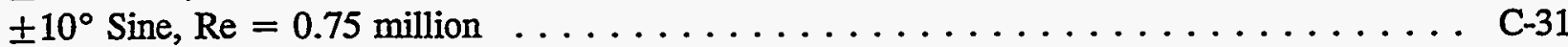

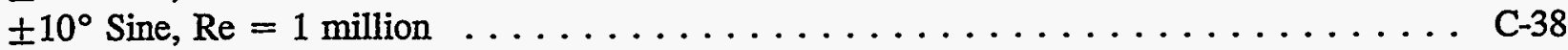

$\pm 10^{\circ}$ Sine, $\operatorname{Re}=1.25$ million $\ldots \ldots \ldots \ldots \ldots \ldots \ldots \ldots \ldots \ldots \ldots$

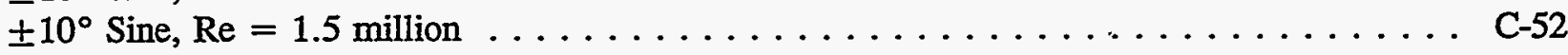




\section{Unsteady Airfoil Characteristics \\ $\pm 5.5^{\circ}$ Sine, $\operatorname{Re}=0.75$ million}




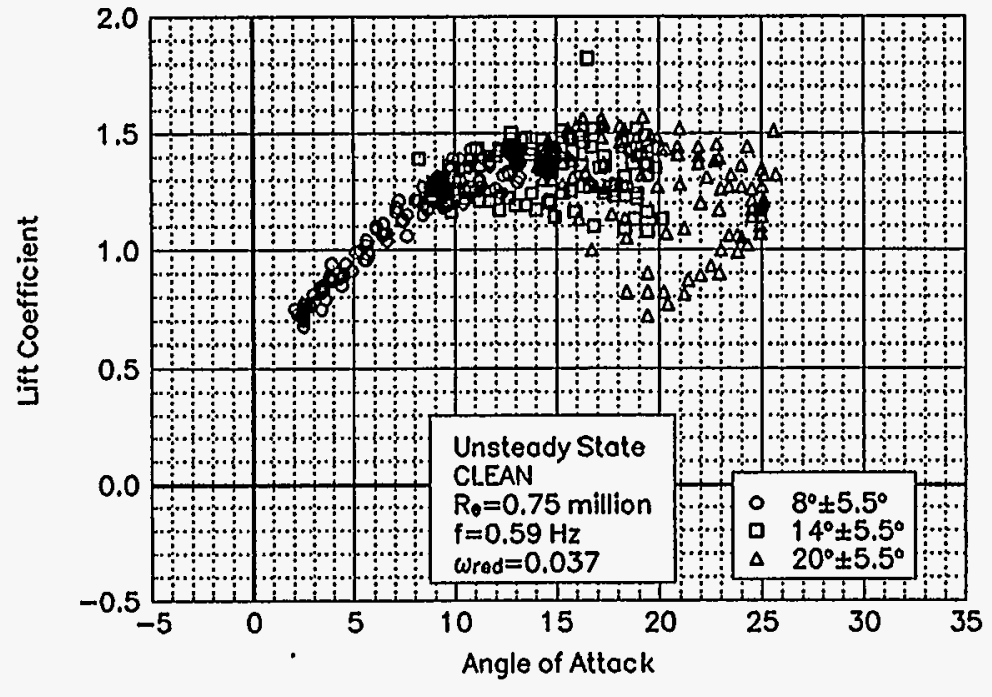

Figure C1. Lift coefficient vs $a$.

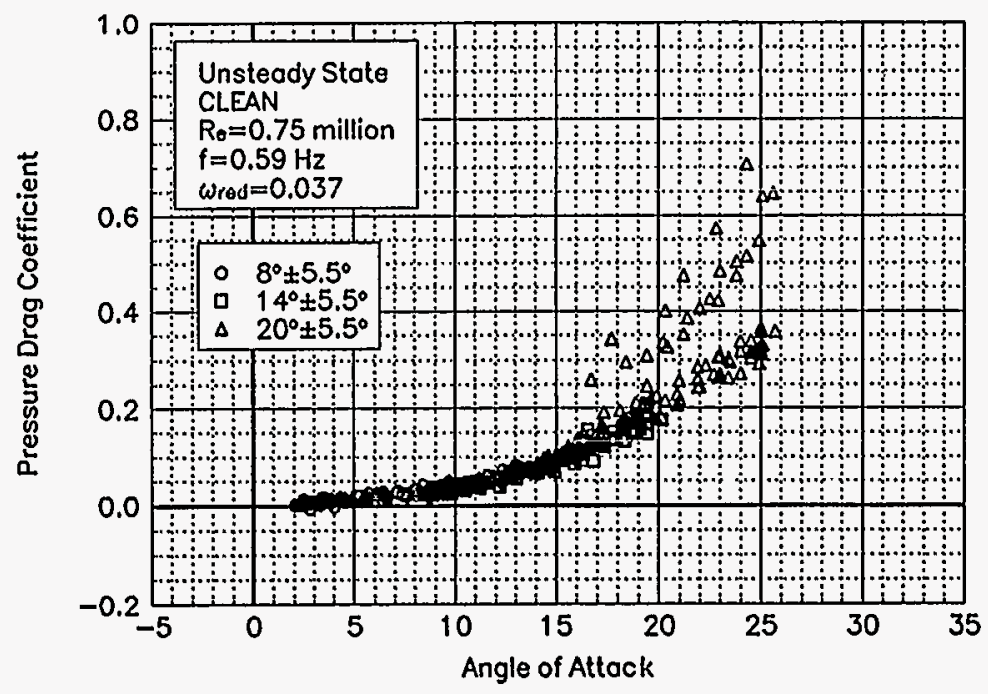

Figure C2. Pressure drag coefficient vs $a$.

\section{NACA 4415 Clean \\ $\mathrm{Re}=\mathbf{0 . 7 5}$ million \\ $\omega_{\text {reduced }}=0.037$}

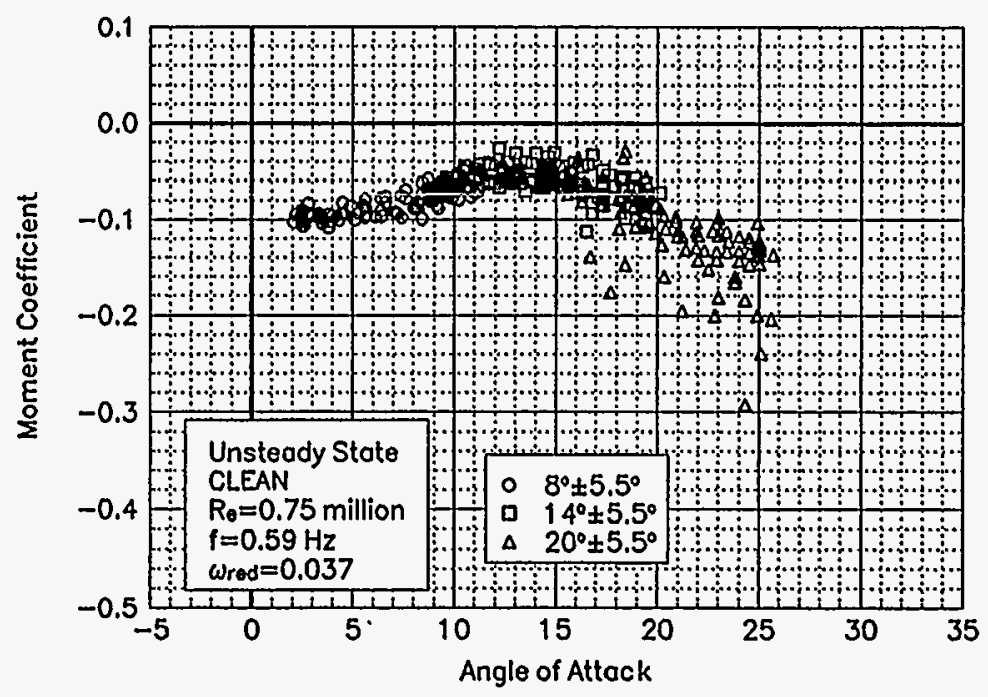

Figure C3. Moment coefficient vs $\alpha$. 


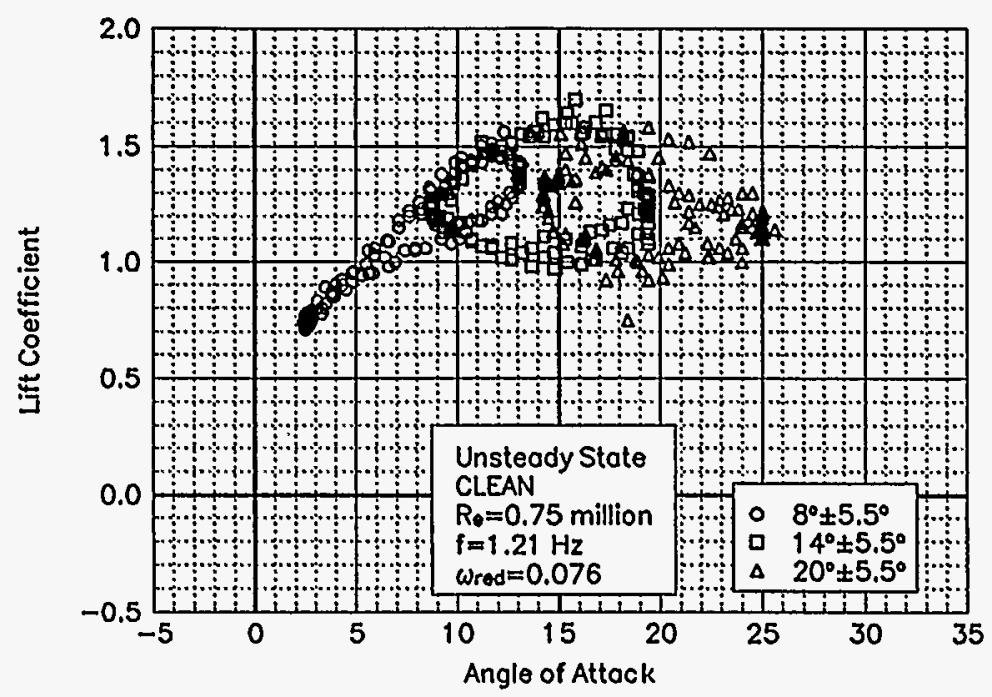

Figure C4. Lift coefficient vs $a$.

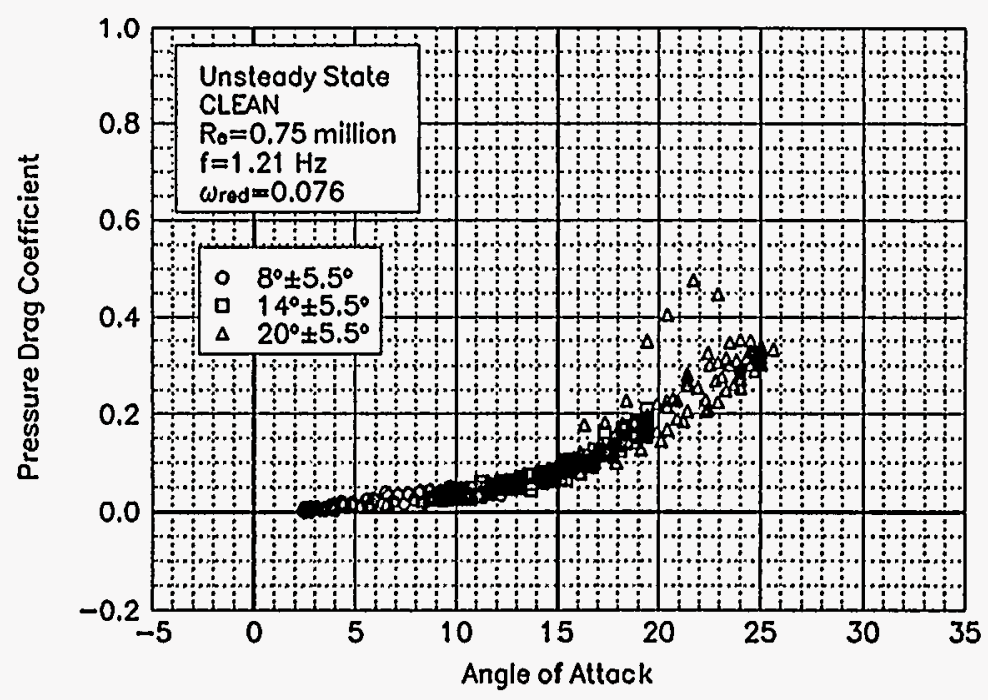

Figure C5. Pressure drag coefficient vs $a$.

\section{NACA 4415 \\ Clean \\ $\mathrm{Re}=\mathbf{0 . 7 5}$ million \\ $\omega_{\text {reduced }}=0.076$}

Figure C6. Moment coefficient vs $a$. 

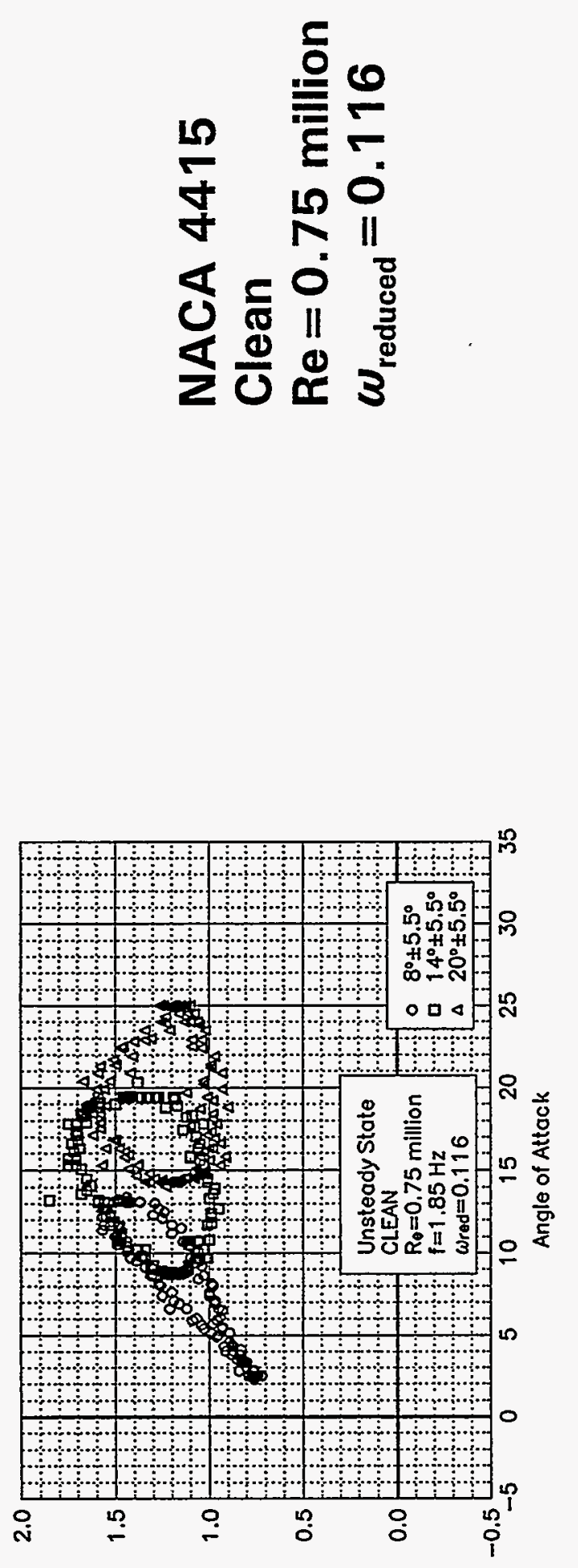

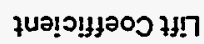

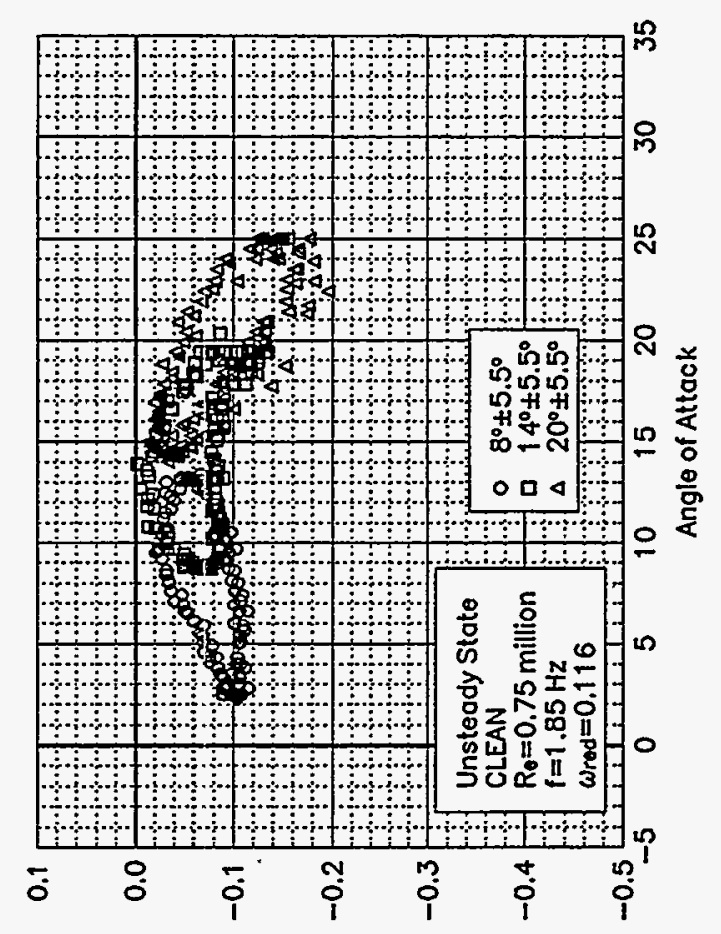

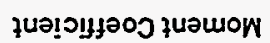

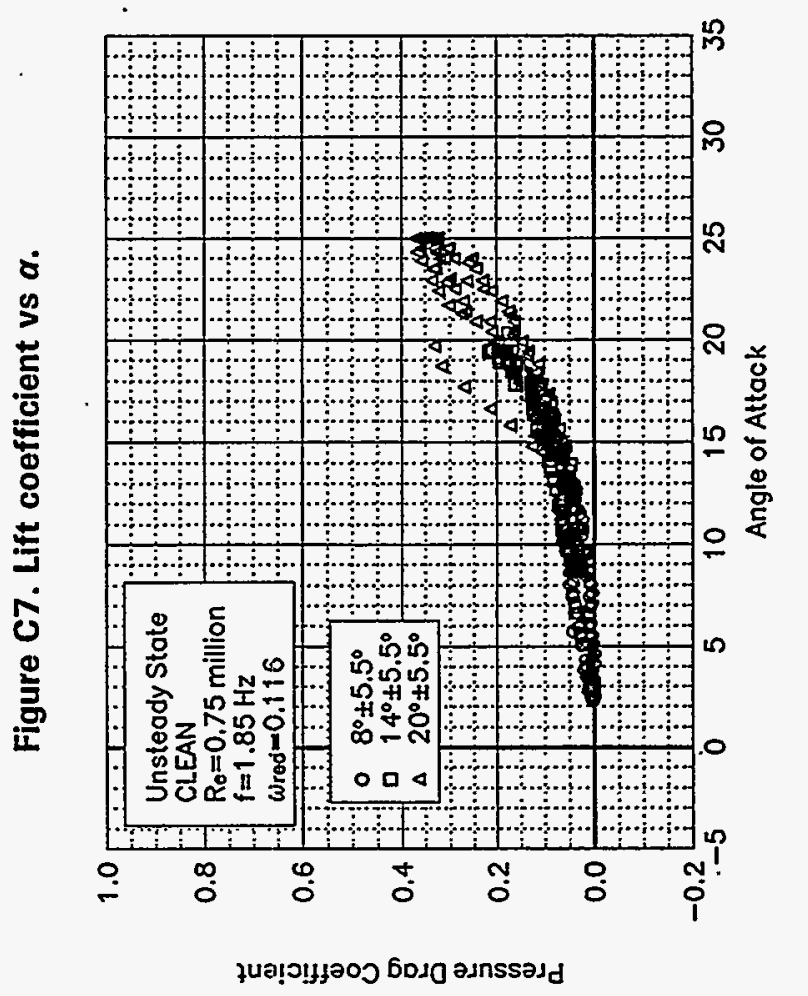

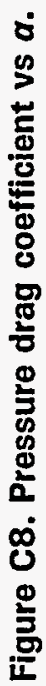

¿ 


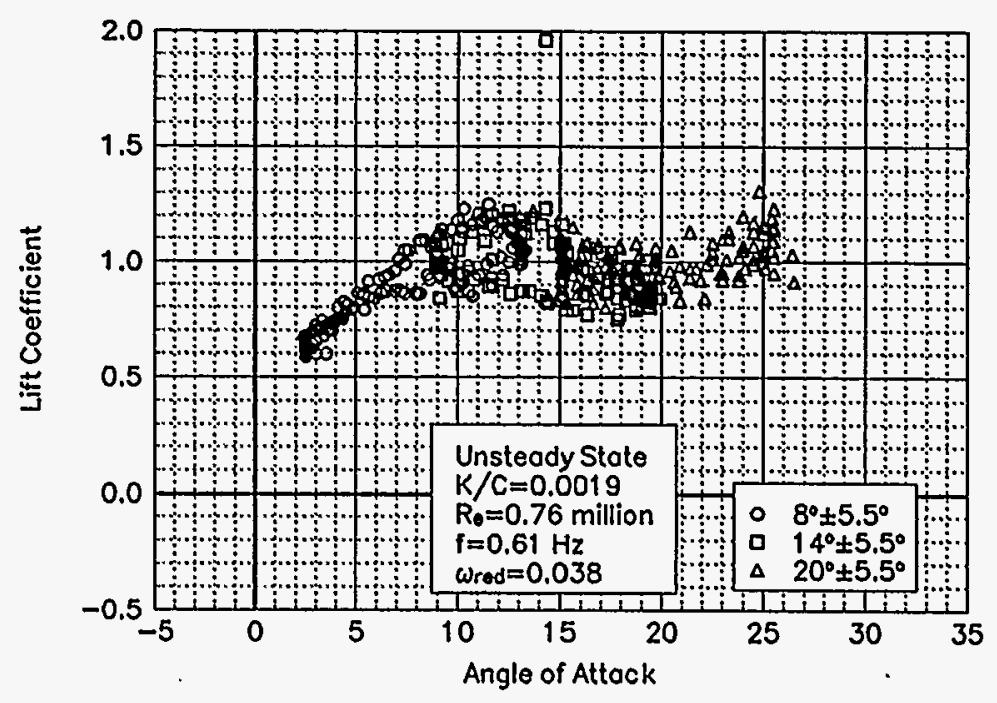

Figure C10. Lift coefficient vs $\alpha$.

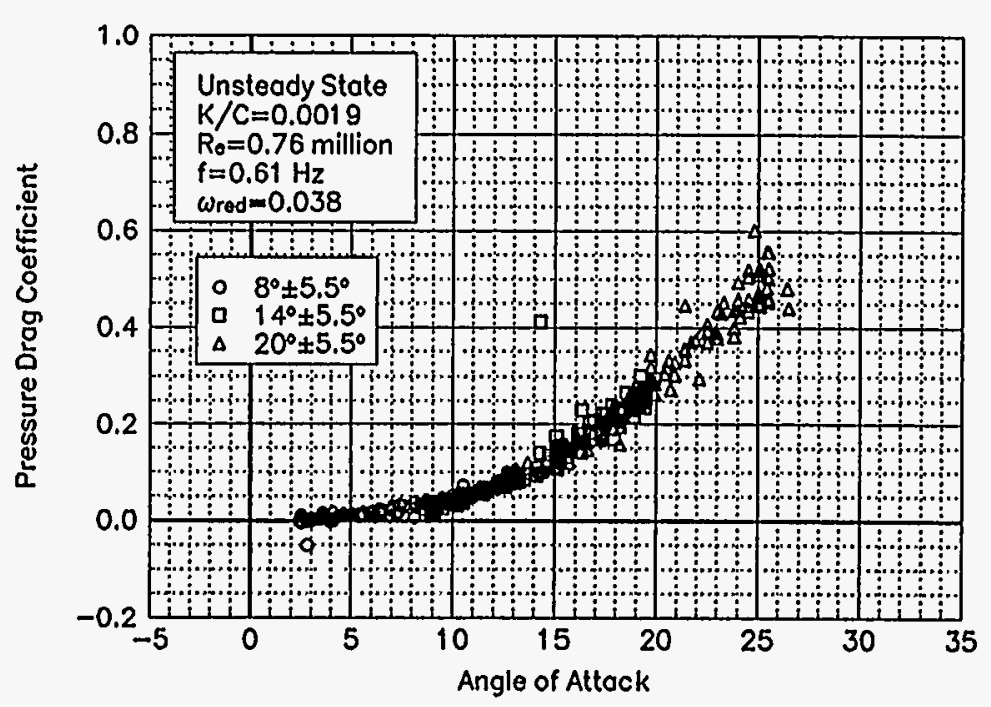

Figure C11. Pressure drag coefficient vs $a$.

\section{NACA 4415 LEGR \\ $\mathbf{R e}=\mathbf{0 . 7 6}$ million \\ $\omega_{\text {reduced }}=0.038$}

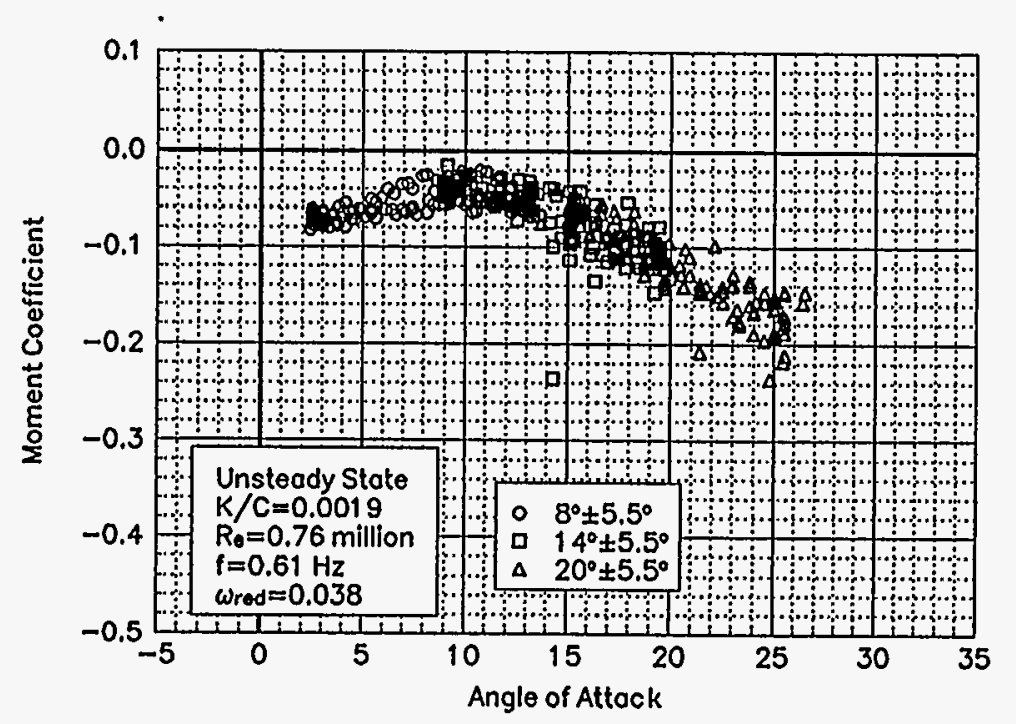

Figure C12. Moment coefficient vs $a$. 

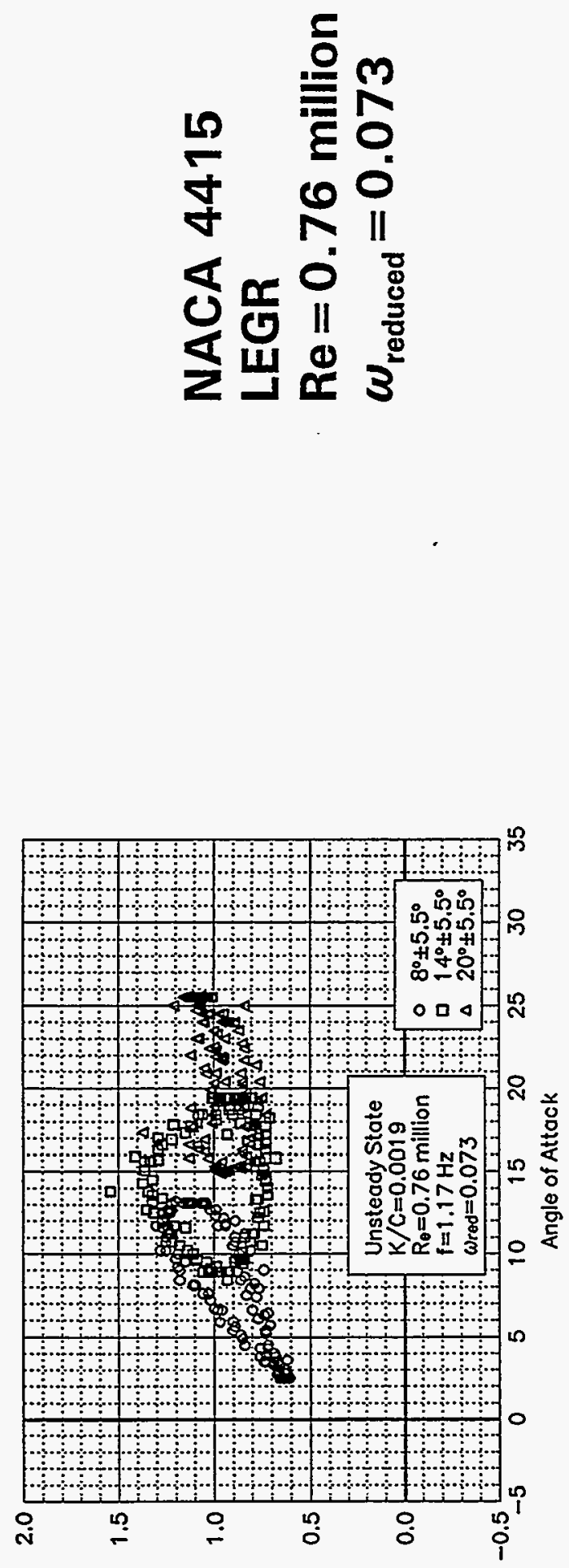

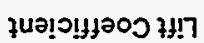

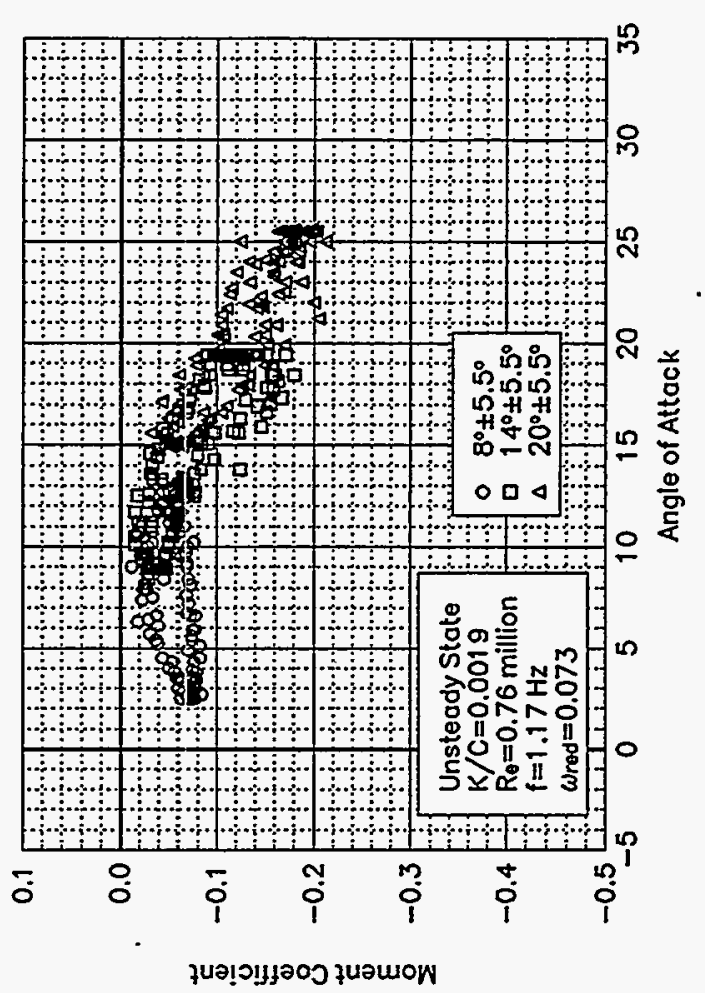

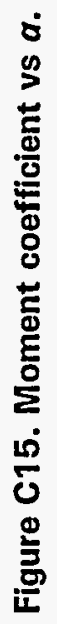

8

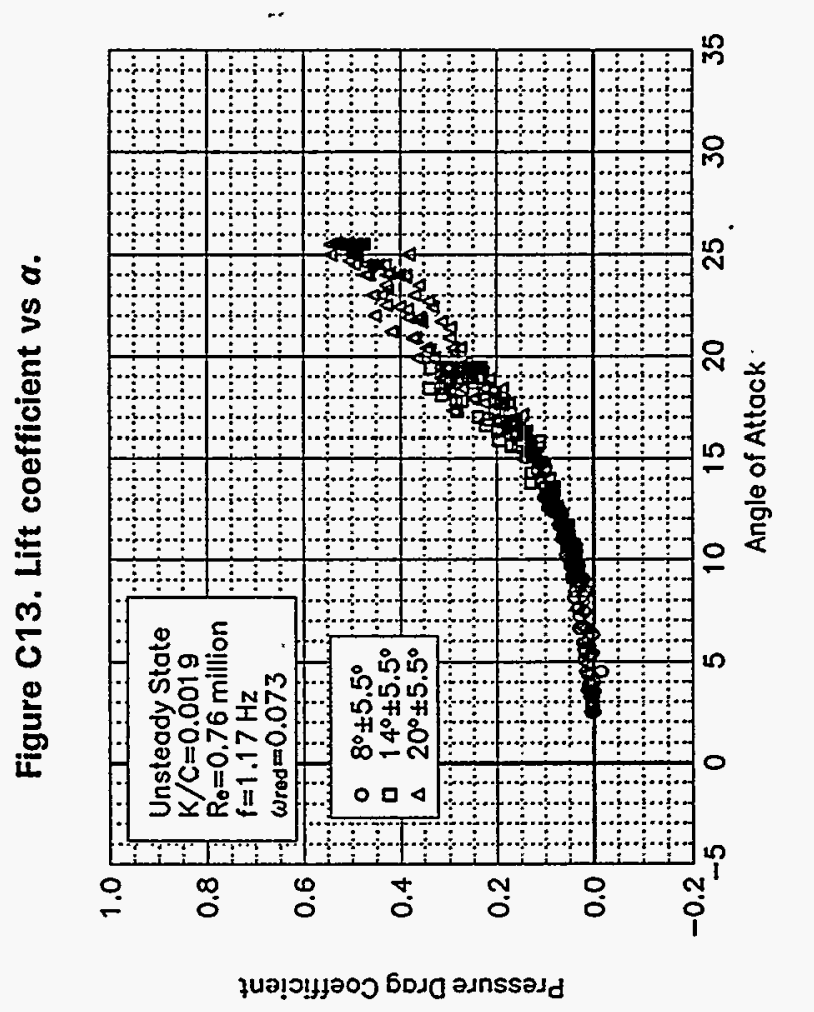

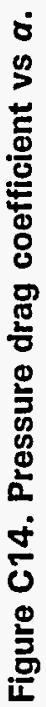



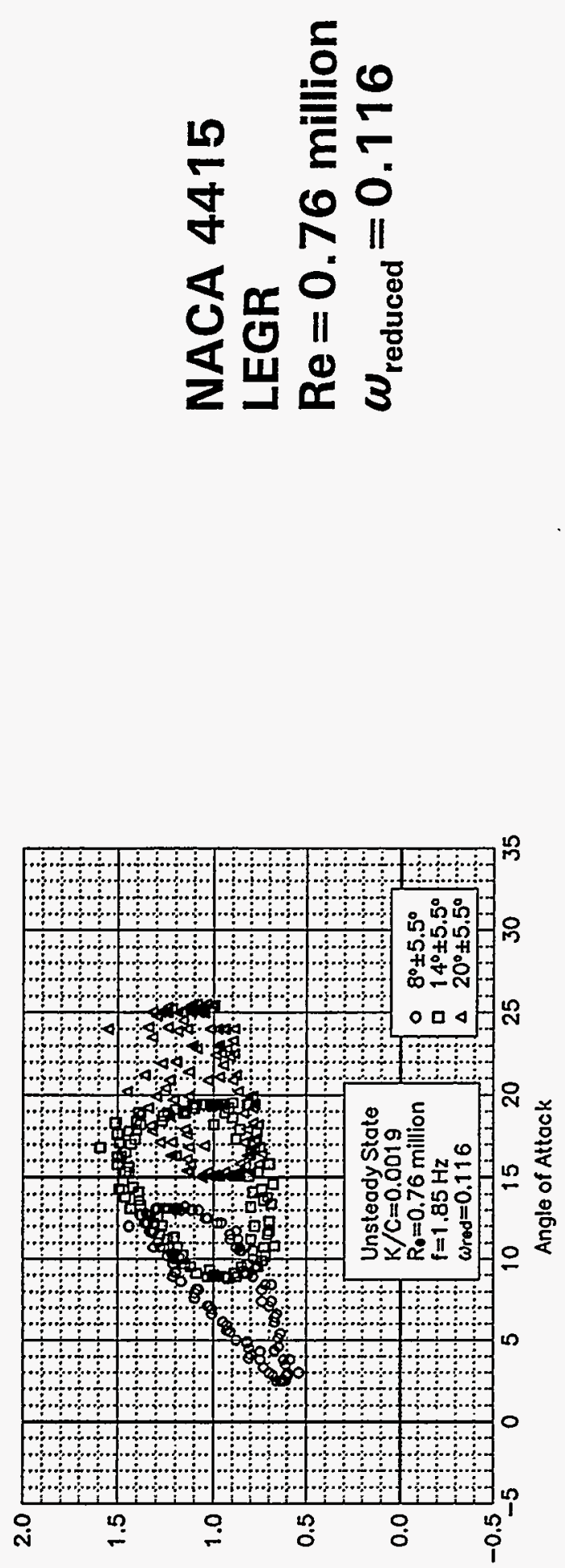

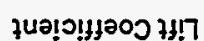

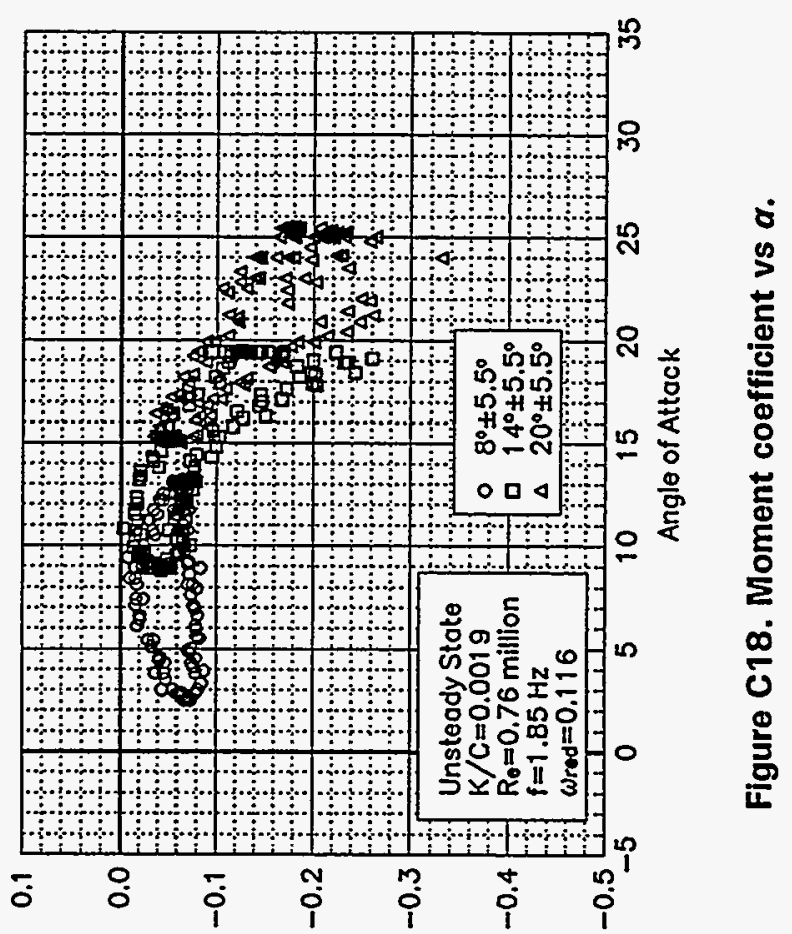

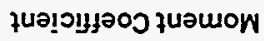

i

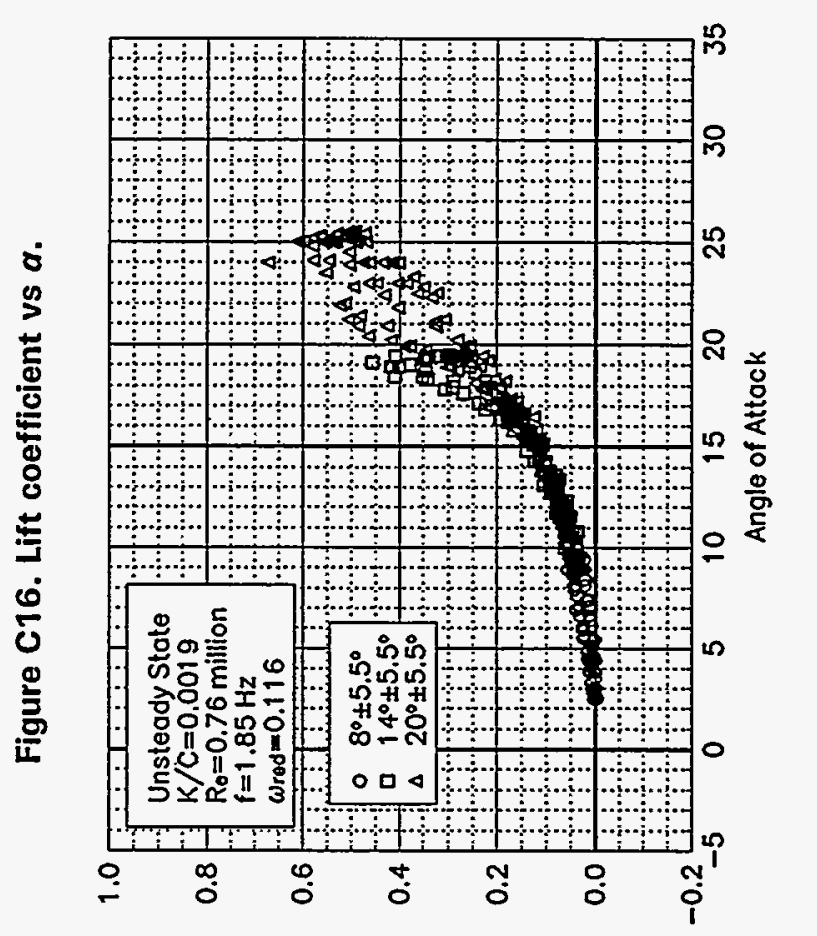

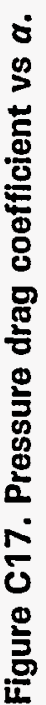

fua!วนyว 


\section{Unsteady Airfoil Characteristics}

$\pm 5.5^{\circ}$ Sine, $\operatorname{Re}=1$ million 

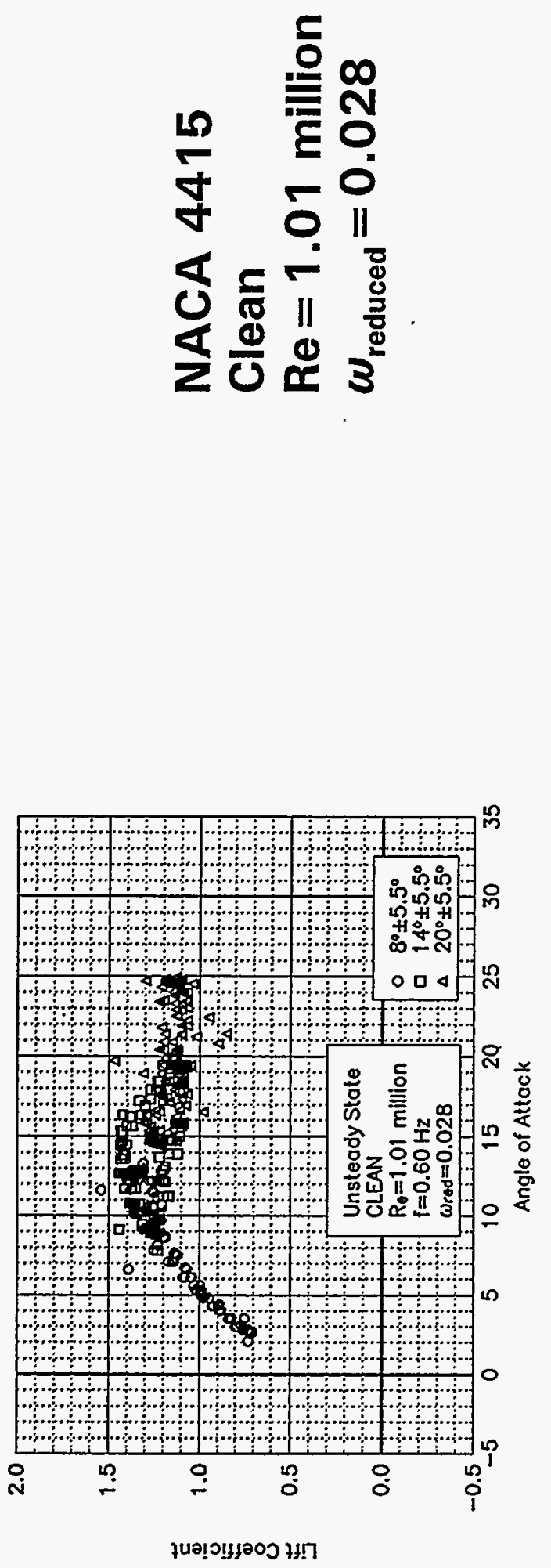

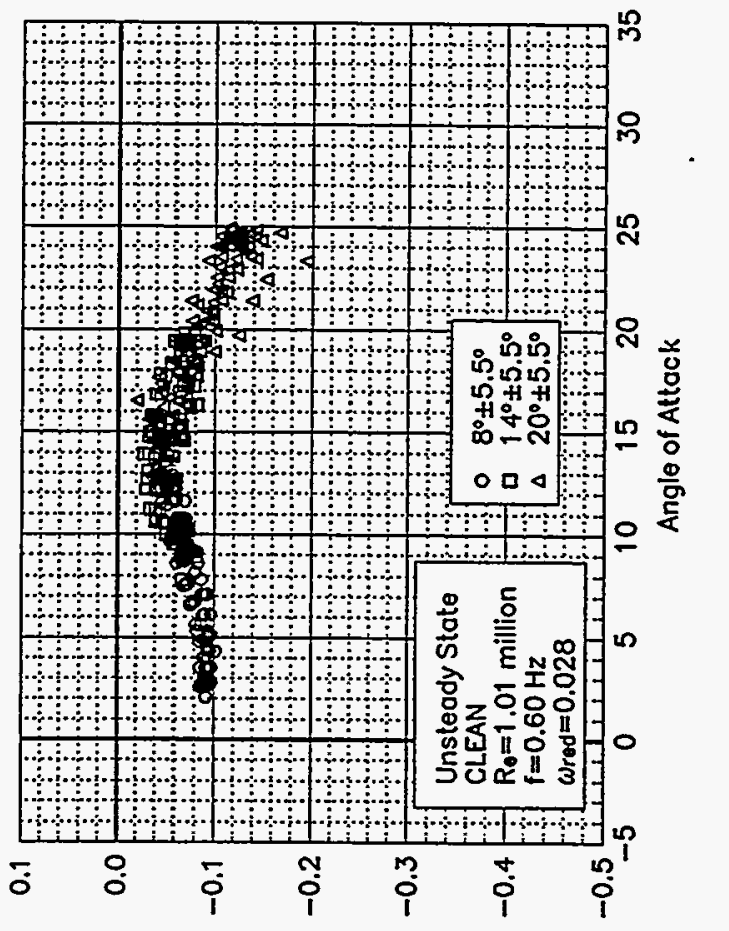

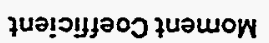

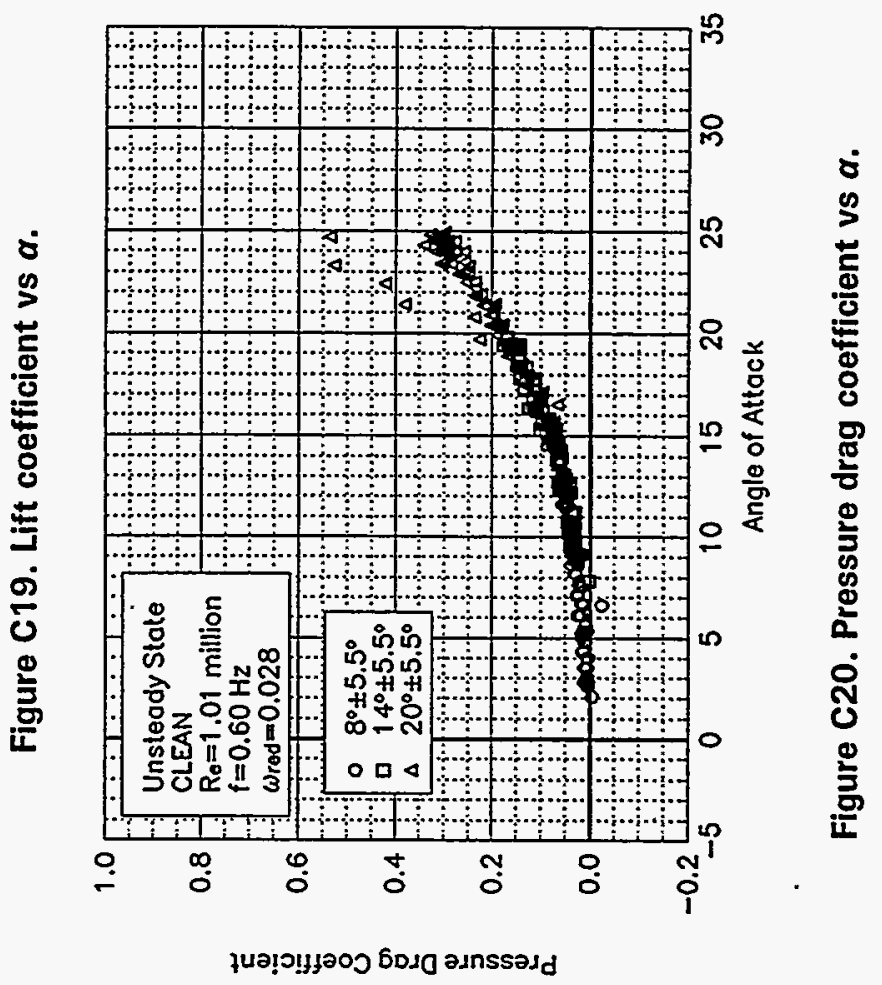



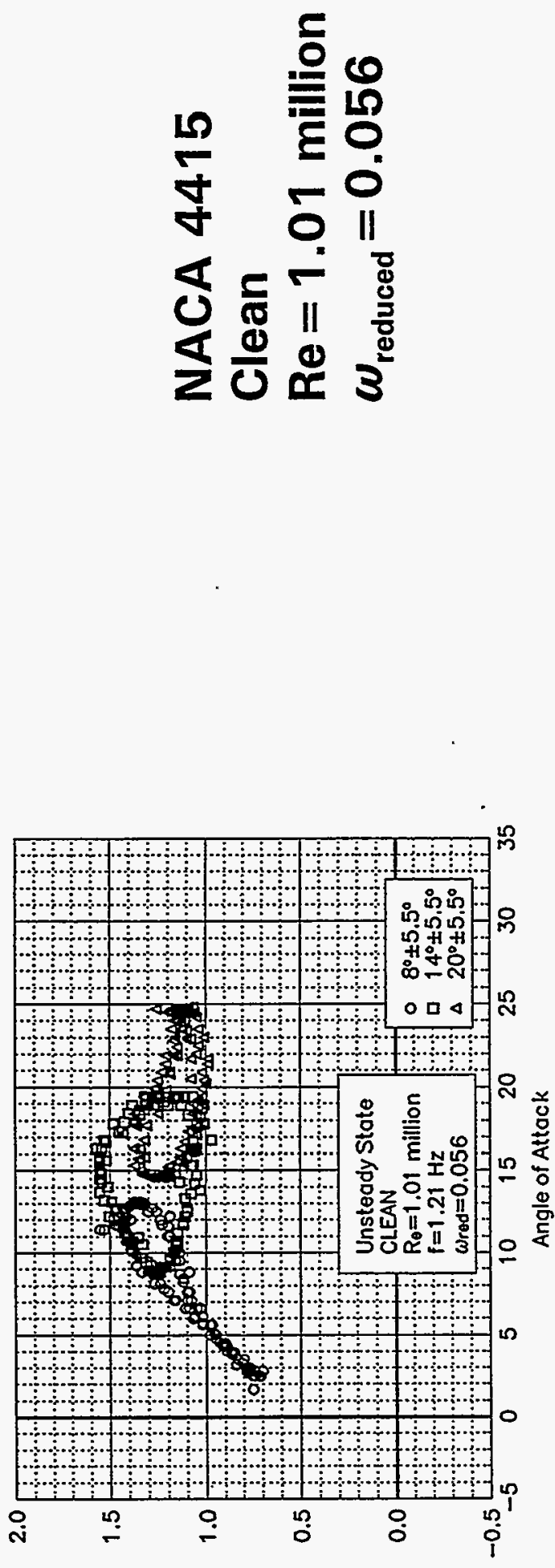

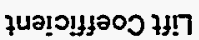

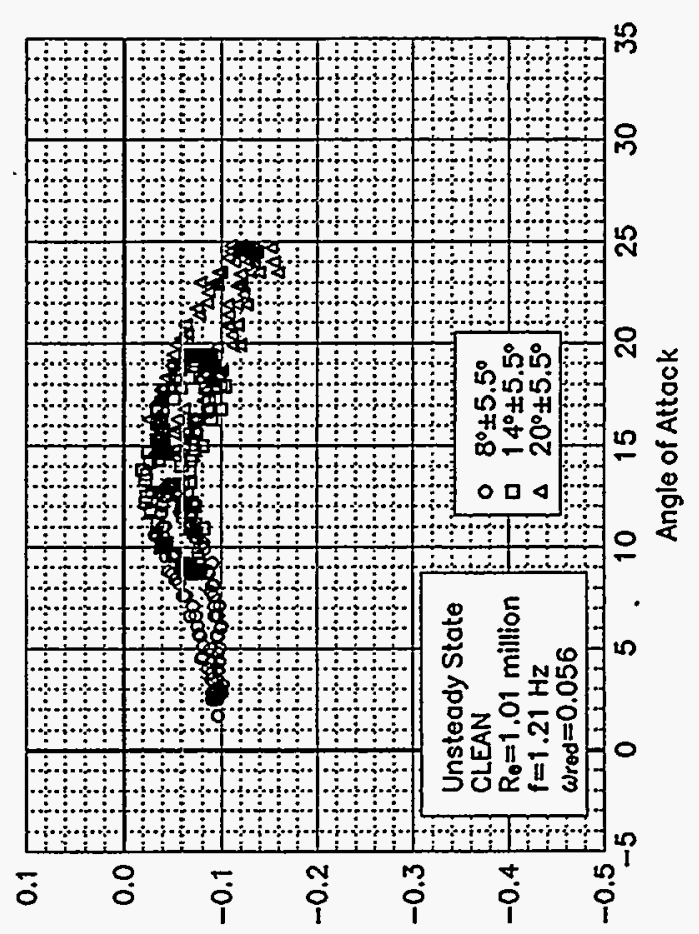

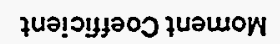

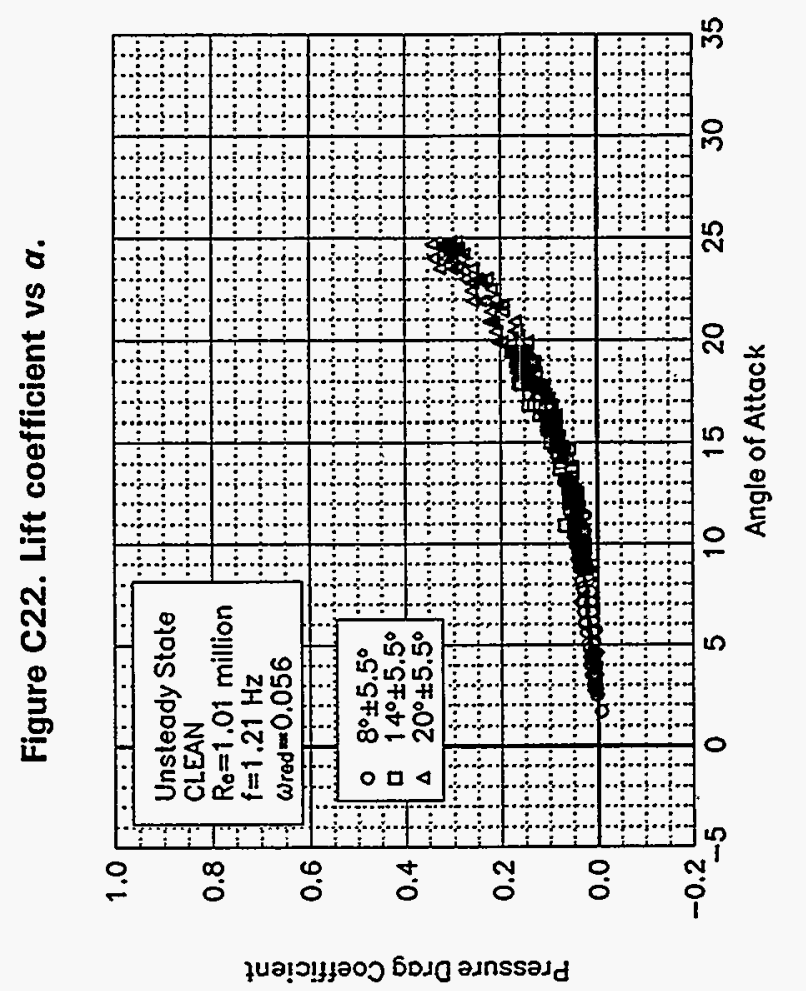

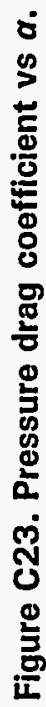



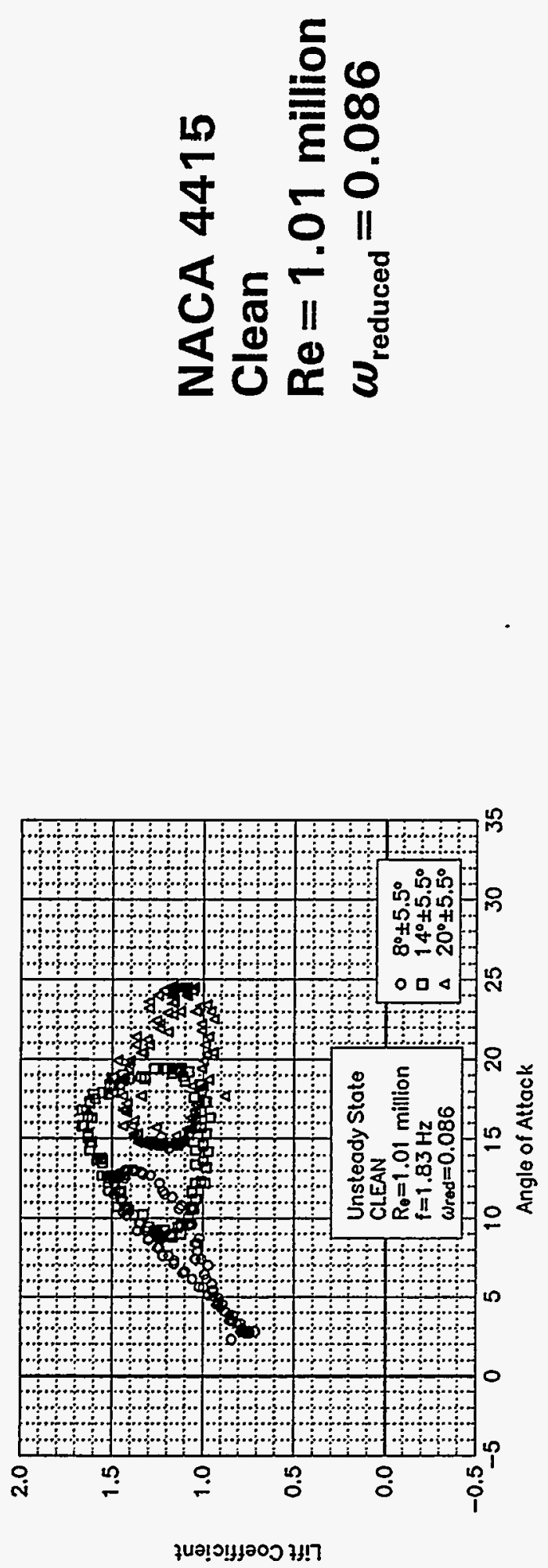

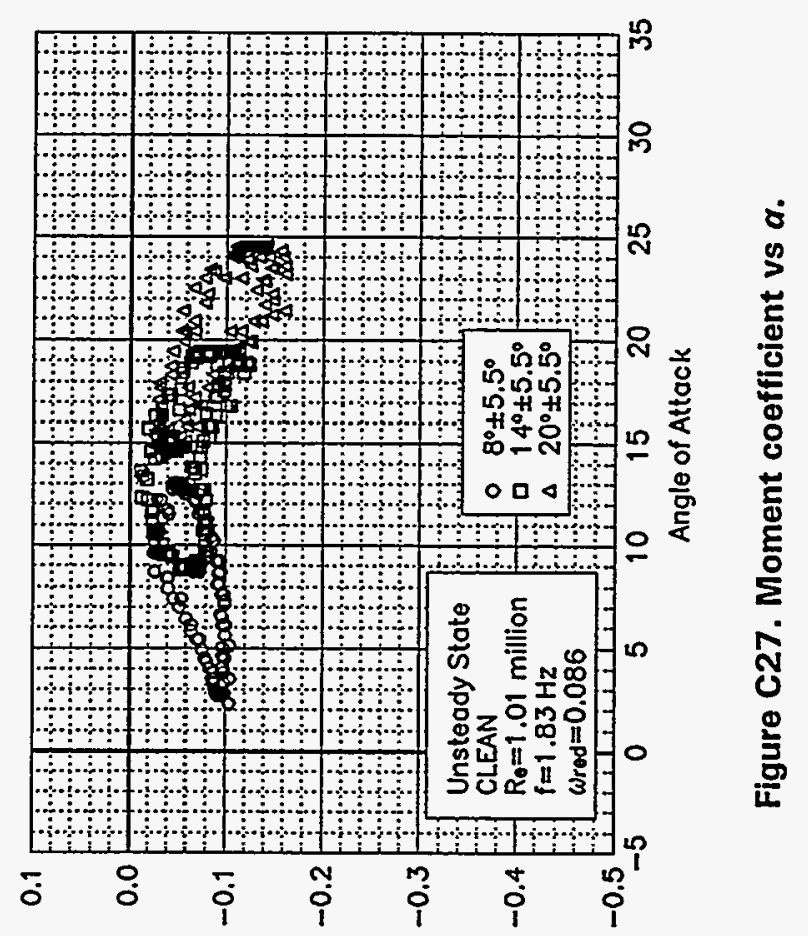

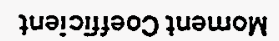

$\stackrel{m}{3}$

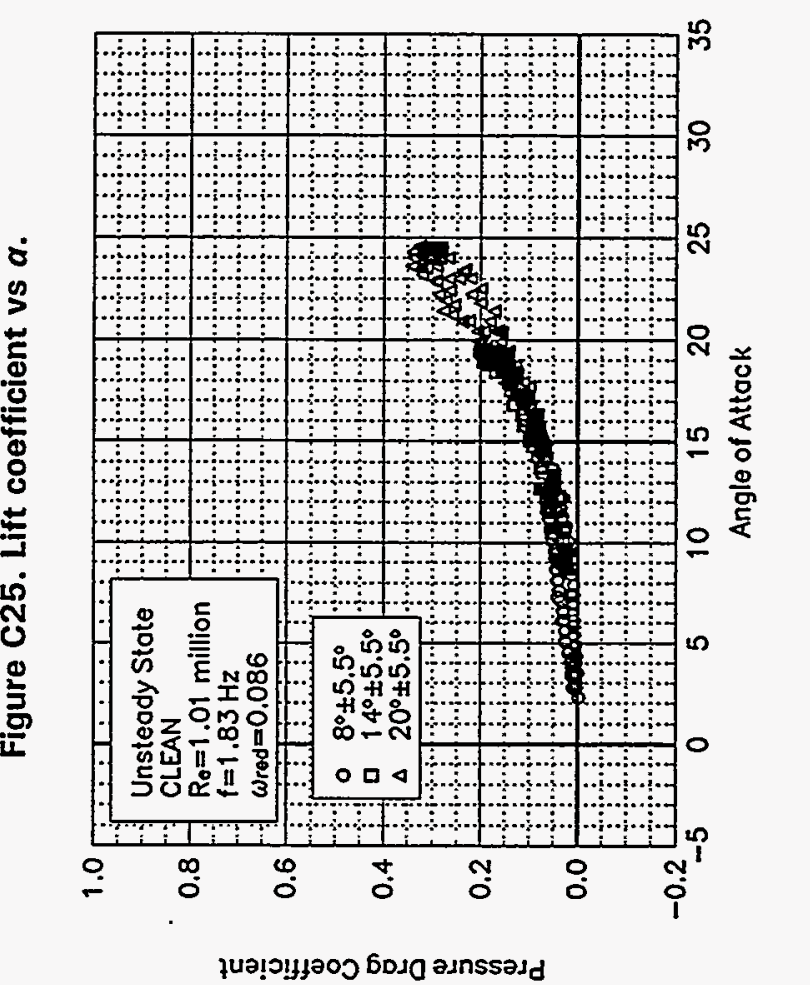

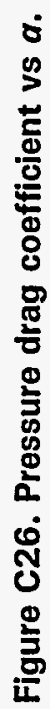



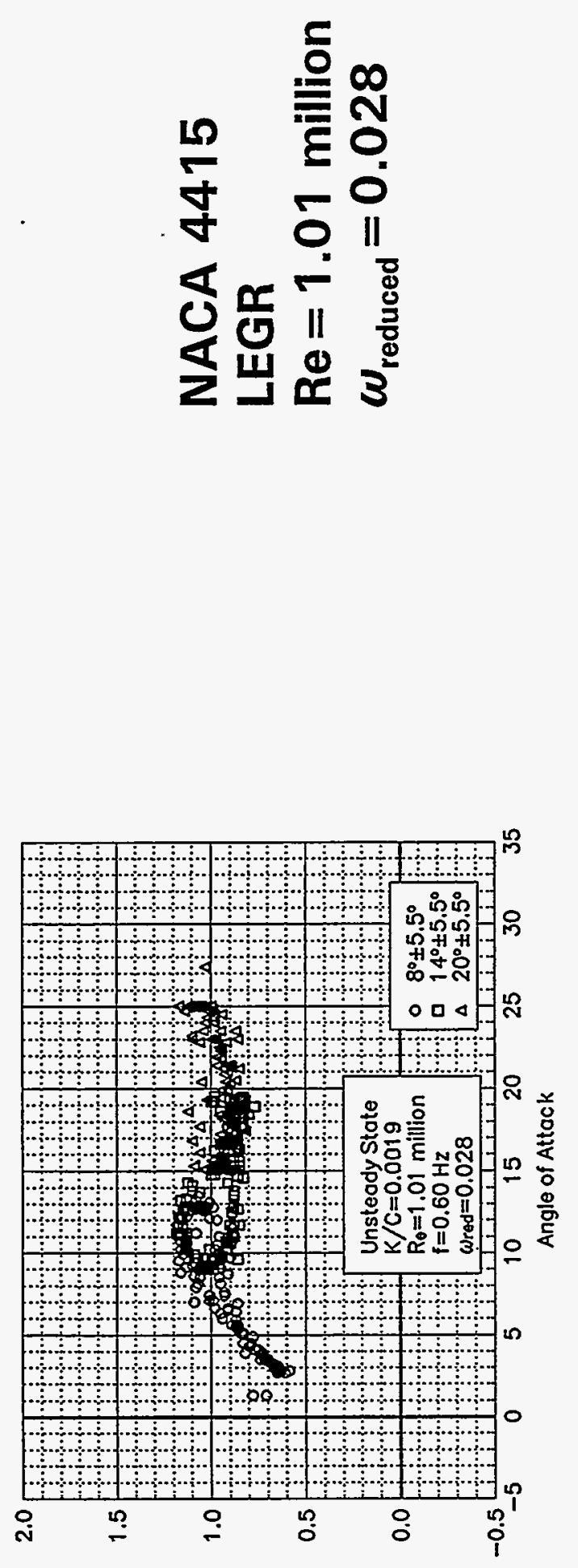

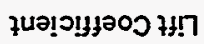

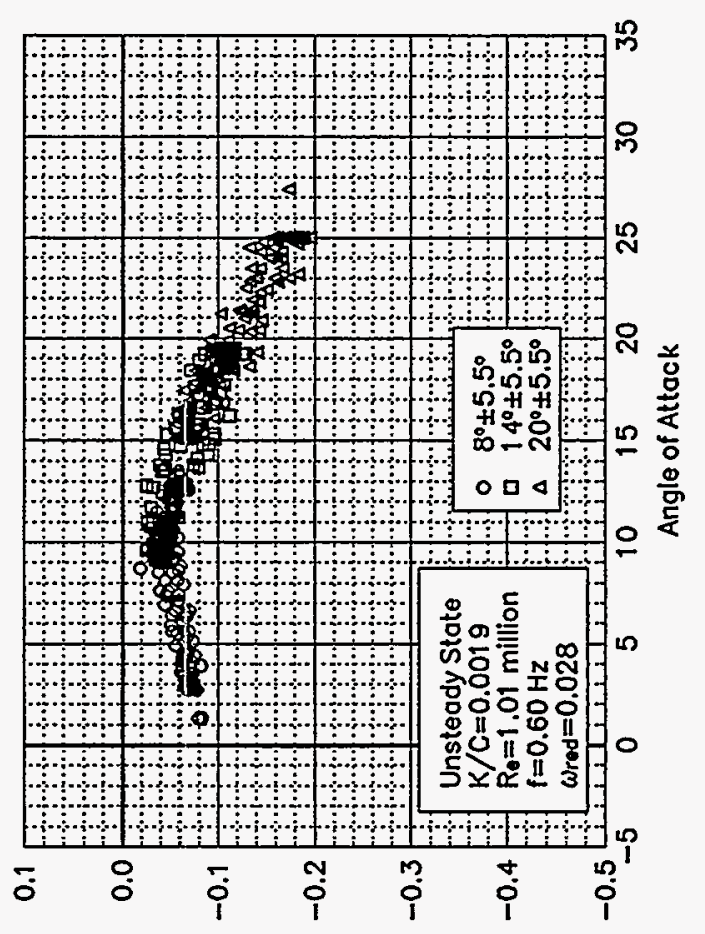

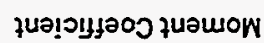

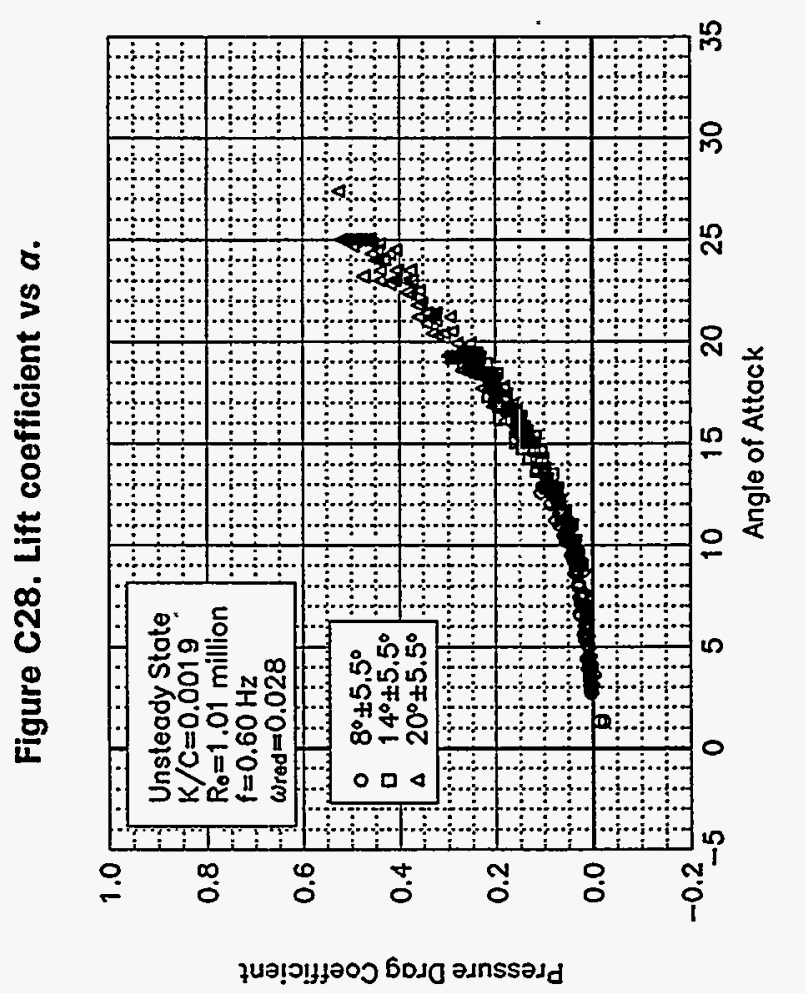

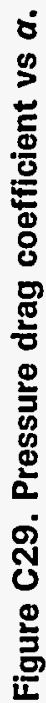




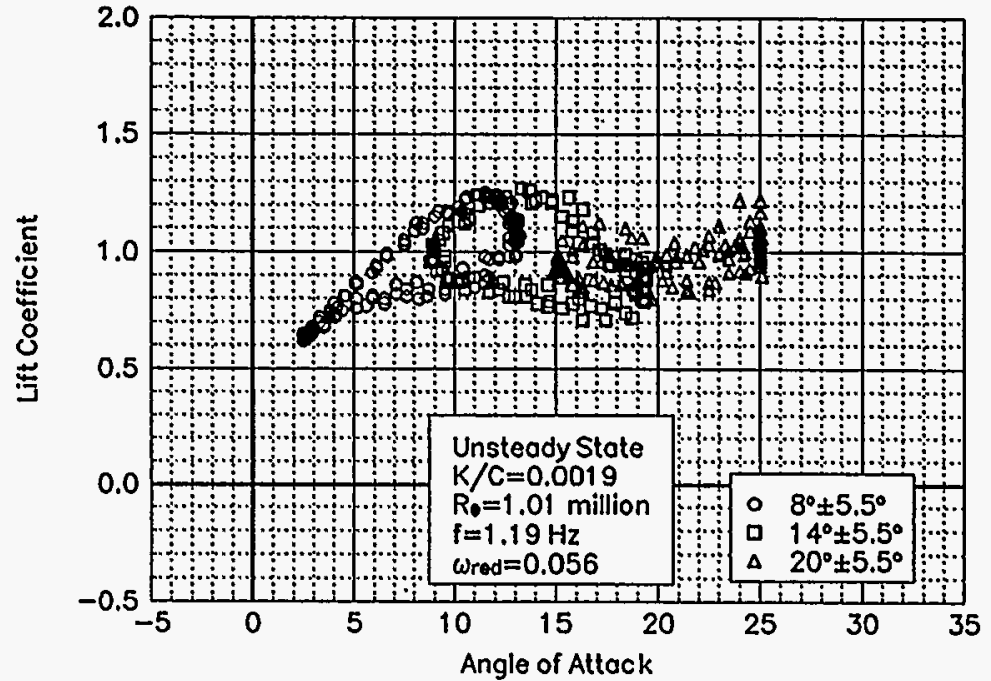

Figure C31. Lift coefficient vs $a$.

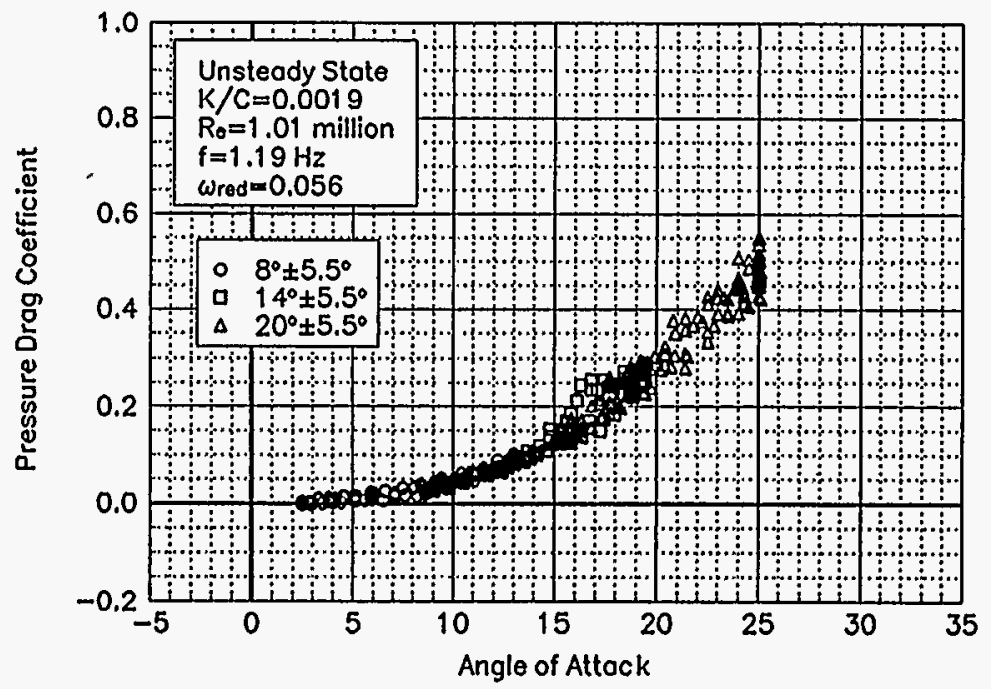

Figure C32. Pressure drag coefficient vs $a$.

\section{NACA 4415 LEGR \\ $\operatorname{Re}=1.01$ million \\ $\omega_{\text {reduced }}=0.056$}

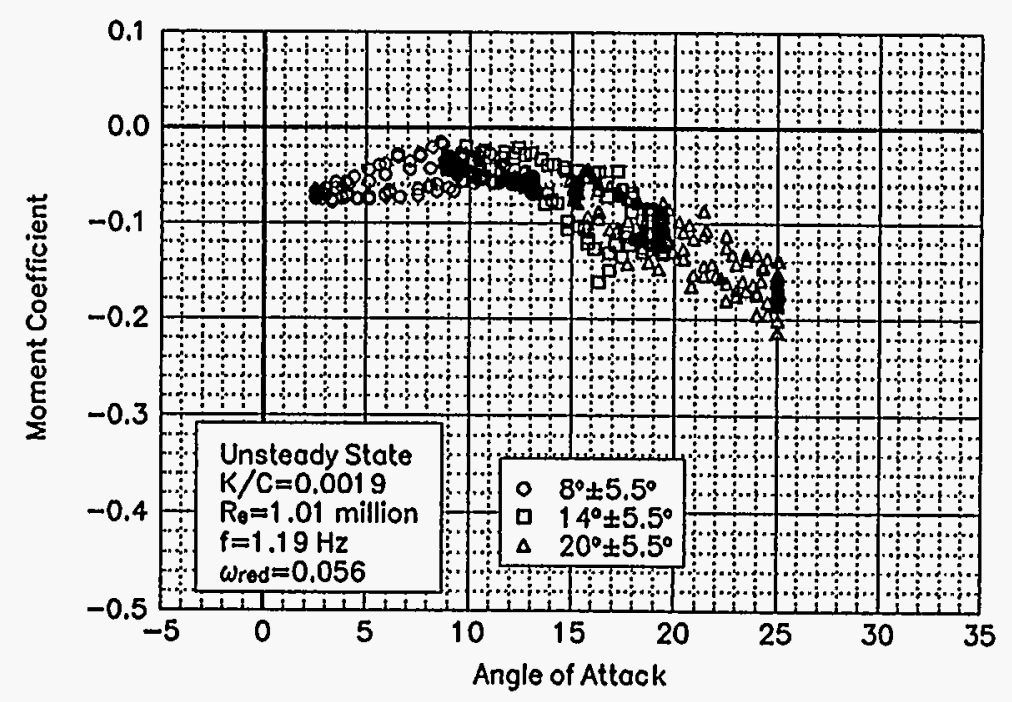

Figure C33. Moment coefficient vs a. 

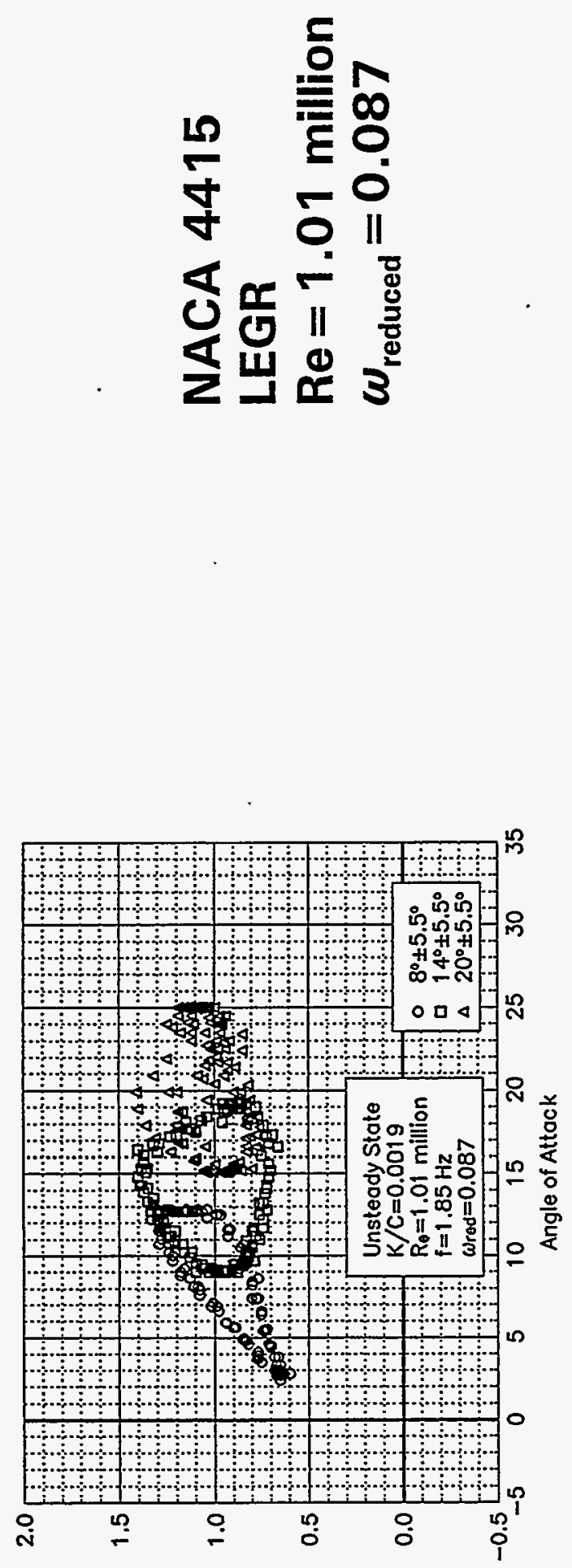

ในข!จ!มรวัว ใน!า

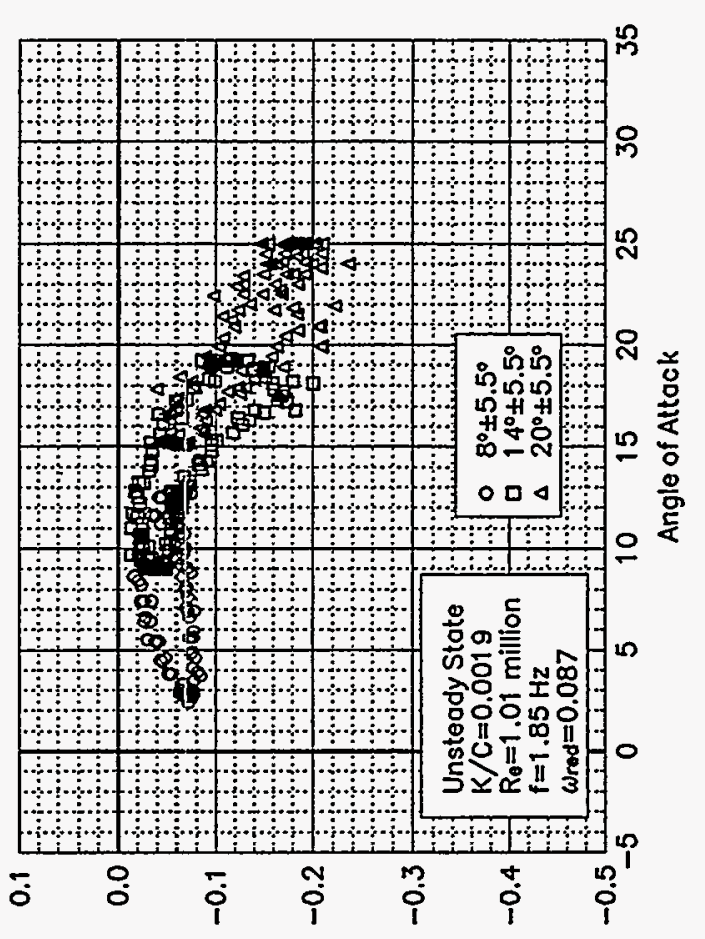

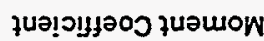

$\stackrel{\circ}{\circ}$

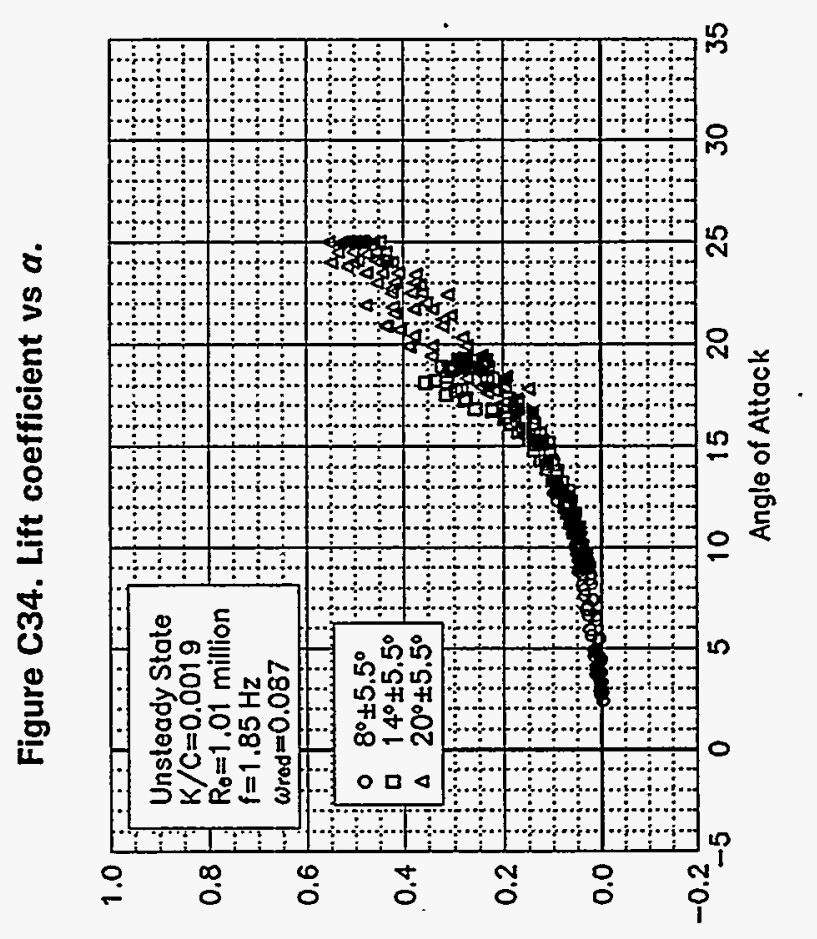

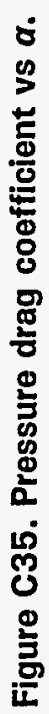




\section{Unsteady Airfoil Characteristics \\ $\pm 5.5^{\circ}$ Sine, $R e=1.25$ million}




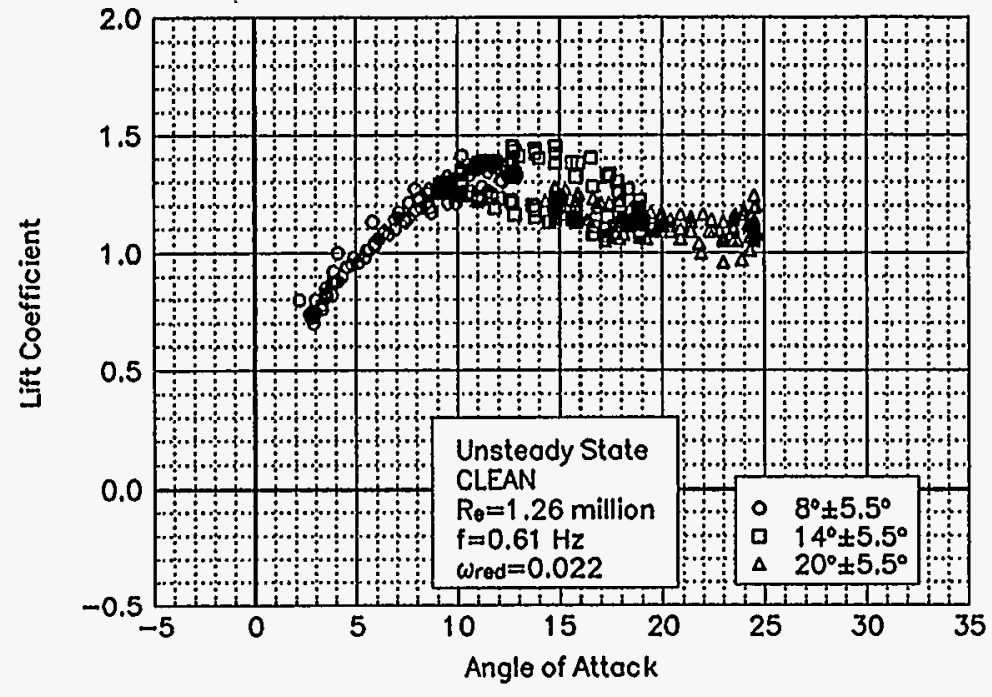

Figure C37. Lift coefficient vs $\alpha$.

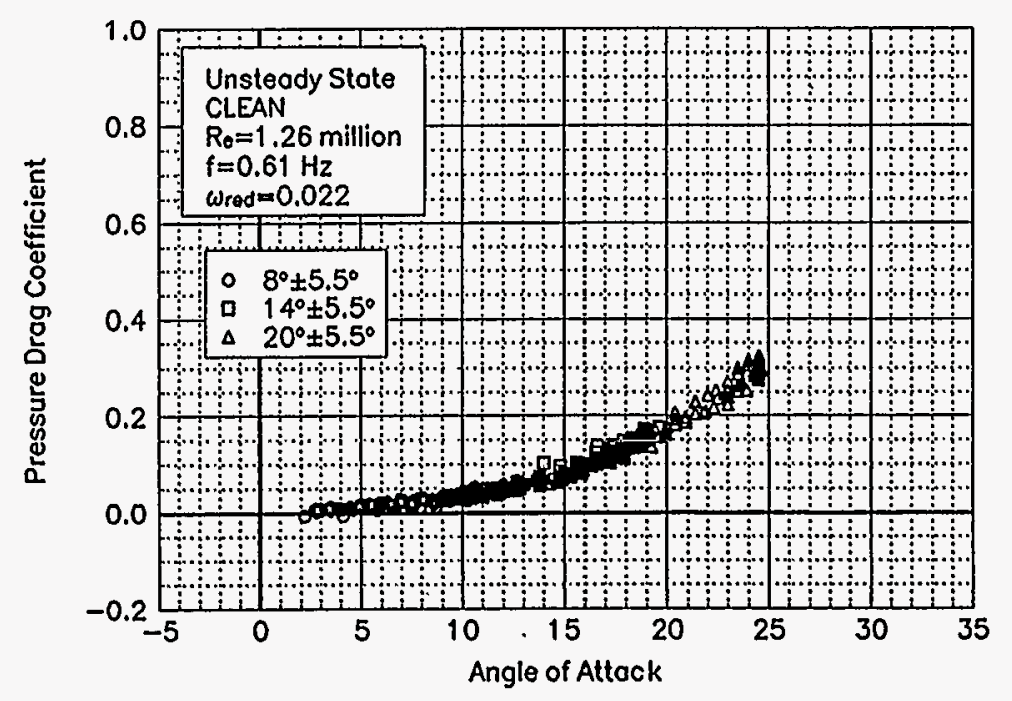

Figure C38. Pressure drag coefficient vs a.

\section{NACA 4415 \\ Clean \\ $\mathrm{Re}=1.26$ million \\ $\omega_{\text {reduced }}=0.022$}

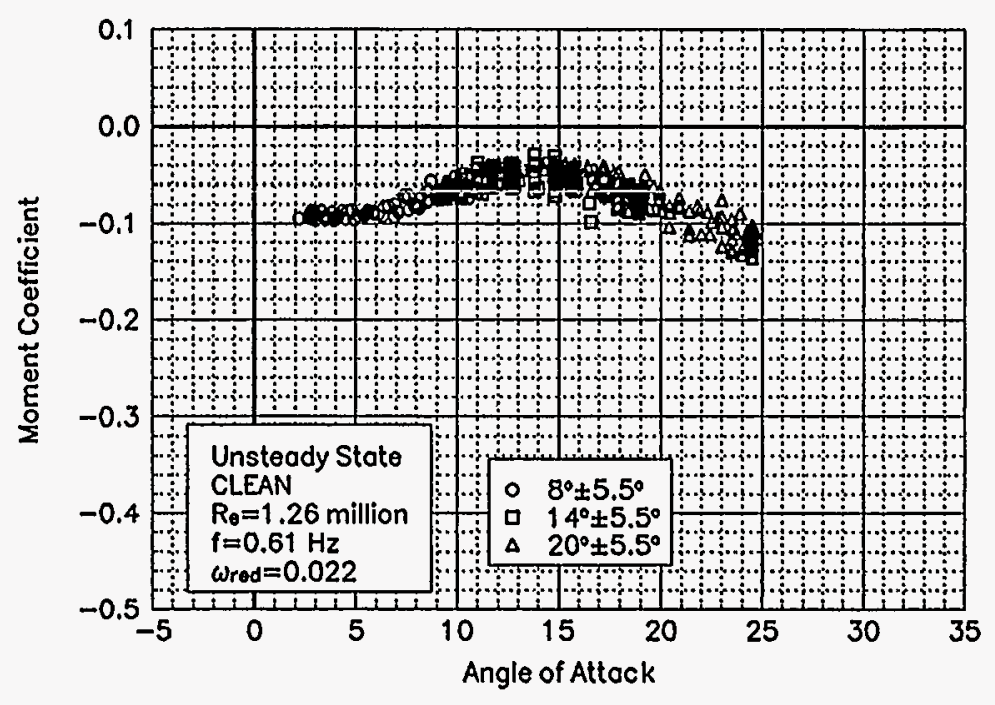

Figure C39. Moment coefficient vs $\alpha$. 

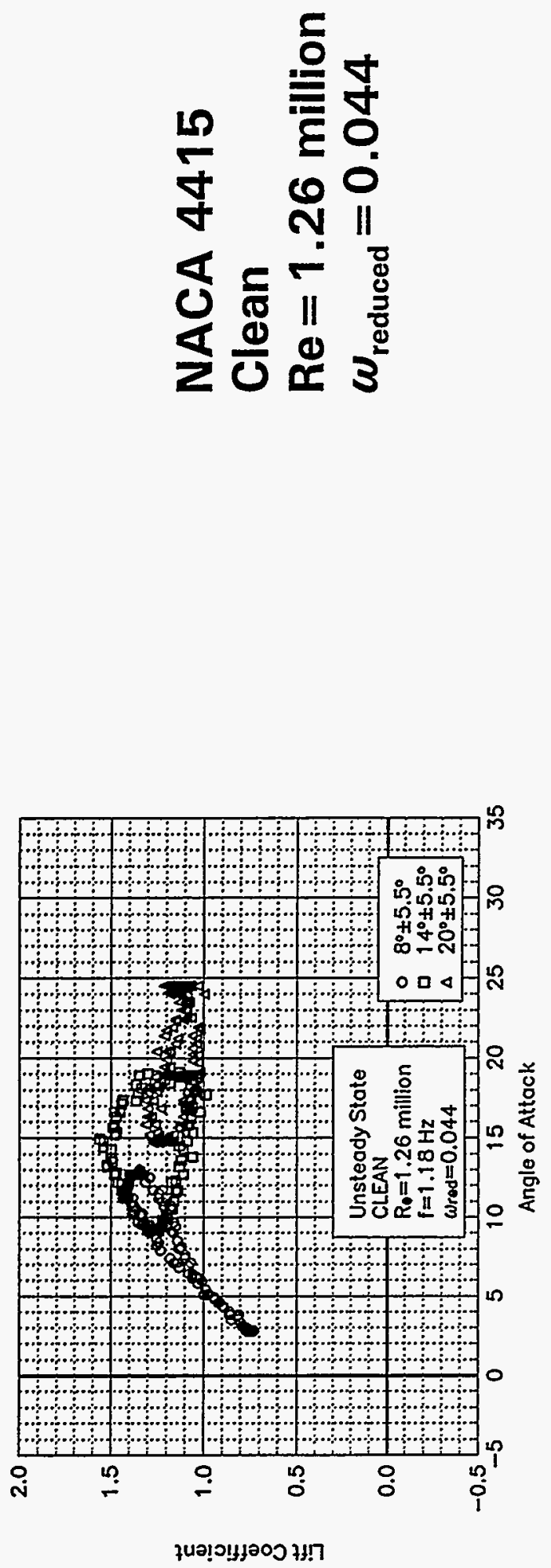

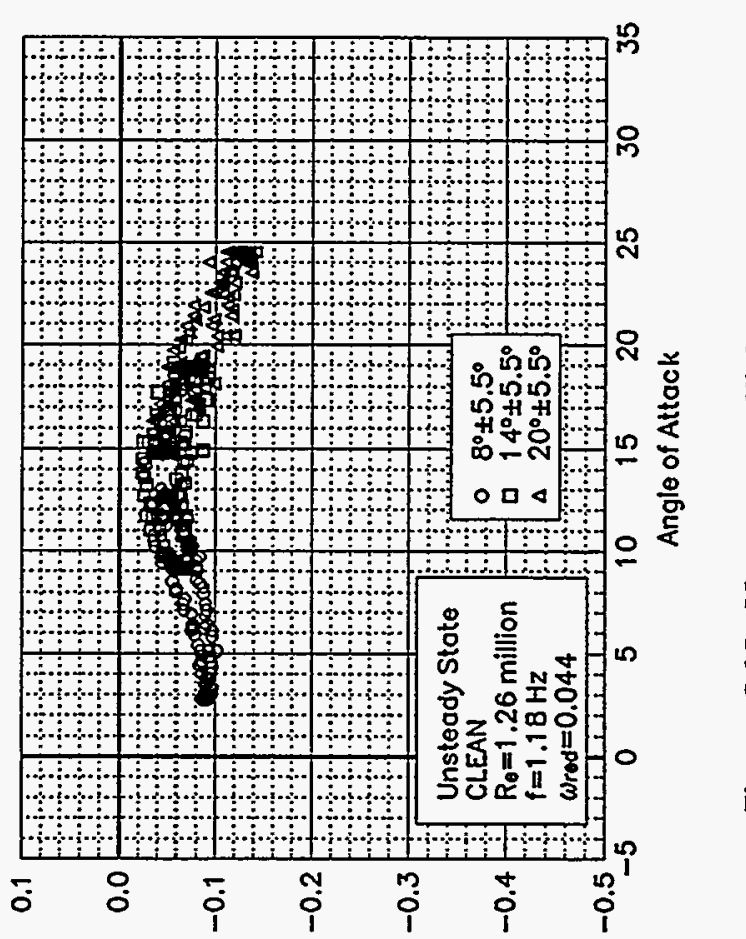

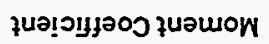

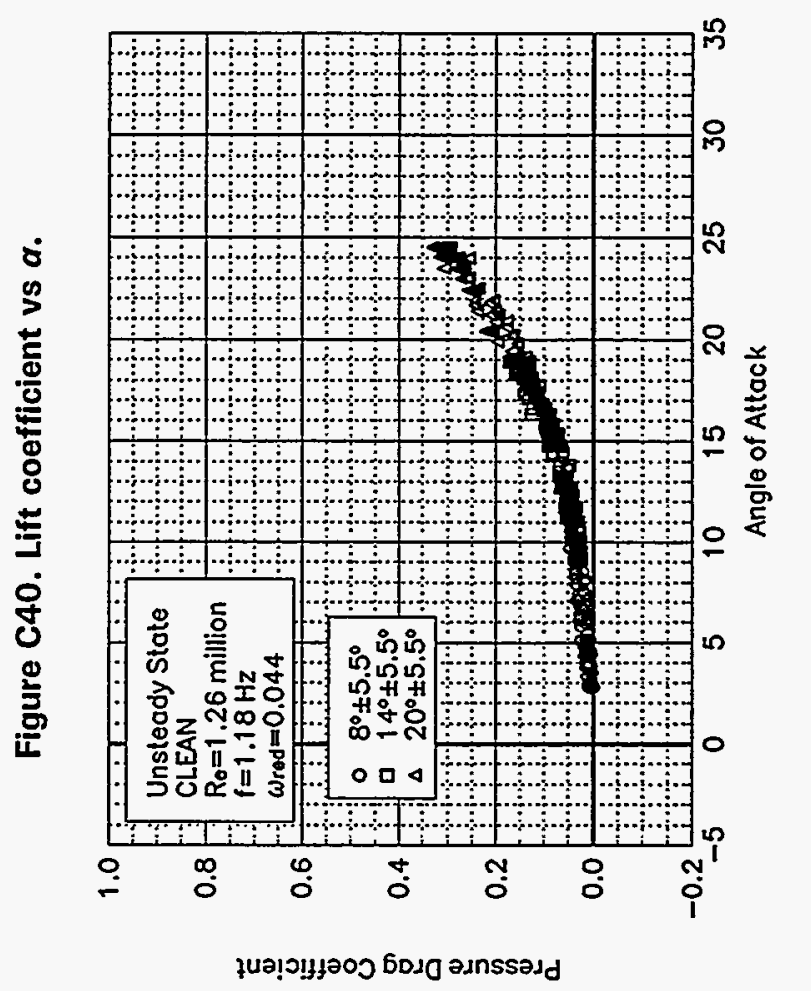

ì 

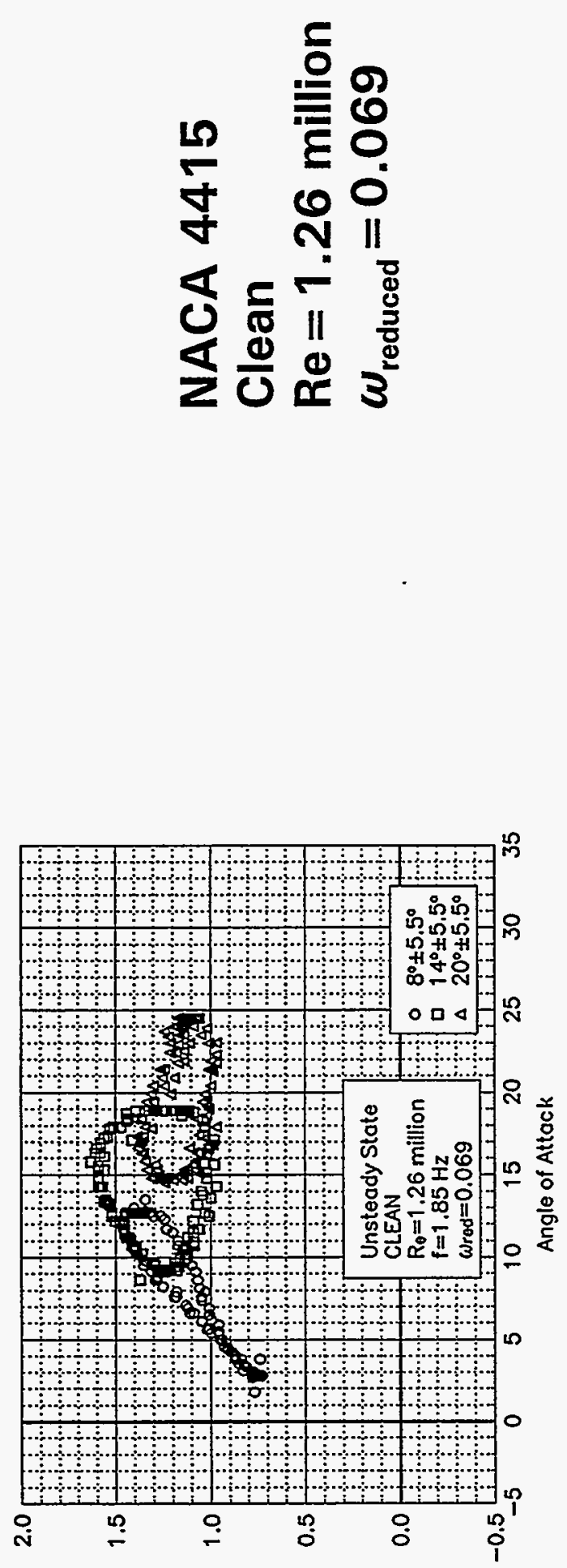

ชนว! จุมวัว

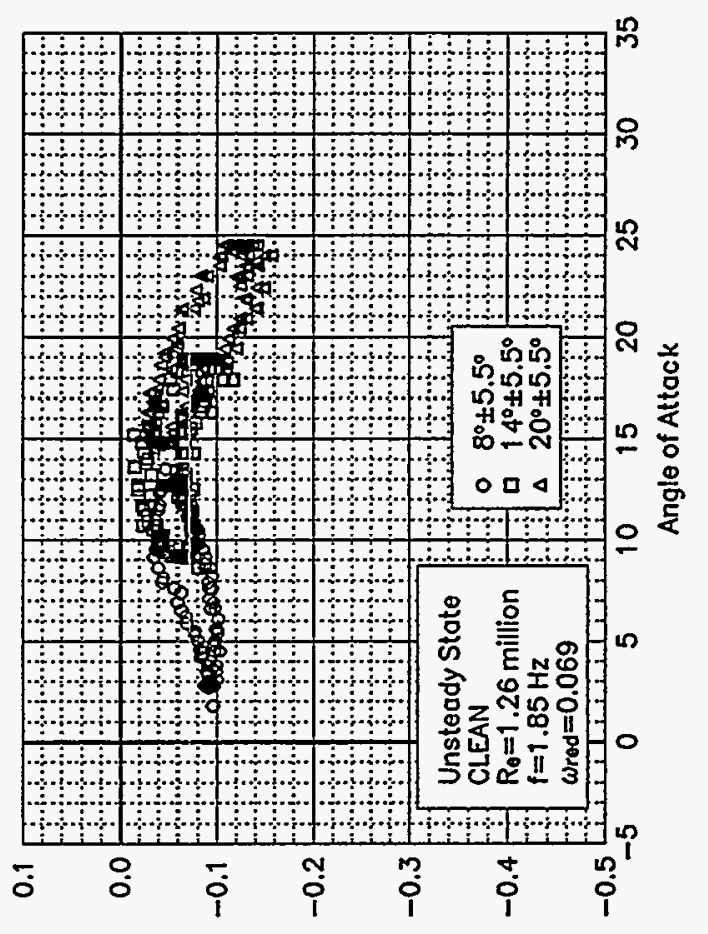

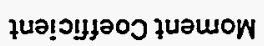

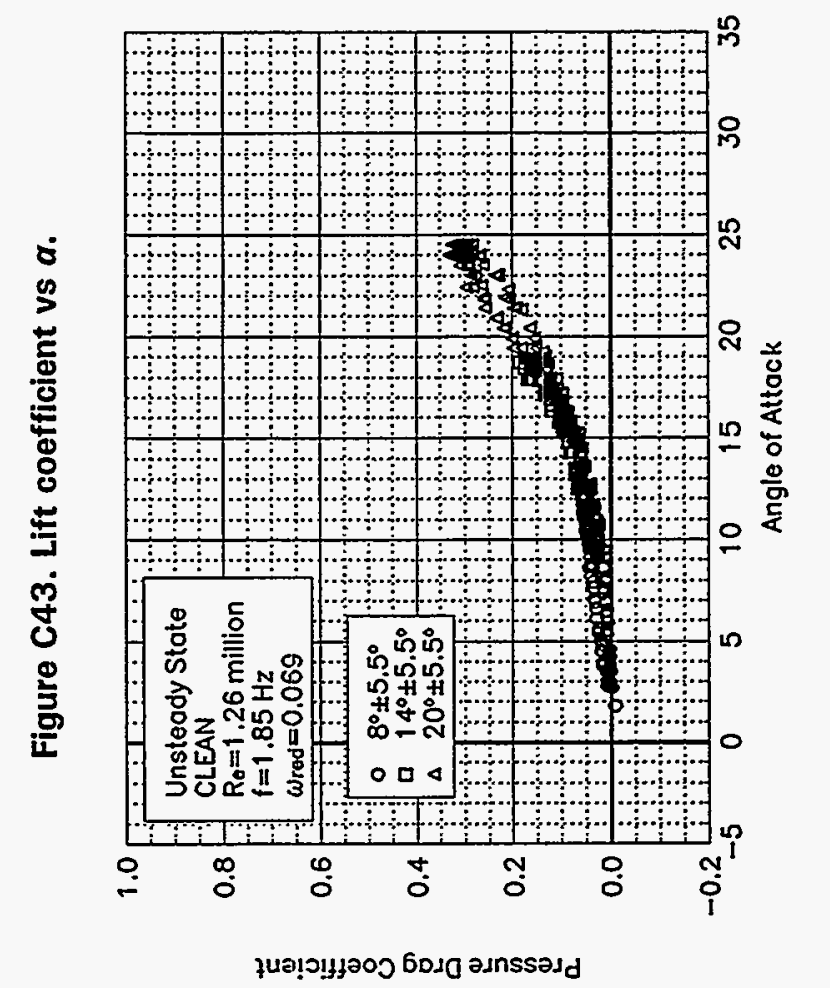

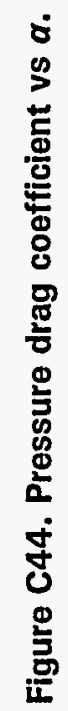



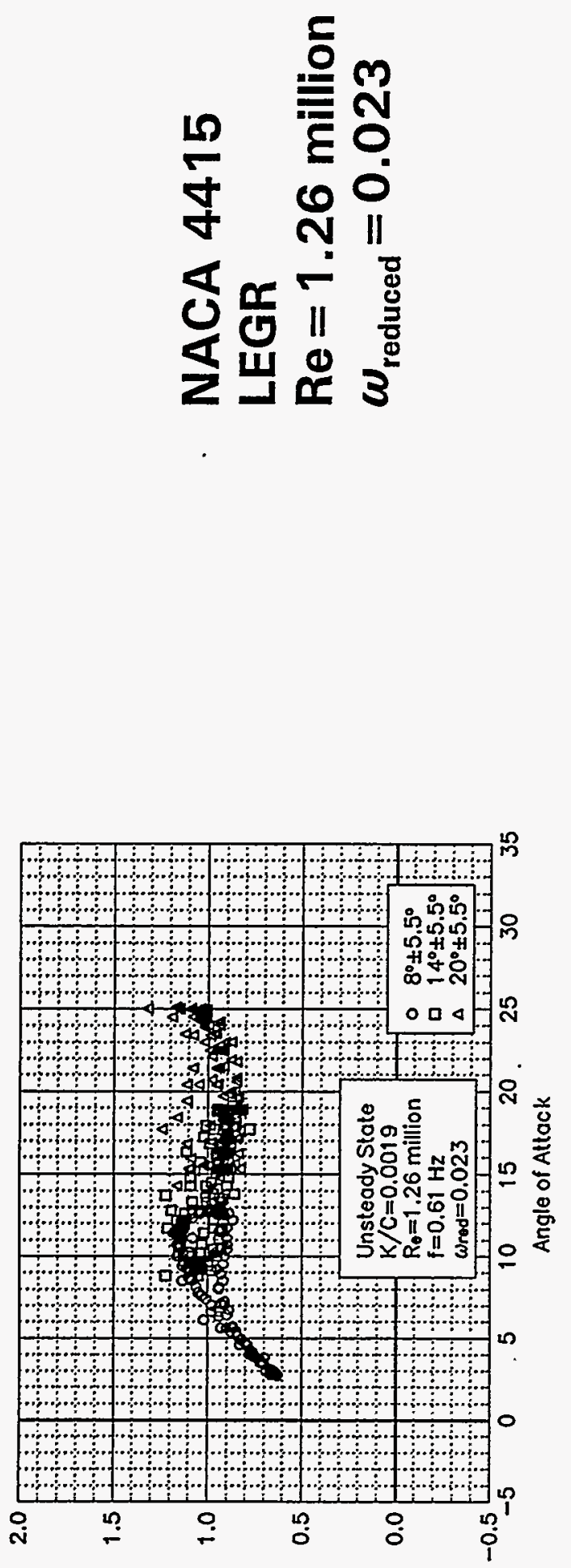

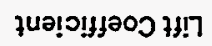

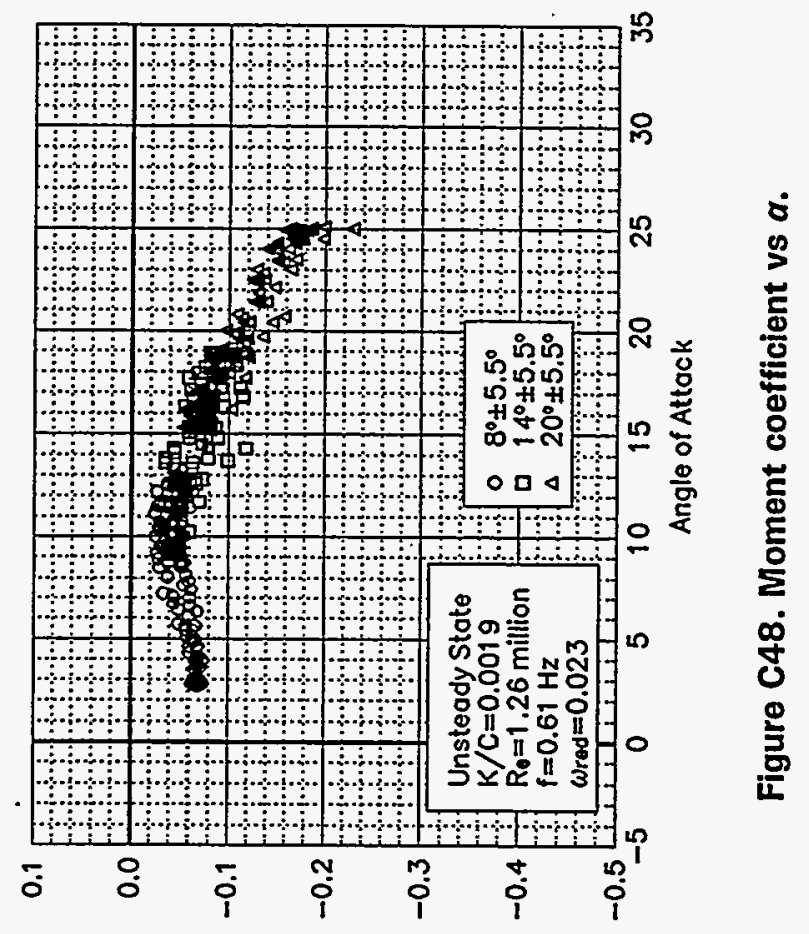

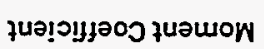

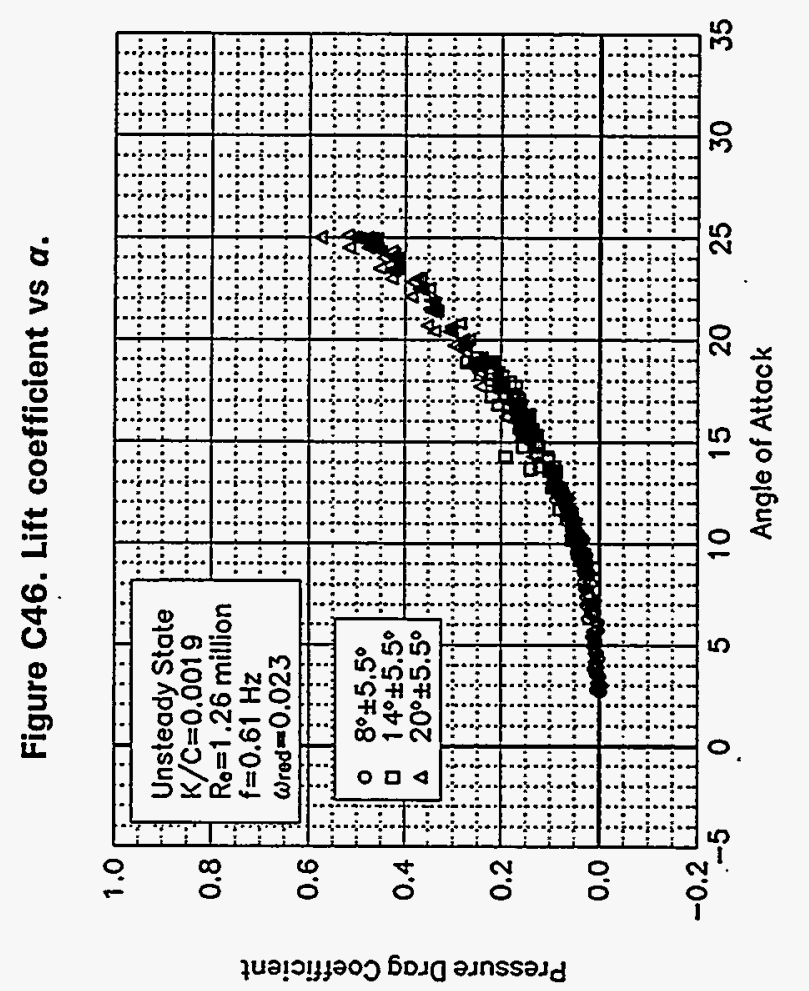

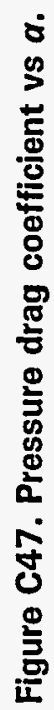

$\vec{\jmath}$ 

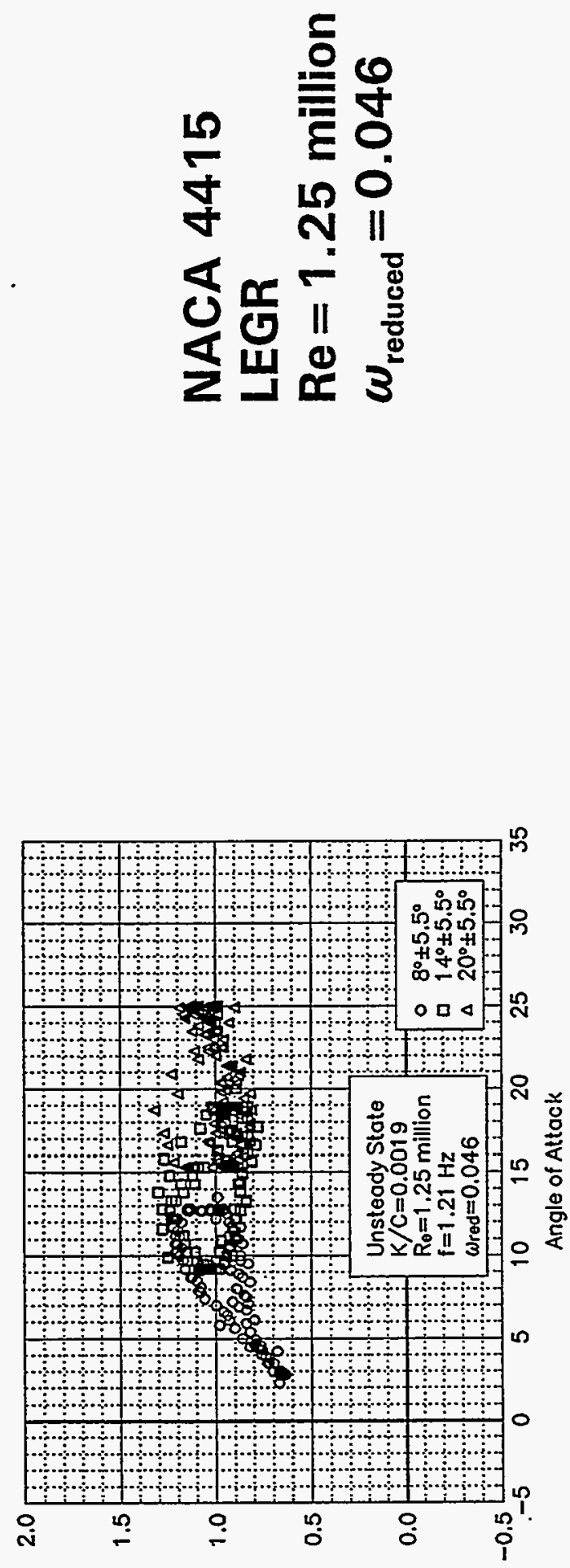

భนอ!ว!มวัว มฺก

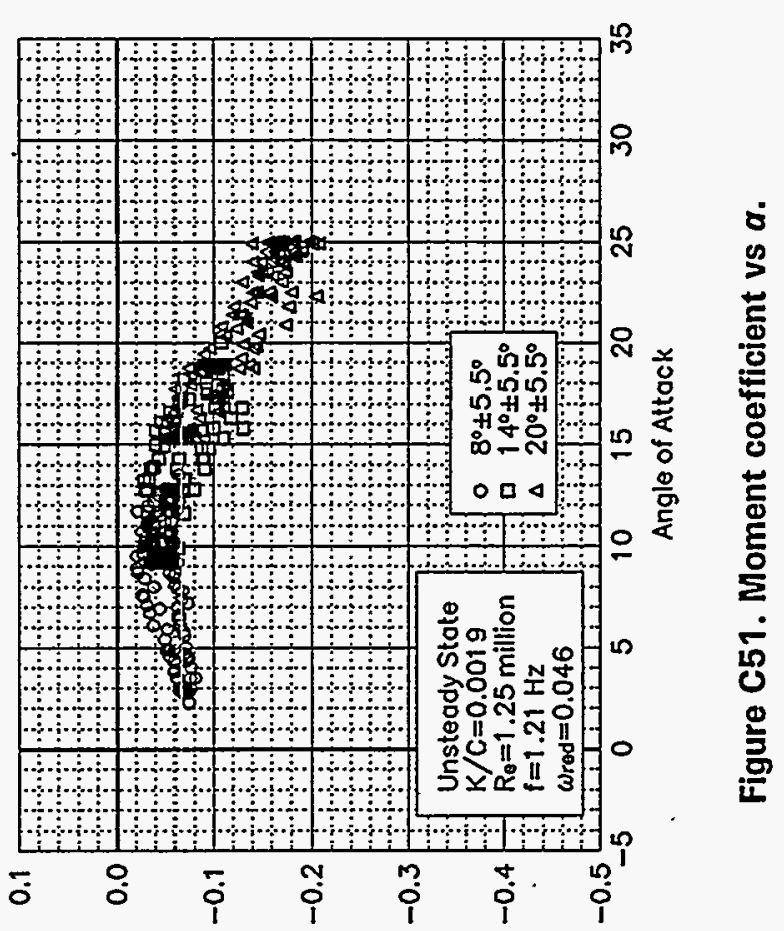

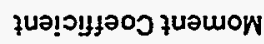

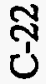

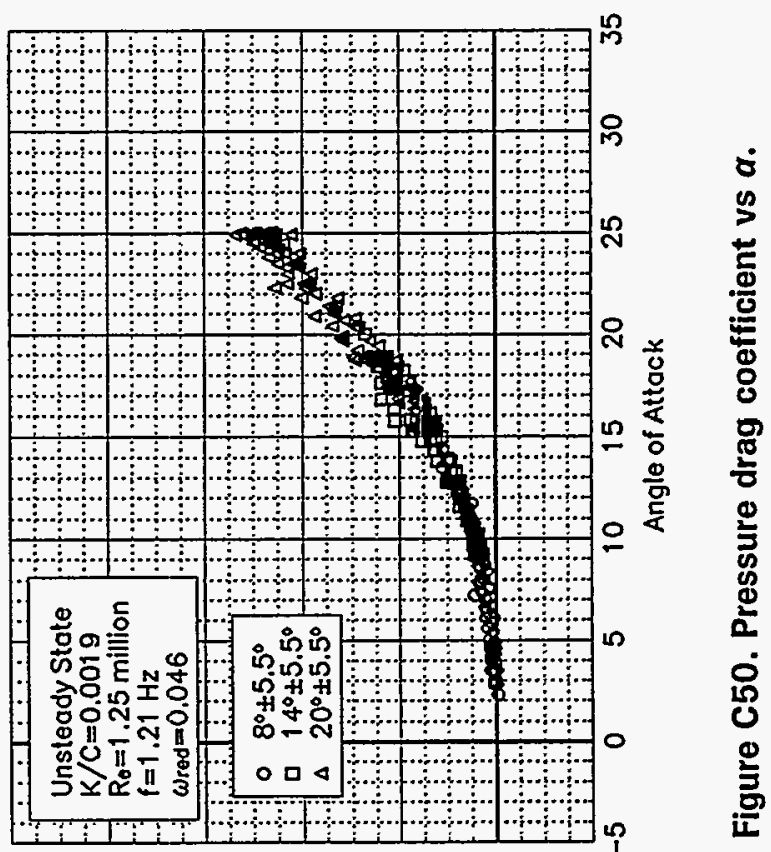

fua! Iy 

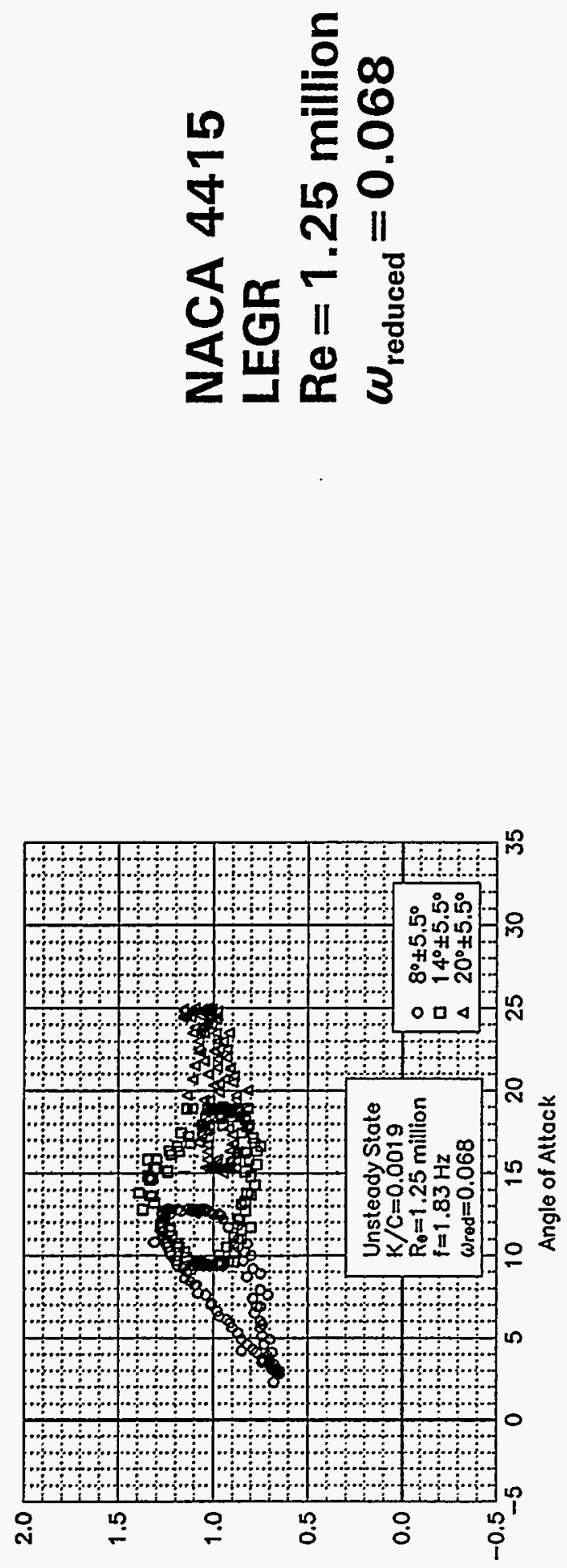

\}บข!อ!มมอว $4 ! ! 7$

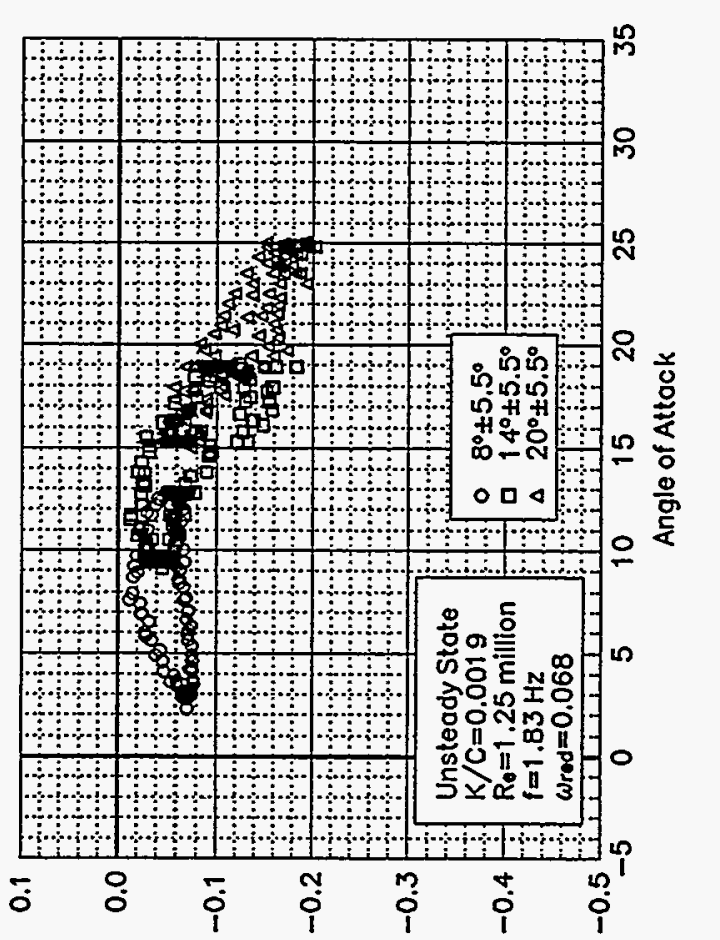

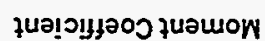

ֻิ

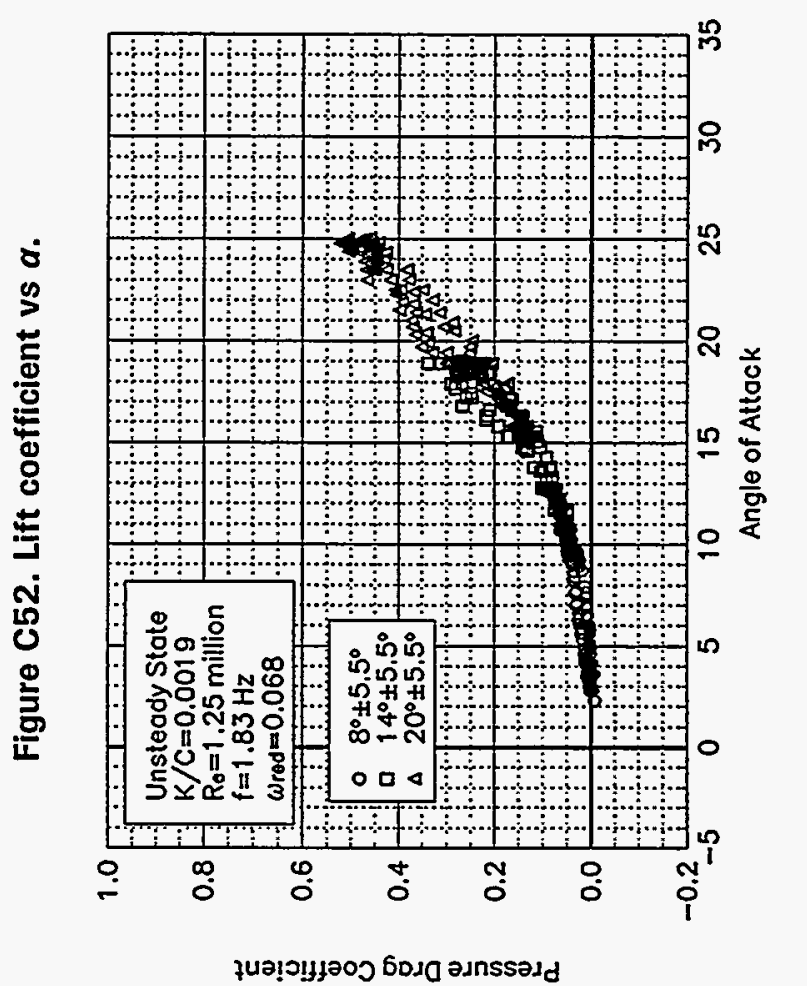

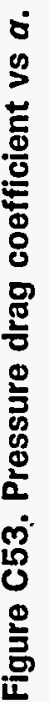




\section{Unsteady Airfoil Characteristics}

\section{$\pm 5.5^{\circ}$ Sine, $\operatorname{Re}=1.5$ million}



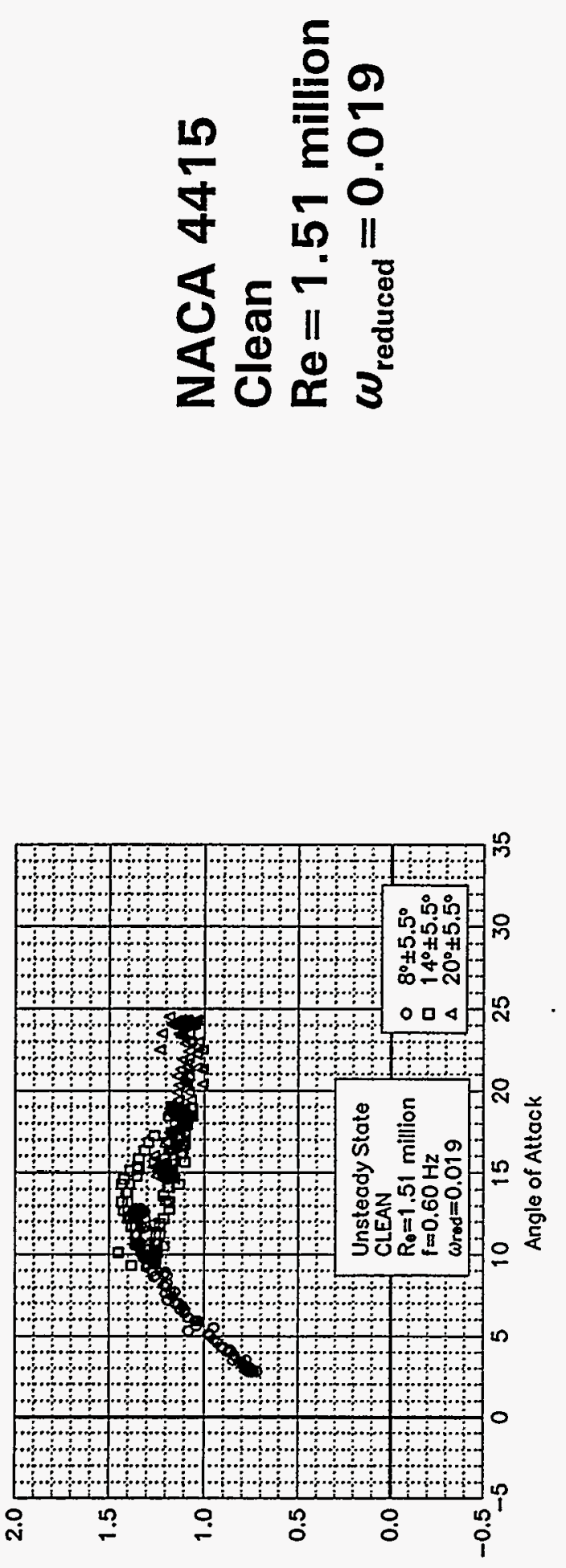

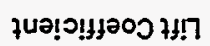

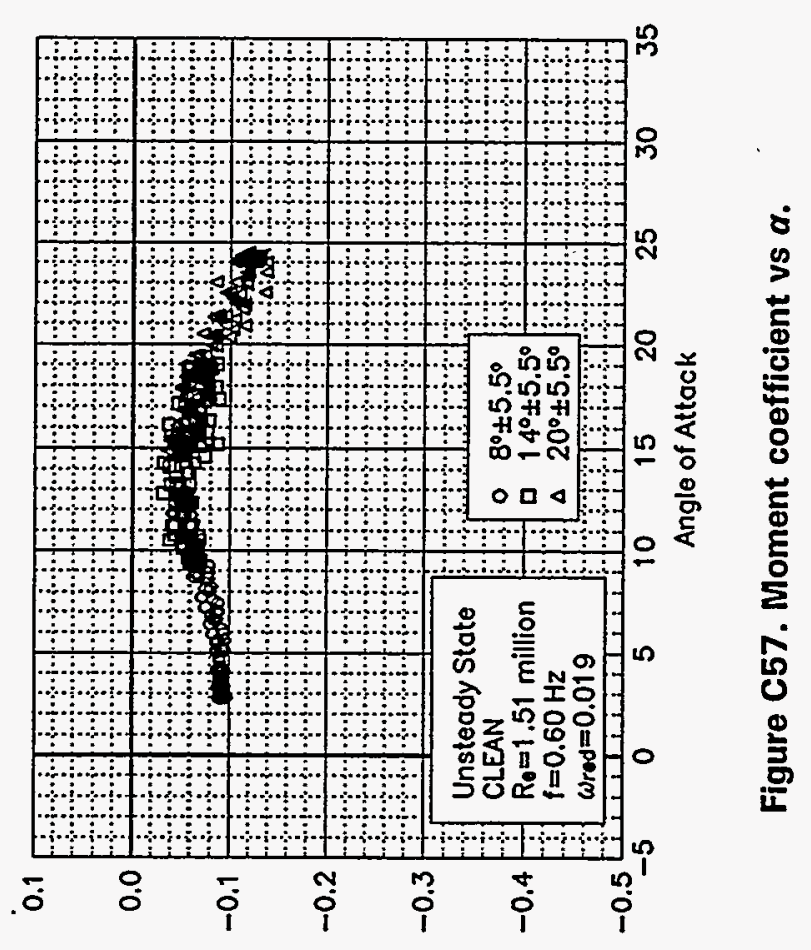

quə!จ

.8

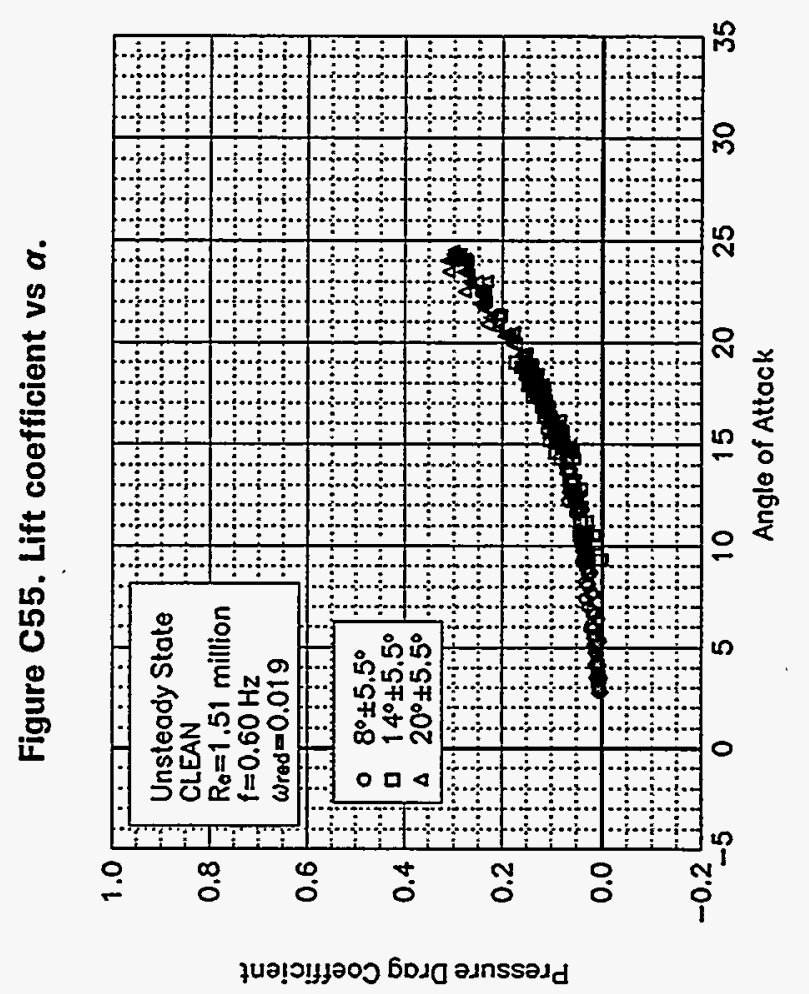

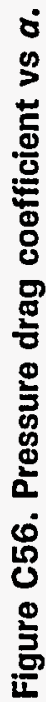



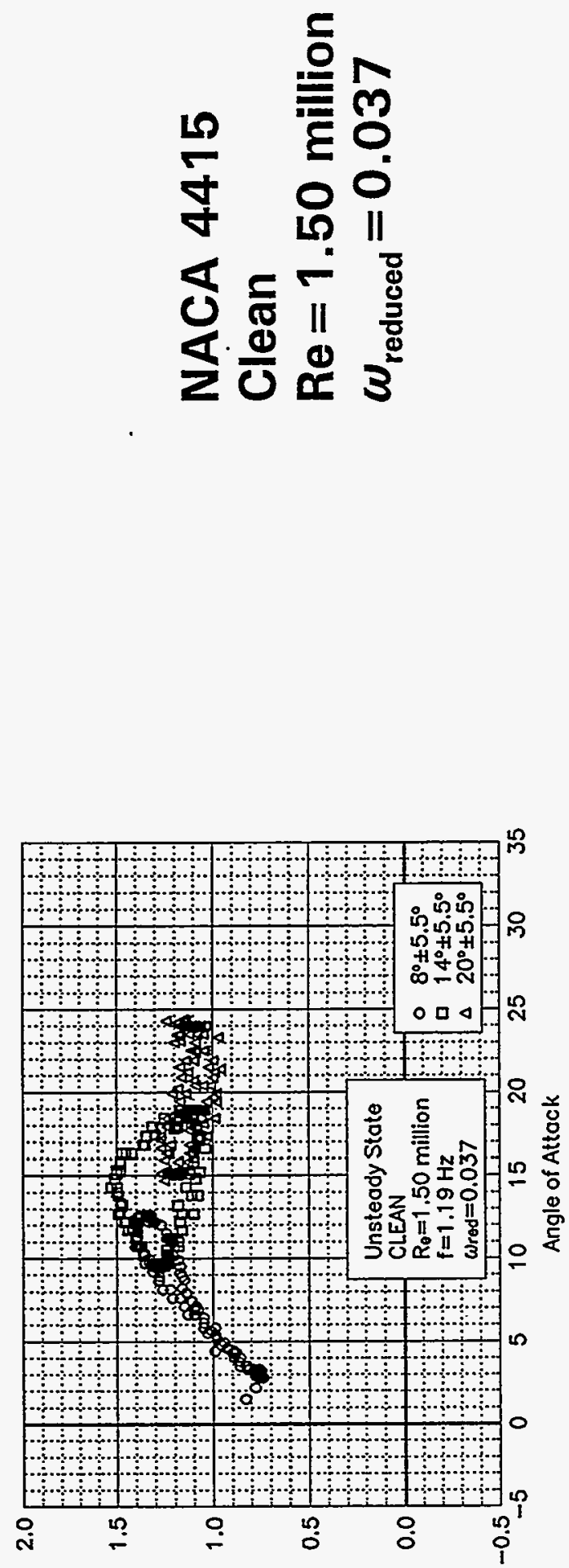

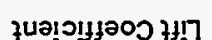

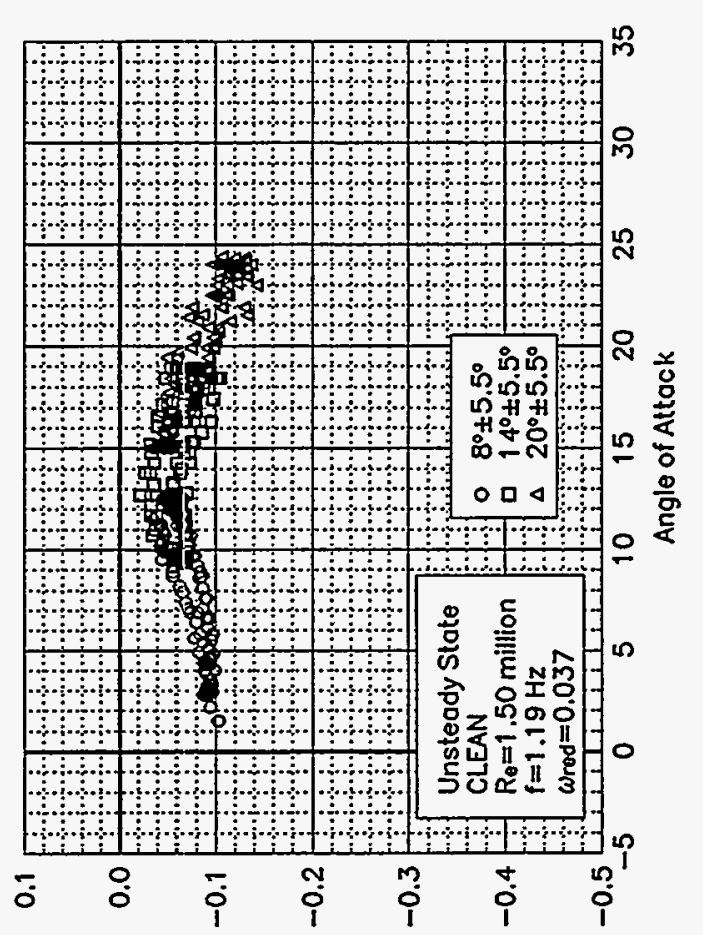

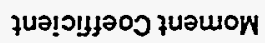

ชัง

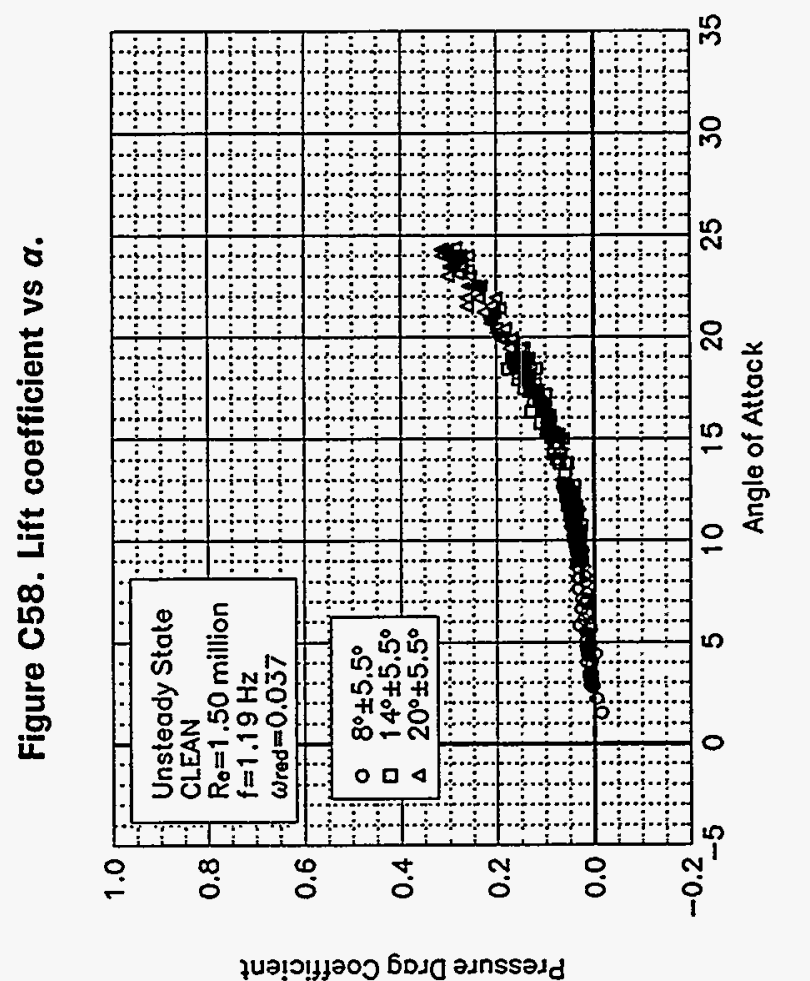

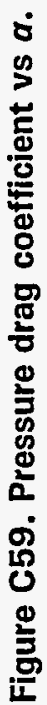



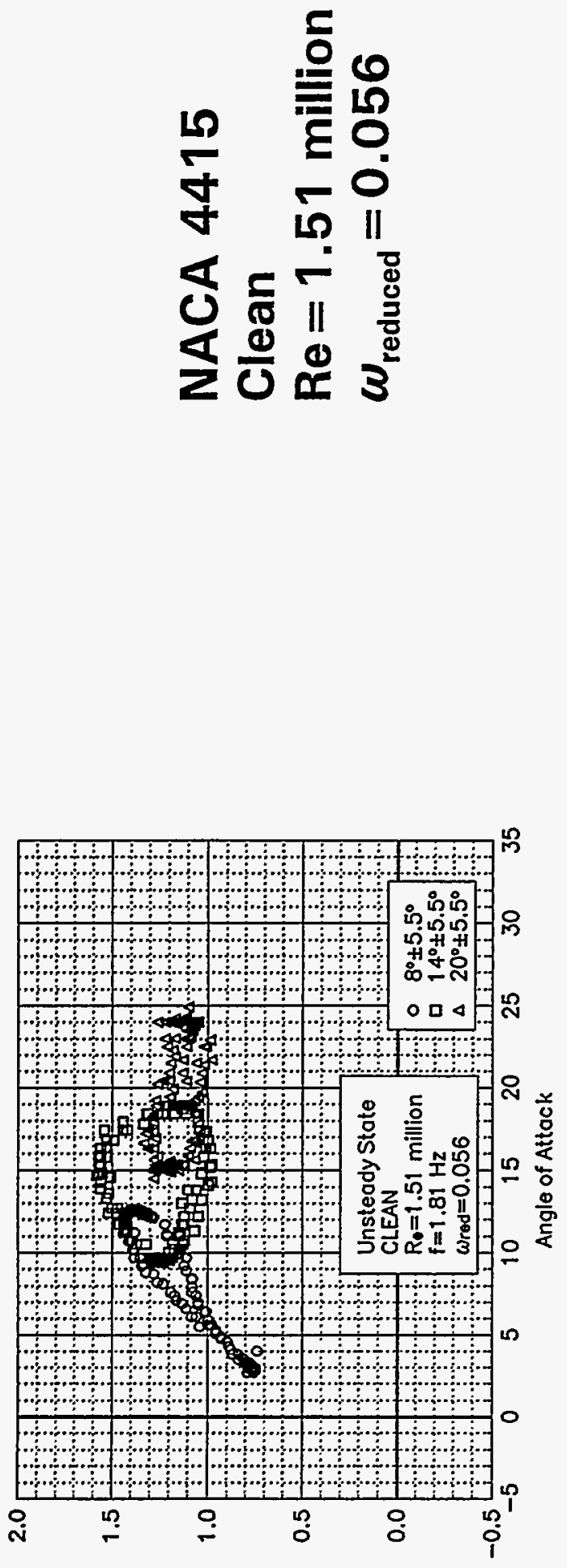

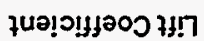

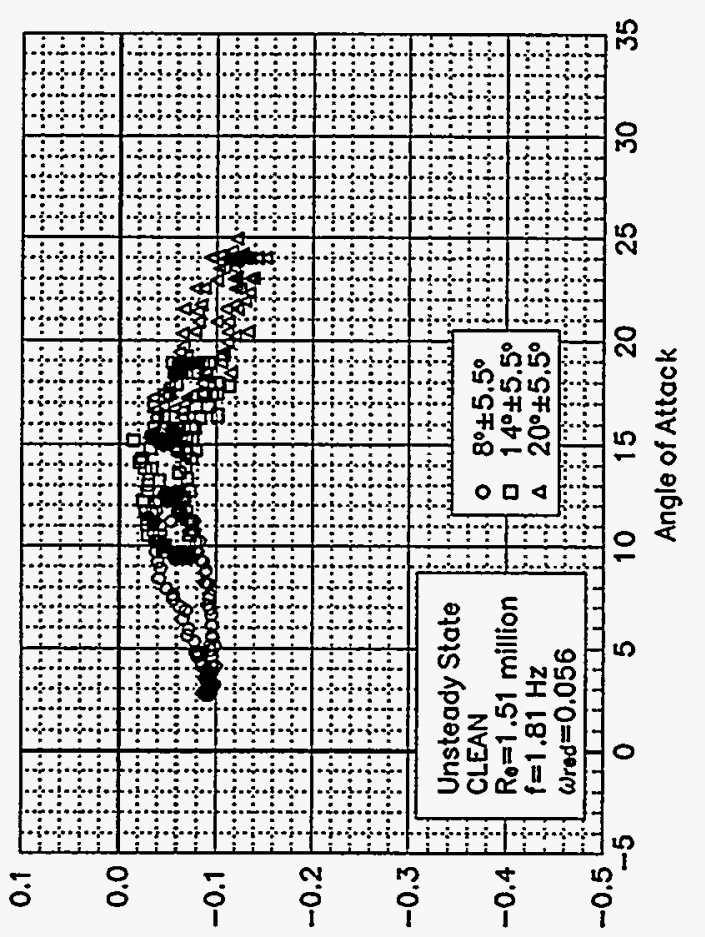

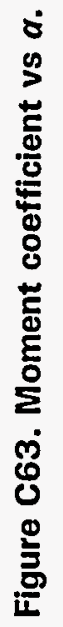

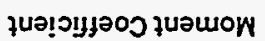

ธิ่

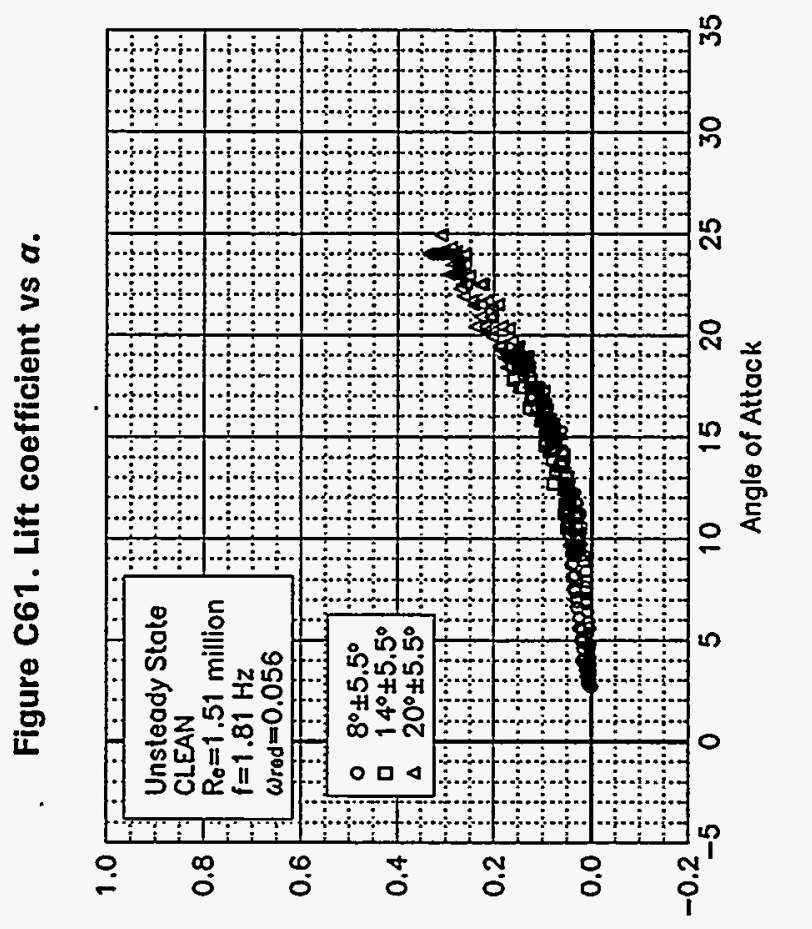

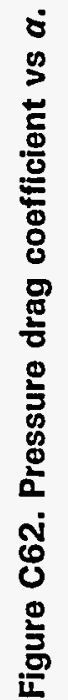

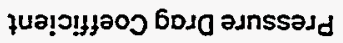



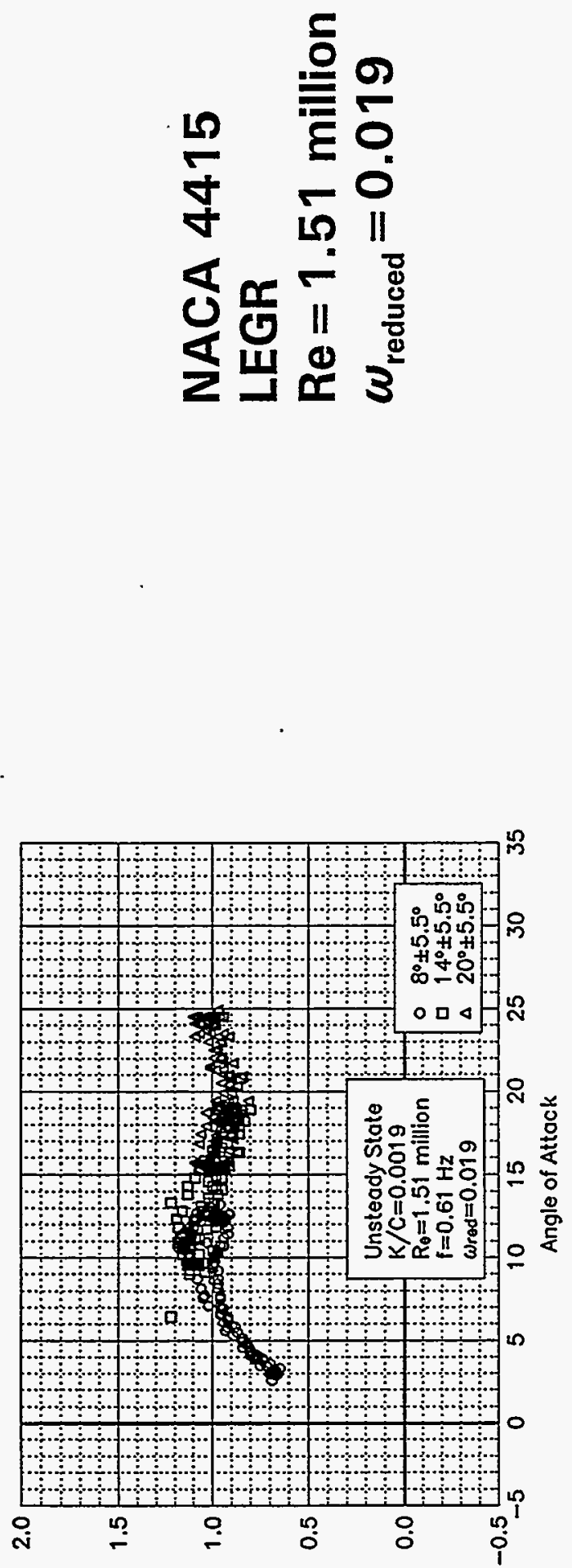

ในอ!จแรอัว $3 ! า$

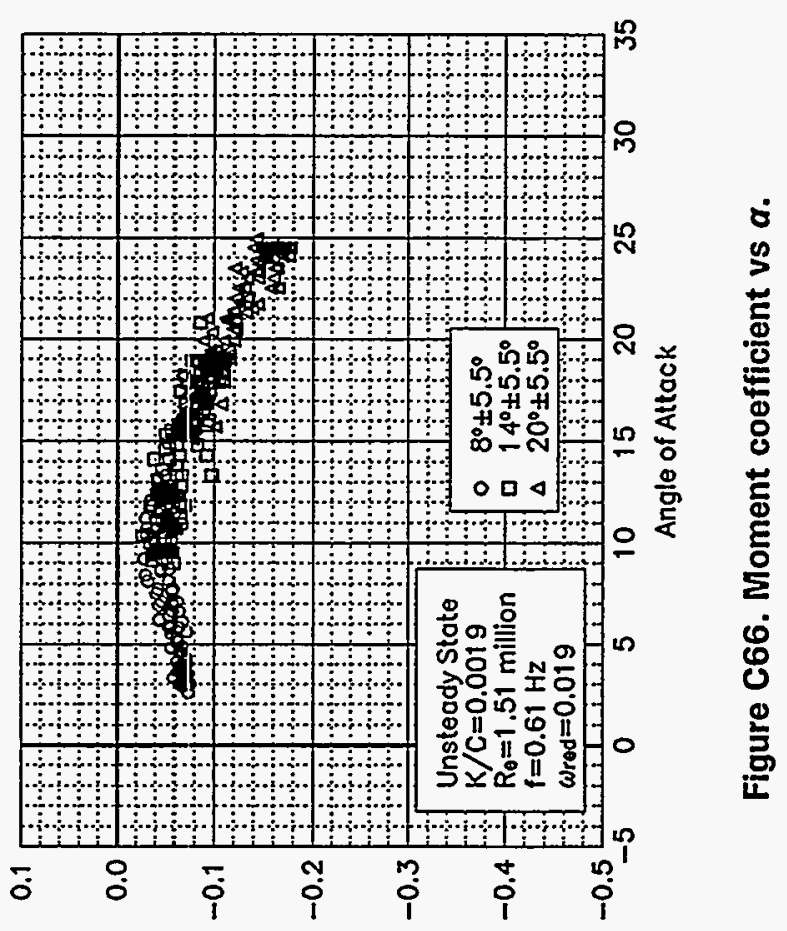

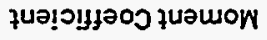

$\stackrel{\infty}{0}$

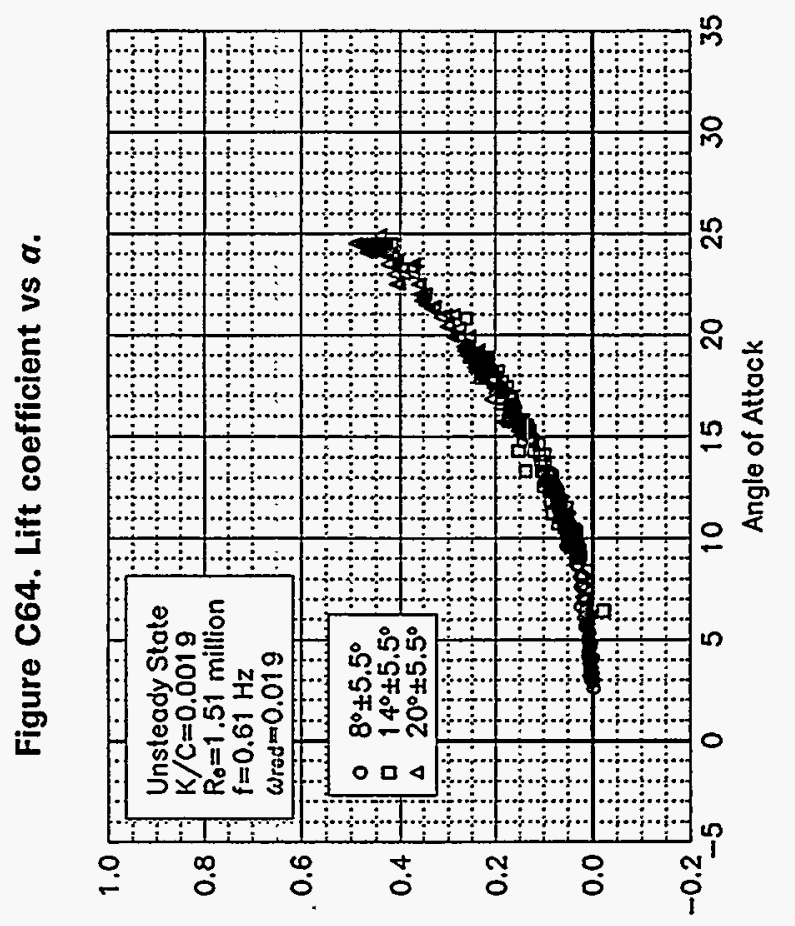

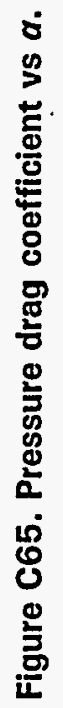

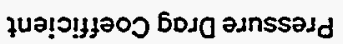


Pressure Drag Coefficient

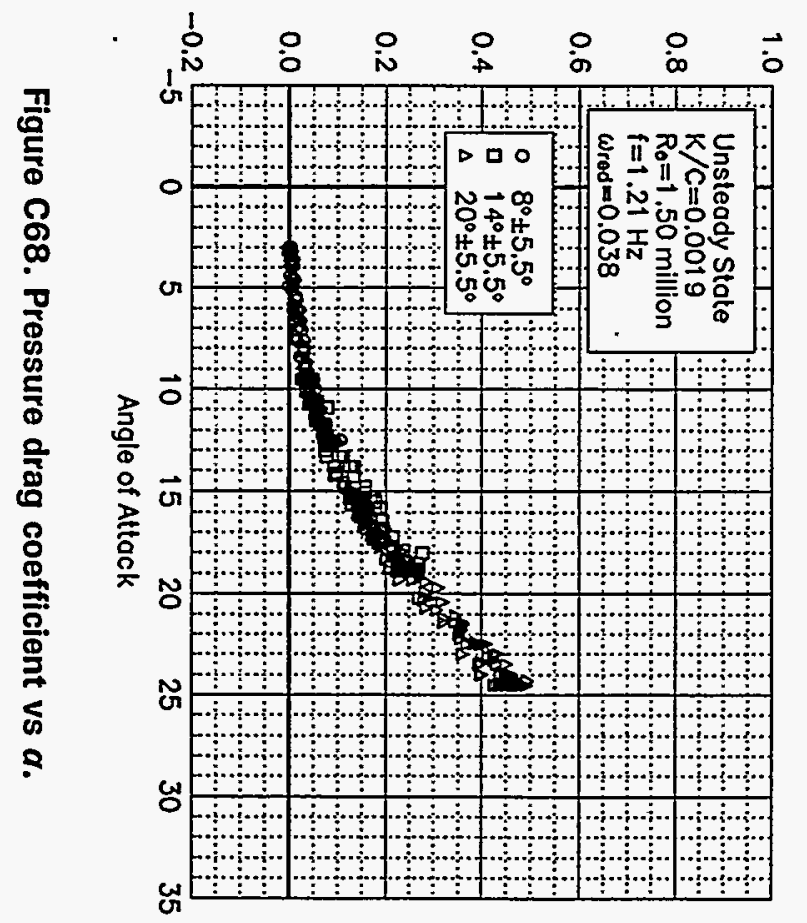

Lift Coefficient

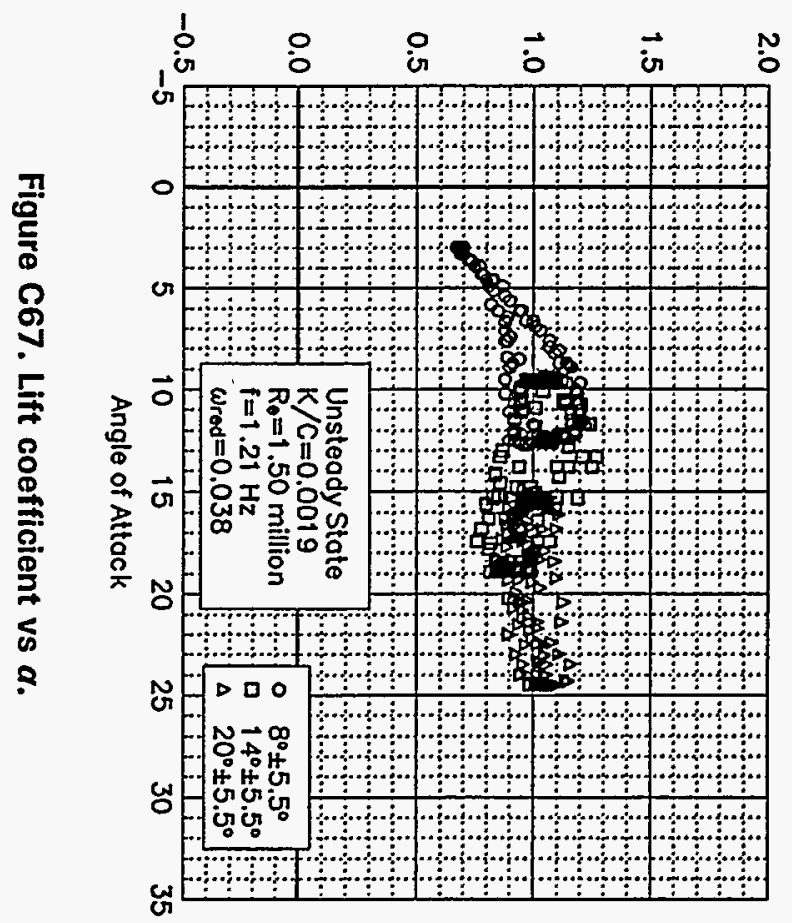

ज़
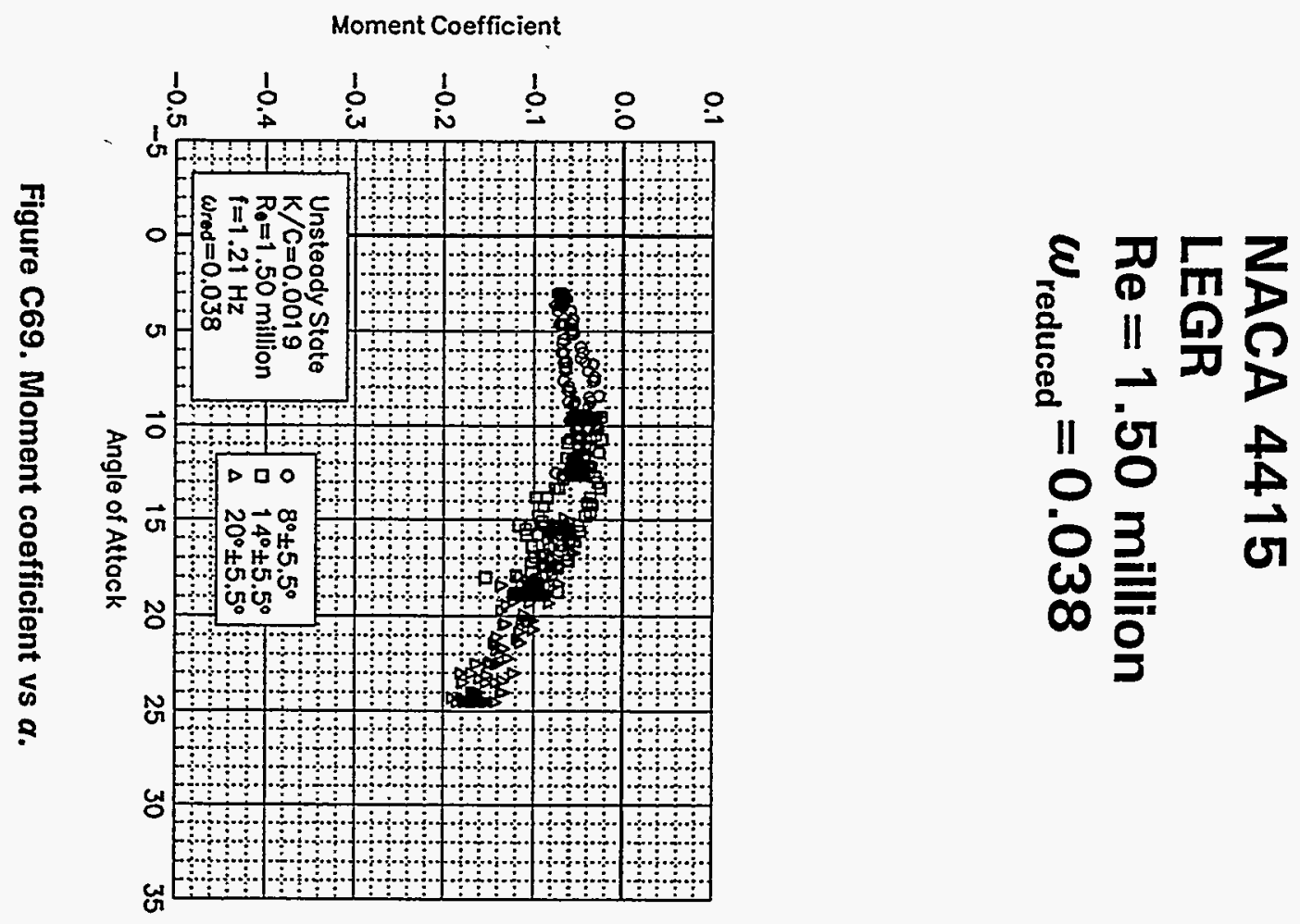

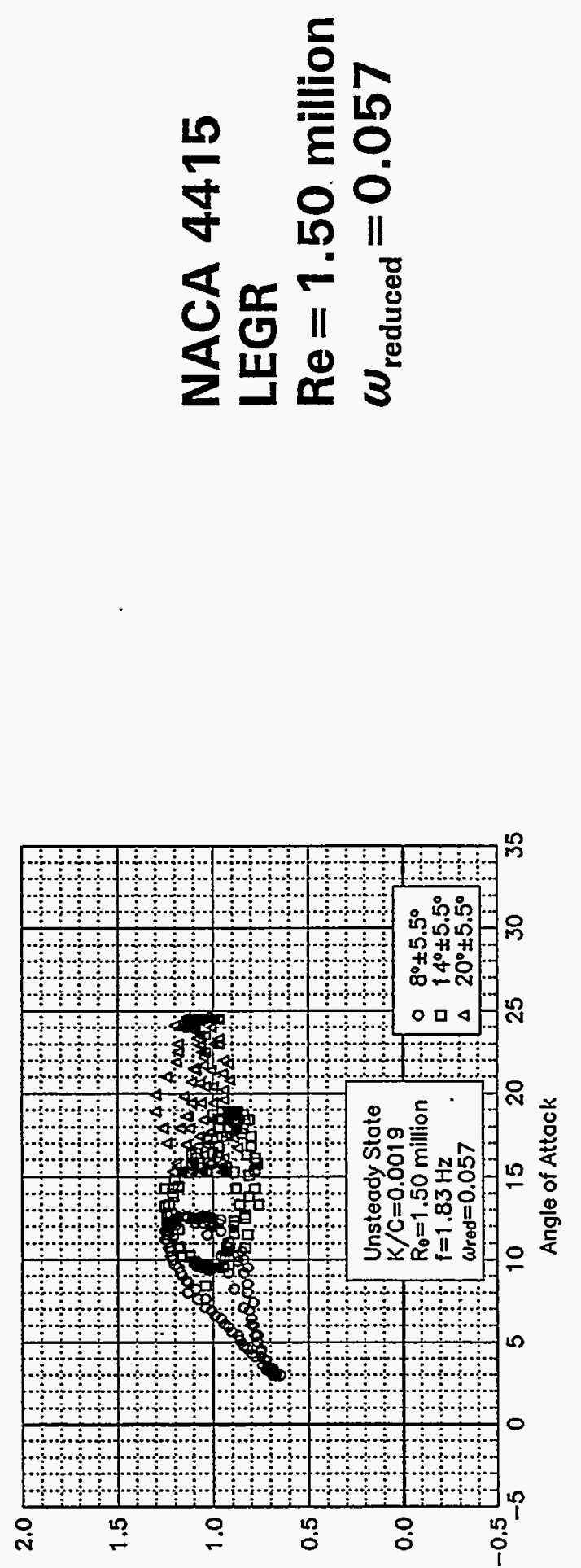

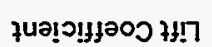

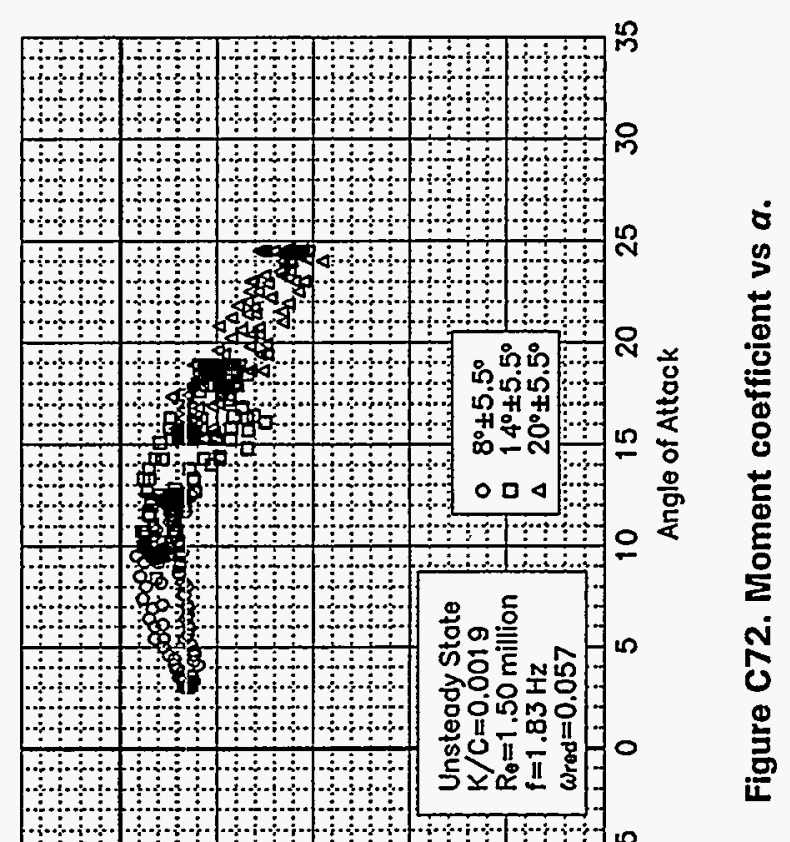

8

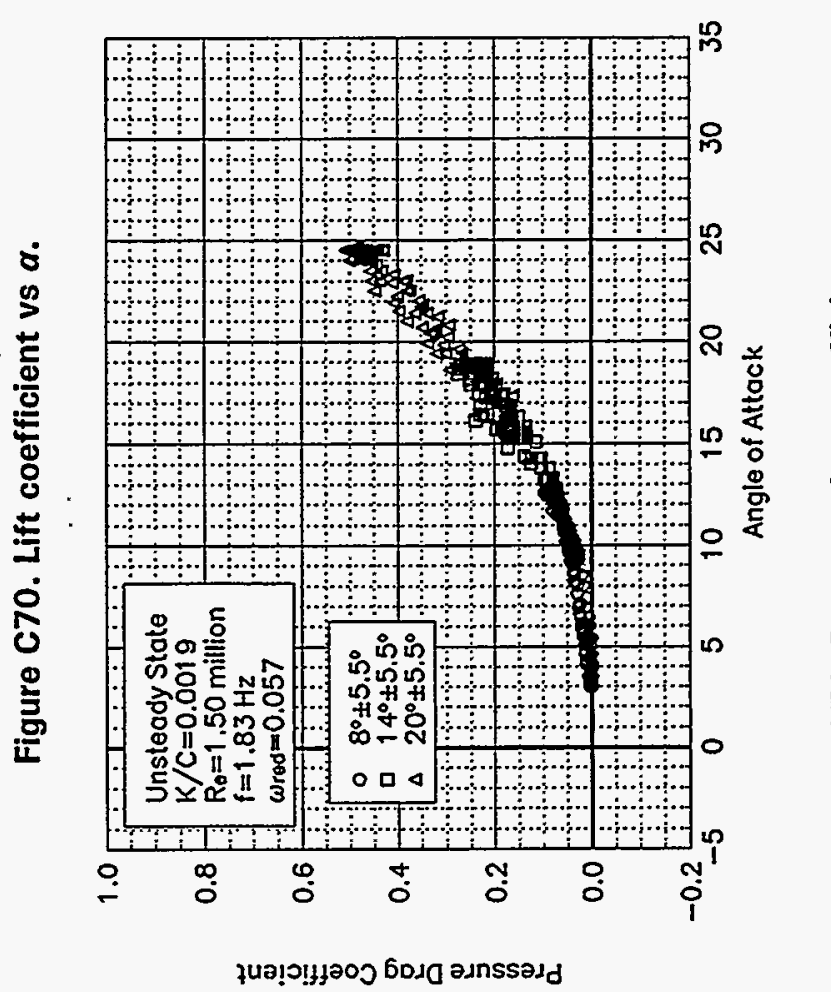

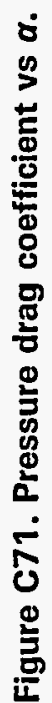




\section{Unsteady Airfoil Characteristics \\ $\pm 10^{\circ}$ Sine, $\operatorname{Re}=0.75$ million}




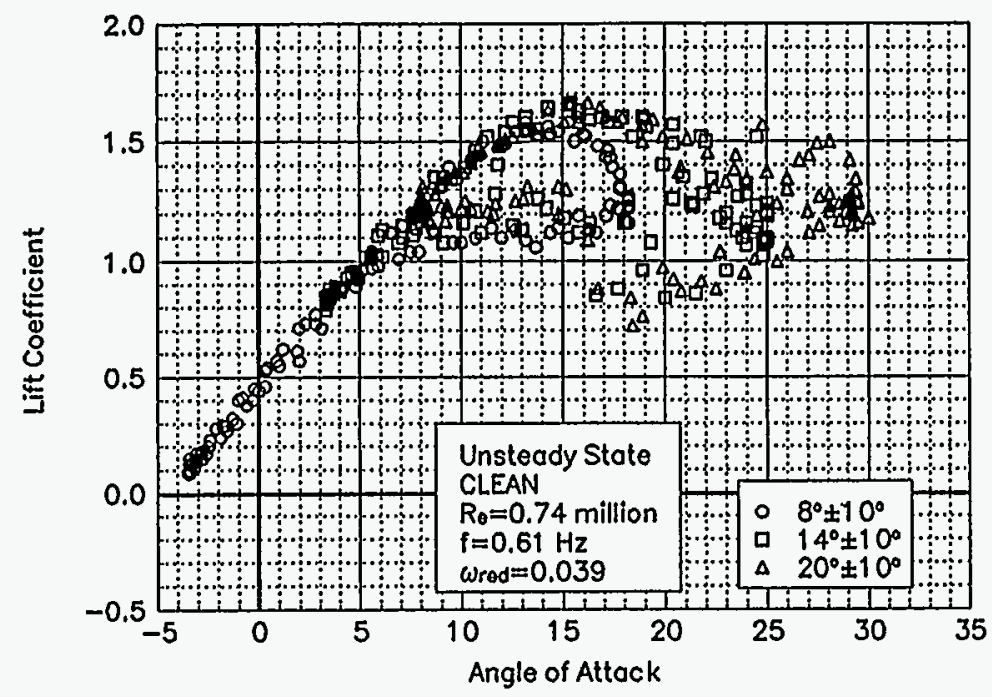

Figure C73. Lift coefficient vs $a$.

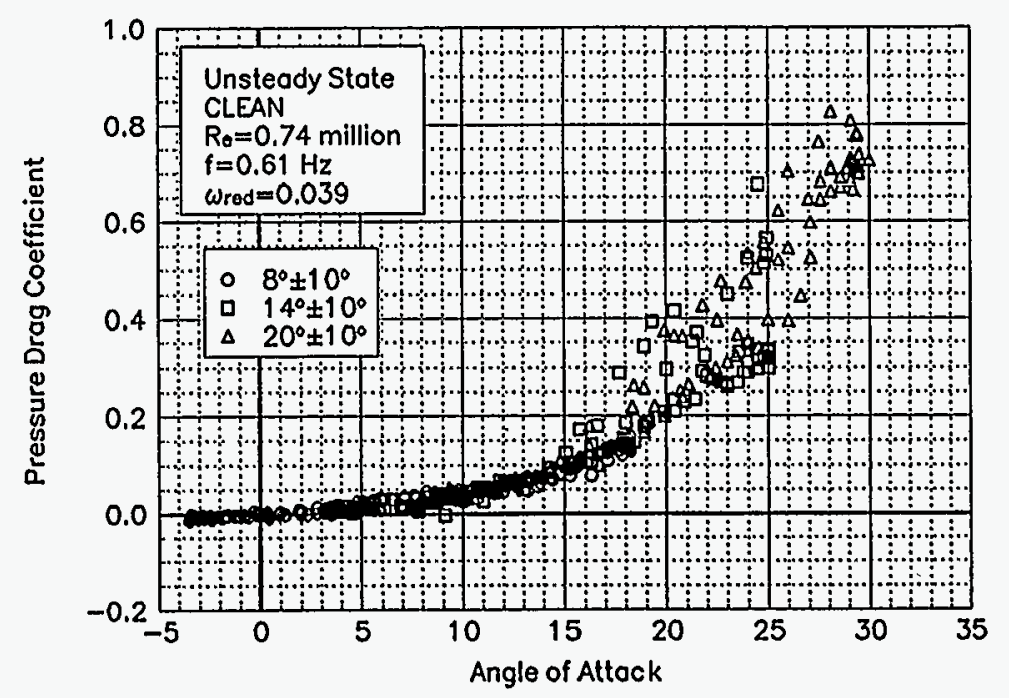

Figure C74. Pressure drag coefficient vs $a$.

\section{NACA 4415 \\ Clean \\ $\mathrm{Re}=\mathbf{0 . 7 4}$ million \\ $\omega_{\text {reduced }}=0.039$}

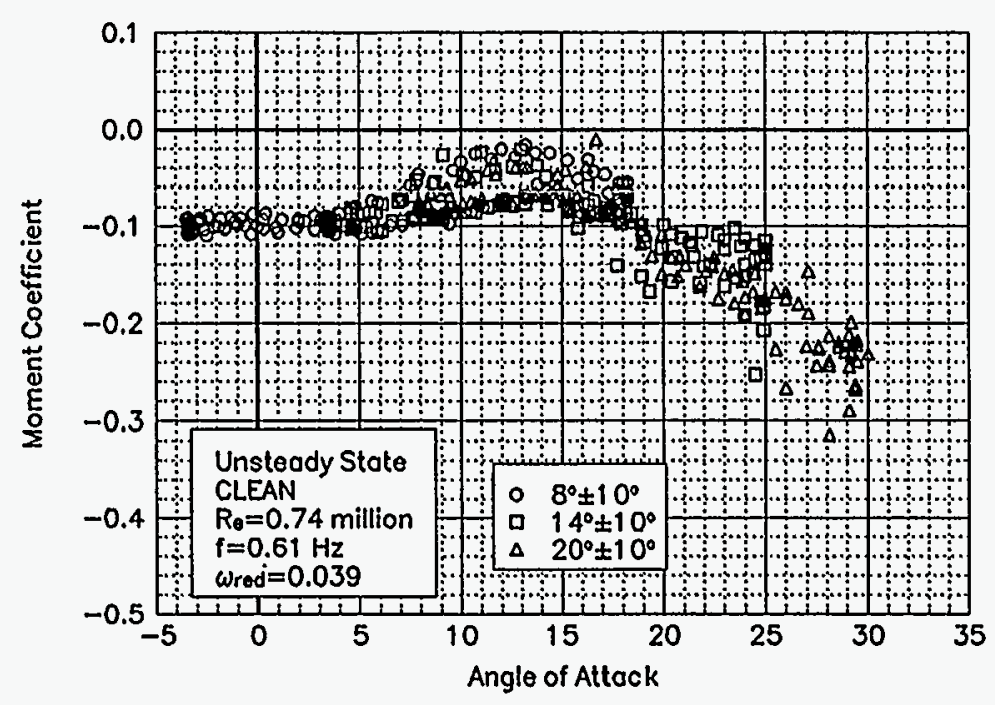

Figure C75. Moment coefficient vs $a$. 

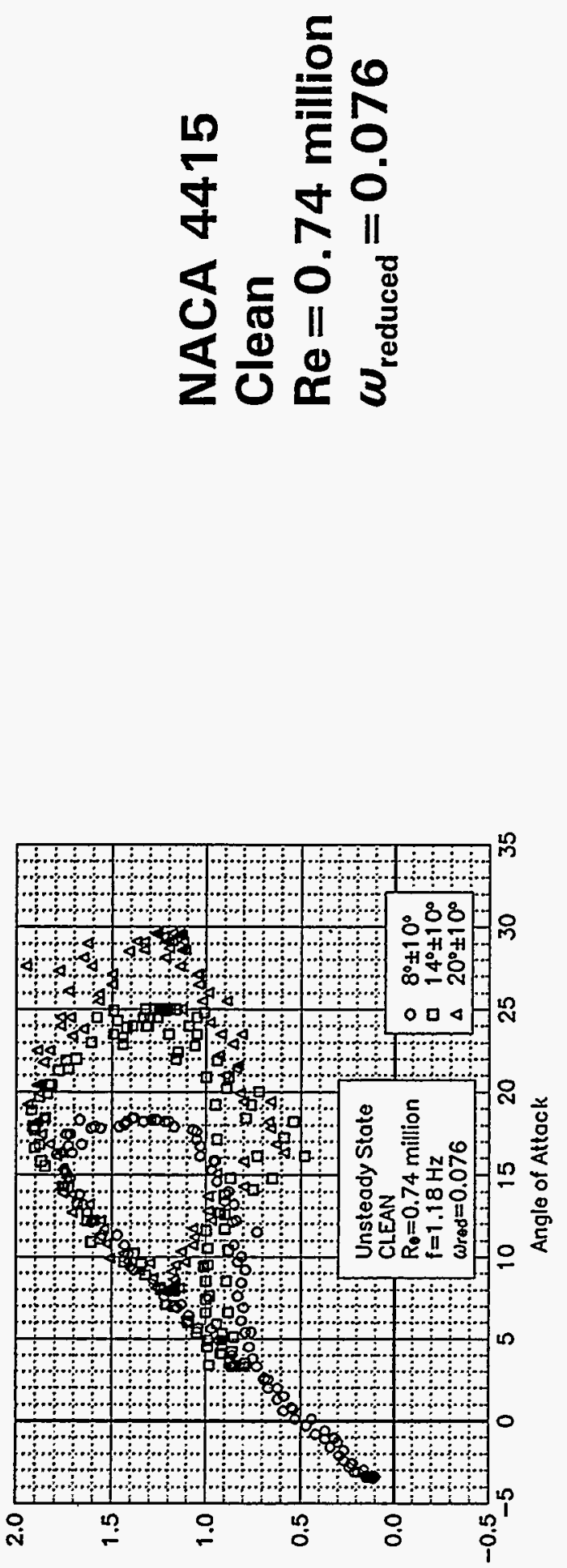

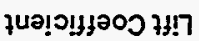

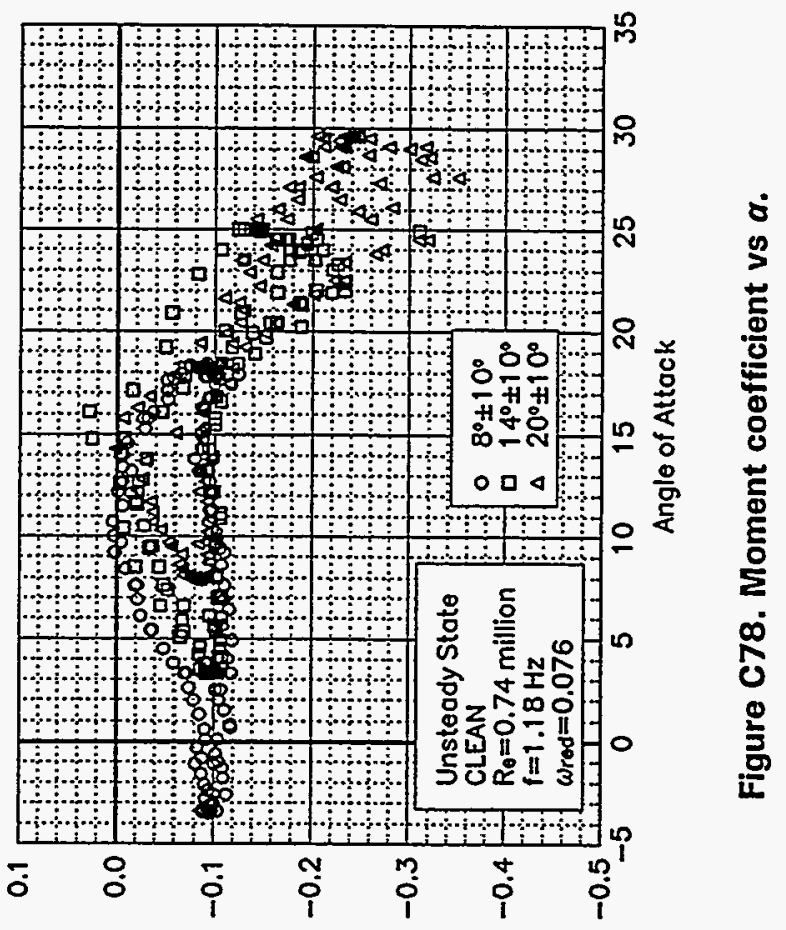

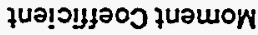

8

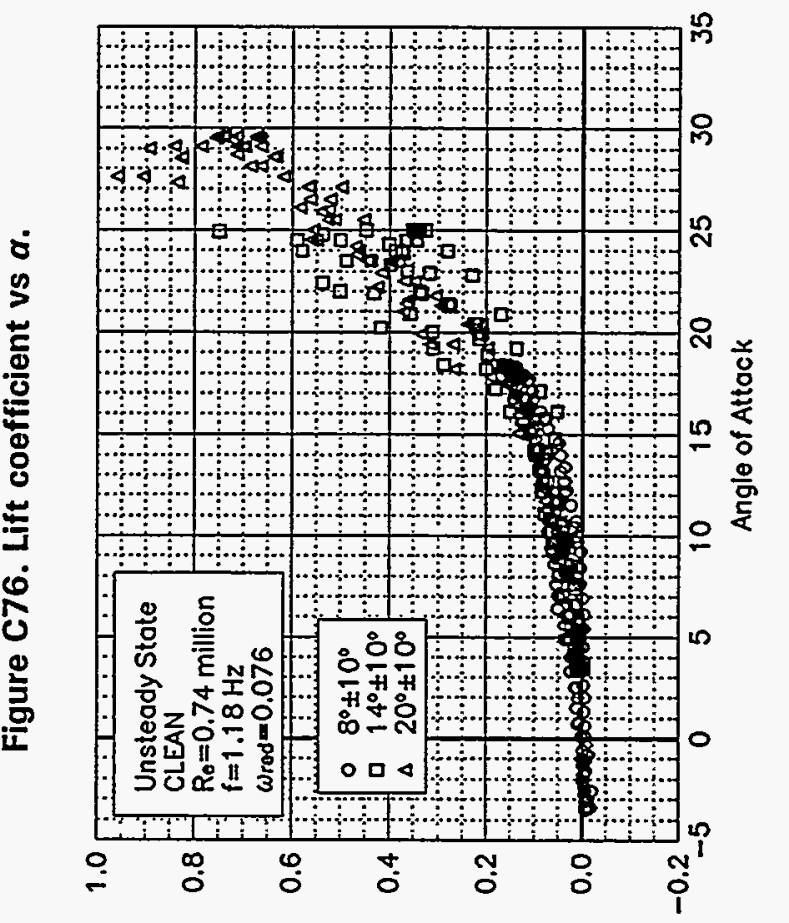

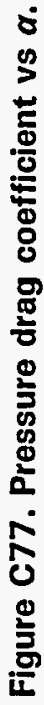

zนจ!ฺ! 


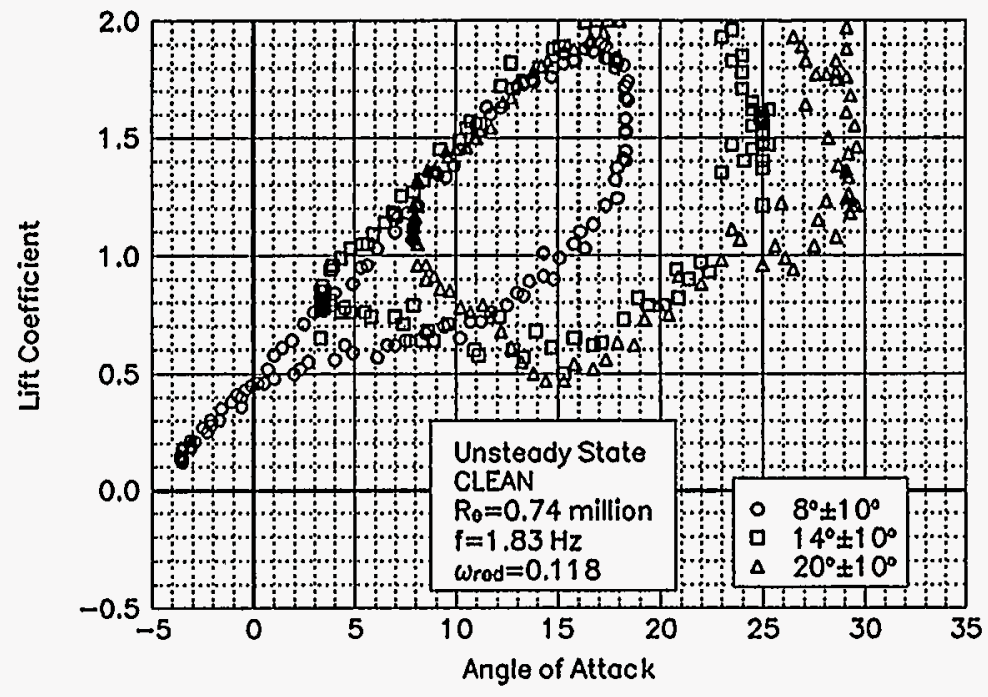

Figure C79. Lift coefficient vs $a$.

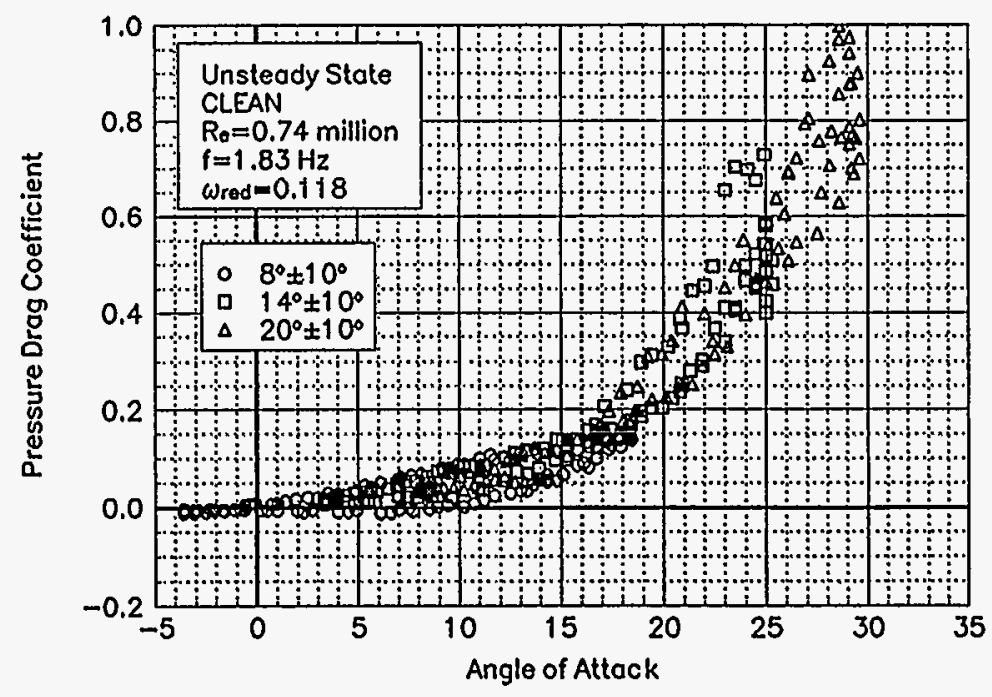

Figure C80. Pressure drag coefficient vs $a$.

\section{NACA 4415 \\ Clean \\ $\mathrm{Re}=0.74$. million \\ $\omega_{\text {reduced }}=0.118$}

Figure C81. Moment coefficient vs $a$. 


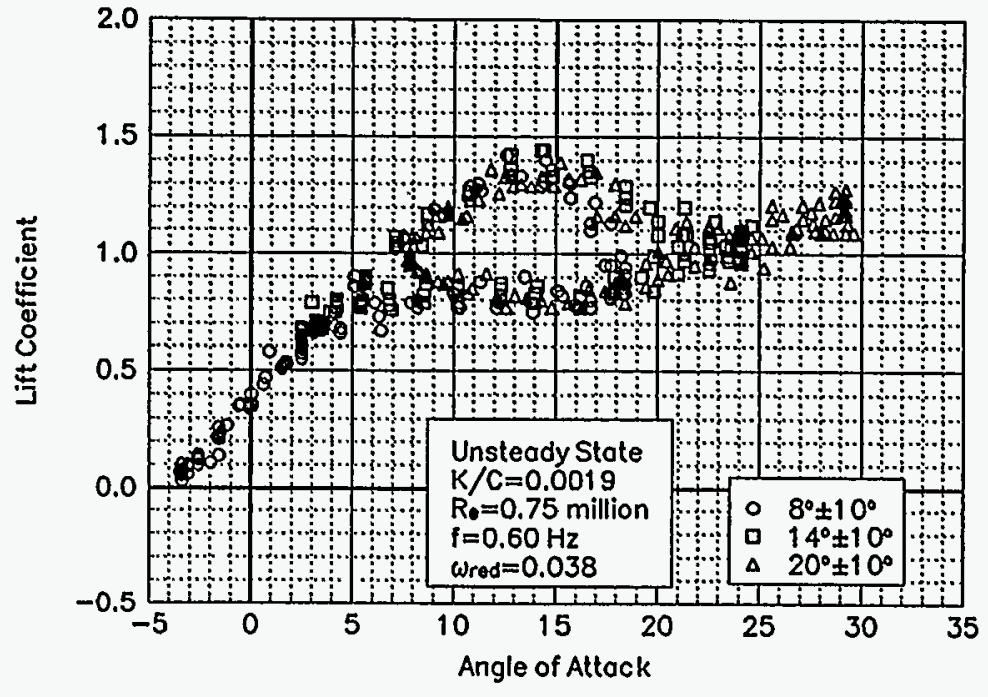

Figure C82. Lift coefficient vs $a$.

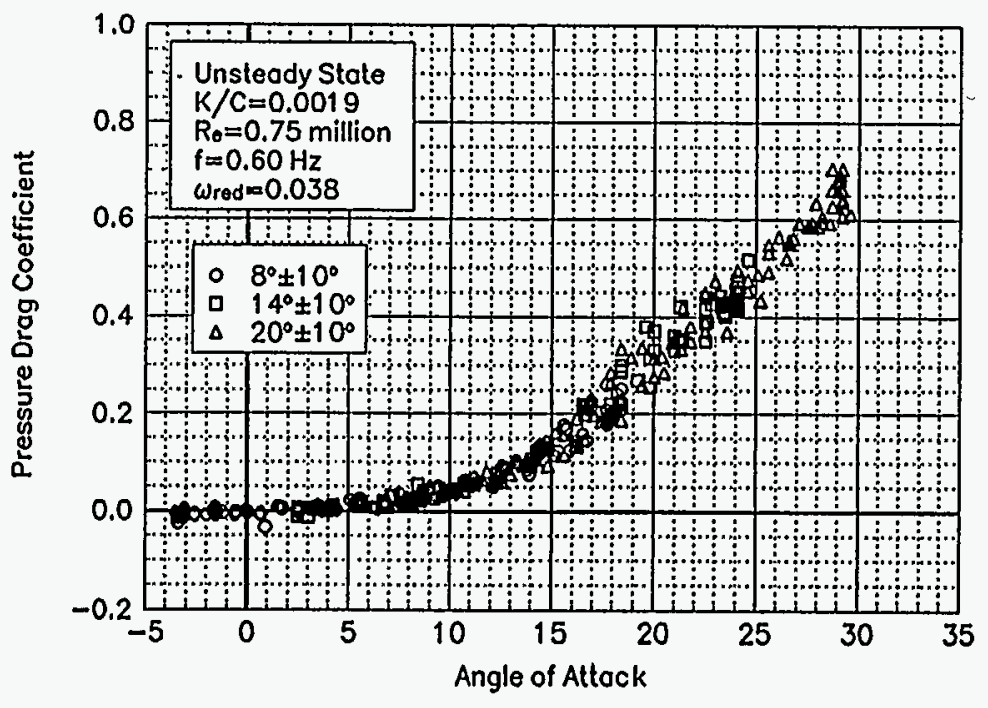

Figure C83. Pressure drag coefficient vs $a$.

\section{NACA 4415 LEGR \\ $\mathrm{Re}=\mathbf{0 . 7 5}$ million \\ $\omega_{\text {reduced }}=0.038$}

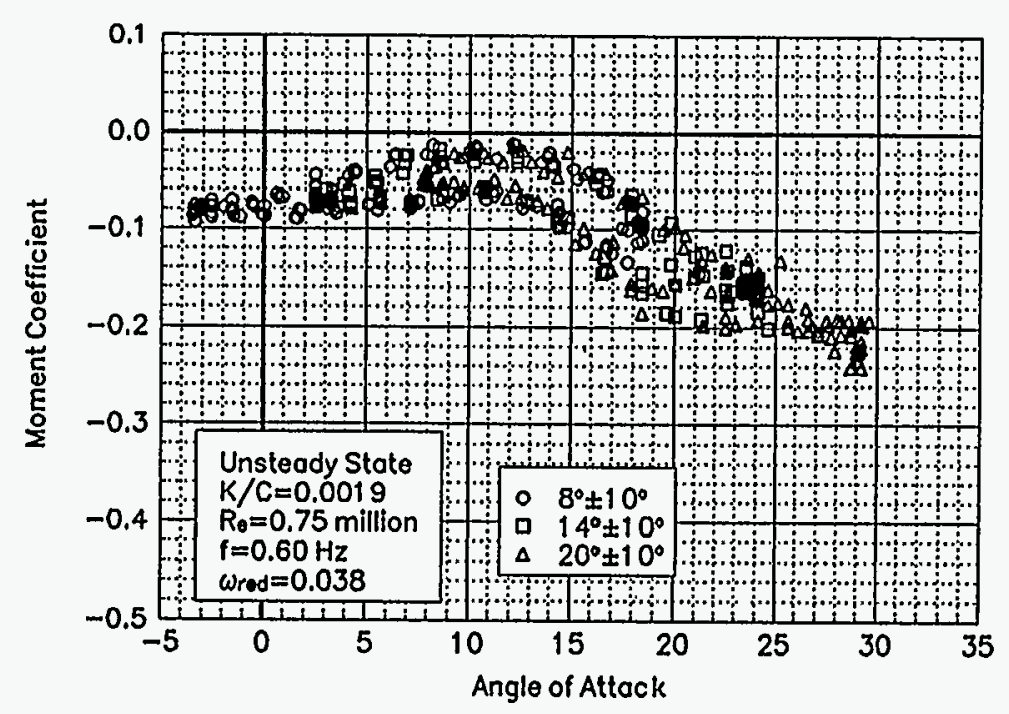

Figure C84. Moment coefficient vs $a$. 

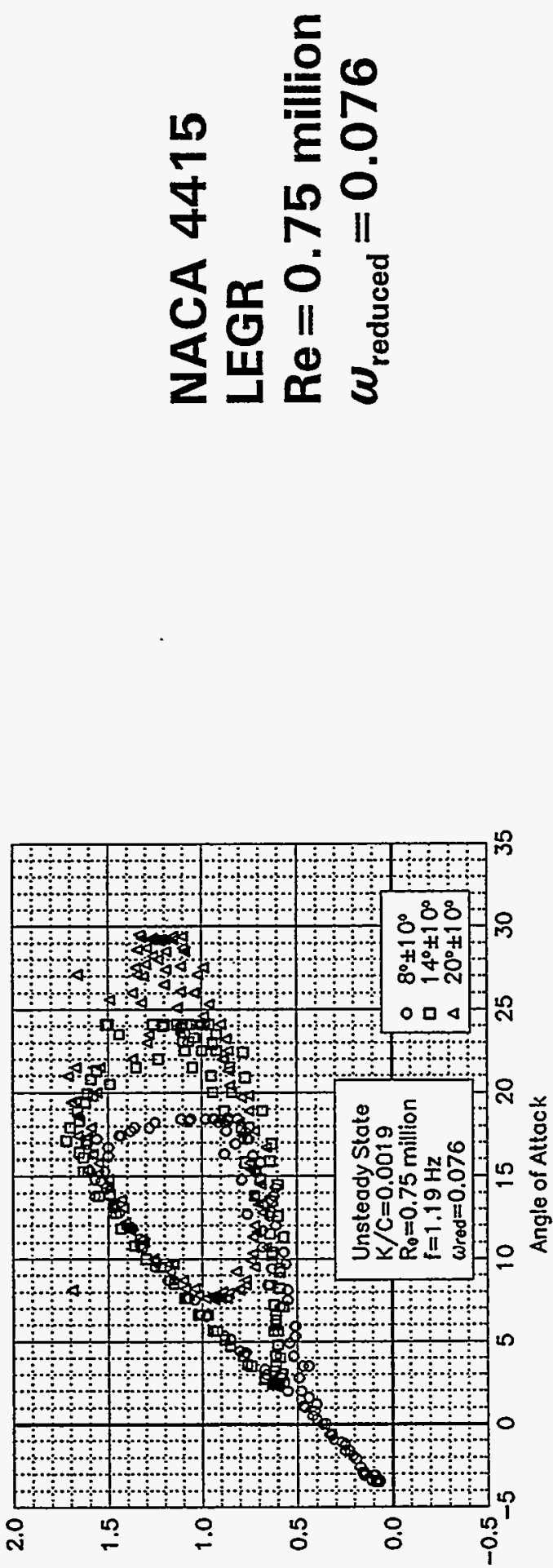

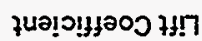

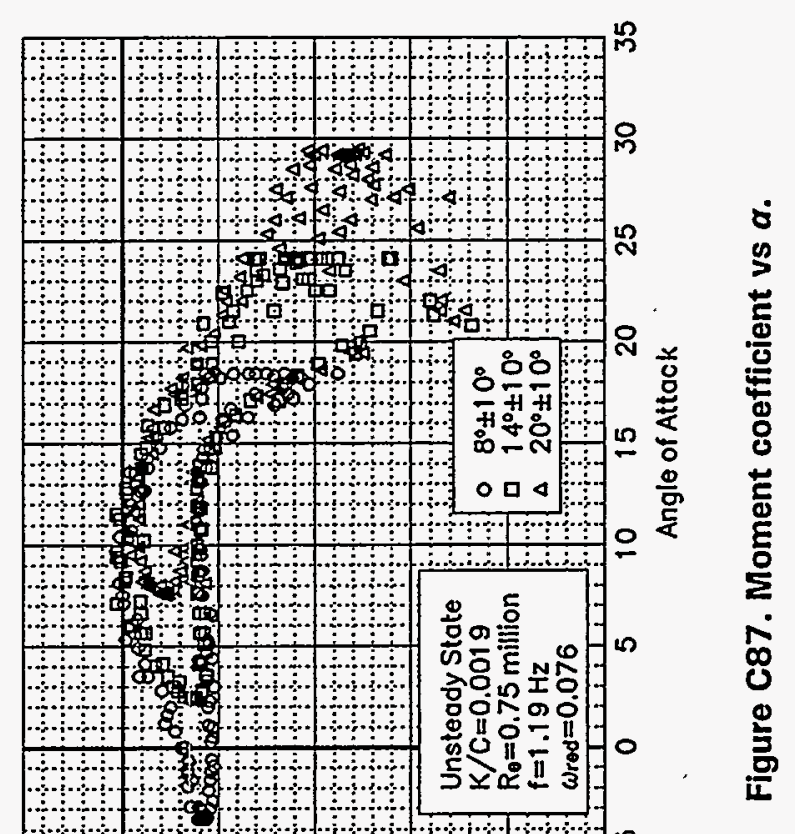

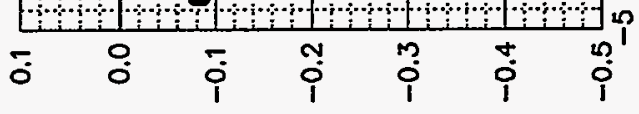

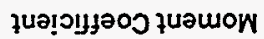

i̊

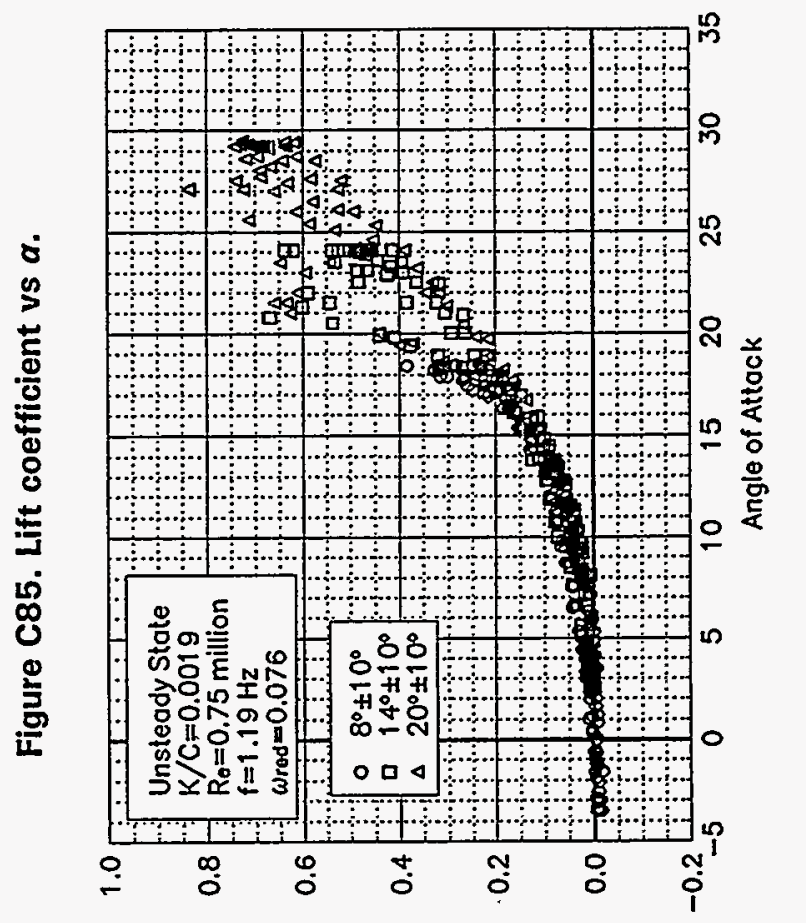

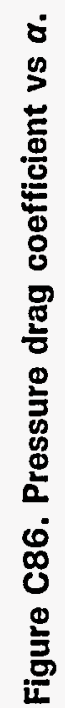



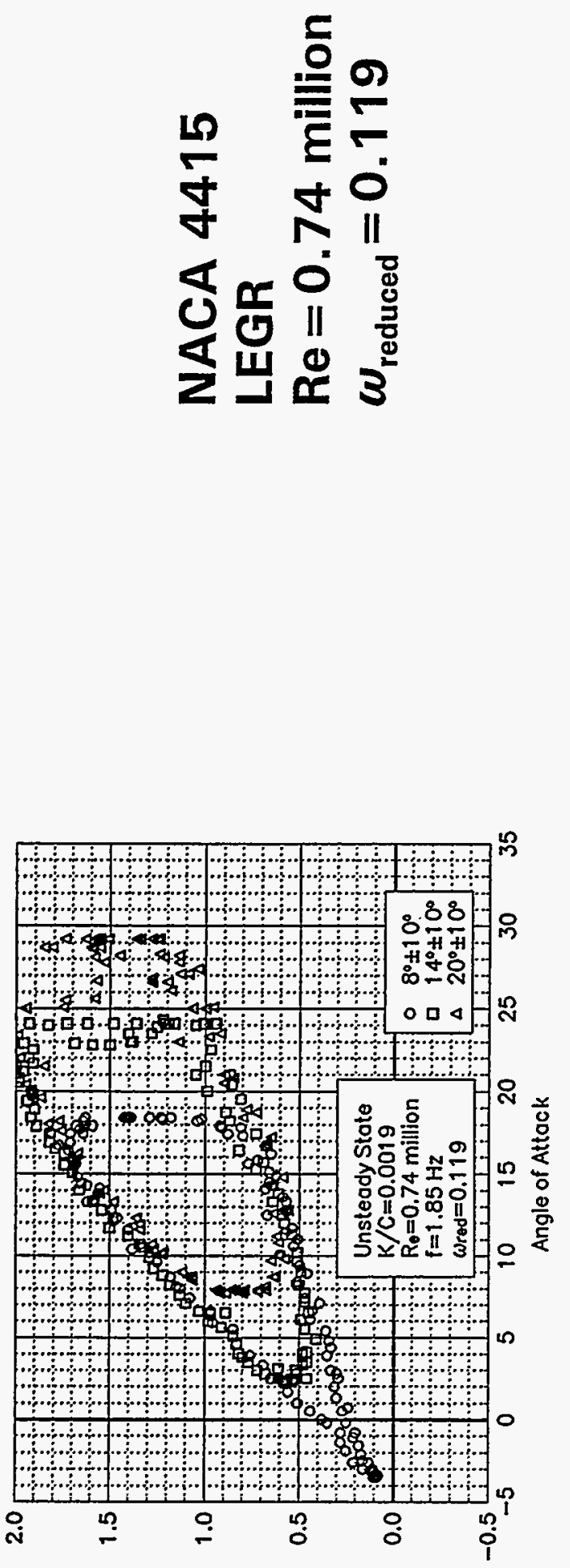

วนจุว!มรวัว $7 ! า$

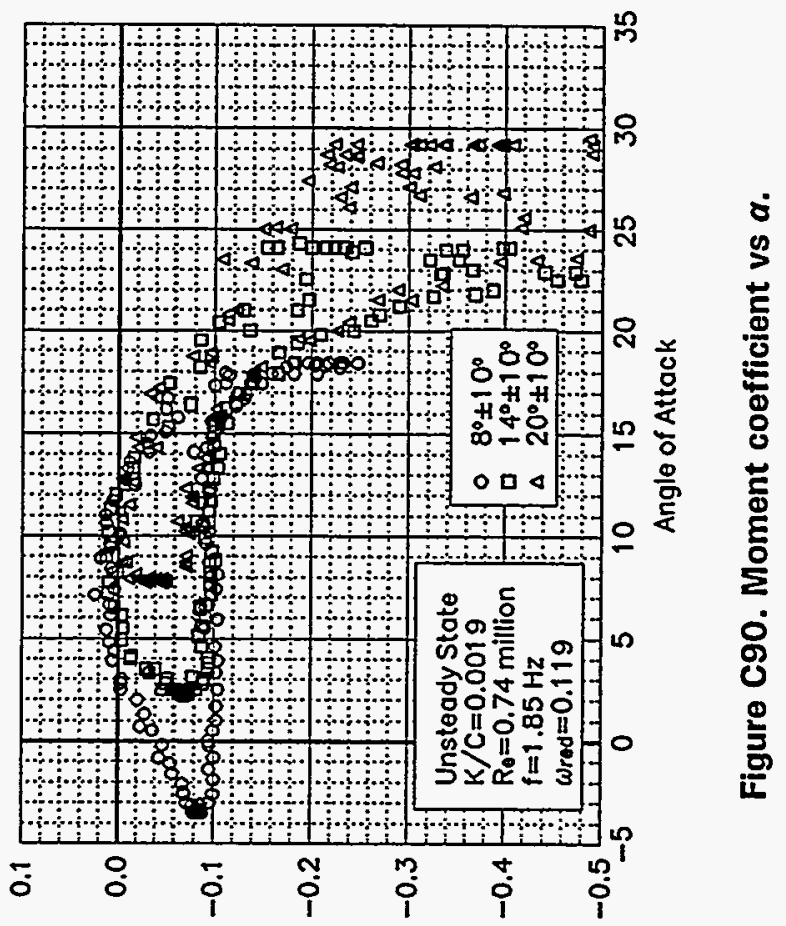

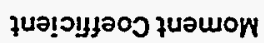

岛

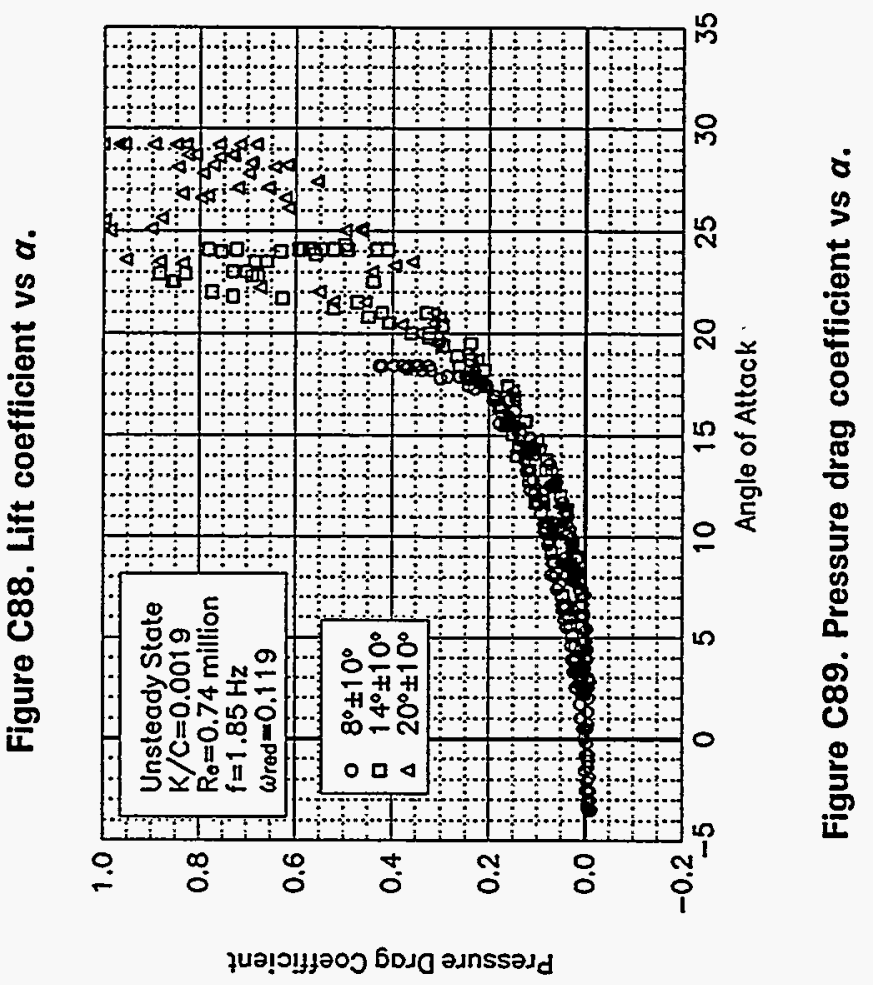




\section{Unsteady Airfoil Characteristics}

$$
\pm 10^{\circ} \text { Sine, } \mathrm{Re}=1 \text { million }
$$



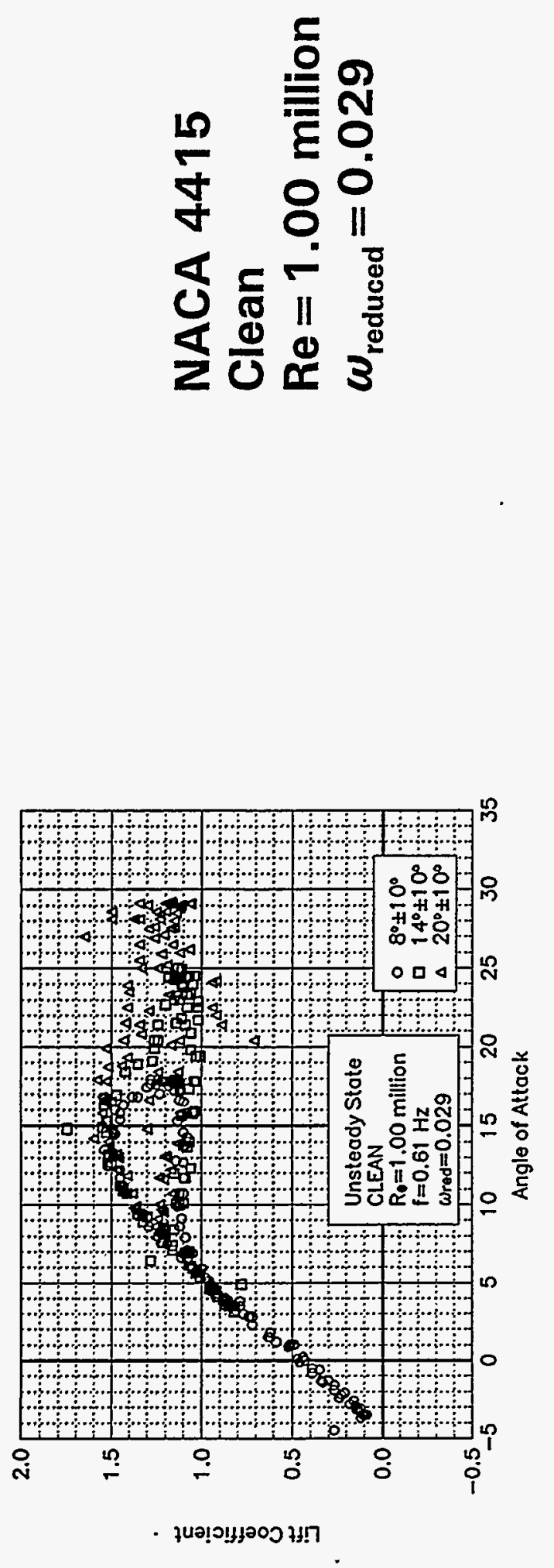

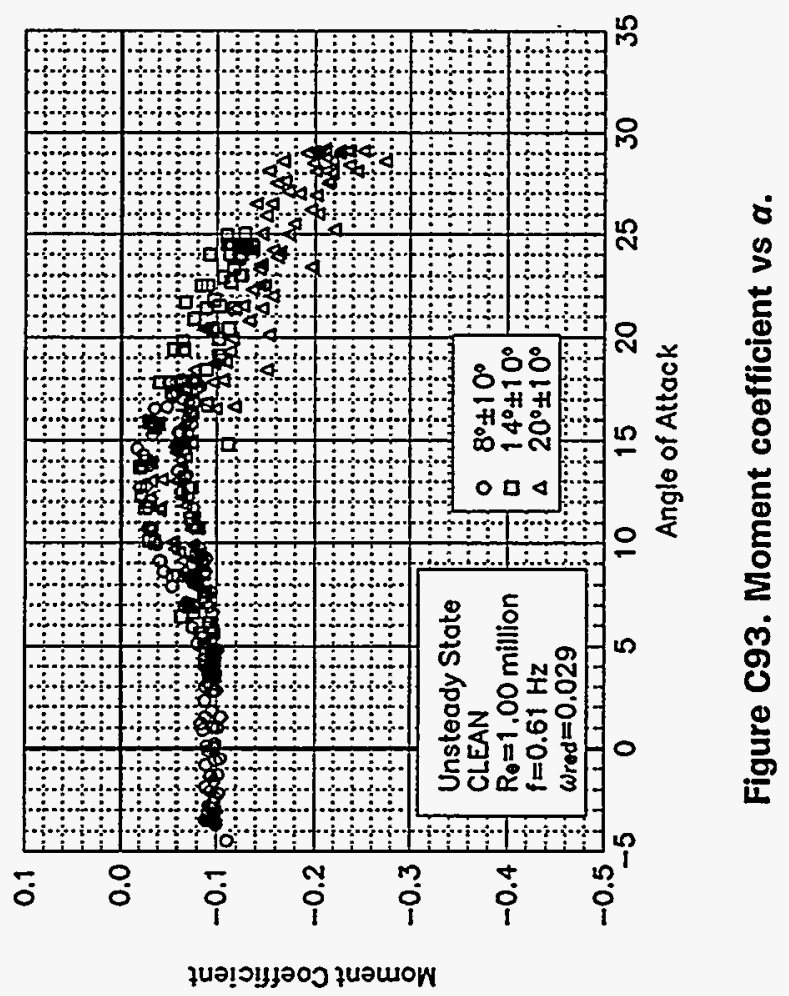

8

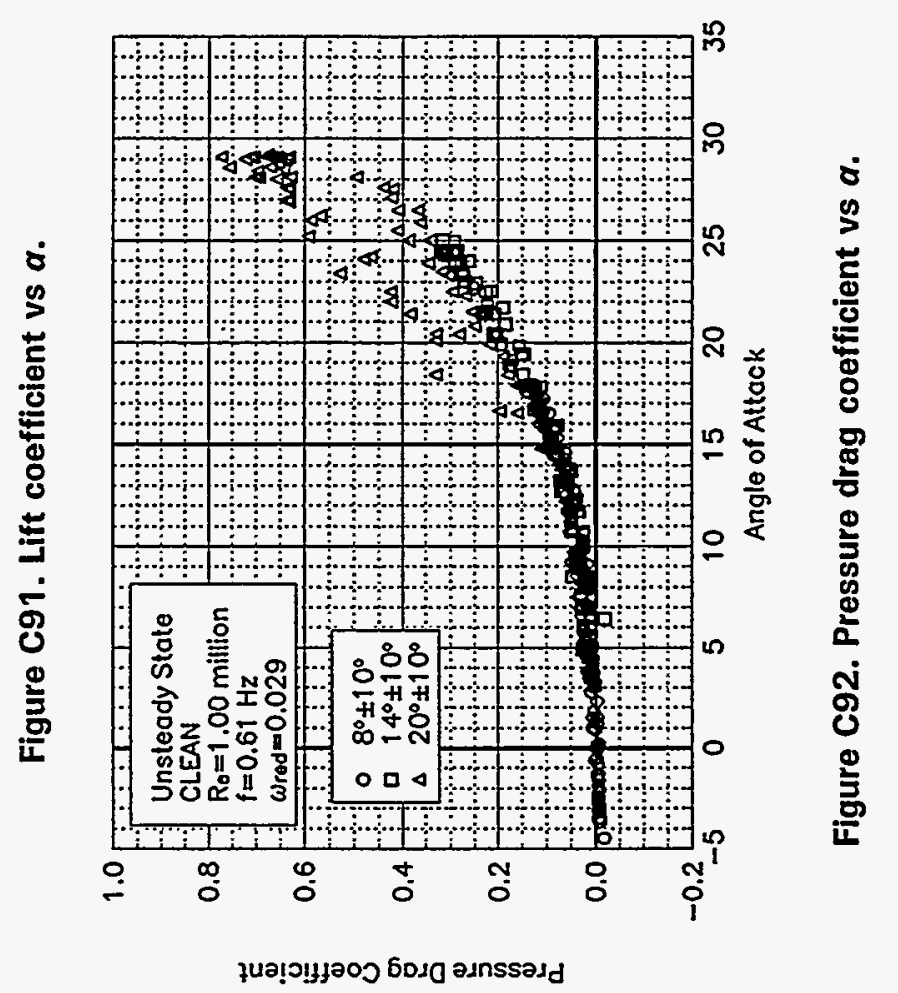



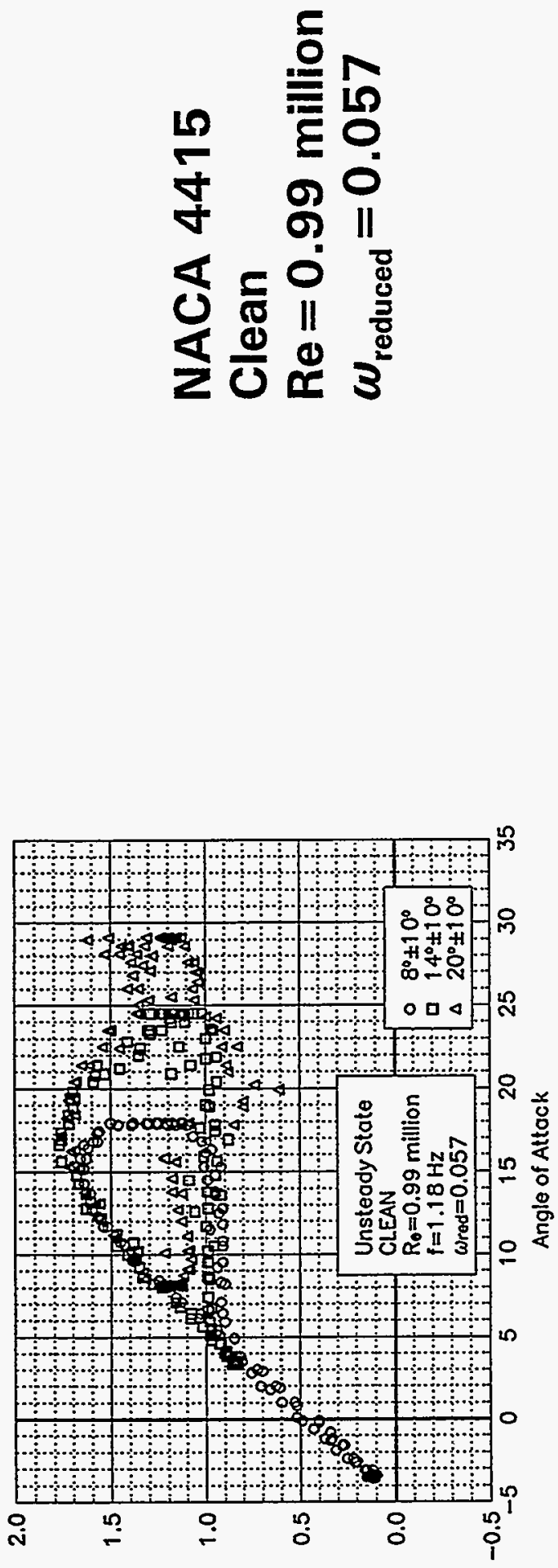

\}นขเจ!มวคว ¥แ!า

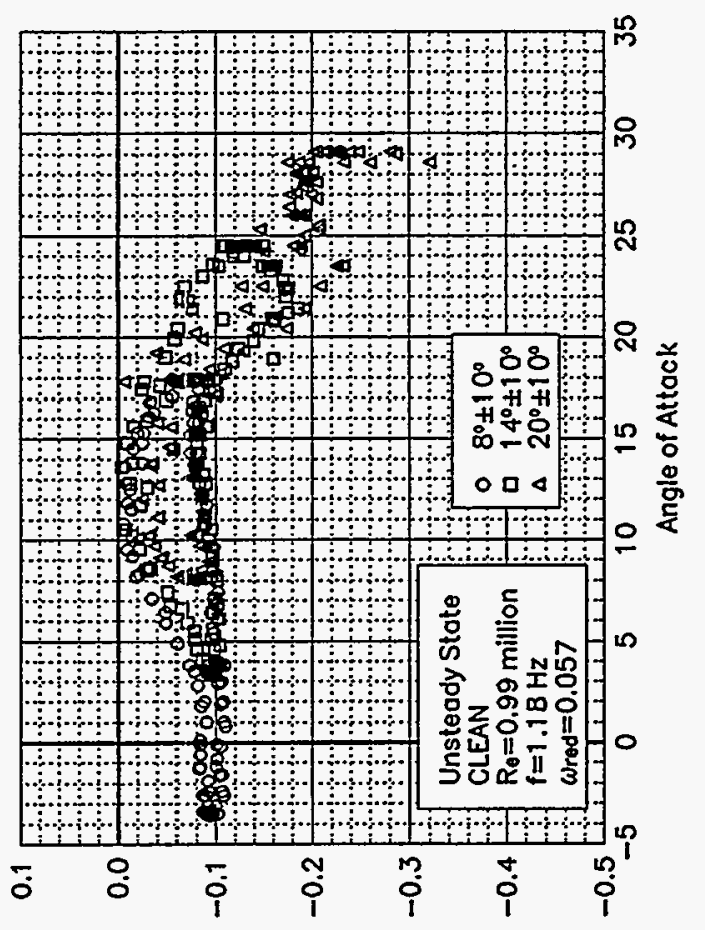

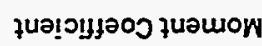

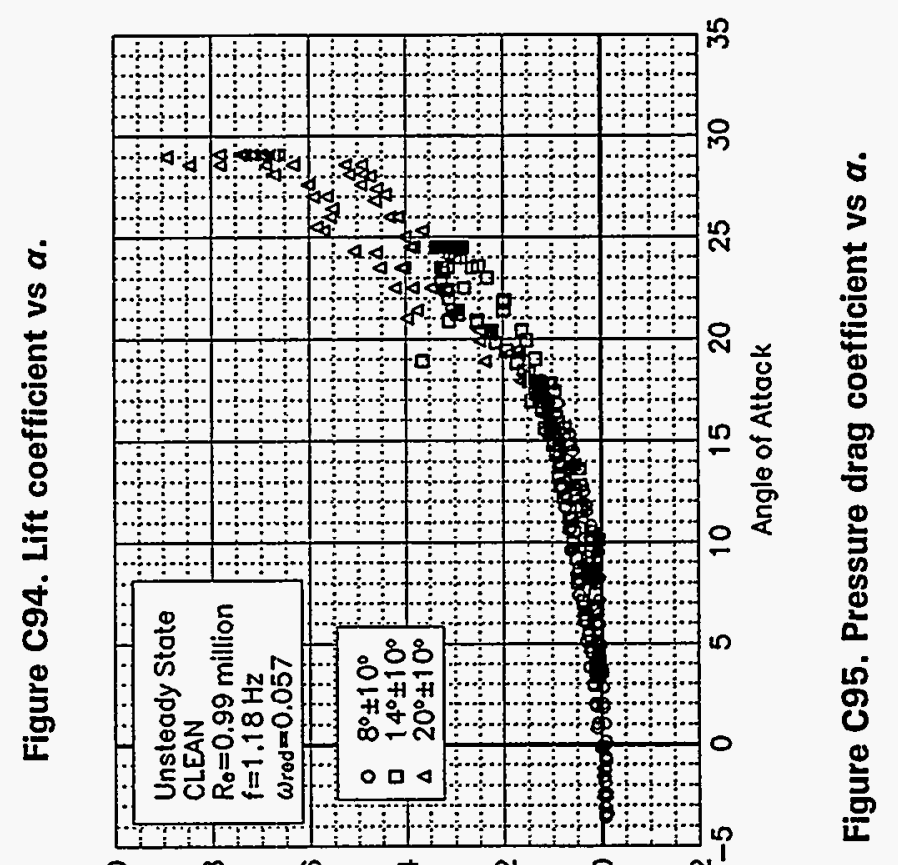

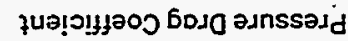



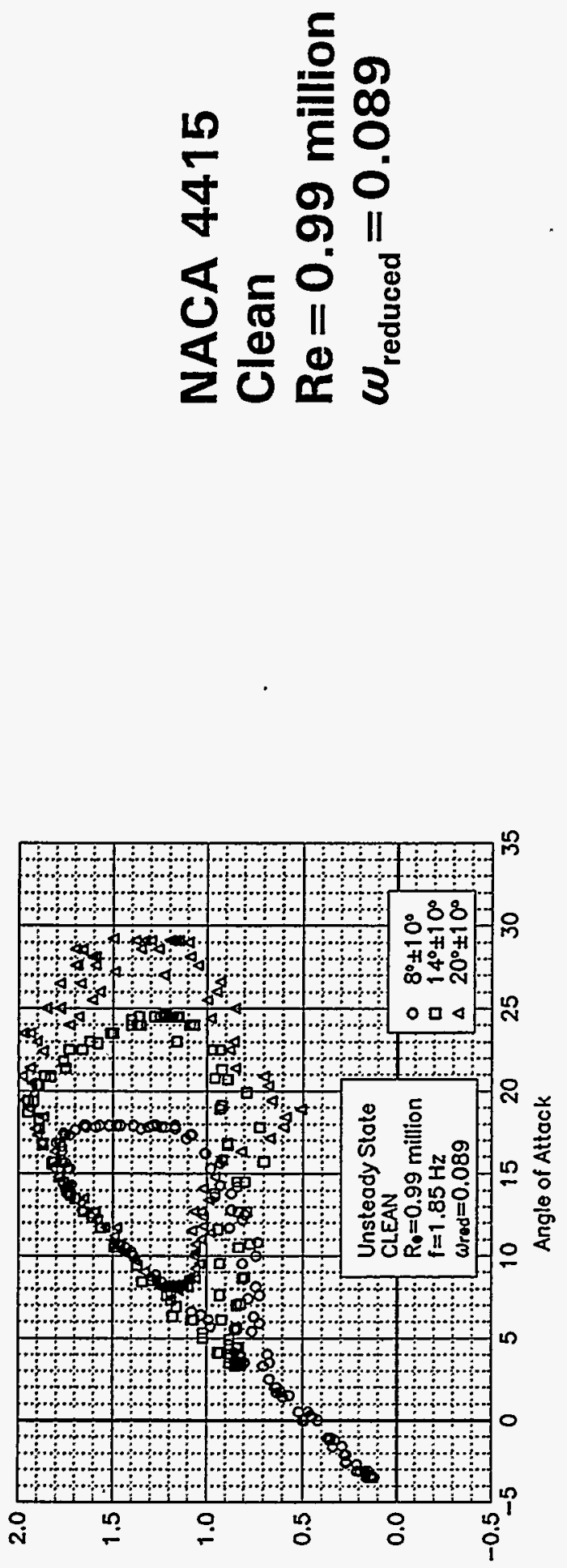

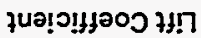

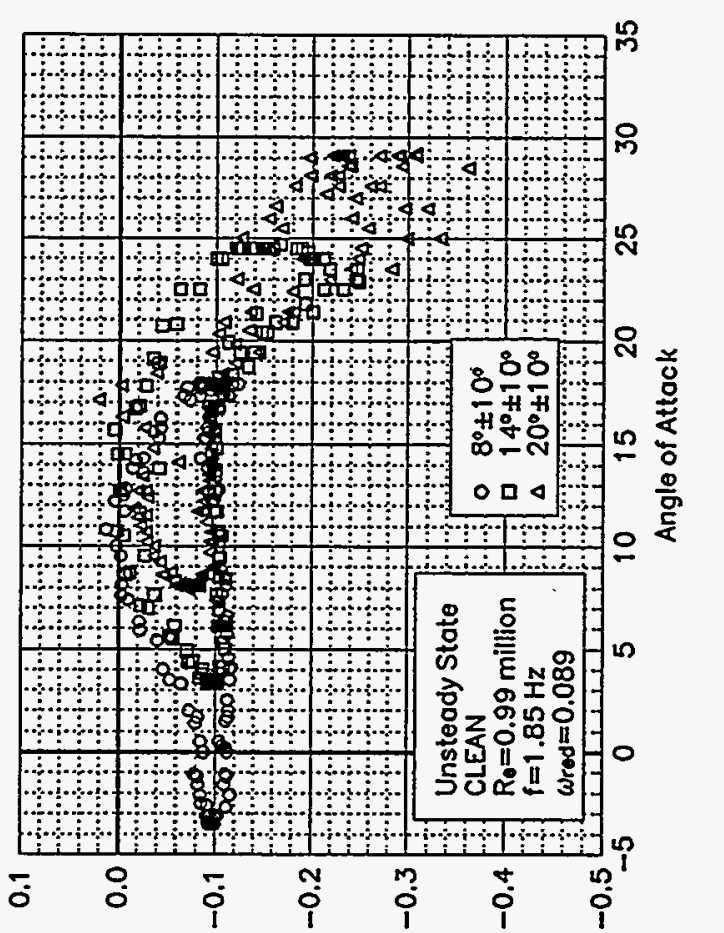

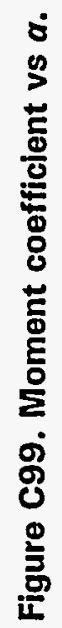

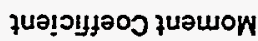

F

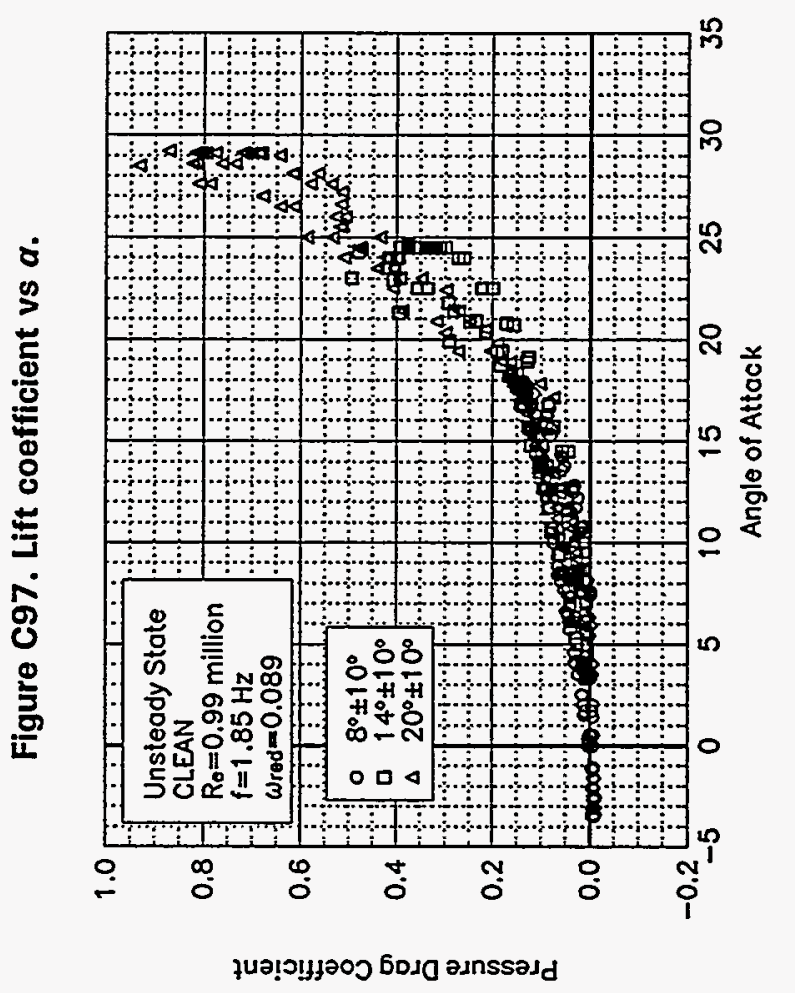

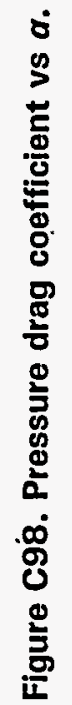



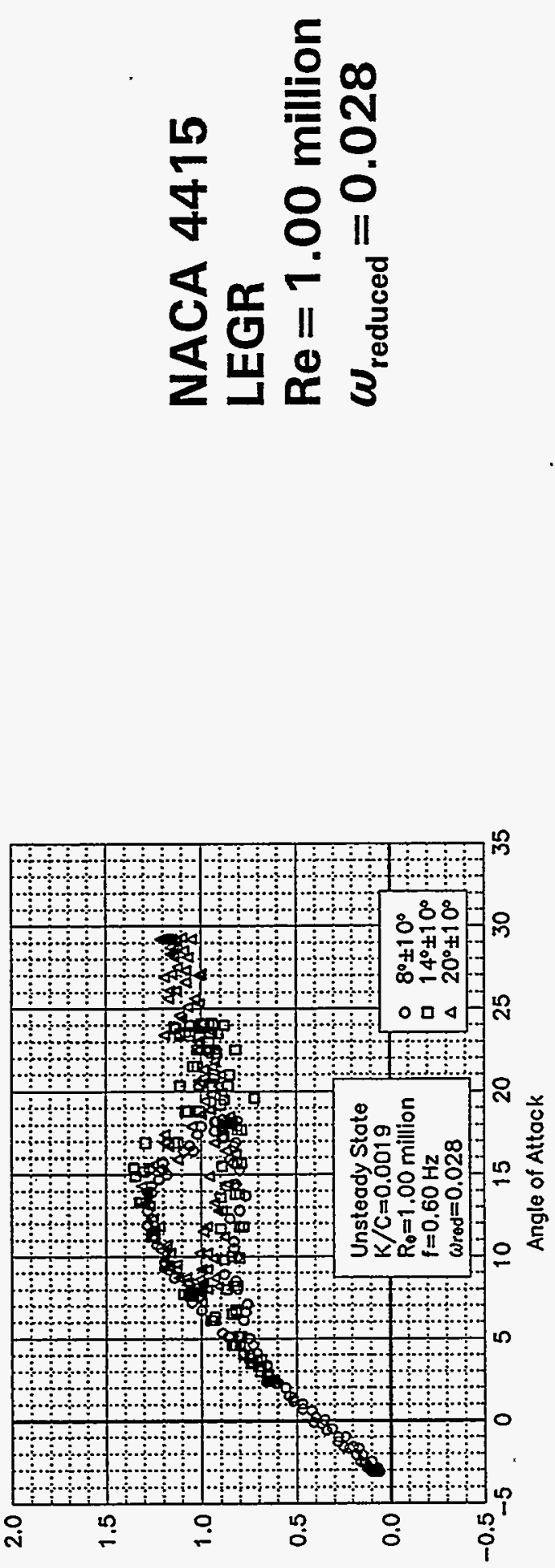

Ұนว!ว!มรว०ว 7!!7

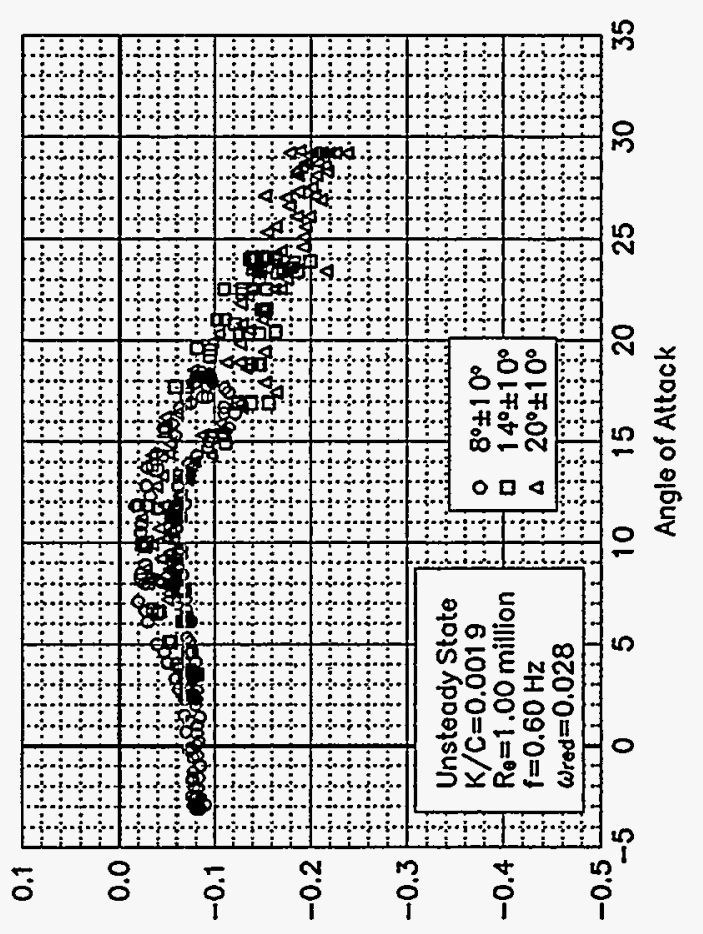

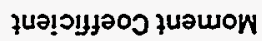

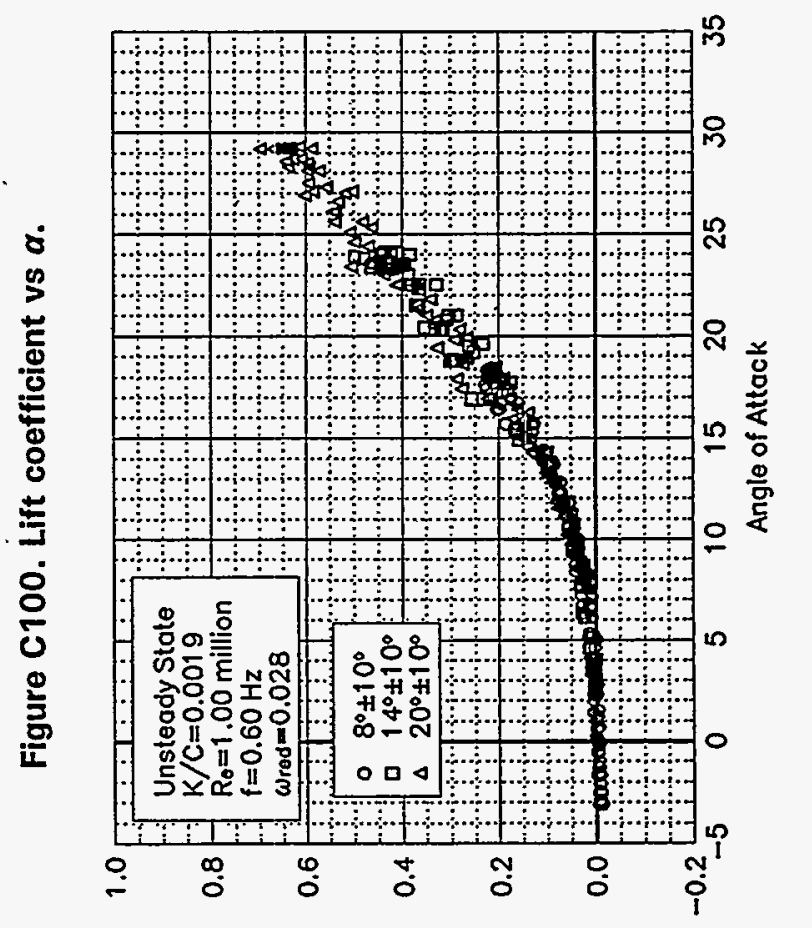

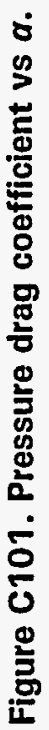



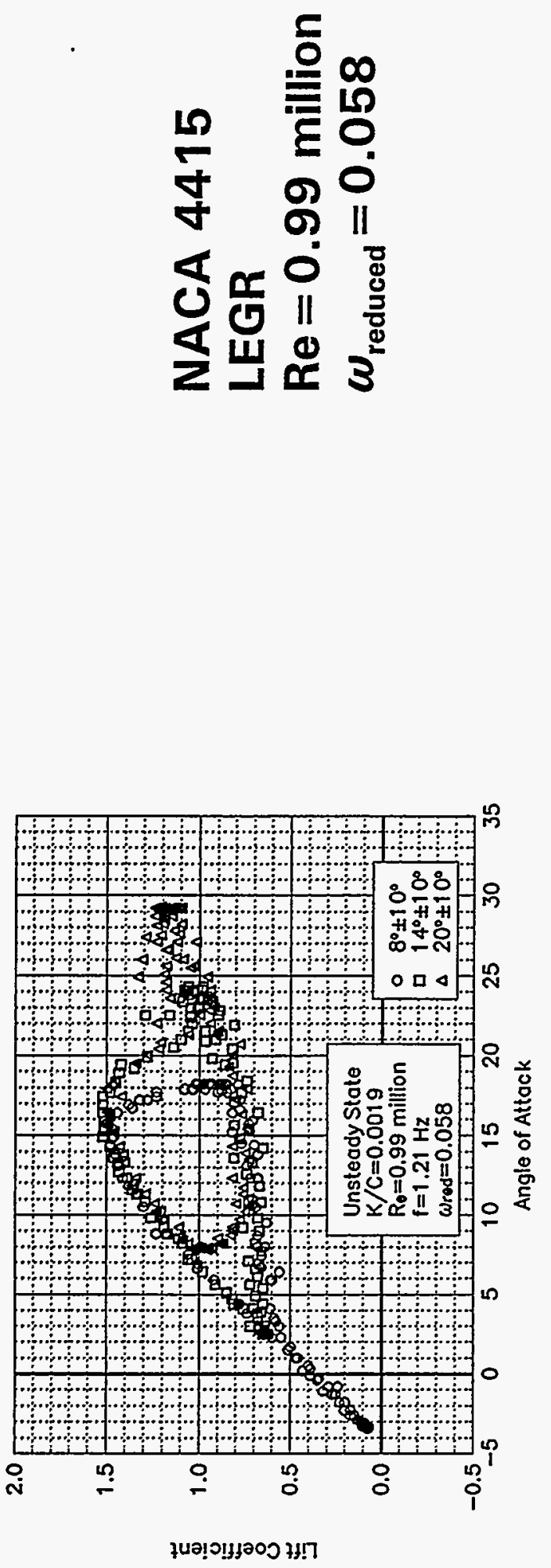

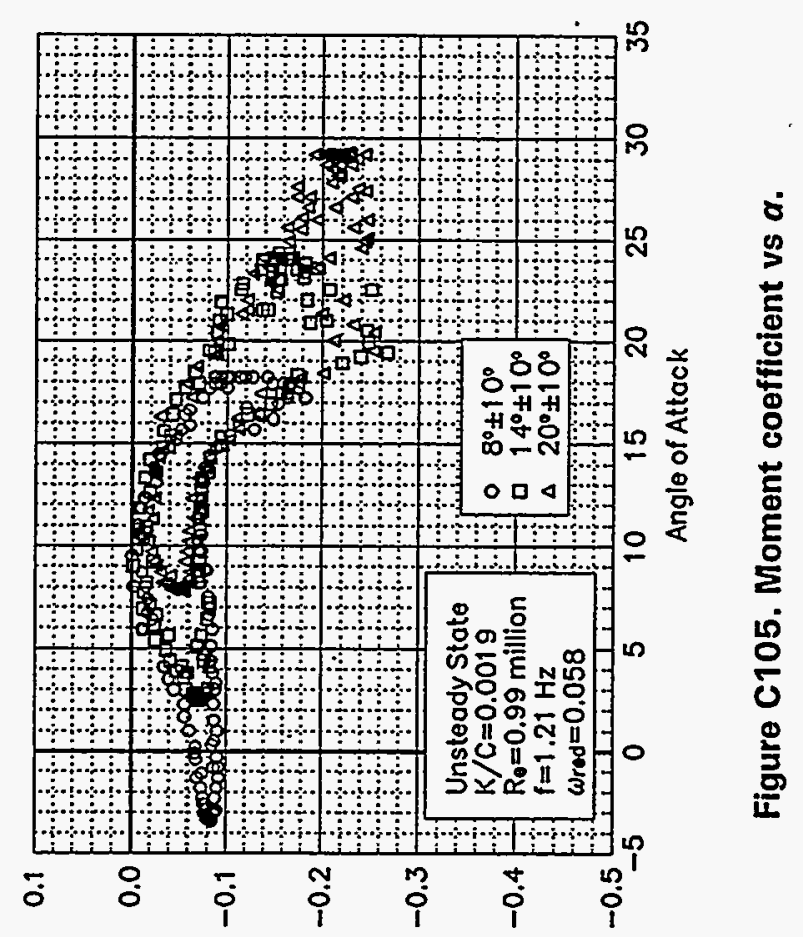

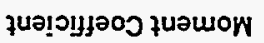

$\underset{J}{J}$

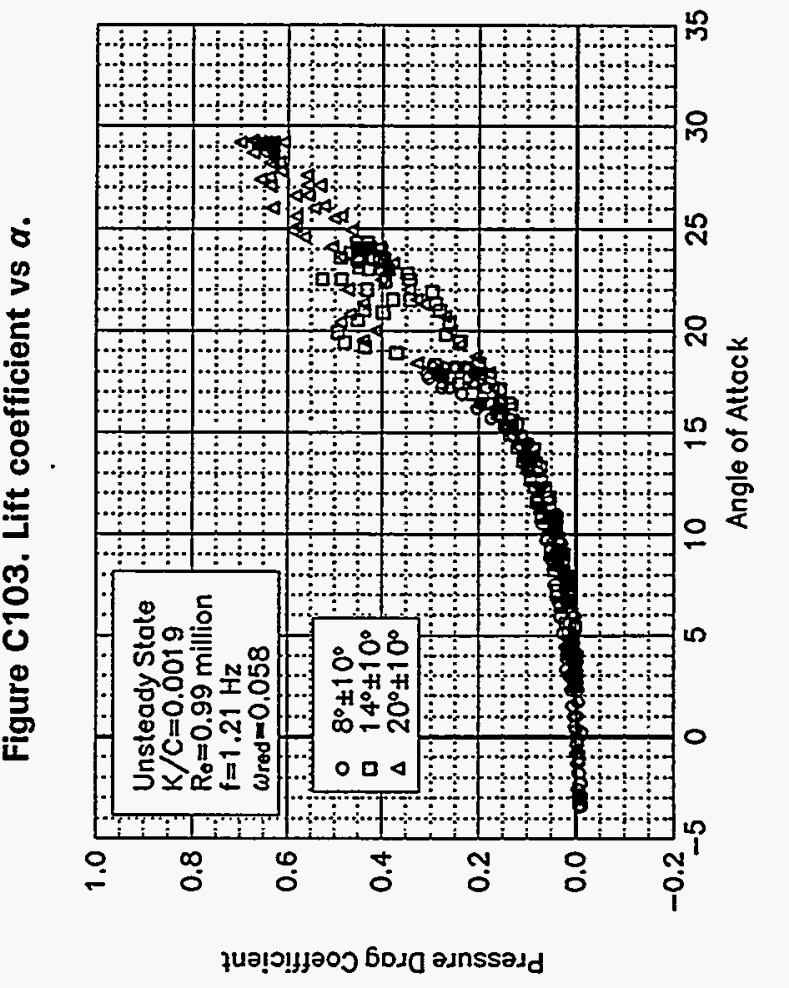



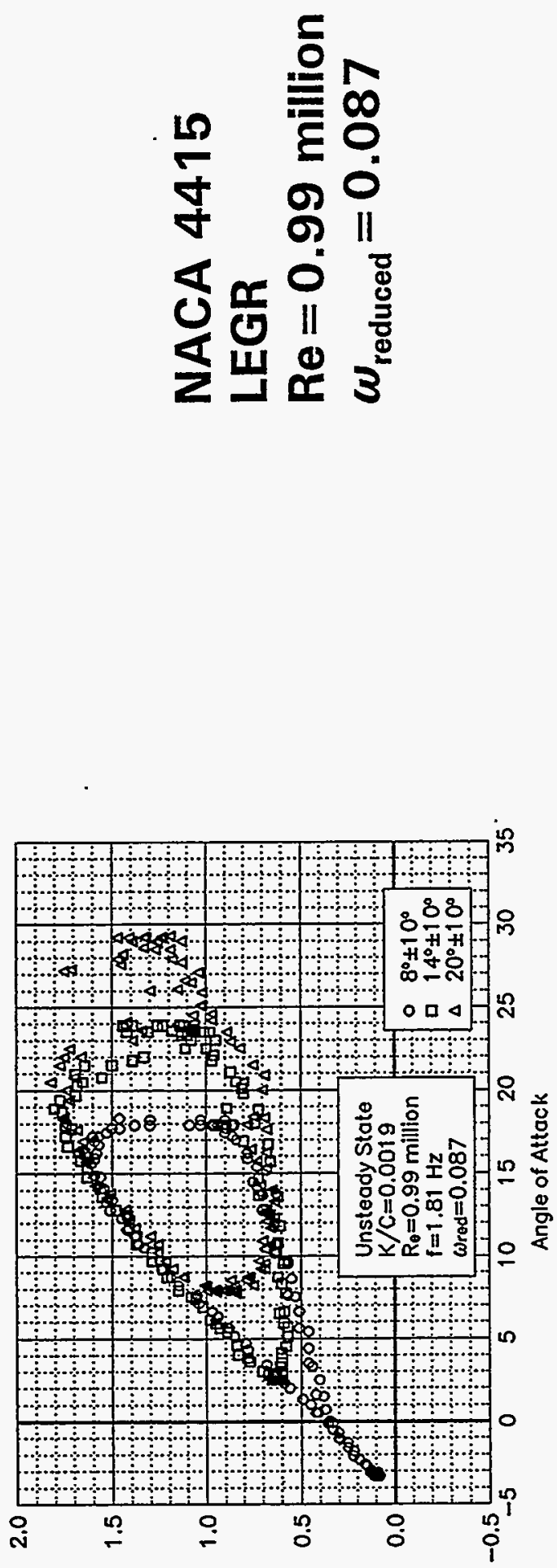

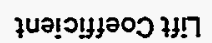

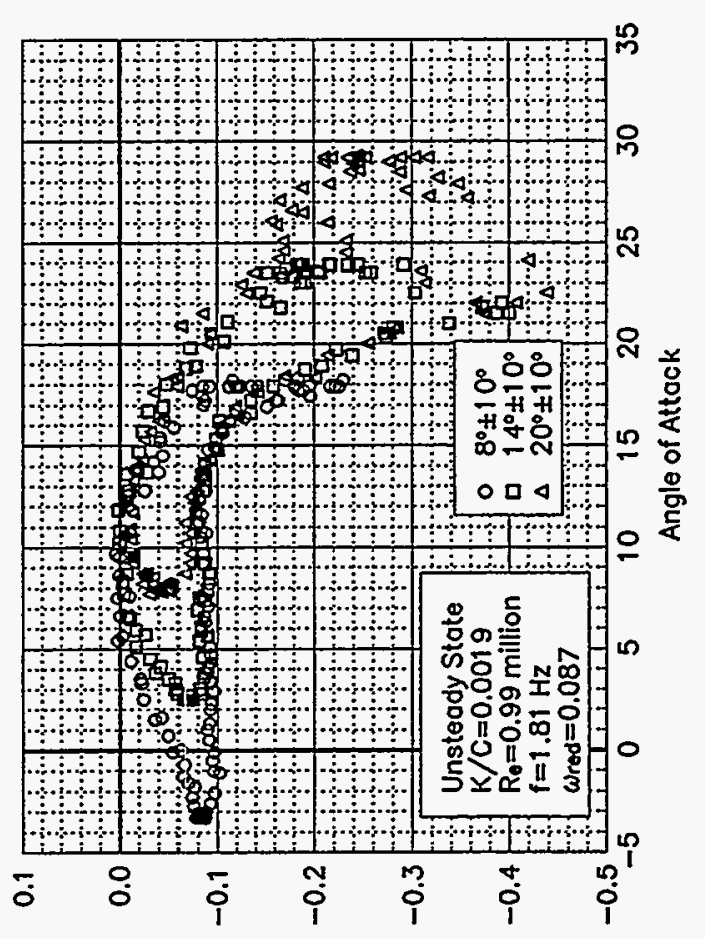

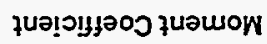

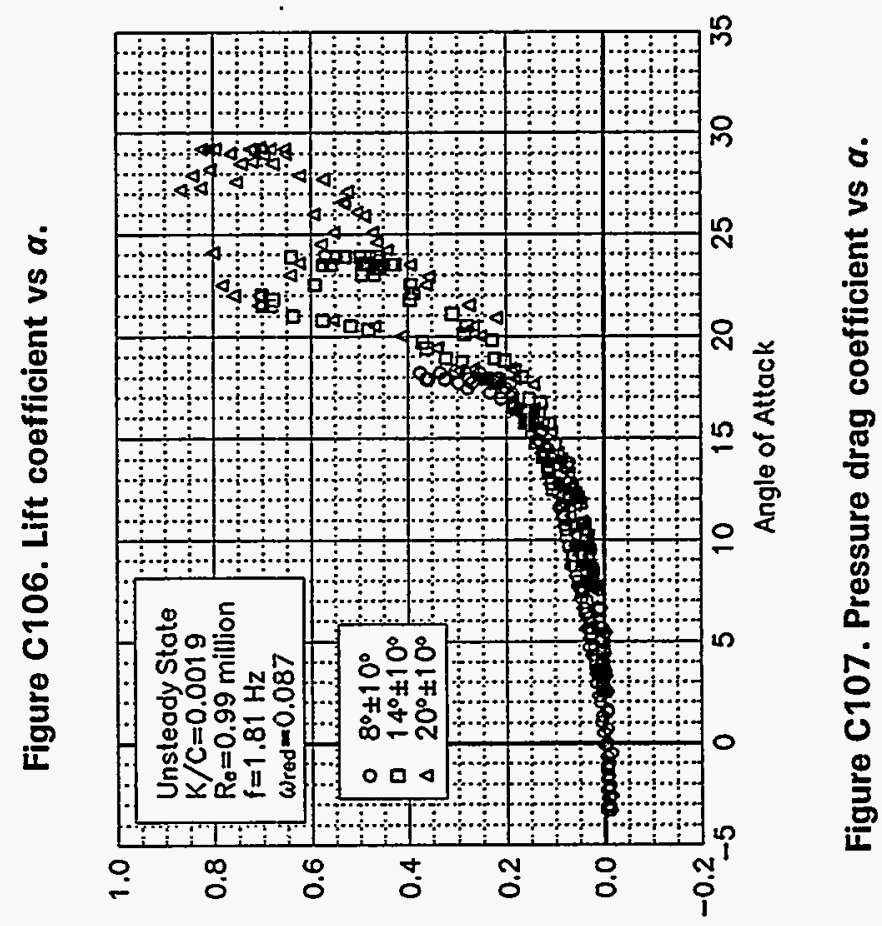

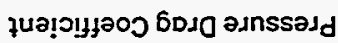




\section{Unsteady Airfoil Characteristics \\ $\pm 10^{\circ}$ Sine, $\operatorname{Re}=1.25$ million}



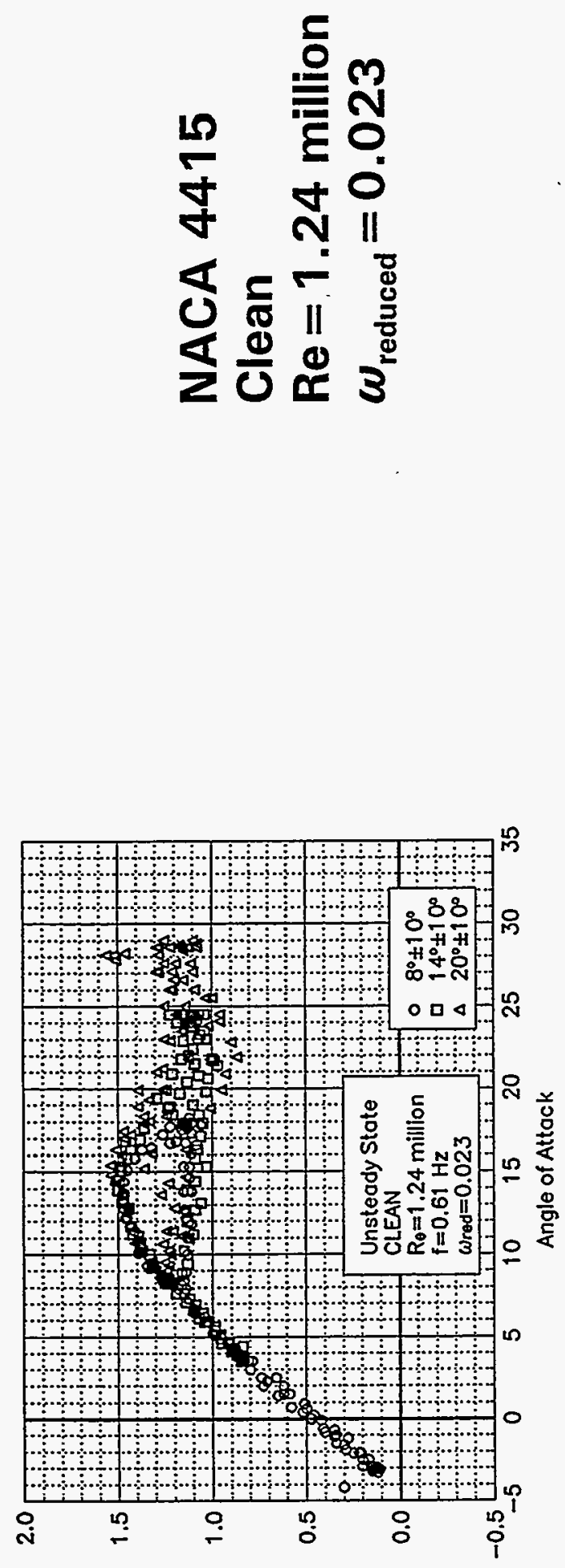

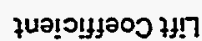

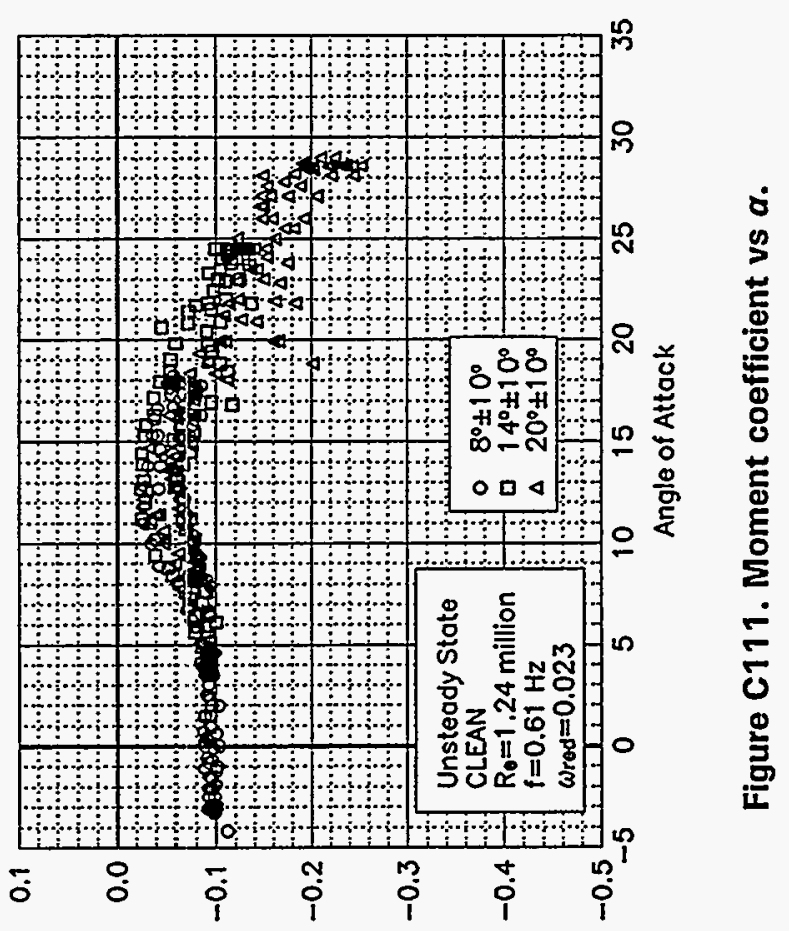

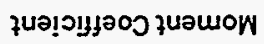

J

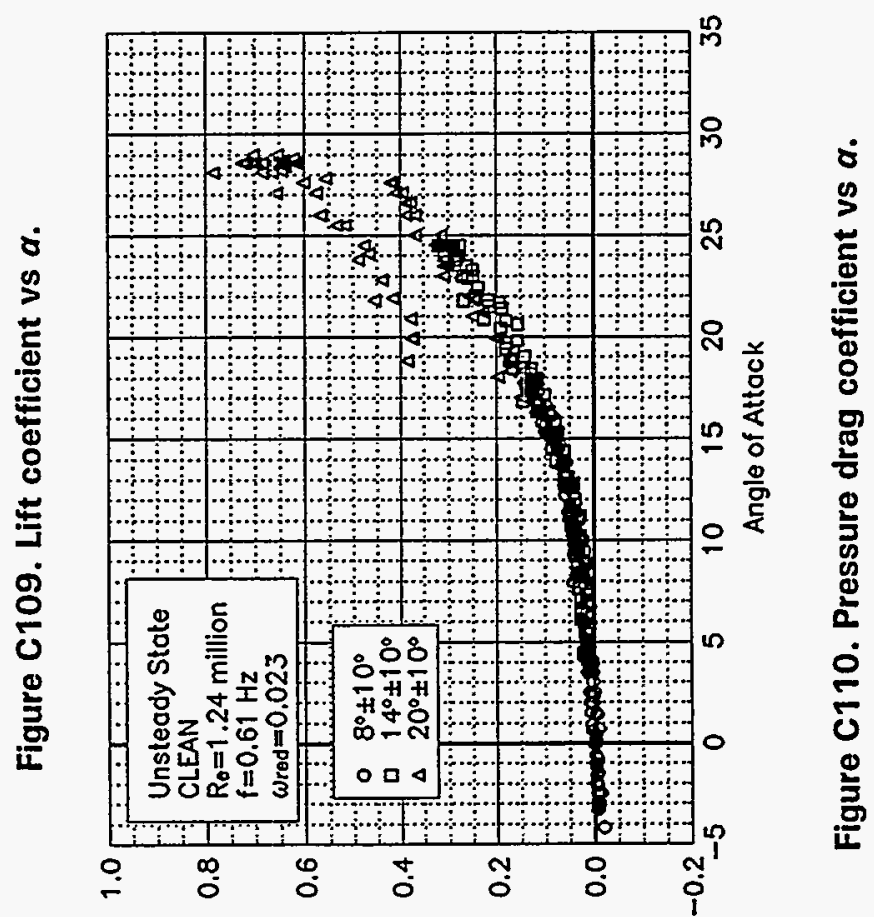

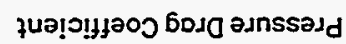




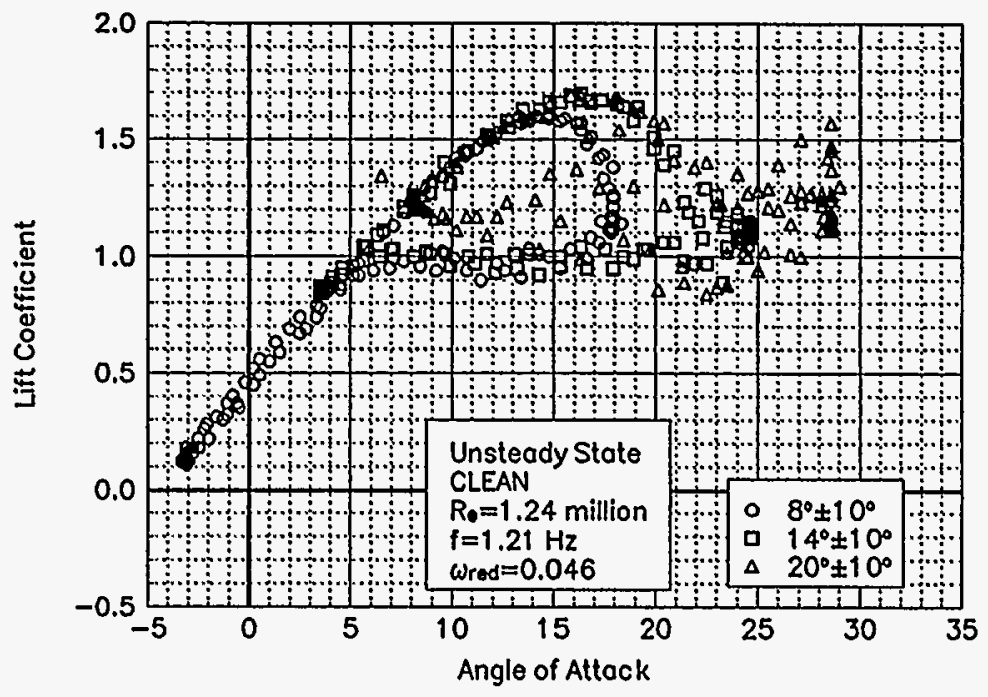

Figure C112. Lift coefficient vs $a$.

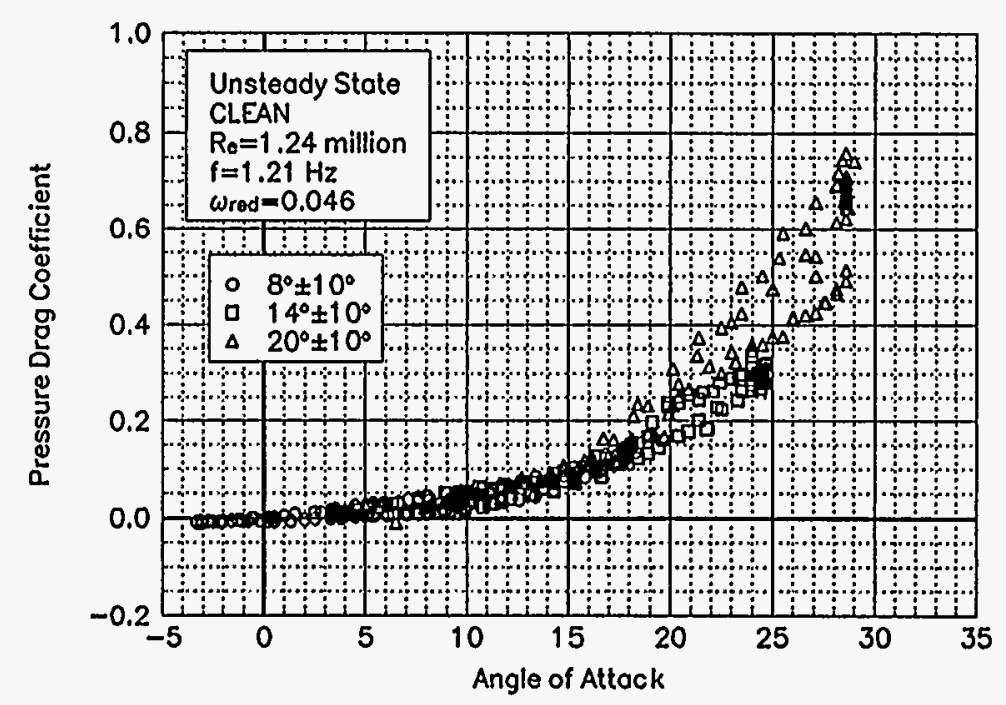

Figure C113. Pressure drag coefficient vs $a$.

\section{NACA 4415 \\ Clean \\ $\mathrm{Re}=1.24$ million \\ $\omega_{\text {reduced }}=0.046$}

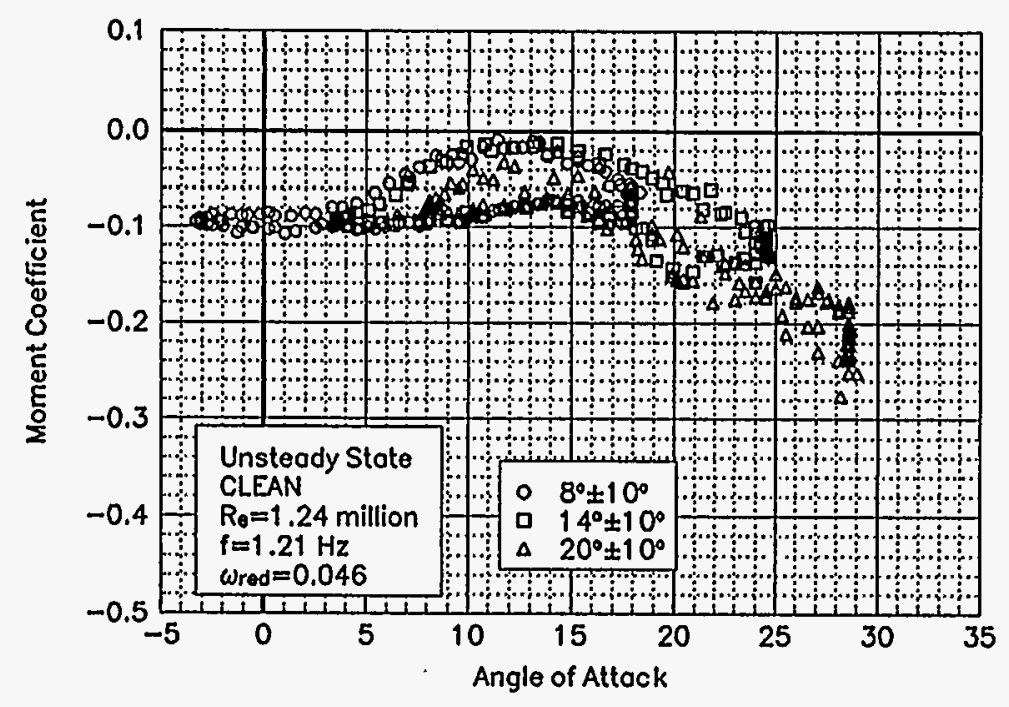

Figure C114. Moment coefficient vs $\alpha$. 

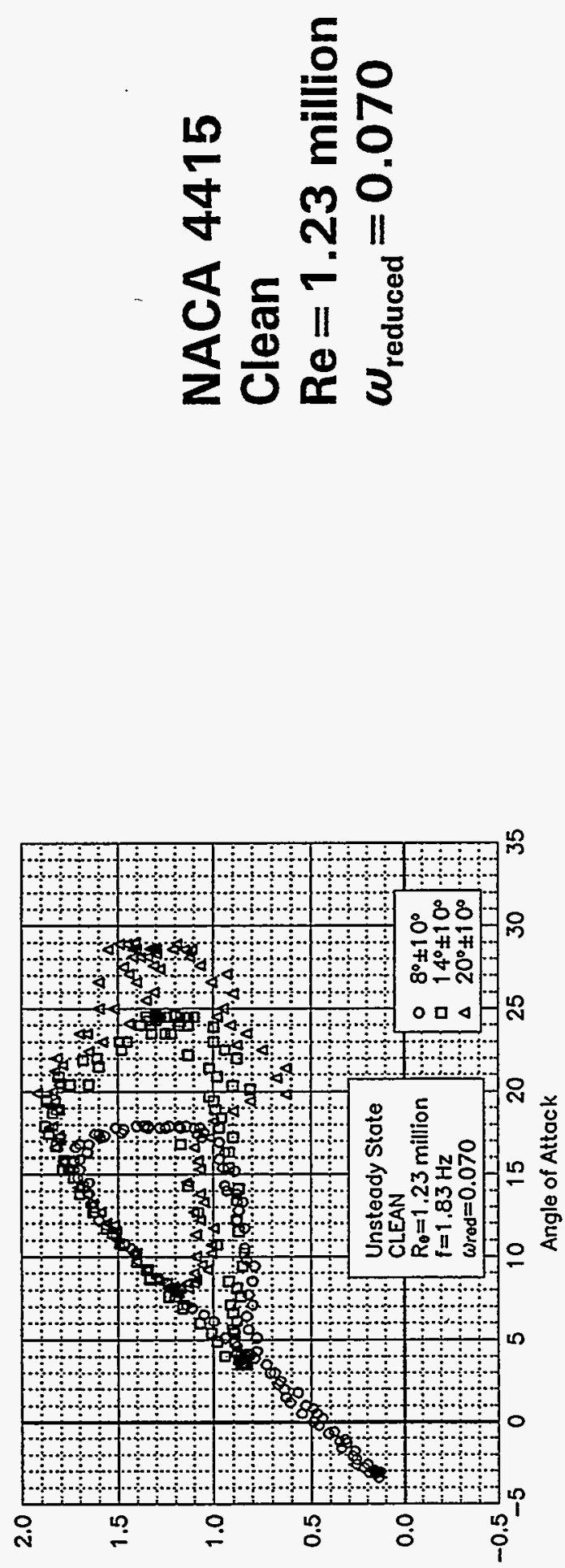

qua!ว!มมอว $\{1 ! 7$

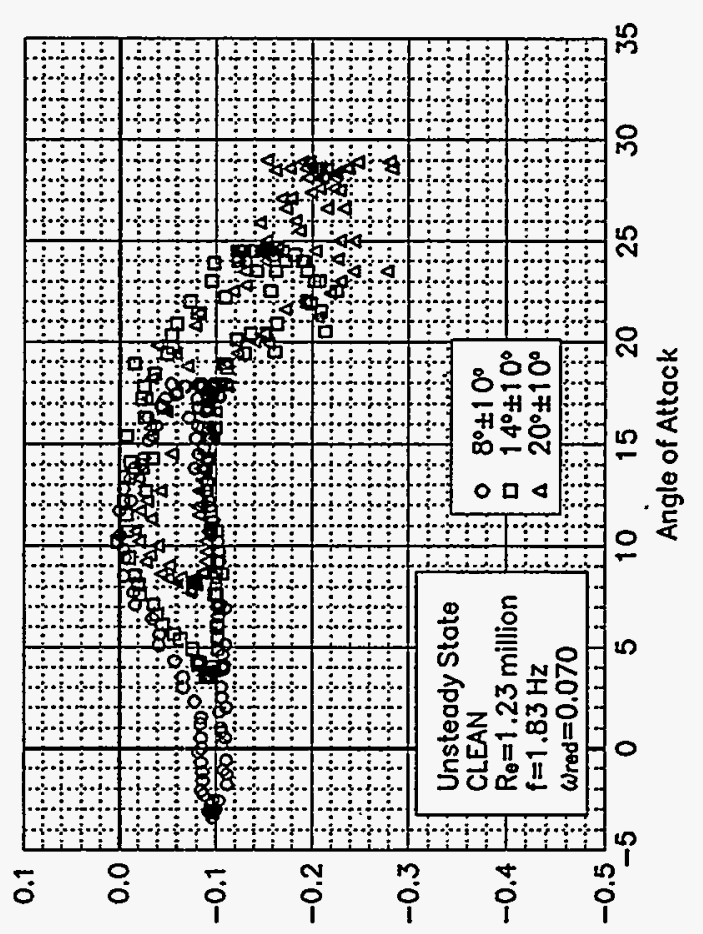

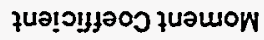

\section{\%}

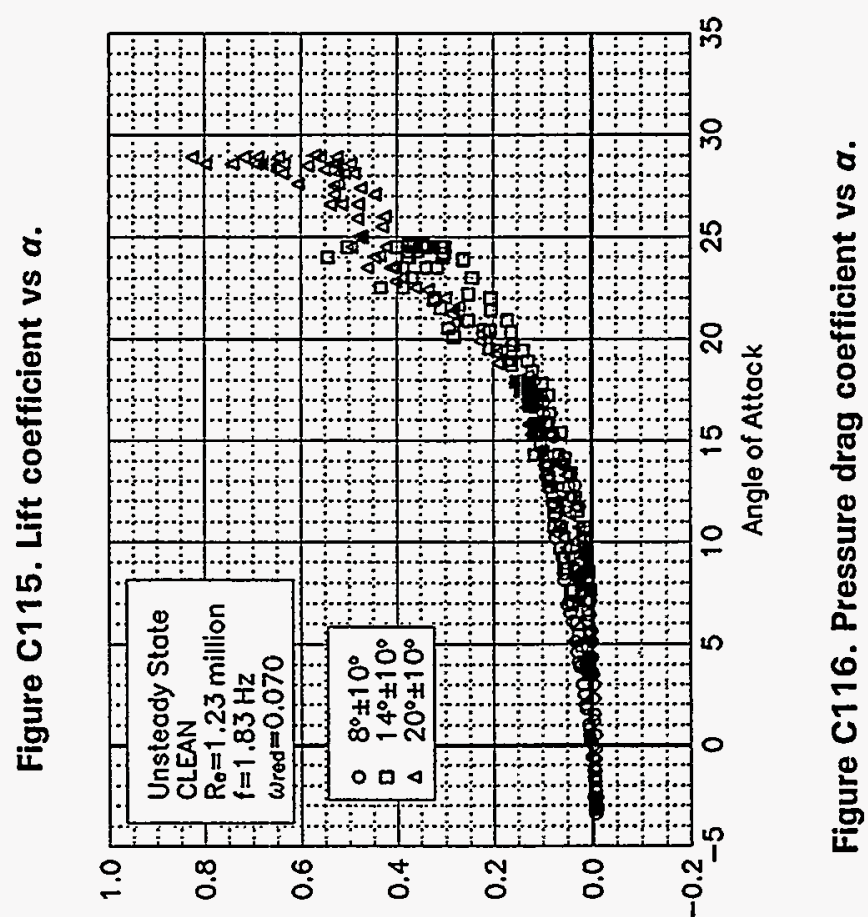

qua!ว!f\}ə0ว 60دo asnssadd 
Pressure Drag Coefficient

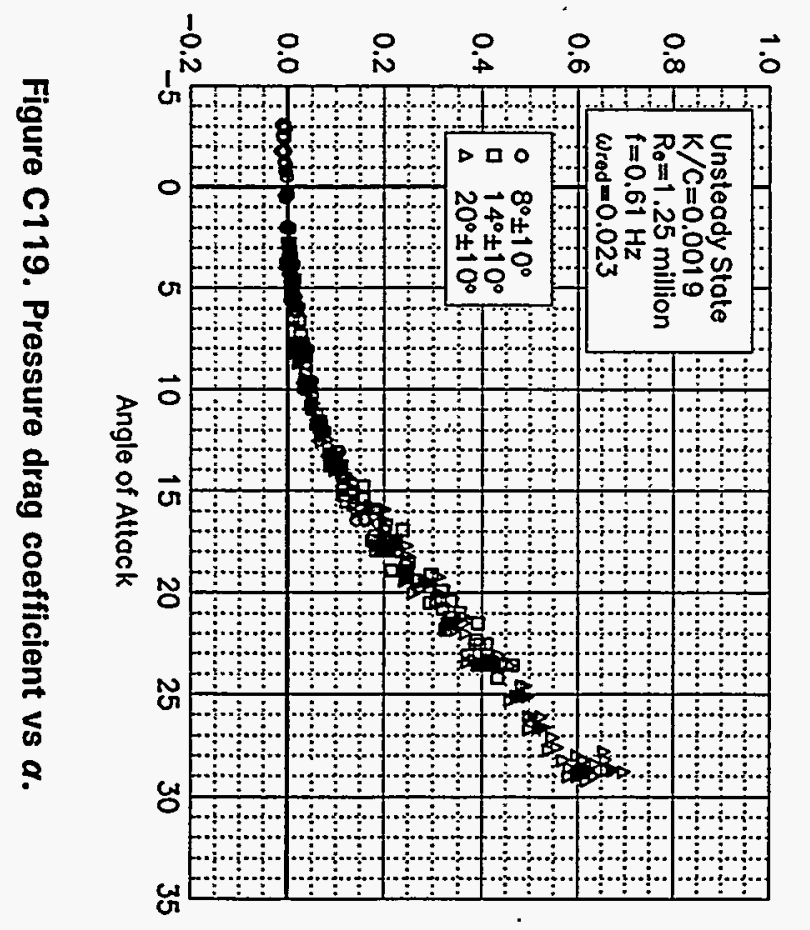

Lift Coefficient

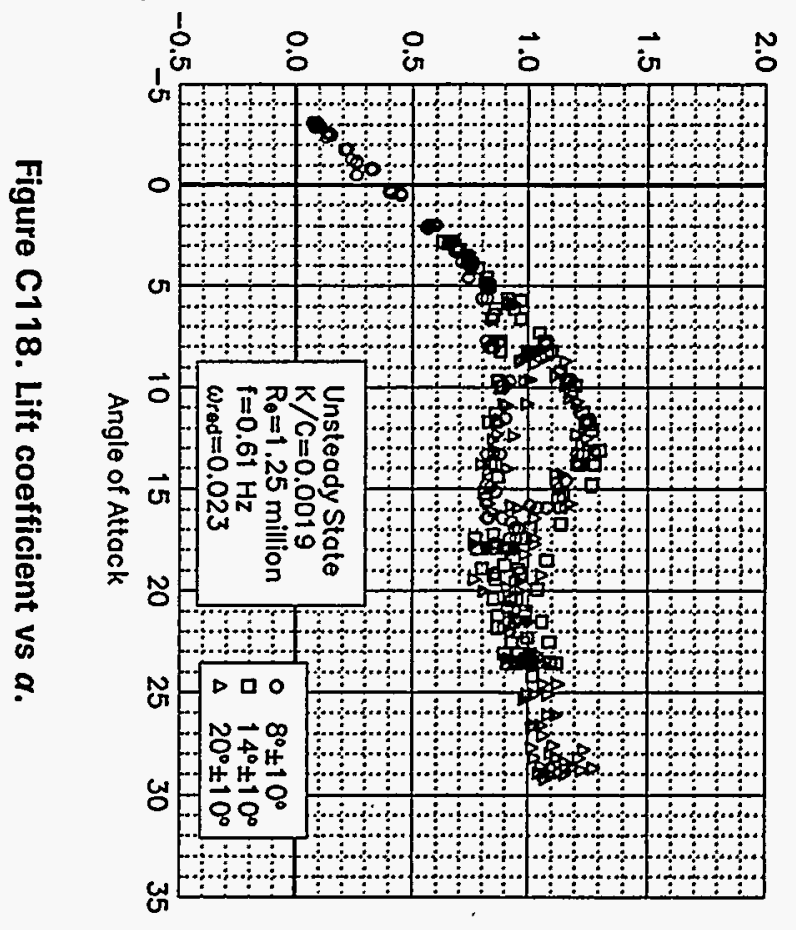

$\frac{1}{6}$
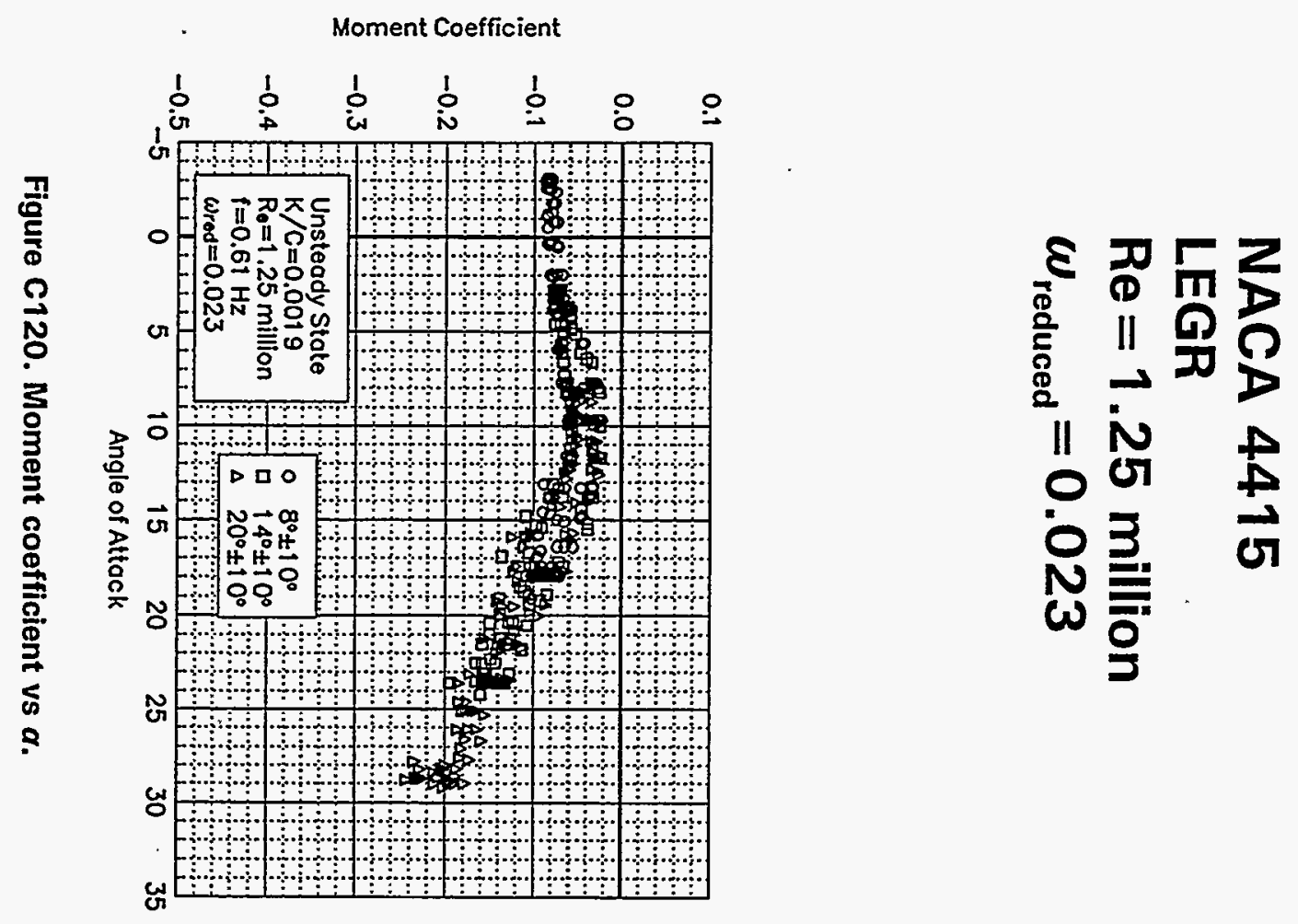


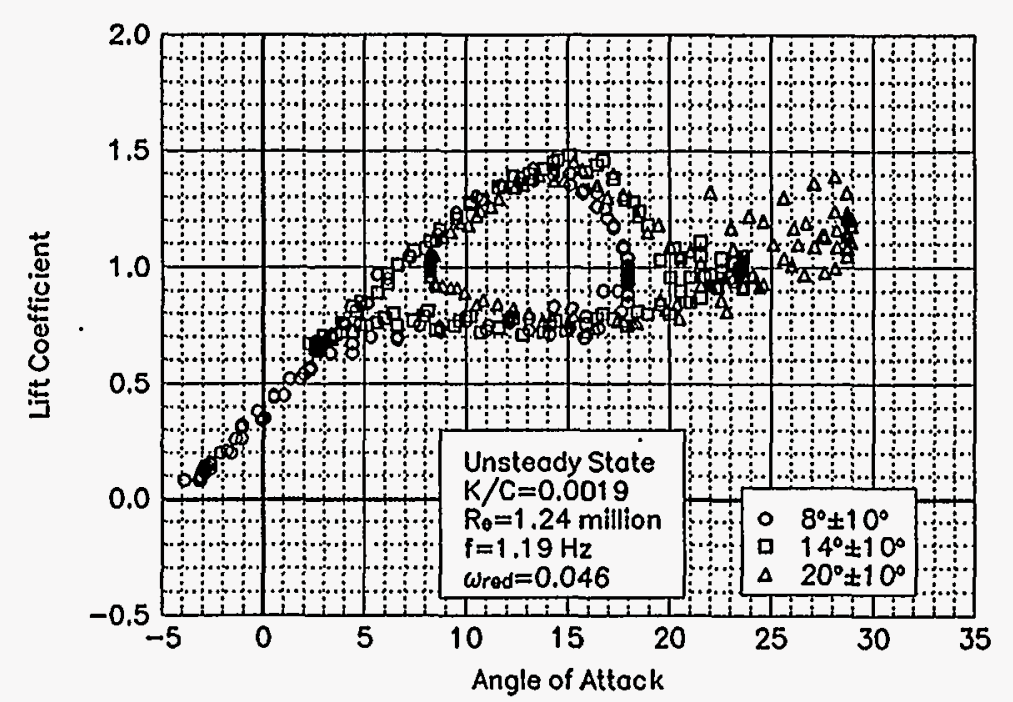

Figure C121. Lift coefficient vs $a$.

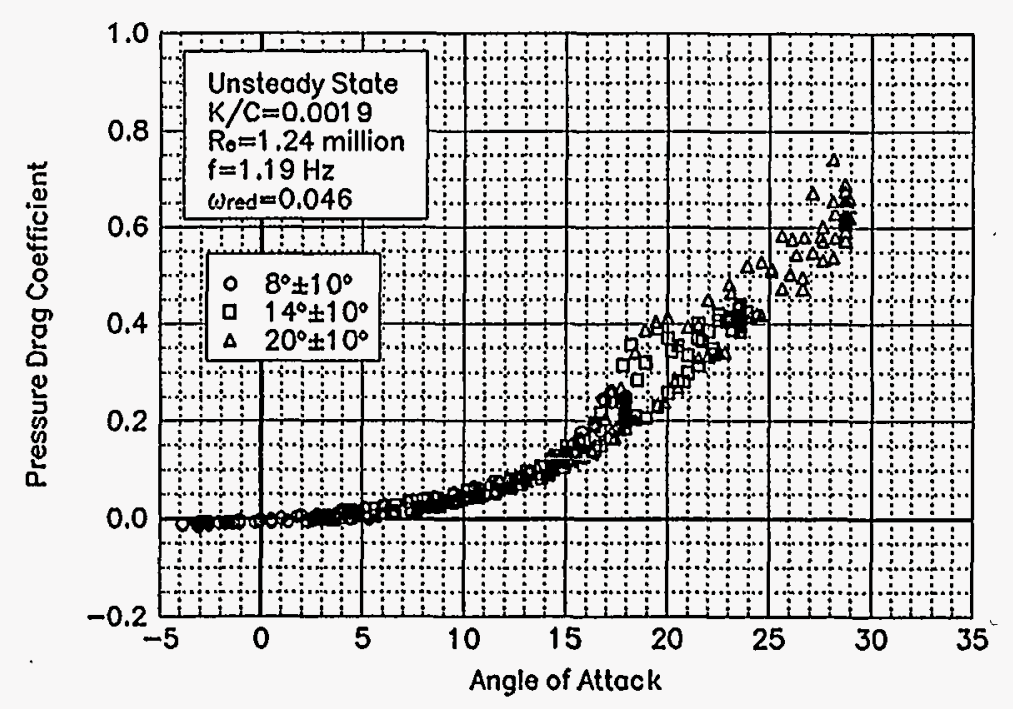

Figure C122. Pressure drag coefficient vs $a$.

\section{NACA 4415 LEGR \\ $\mathrm{Re}=1.24$ million $\omega_{\text {reduced }}=0.046$}

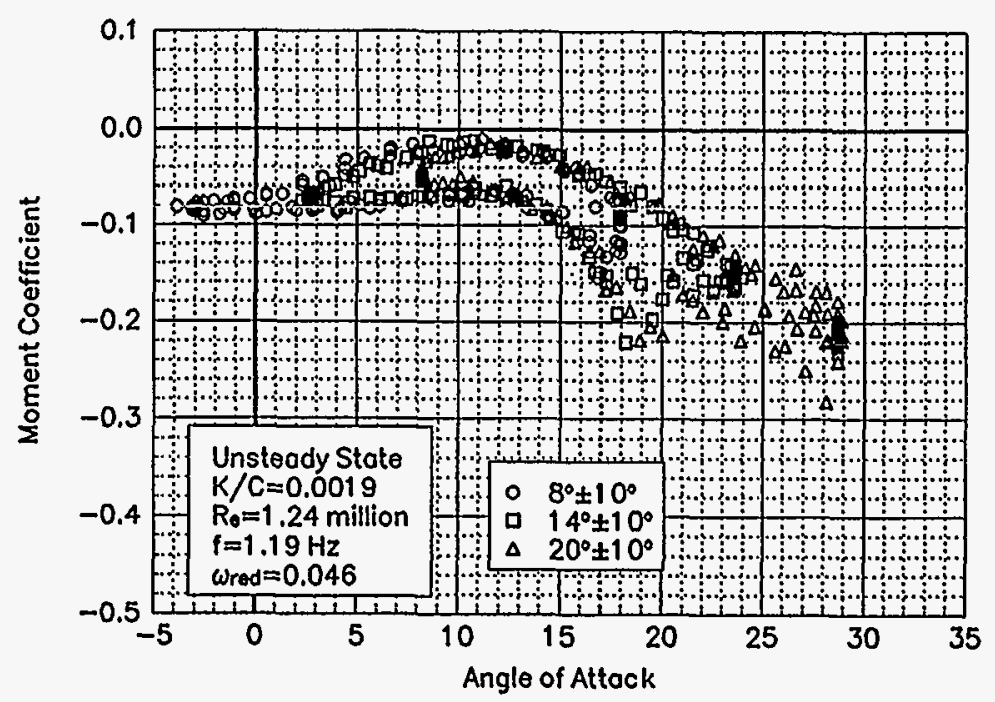

Figure C123. Moment coefficient vs $a$. 

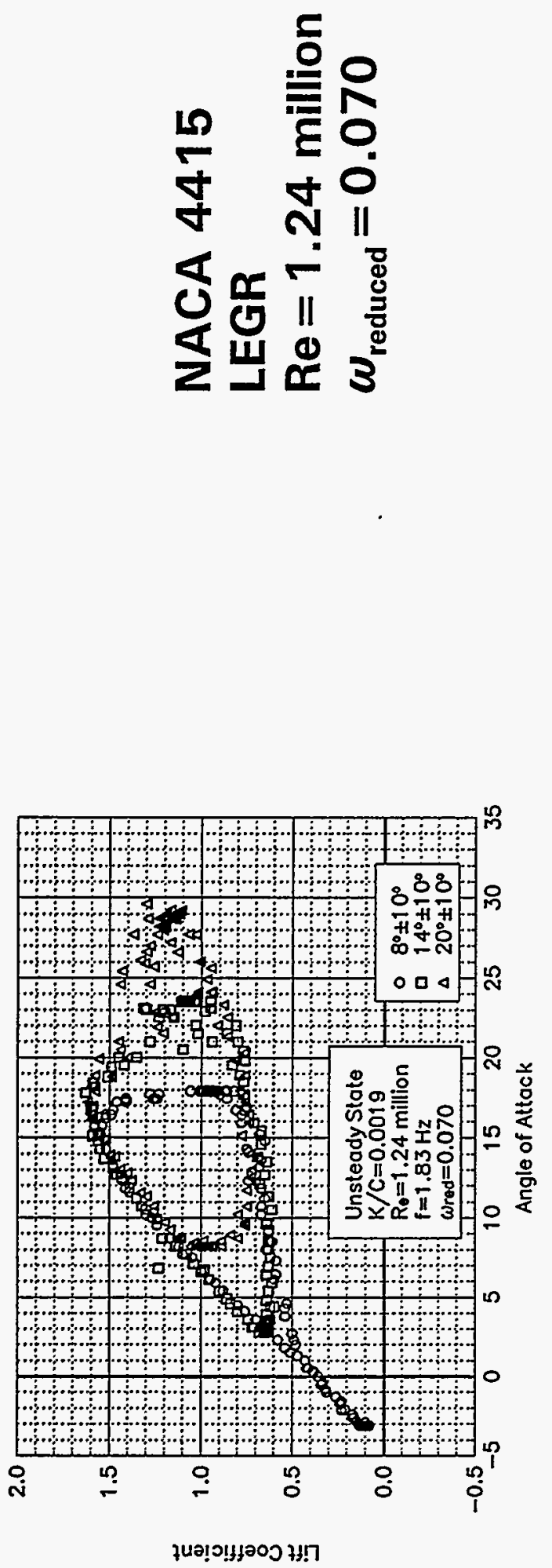

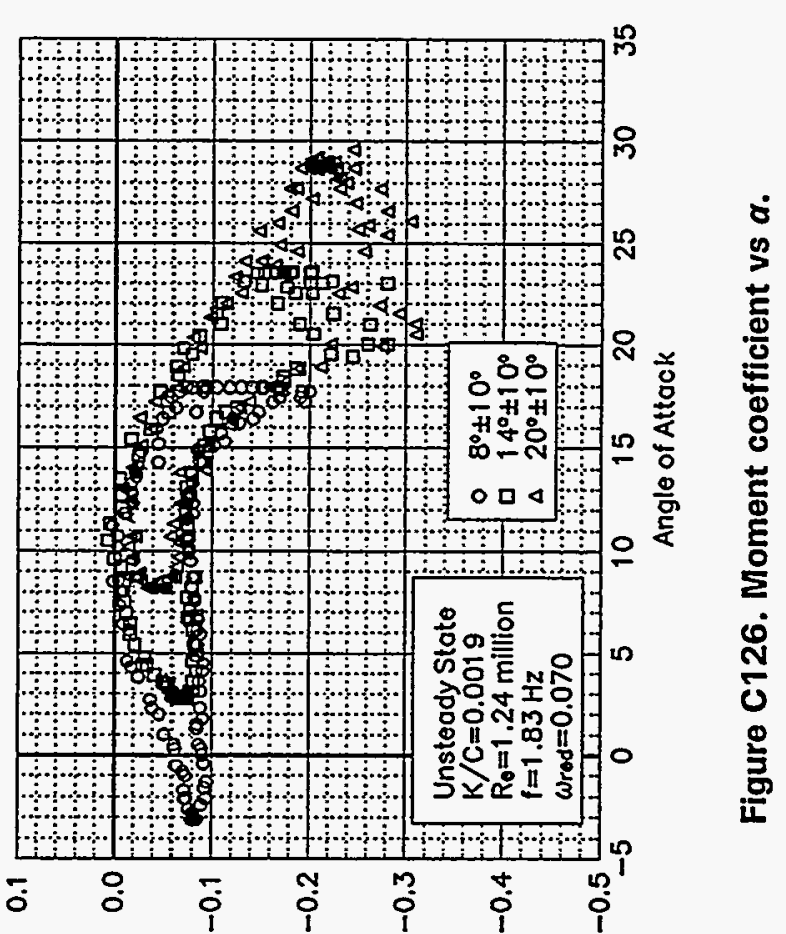

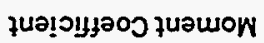

$\overrightarrow{3}$

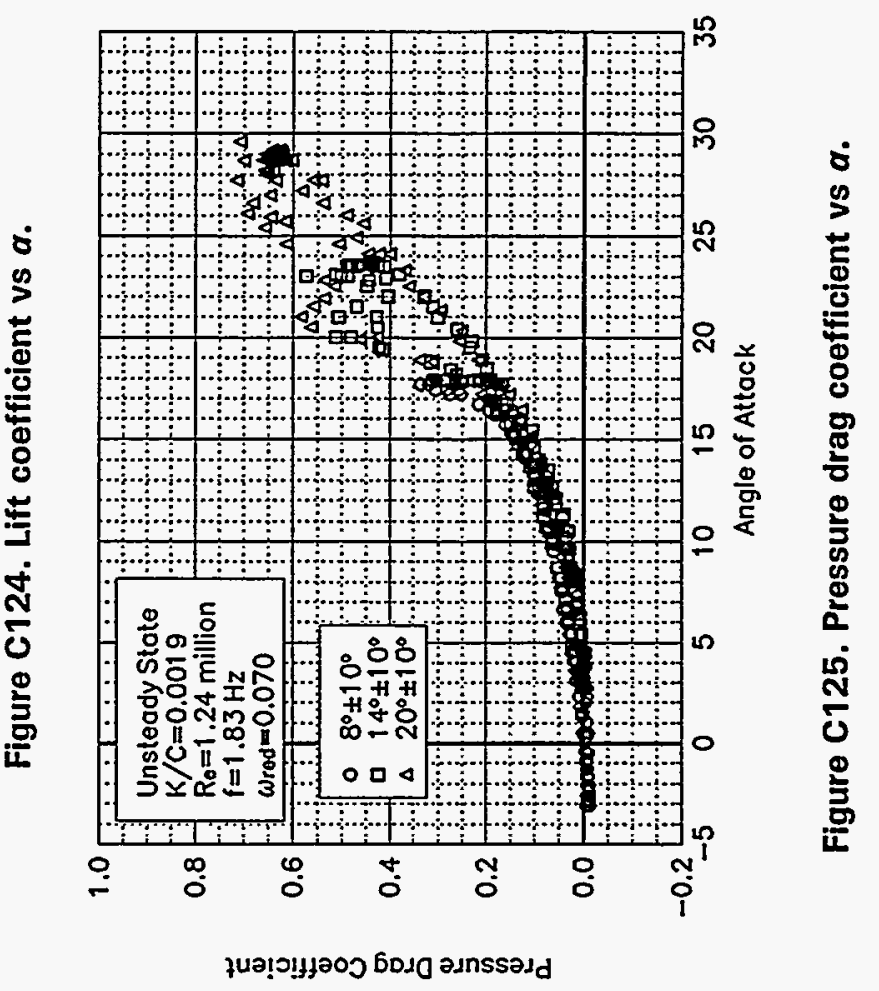




\section{Unsteady Airfoil Characteristics \\ $\pm 10^{\circ}$ Sine, $\operatorname{Re}=1.5$ million}



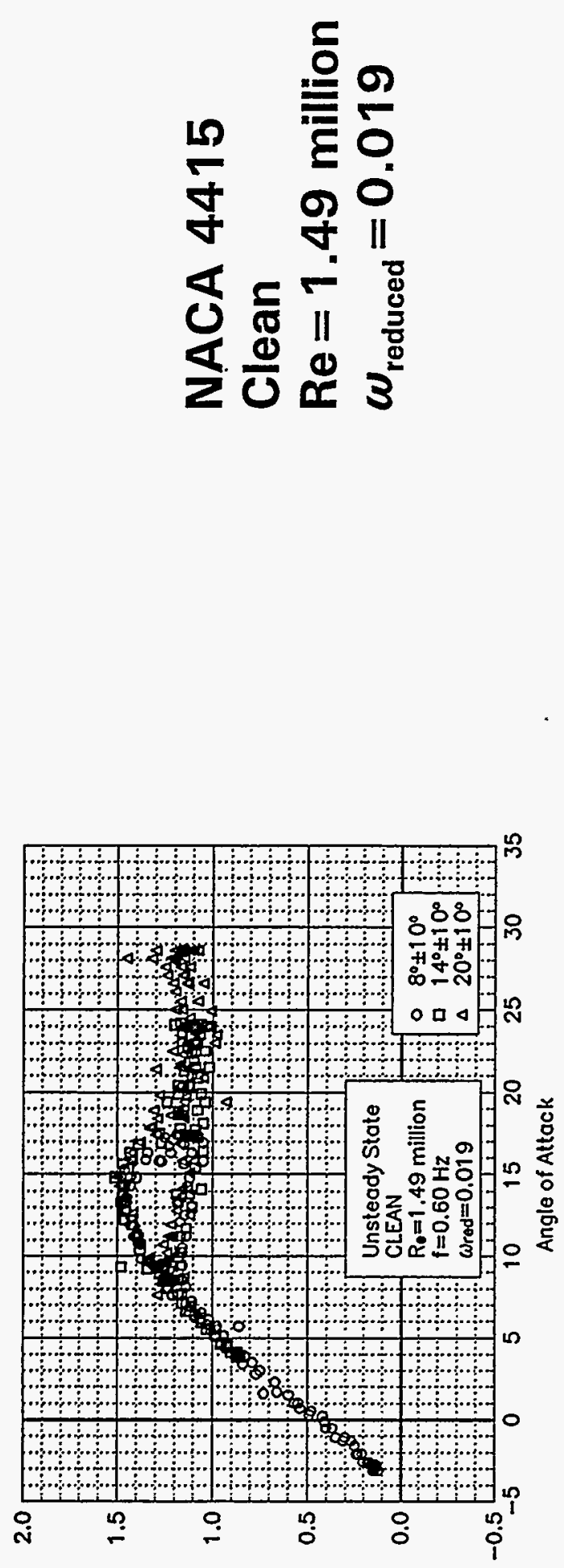

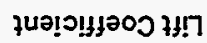

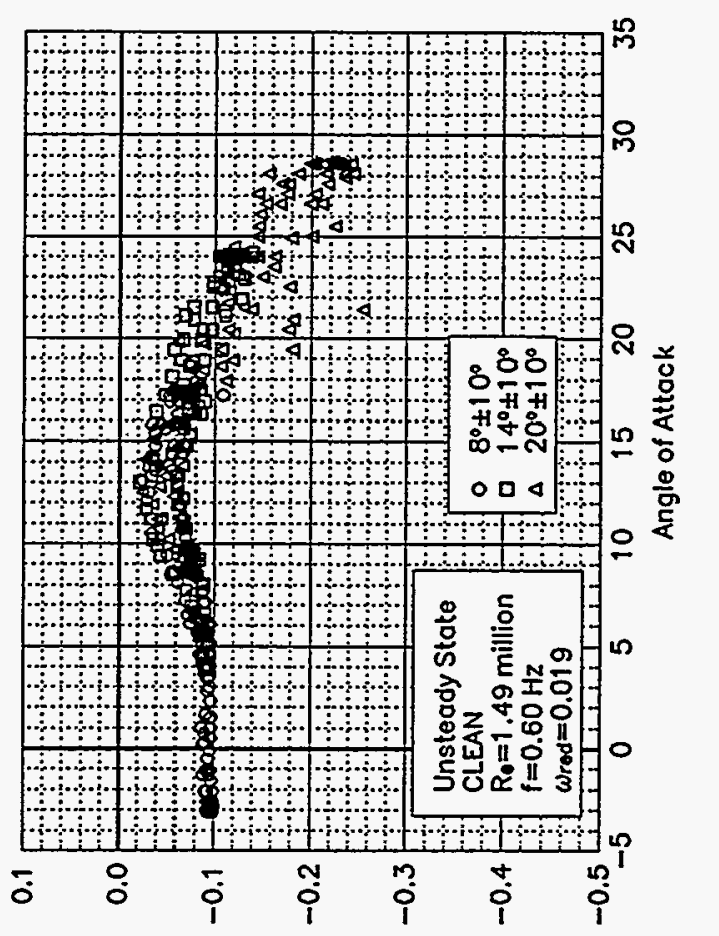

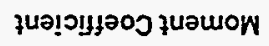

น

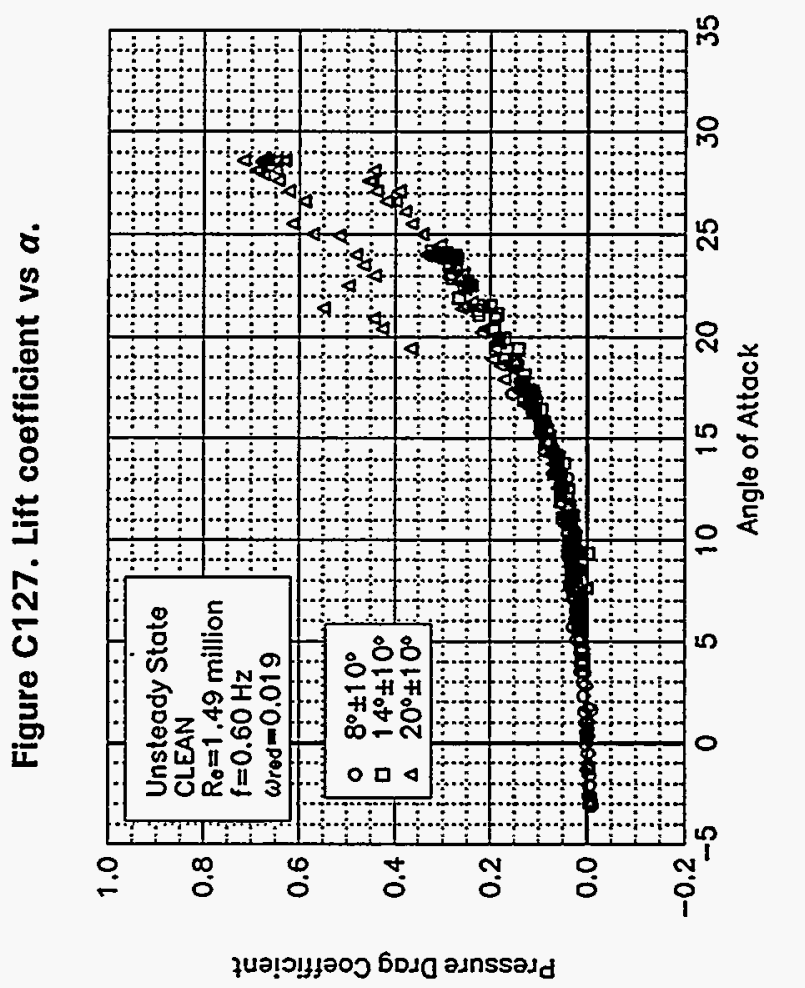

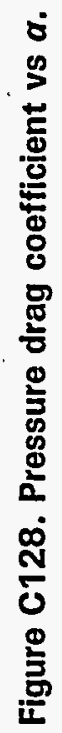



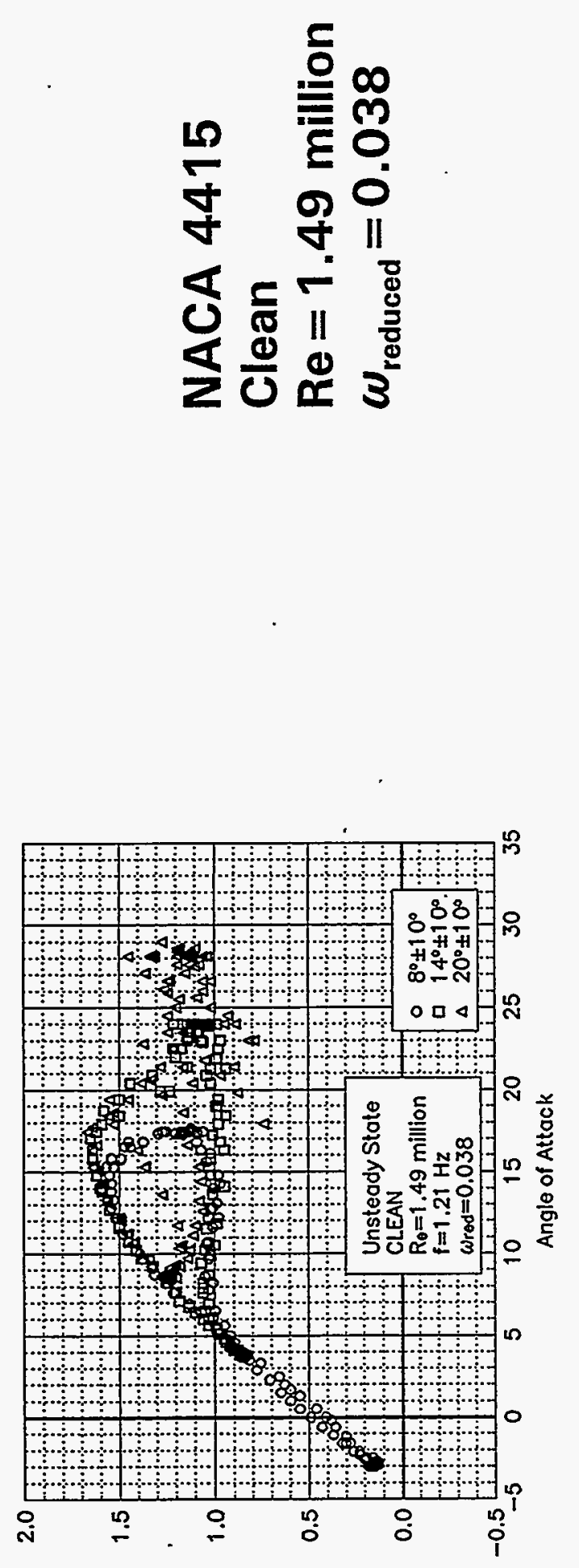

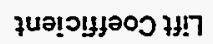

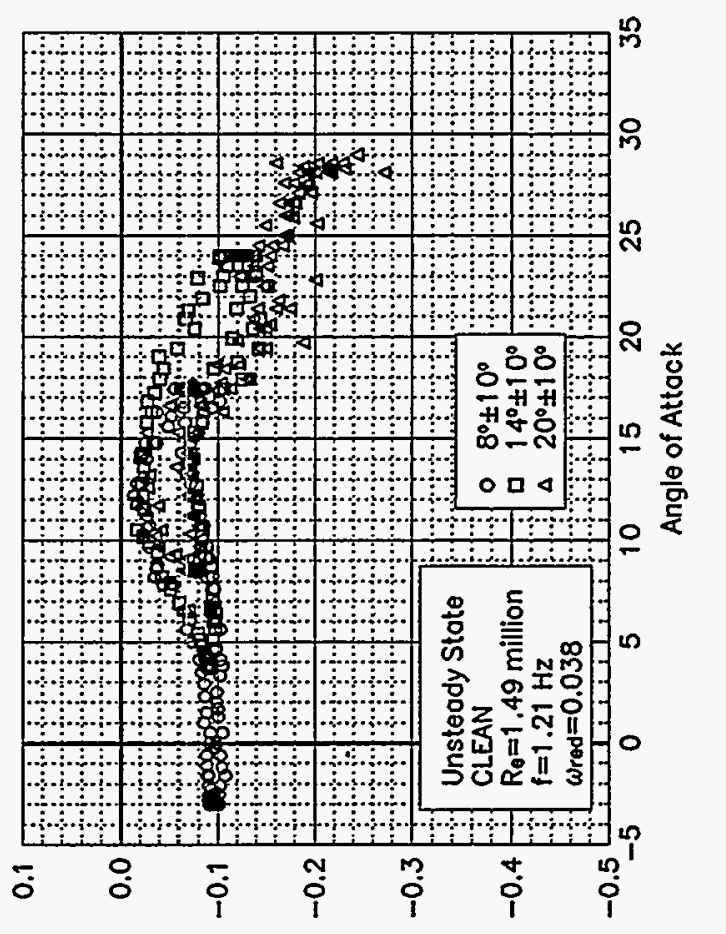

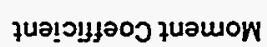

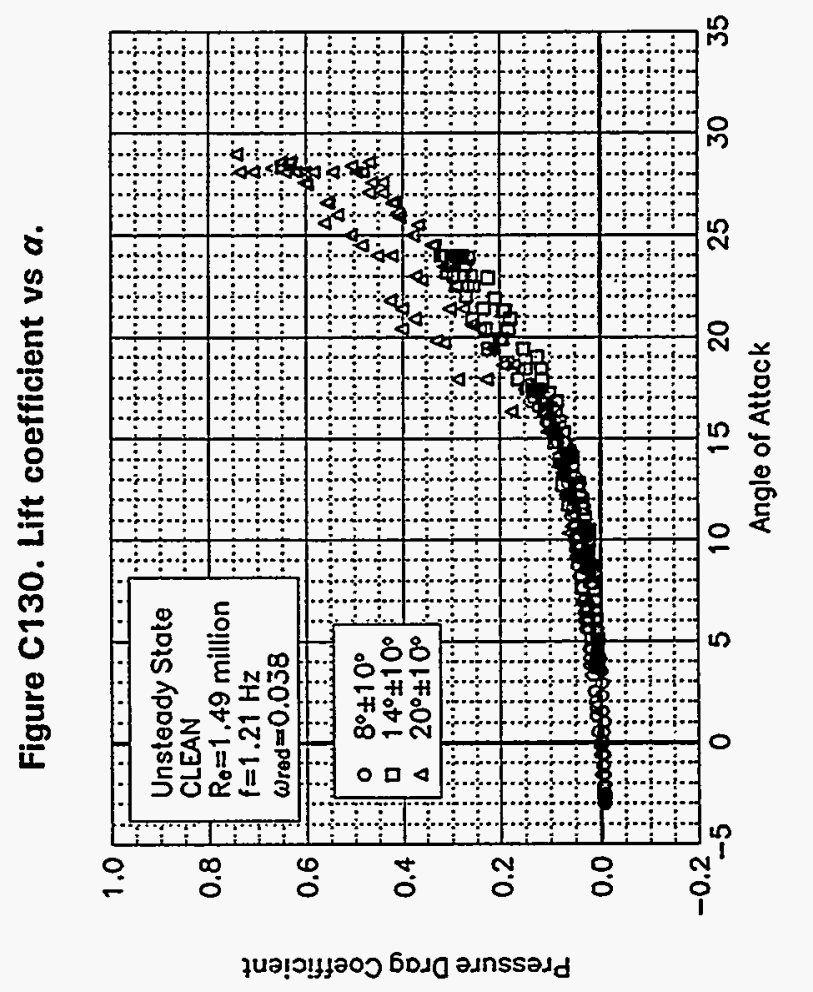

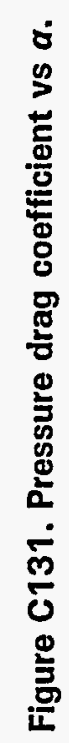



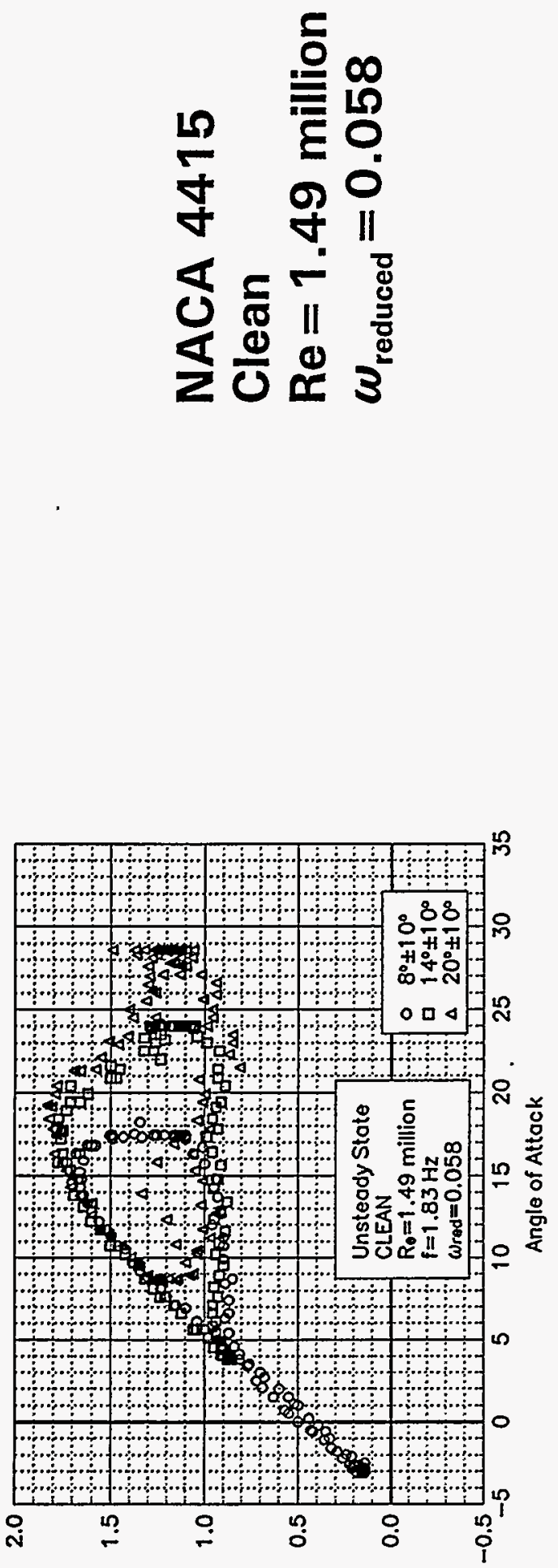

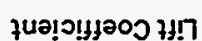

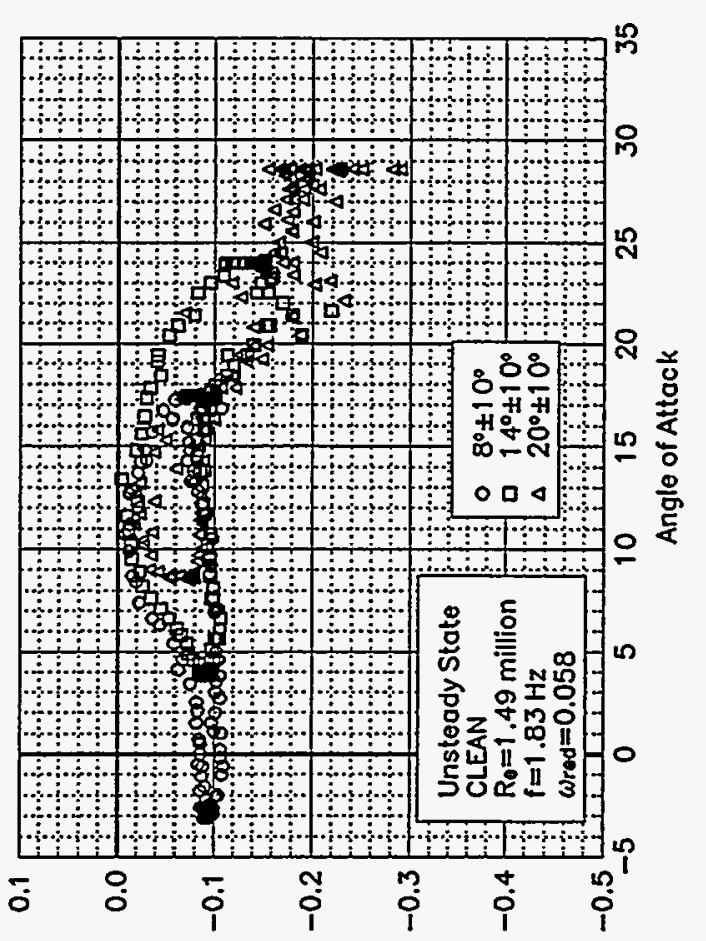

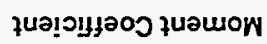

น

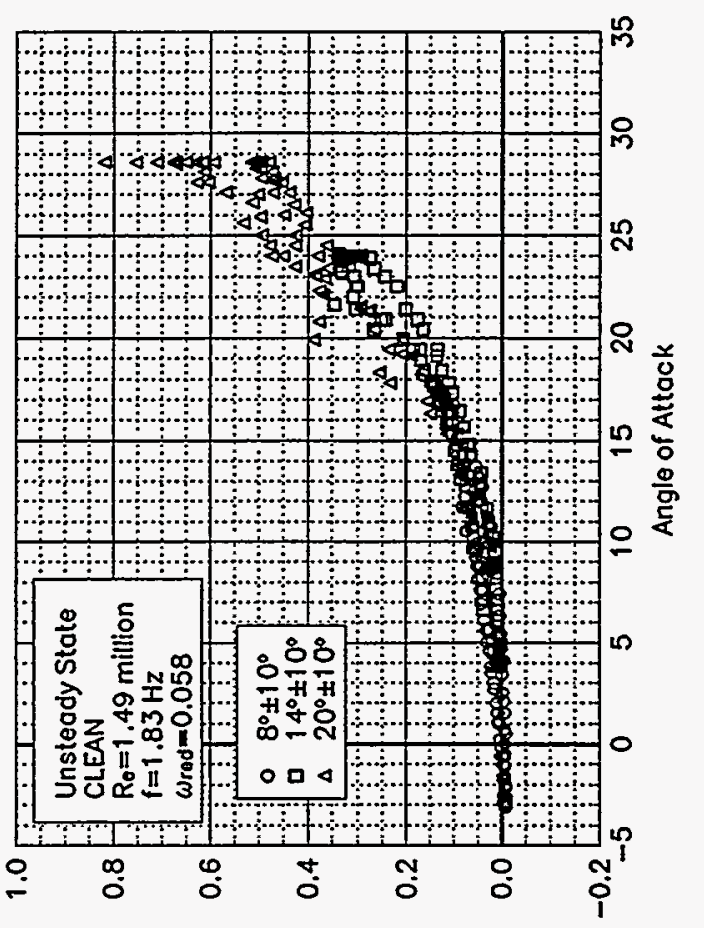

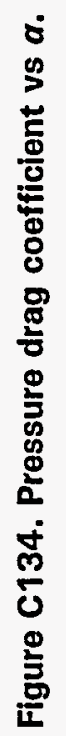

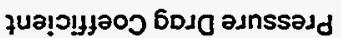

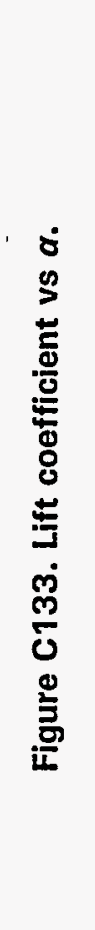



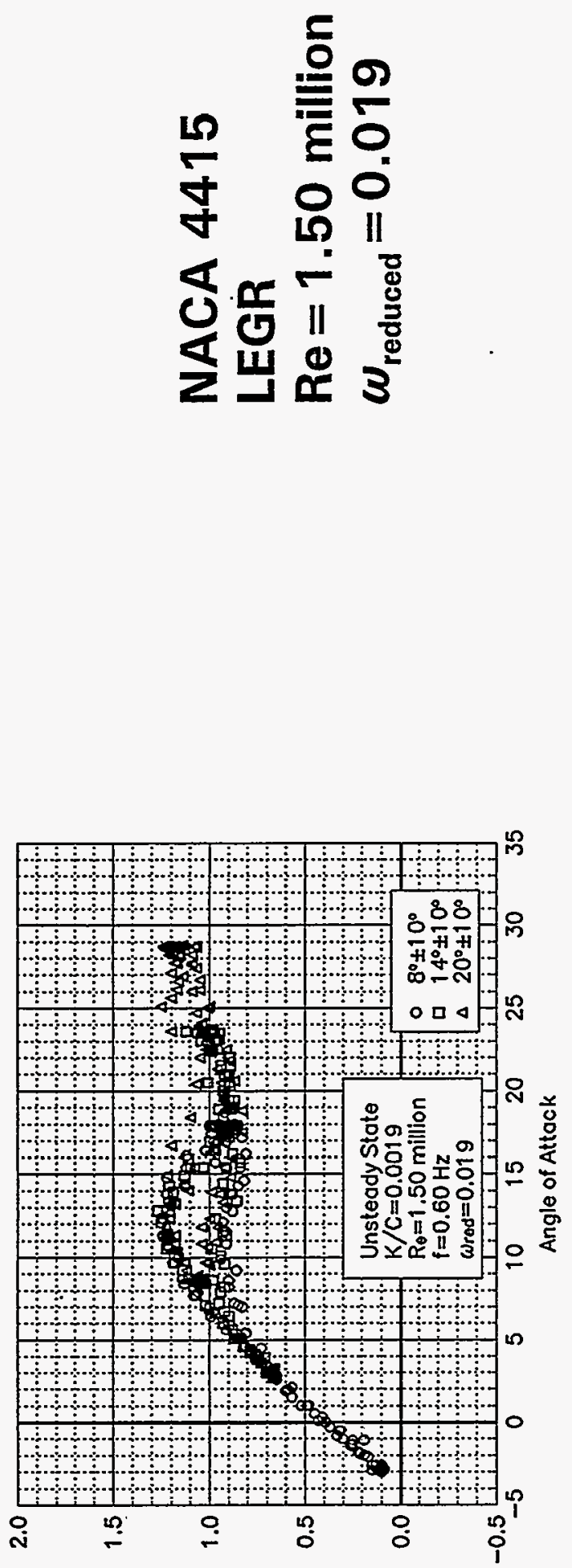

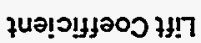

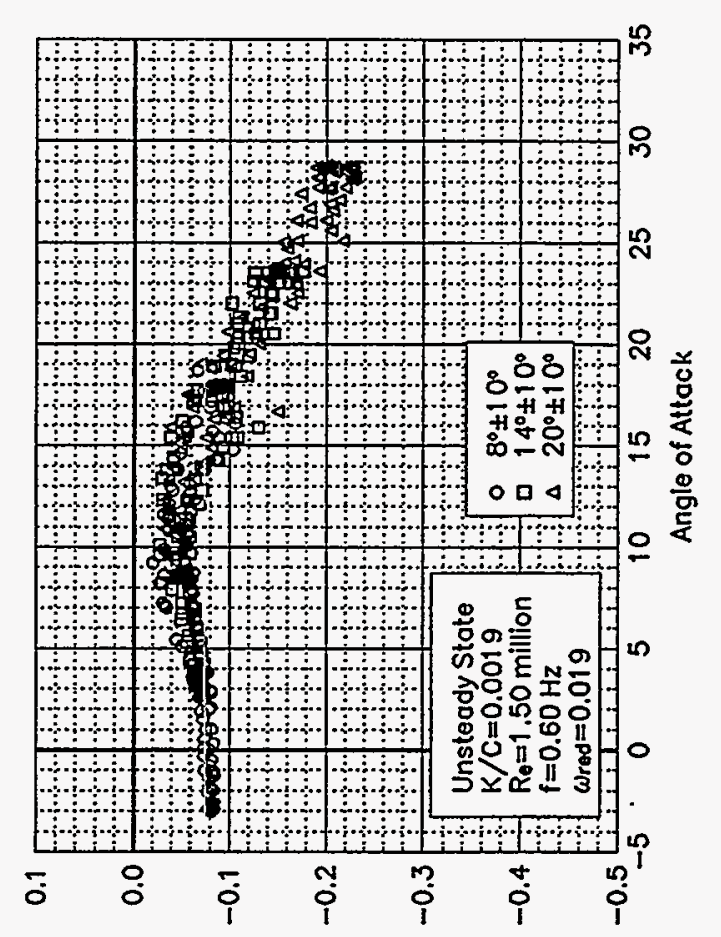

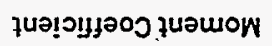

号

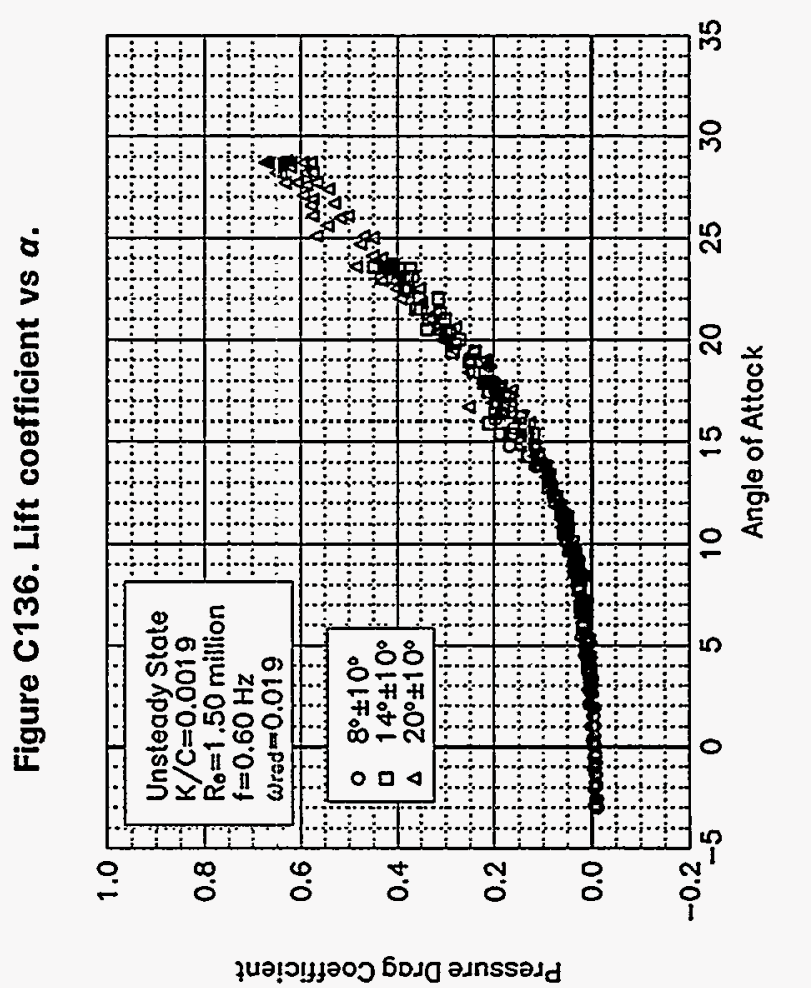

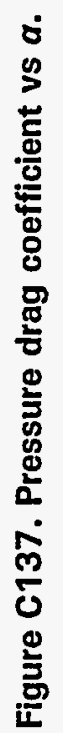



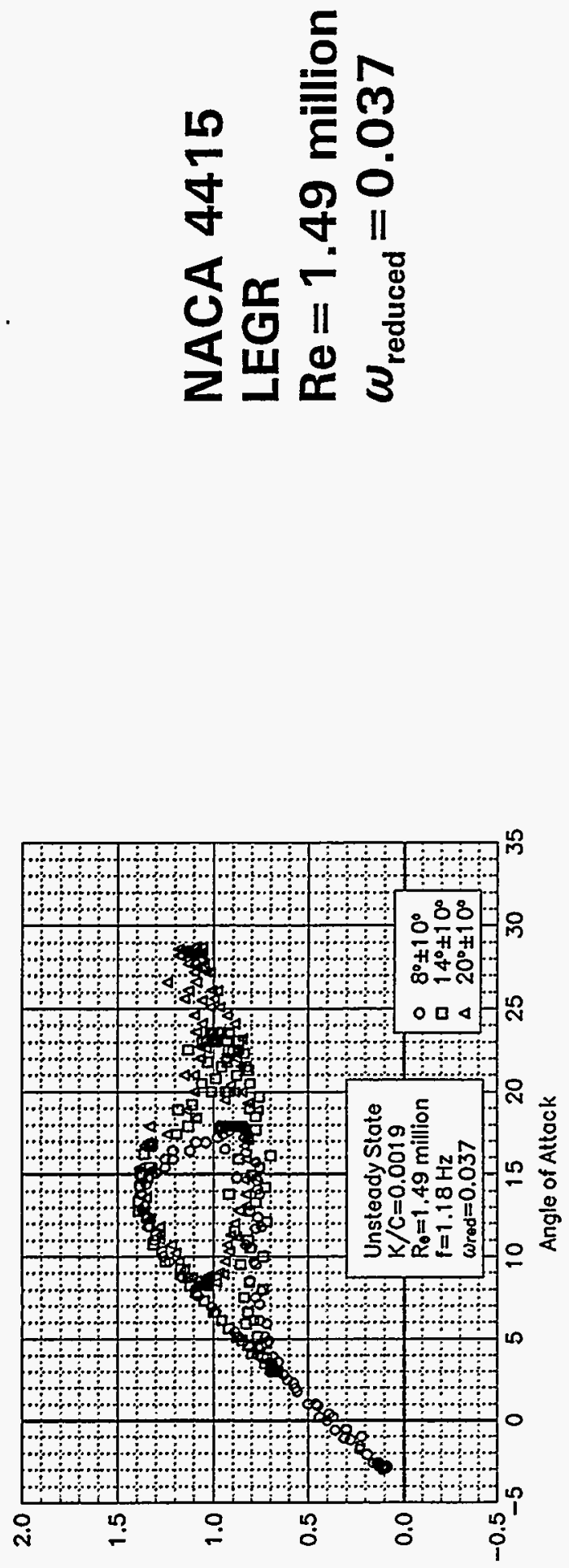

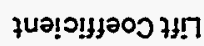

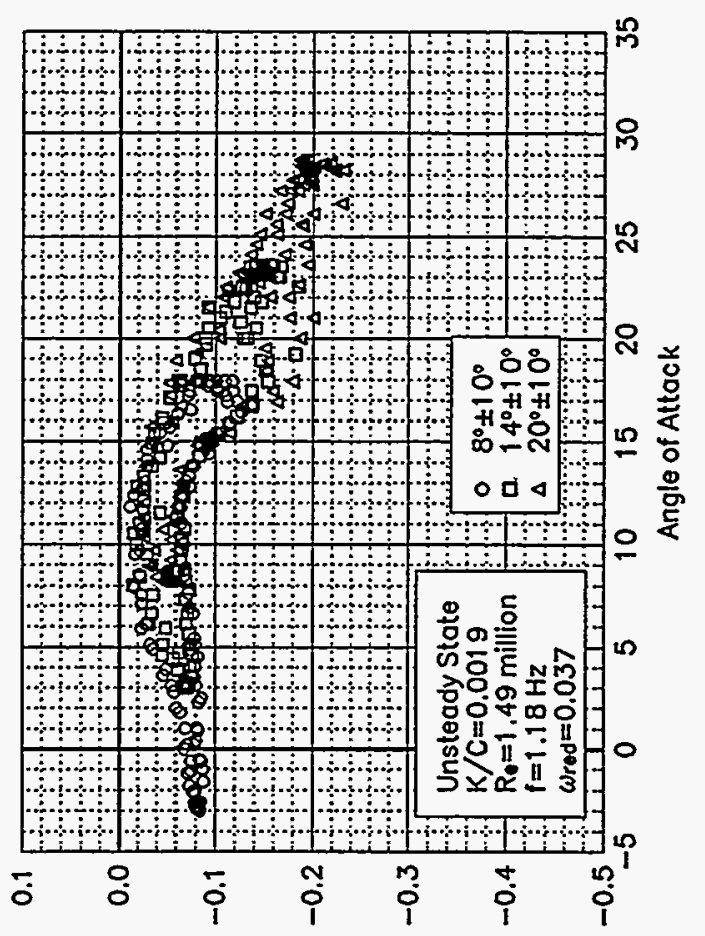

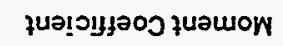

in

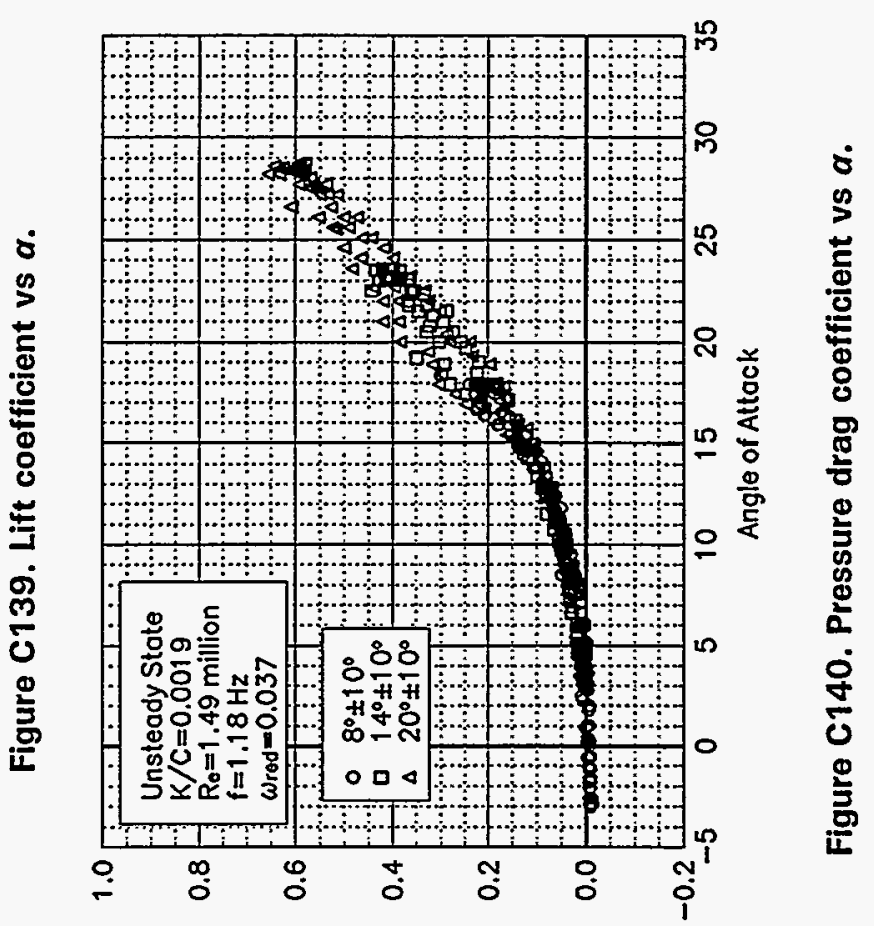

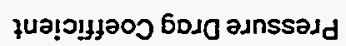



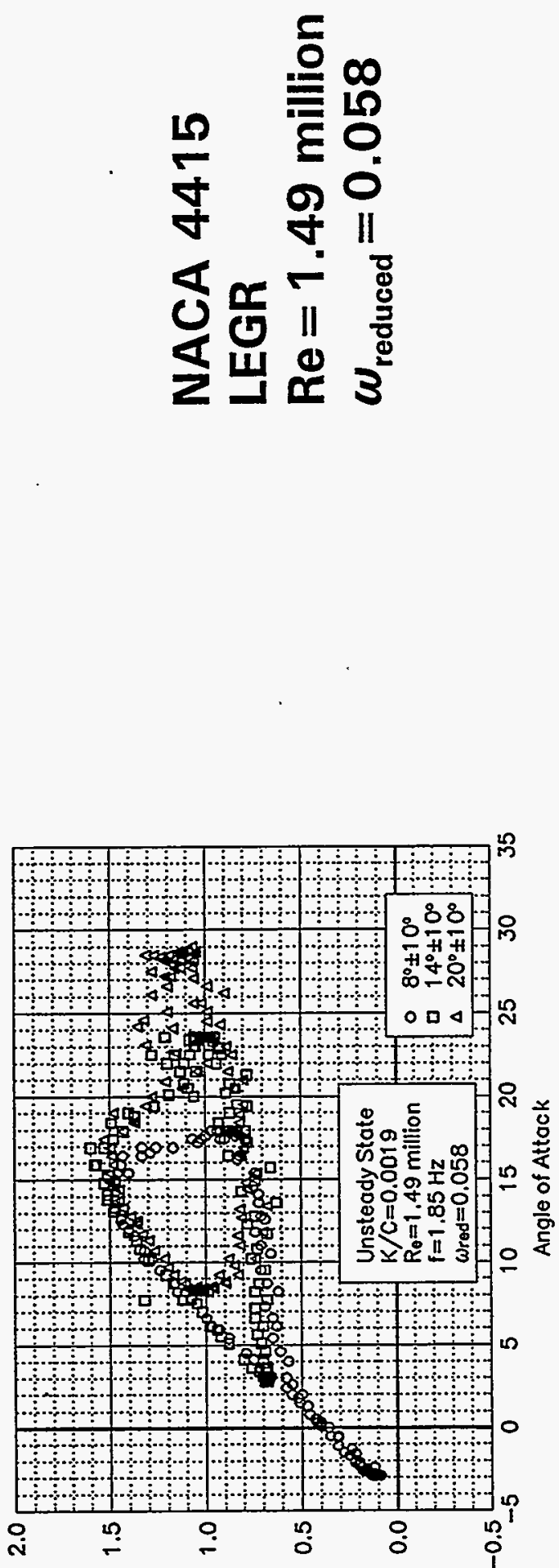

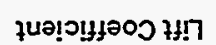

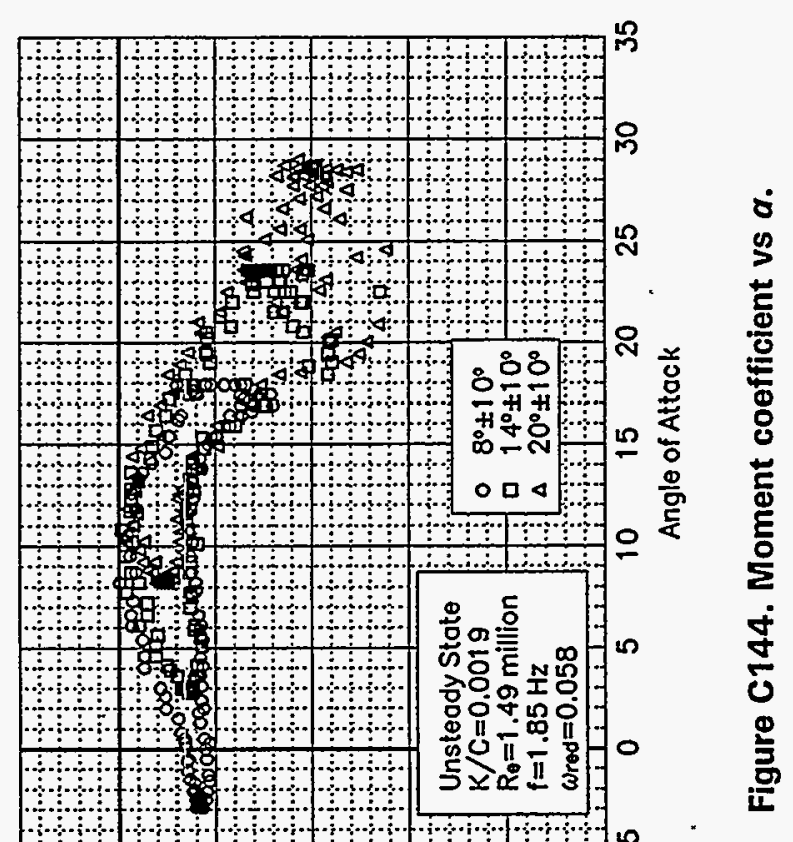

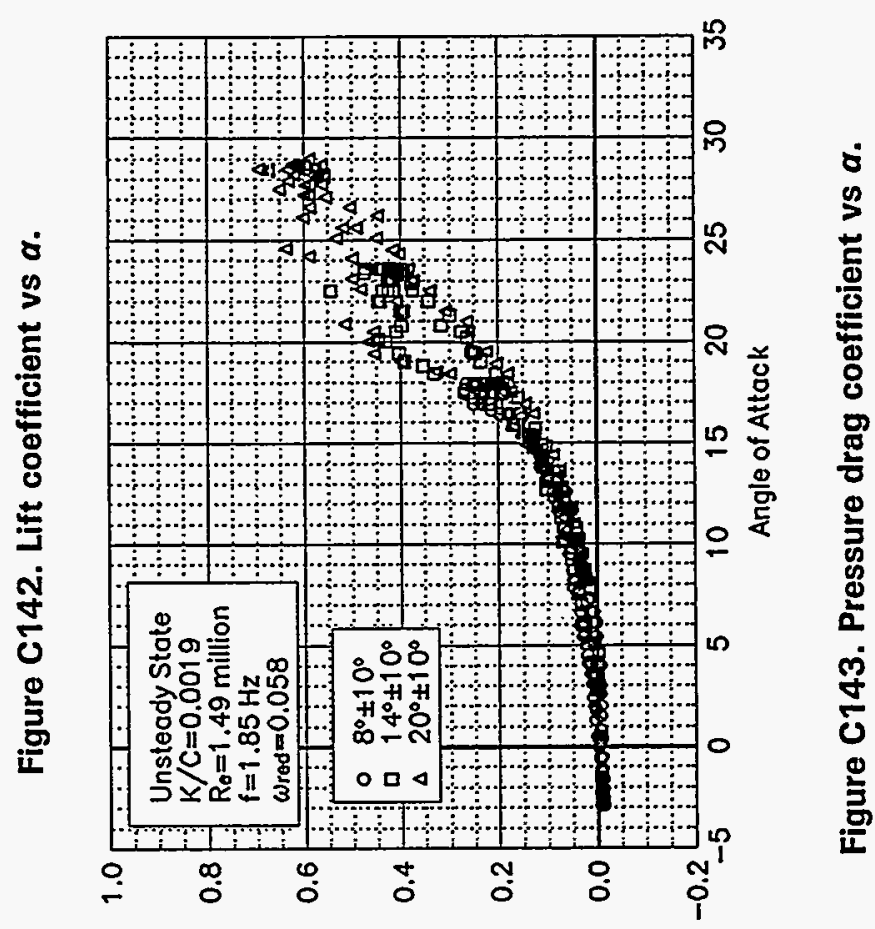
qua!วyว 


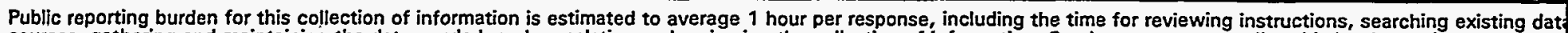

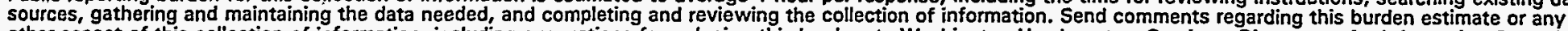

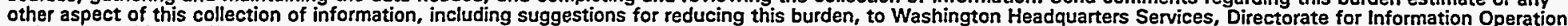

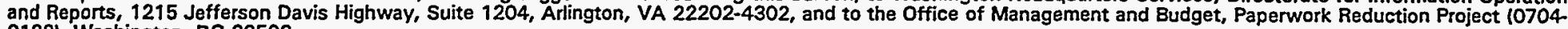
0188), Washington, DC 20503.

\begin{tabular}{l|l|l|}
\hline 1. & $\begin{array}{l}\text { 2. REPORT DATE } \\
\text { July } 1996\end{array}$ & $\begin{array}{l}\text { 3. REPORT TYPE AND DATES COVERED } \\
\text { Subcontract Report }\end{array}$ \\
\hline
\end{tabular}

4. TITLE AND SUBTITLE
Effects of Grit Roughness and Pitch Oscillations on the NACA 4415 Airfoil

6. AUTHOR(S)

M. J. Hoffmann, R. Reuss Ramsay, G. M. Gregorek

5. FUNDING NUMBERS

C:

TA: WE619030

7. PERFORMING ORGANIZATION NAME(S) AND ADDRESS(ES)

Dr. Gerald Gregorek

8. PERFORMING ORGANIZATION

The Ohio State University REPORT NUMBER

Aero \& Astronautical Research

2300 West Case Road

Columbus, Ohio 43220

(614) 292-5491

National Renewable Energy Laboratory

1617 Cole Blvd.

Golden, CO 80401-3393

10. SPONSORING/MONITORING

AGENCY REPORT NUMBER

TP-442-7815

DE96007943

11. SUPPLEMENTARY NOTES

NREL Technical Monitor: C. P. Butterfield

12a. DISTRIBUTION/AVAILABILITY STATEMENT

National Technical Information Service

U.S. Department of Commerce

5285 Port Royal Road

Springfield, VA 22161 12b. DISTRIBUTION CODE

UC-1211

\section{ABSTRACT (Maximum 200 words)}

Horizontal axis wind turbine rotors experience unsteady aerodynamics due to wind shear when the rotor is yawed, when rotor blades pass through the support tower wake, and when the wind is gusting. An understanding of this unsteady behavior is necessary to assist in the calculation of rotor performance and loads. The rotors also experience performance degradation due to surface roughness. These surface irregularities are caused by the accumulation of insect debris, ice, and the aging process. Wind tunnel studies that examine both the steady and unsteady behavior of airfoils can help define pertinent flow phenomena, and the resultant data can be used to validate analytical computer codes.

A NACA 4415 airfoil model was tested in The Ohio State University Aeronautical and Astronautical Research Laboratory (OSU/AARL) $3 \times 5$ subsonic wind tunnel $(3 \times 5)$ under steady flow and stationary model conditions, as well as with the model undergoing pitch oscillations. To study the possible extent of performance loss due to surface roughness, a standard grit pattern (LEGR) was used to simulate leading edge contamination. After baseline cases were completed, the LEGR was applied for both steady state and model pitch oscillation cases. The Reynolds numbers for steady state conditions were $0.75,1,1.25$, and 1.5 million, while the angle of attack ranged from $-10^{\circ}$ to $+40^{\circ}$. With the model undergoing pitch oscillations, data were acquired at Reynolds numbers of 0.75 , $1,1.25$, and 1.5 million, at frequencies of $0.6,1.2$, and $1.8 \mathrm{~Hz}$. Two sine wave forcing functions were used, $\pm 5.5^{\circ}$ and $\pm 10^{\circ}$, at mean angles of attack of $8^{\circ}, 14^{\circ}$, and $20^{\circ}$. For purposes herein, any reference to unsteady conditions means the airfoil model was in pitch oscillation about the quarter chord.

14. SUBJECT TERMS

wind energy; horizontal-axis wind turbine; wind tunnel test data; wind turbine airfoil

\section{NUMBER OF PAGES}

16. PRICE CODE

20. LIMITATION OF ABSTRACT

UL
17. SECURITY CLASSIFICATION OF REPORT Unclassified
18. SECURITY CLASSIFICATION OF THIS PAGE Unclassified
19. SECURITY CLASSIFICATION OF ABSTRACT

Unclassified 
